\title{
Design and Development of a Multi-Nodal Methane Detection System for Longwall Coal Mining
}

Amber P. Barr

apb0002@mix.wvu.edu

Follow this and additional works at: https://researchrepository.wvu.edu/etd

Part of the Mechanical Engineering Commons, and the Mining Engineering Commons

\section{Recommended Citation}

Barr, Amber P., "Design and Development of a Multi-Nodal Methane Detection System for Longwall Coal Mining" (2020). Graduate Theses, Dissertations, and Problem Reports. 7949.

https://researchrepository.wvu.edu/etd/7949

This Thesis is protected by copyright and/or related rights. It has been brought to you by the The Research Repository @ WVU with permission from the rights-holder(s). You are free to use this Thesis in any way that is permitted by the copyright and related rights legislation that applies to your use. For other uses you must obtain permission from the rights-holder(s) directly, unless additional rights are indicated by a Creative Commons license in the record and/ or on the work itself. This Thesis has been accepted for inclusion in WVU Graduate Theses, Dissertations, and Problem Reports collection by an authorized administrator of The Research Repository @ WVU. For more information, please contact researchrepository@mail.wvu.edu. 
Design and Development of a Multi-Nodal Methane Detection System for Longwall Coal Mining

Amber P. Barr

Thesis submitted to the Benjamin M. Statler College of Engineering and Mineral Resources At West Virginia University

In partial fulfillment of the requirements for the degree of

Master of Science in

Mechanical Engineering

Derek Johnson, PhD, PE, Chair

V'yacheslav Akkerman, $\mathrm{PhD}$

Hailin $\mathrm{Li}, \mathrm{PhD}$

Department of Mechanical and Aerospace Engineering

Morgantown, West Virginia

2020

Keywords: Methane Detection, Multi-Nodal System, Longwall Coal Mining, Water Ejector Copyright 2020 Amber Barr 


\title{
ABSTRACT \\ Design and Development of a Multi-Nodal Methane Detection System for Longwall Coal Mining
}

\author{
Amber P. Barr
}

Methane $\left(\mathrm{CH}_{4}\right)$ explosions pose significant dangers in longwall mining that may lead to injuries and fatalities. Safety is improved through diligent monitoring of $\mathrm{CH}_{4}$ concentration. Currently, regulations require a $\mathrm{CH}_{4}$ monitor be placed on the shearer, downwind of the cutting head. Portable monitor measurements must be taken at various times and locations. If any $\mathrm{CH}_{4}$ monitor measures a concentration greater than $1 \%$, a warning signal must be given. Based on previous research and the location of the $\mathrm{CH}_{4}$ monitor mounted on the shearer (closest monitor to the face), if $1 \%$ methane is measured, the concentration at the face may be already be at the lower explosive limit (5\%). If any monitor measures a concentration greater than $2 \%$, production is halted. However, there are spatial and temporal gaps in measurements where a dangerous $\mathrm{CH}_{4}$-air mixture may develop and go undetected. This poses a risk of shearers or other work activity igniting these dangerous mixtures.

Through funding provided by The Alpha Foundation for the Improvement of Mine Safety and Health, Inc., a multi-nodal Methane Watchdog System (MWS) was developed to improve $\mathrm{CH}_{4}$ monitoring by decreasing the spatial and temporal measurement gaps. The prototype consisted of 10 sampling nodes distributed along the longwall. Each node had a sampling location near the face and gob. The nodes were connected in series and communicated with a central processing hub. Each node consisted of a sealed box which housed sensors and other components. Two $\mathrm{CH}_{4}$ sensors (metal-oxide and infrared) were mounted in a custom sampling block with climate sensors. Two tubes transported gas samples from relevant locations to the sampling block at the node. The units could sample continuously, alternating between each location. The MWS nodes were powered by low voltage DC power common among shields. In addition, a custom water powered ejector was designed to provide the motive sampling force and represented a critical system component.

The ejector was designed to provide sampling for a single unit at flowrate of 2 SLPM. Pressurized water, already powering spray nozzles, would provide an inherently explosion proof motive energy source for active sampling. Ideally, water consumption should be minimized while maintaining enough suction force to draw the sample through the unit at the desired flowrate. An initial ejector design was 3D printed and tested to access its performance. During experimental testing, the ejector demonstrated two distinct operational curves ("High" and "Low" pressure), between which it was believed a flow regime transition from bubble to jet flow occurred. Based on a significant increase in performance post-transition, it was recommended that the ejector operate on the "Low" pressure curve. However, this mode did not meet the flowrate requirement. Thus, a multi-nozzle design was developed and tested, demonstrating the same flow transition. The multi-nozzle ejector was also modelled using a computational fluid dynamics (CFD)

software. Experimental points were used to verify the CFD model to predict that a scaled version of the multi-nozzle design met the flowrate and suction force requirements with reduced water consumption. 


\section{Acknowledgements}

Firstly, I would like to thank my fellow graduate student, Mr. Brian Capellini, who worked alongside me on this project from the day I started. Brian has been a great coworker and friend the last two years and has contributed to the success of this research.

I would like to thank my committee members, Dr. V'yacheslav "Slava" Akkerman and Dr. Hailin Li. I have had both professors for various courses, both undergraduate and graduate. They have contributed greatly to my positive college experience and to my interest in becoming a mechanical engineer.

Thank you, also, to Dr. Nigel Clark who was a Co-investigator on this project. Dr. Clark provided his knowledge and enthusiasm, which significantly assisted in the success of this project.

Recognition must be given to the Alpha Foundation for providing the funding that made my research possible.

I would like to give a special thanks to my family, my boyfriend, and my friends for their continued love, support, and encouragement through my college career. My parents have loved and supported me unconditionally, my entire life. They have taught me so much and could not ask for any better parents (best friends). I truly would not be where I am today without them. Love you guys!

Most of all, I have to give my biggest thanks to my boss and advisor, Dr. Derek Johnson. Boss, you have pushed me and have helped me grow so much in the last two years, as a researcher and as a person. Your guidance and friendship are ones I would not have found with anyone else. I am truly glad that I have had the opportunity to have you as my mentor through my graduate education. You made it an experience I will value for the rest of my life. 
Table of Contents

Acknowledgements ......................................................................................................ii

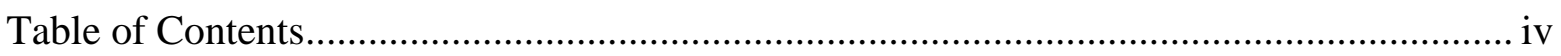

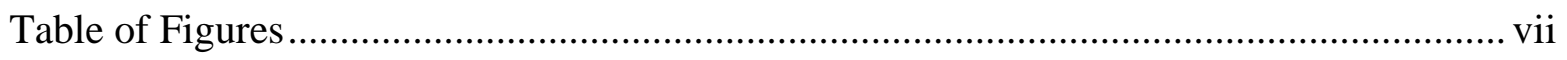

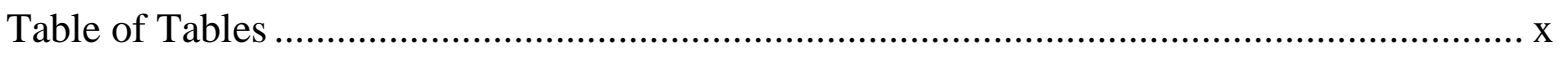

List of Acronyms and Abbreviations............................................................................. xii

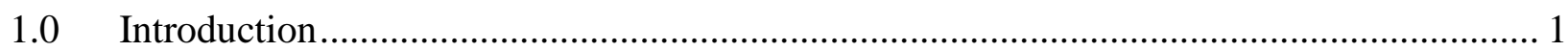

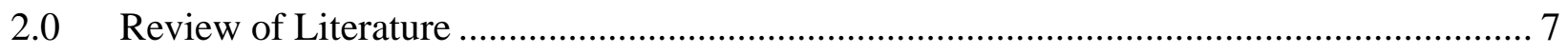

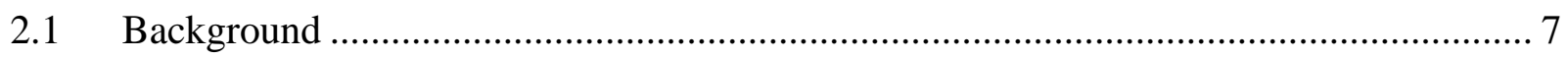

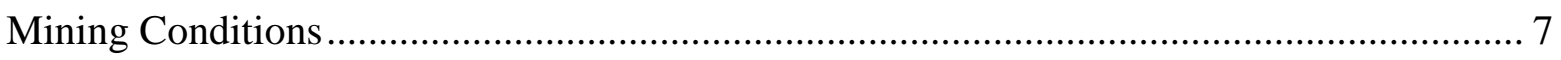

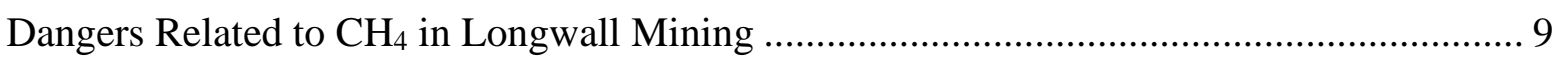

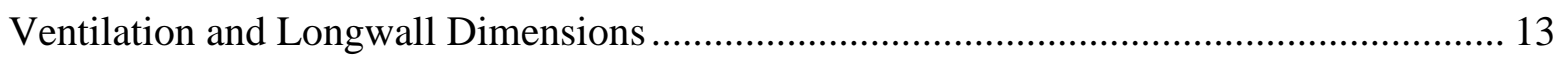

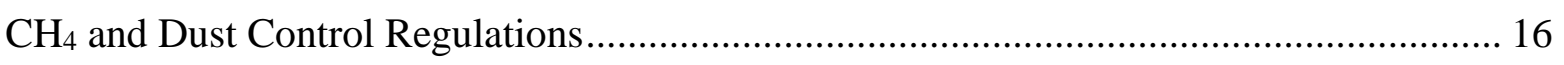

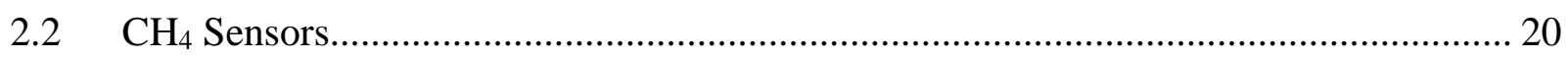

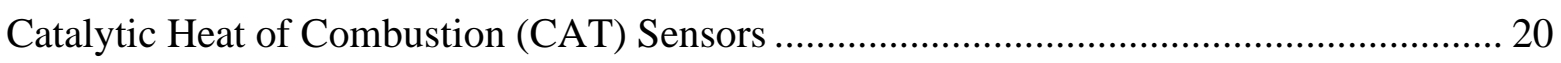

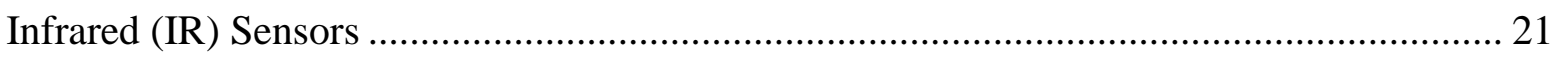

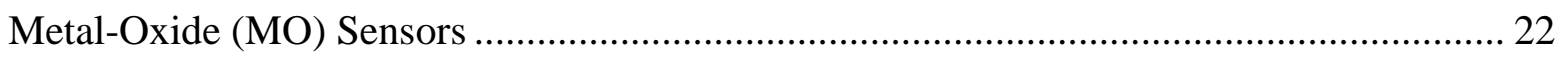

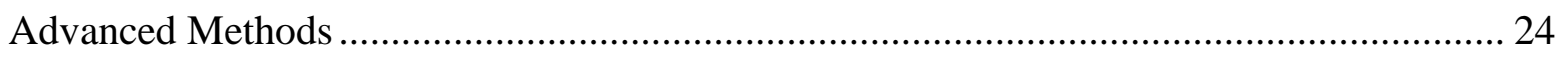

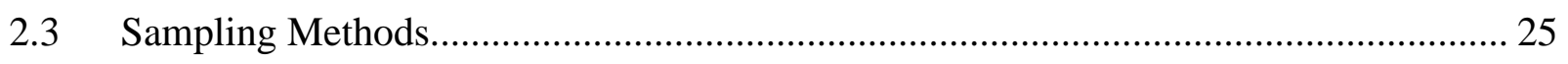

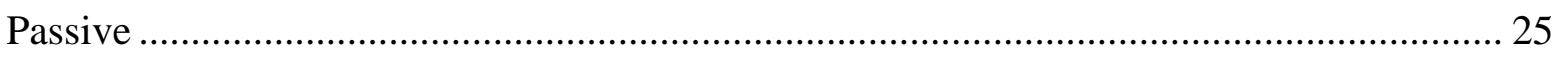

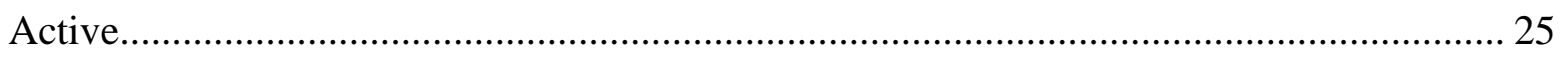

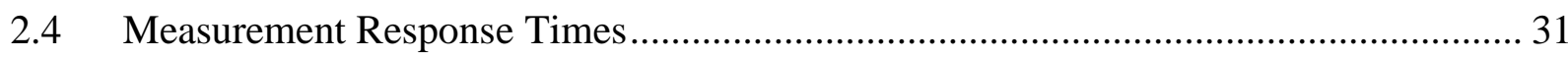

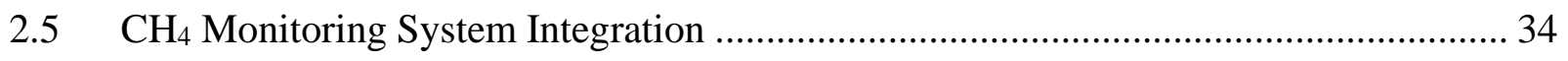

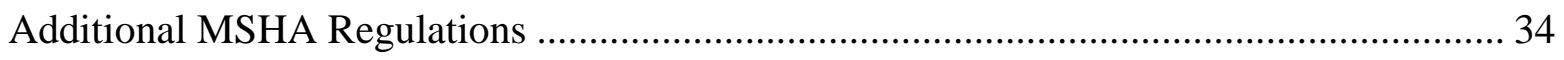

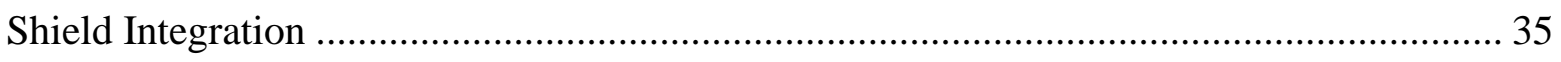

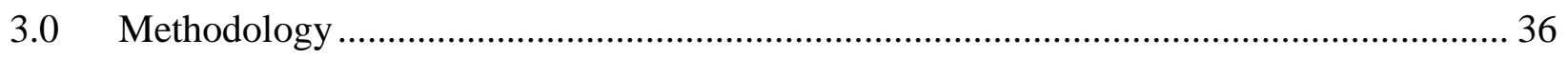

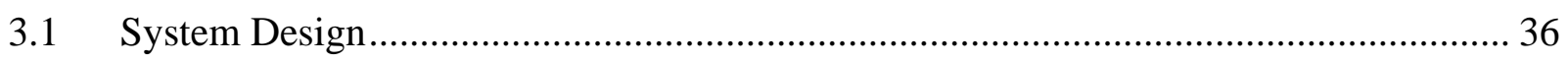

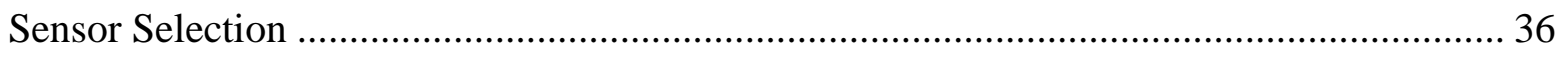

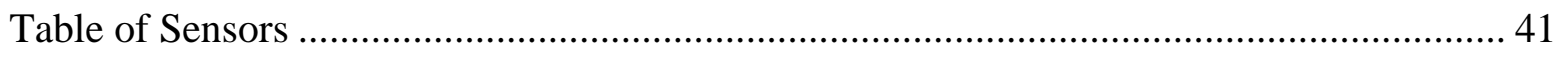

Additional Components for Sensor Mounting.................................................................... 41

Aluminum Sensor Block Design ............................................................................... 42

Integration of Components into the "Sampling Box" ........................................................ 43

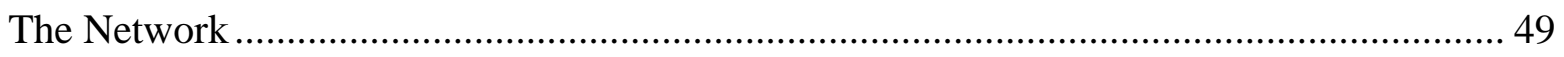

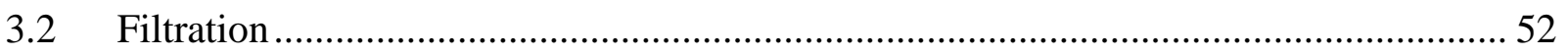




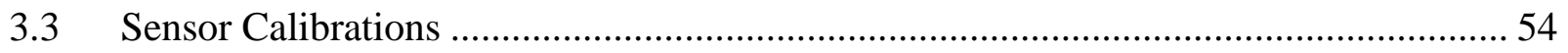

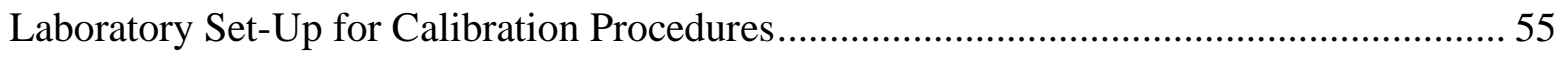

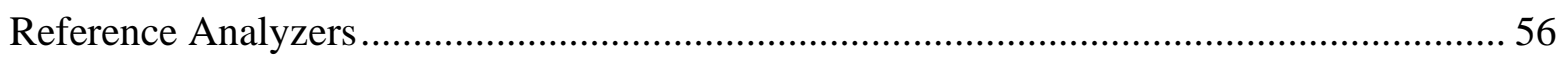

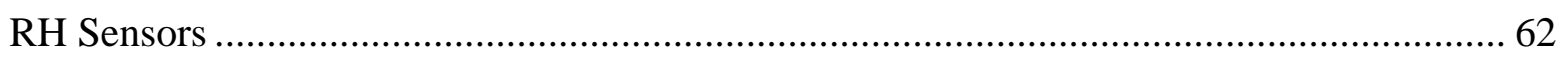

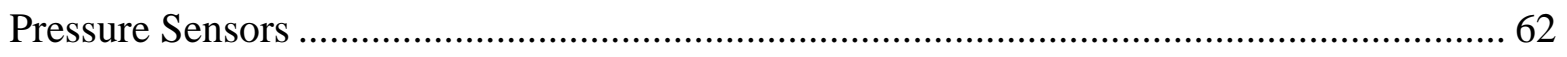

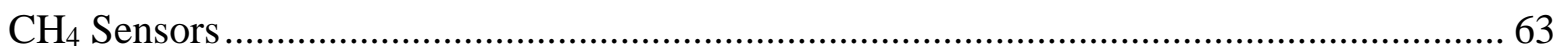

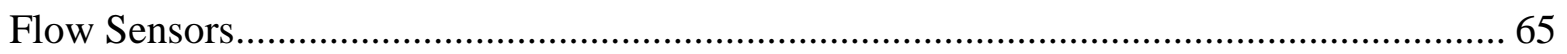

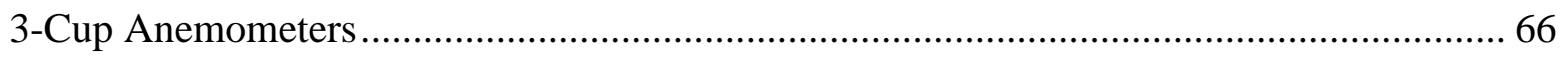

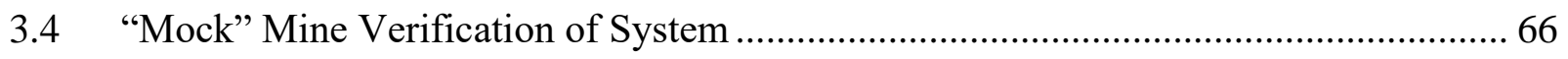

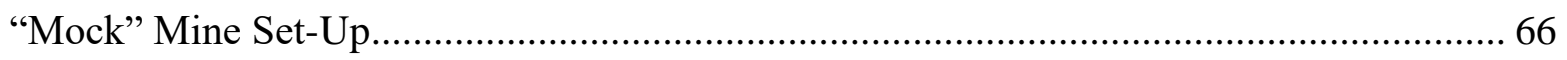

Ambient/Baseline Tests (Temperature, RH, Pressure) .......................................................... 71

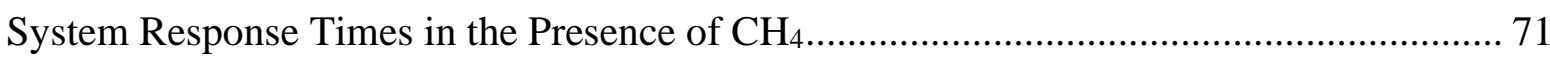

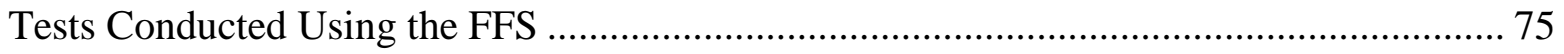

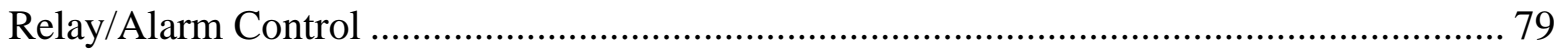

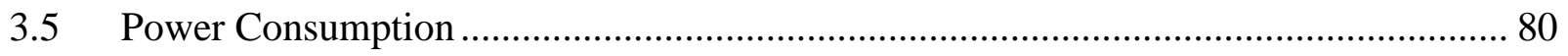

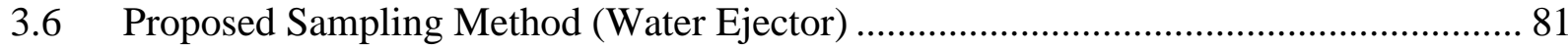

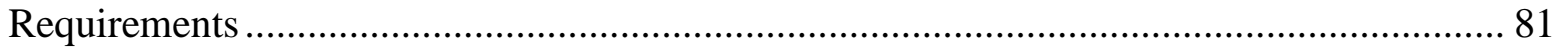

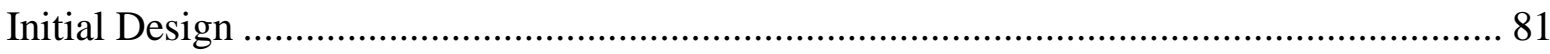

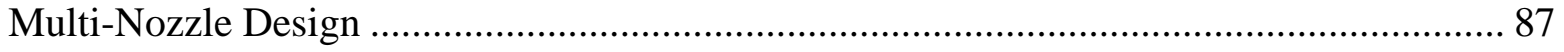

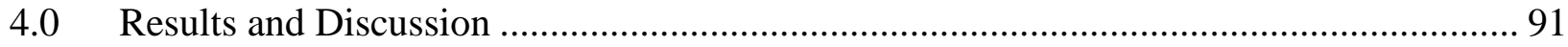

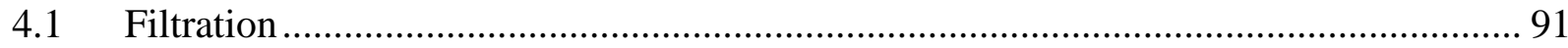

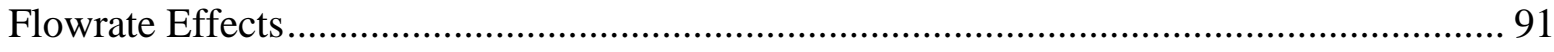

Coal Dust Loading ..................................................................................................... 91

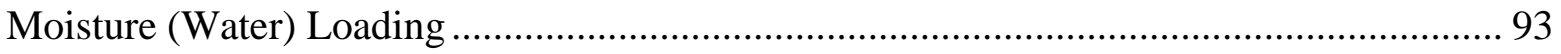

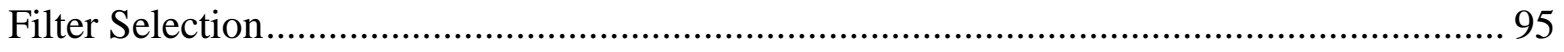

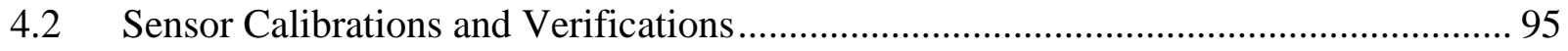

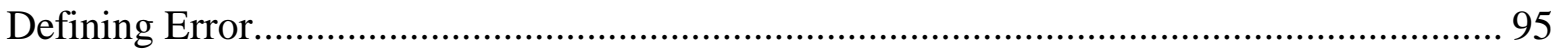

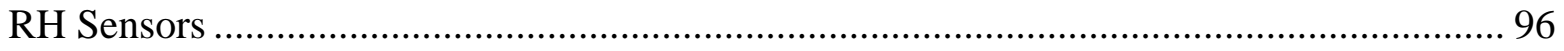

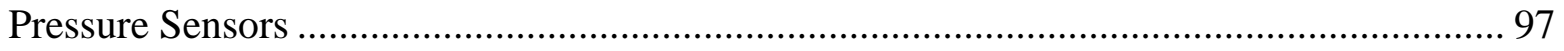

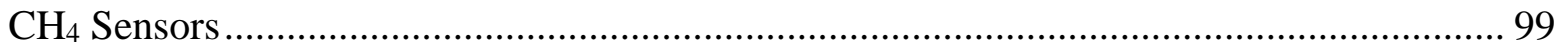

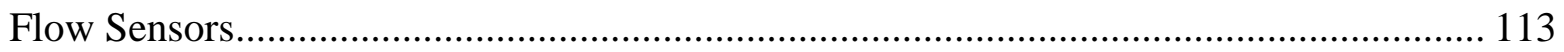

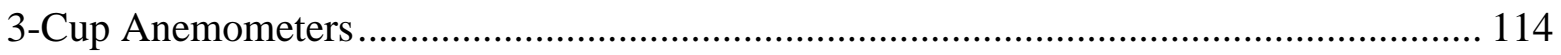

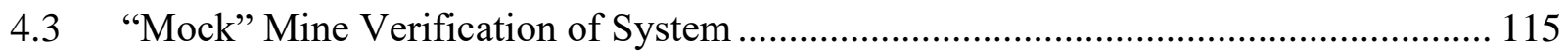

Ambient/Baseline Tests (Temperature, RH, Pressure) ....................................................... 115 


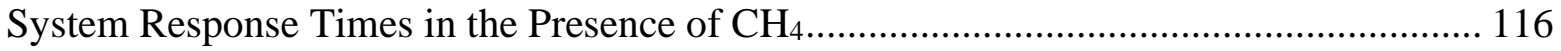

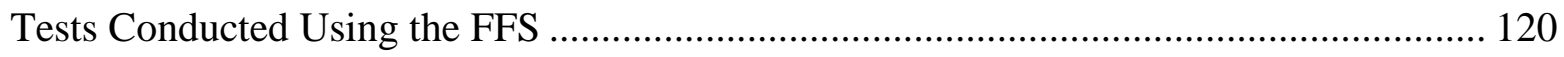

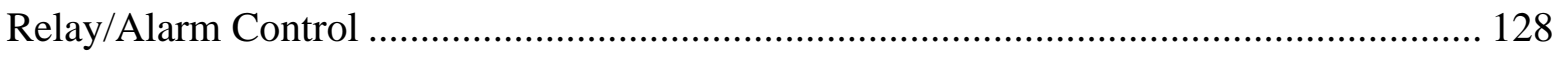

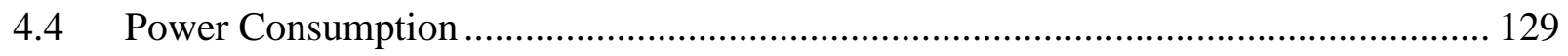

4.5 Proposed Sampling Method (Water Ejector) …………........................................ 130

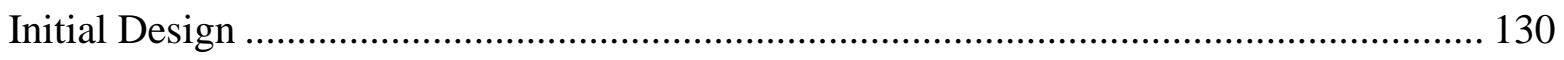

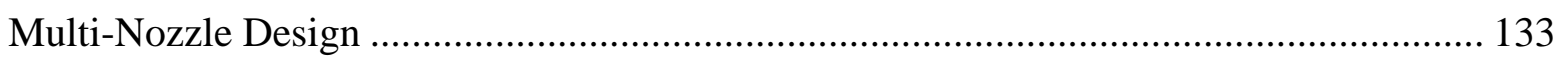

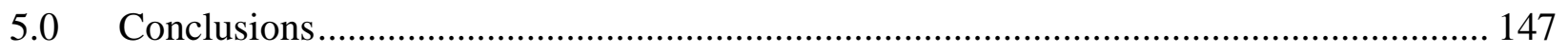

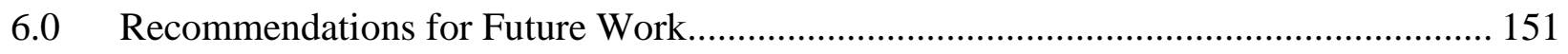

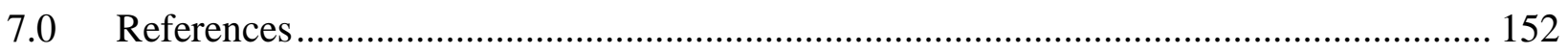

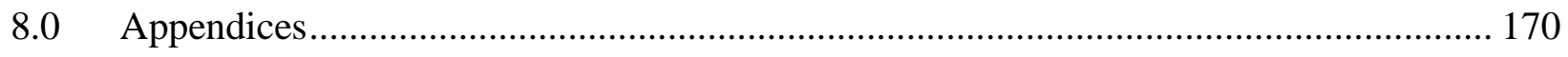

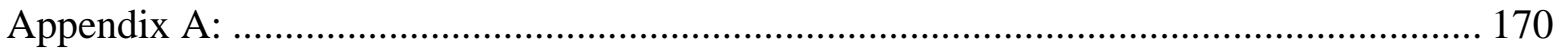

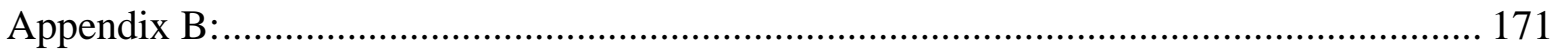

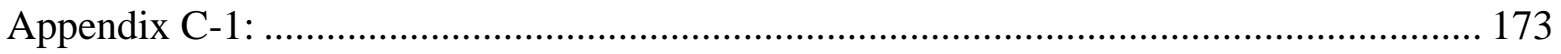

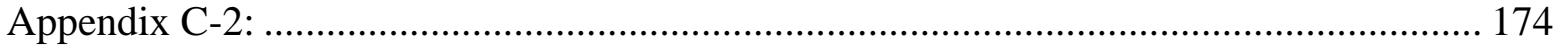

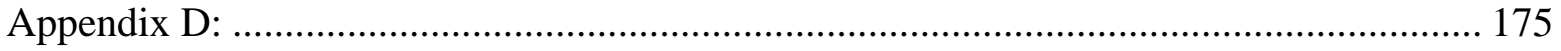

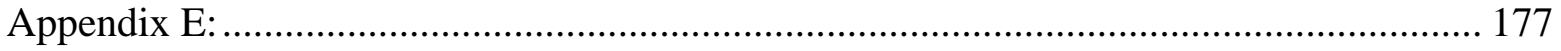

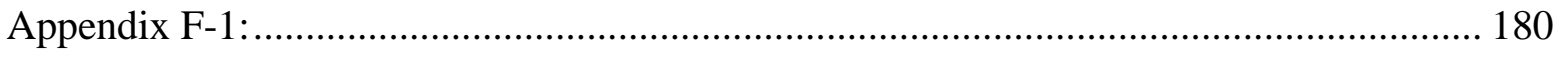

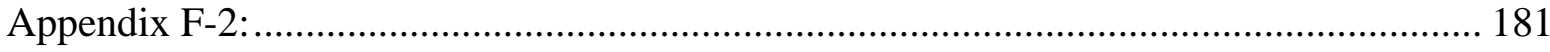

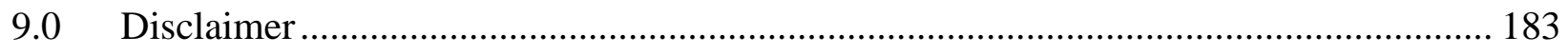


Table of Figures

Figure 1.0-1: Generic overview of longwall mining process. ..................................................... 2

Figure 1.0-2: Example rendering of longwall components at the face [2]. ................................ 2

Figure 2.1-1: Percent of total frictional ignitions based on machine type (data from 1983-2005)

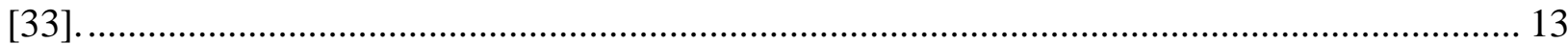

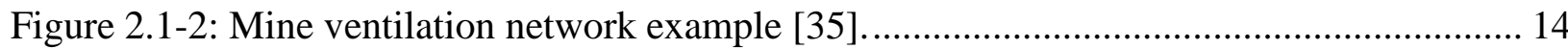

Figure 2.1-3: Ventilation velocities along longwall face for a HG-TG pass [32] ........................ 16

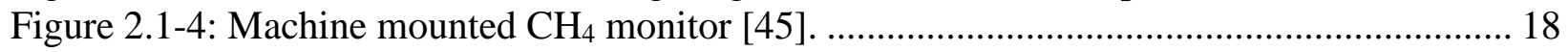

Figure 2.1-5: Portable gas monitor from RKI instruments [46] .............................................. 19

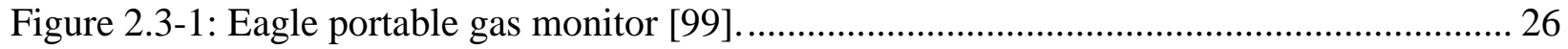

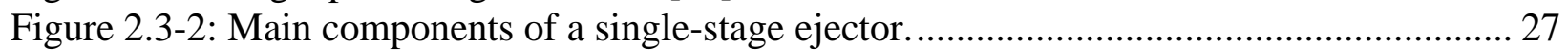

Figure 2.3-3: Ejector refrigeration system (a) with corresponding P-h diagram (b) [102]........... 28

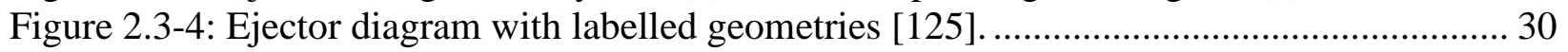

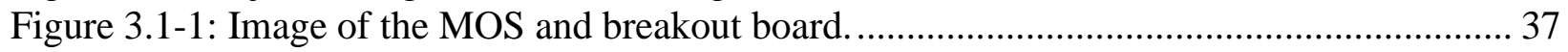

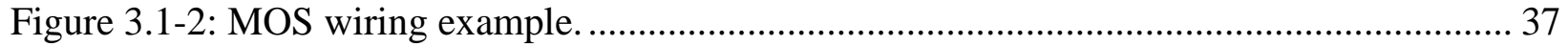

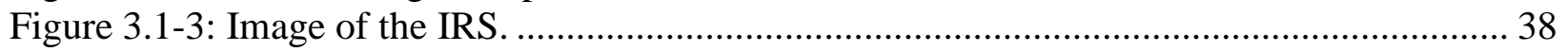

Figure 3.1-4: RH sensor (left), temperature sensor (middle), and pressure sensor (right) ........... 39

Figure 3.1-5: 3-Cup anemometer used to measure ventilation/wind speeds [147]....................... 40

Figure 3.1-6: Flow sensor used in unit for measuring sample flowrate [148] .............................. 40

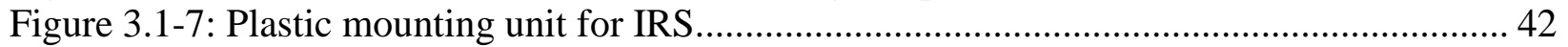

Figure 3.1-8: Metal housing and plate for MOS mounting. ...................................................... 42

Figure 3.1-9: 3-D model of aluminum sensor block...................................................................... 43

Figure 3.1-10: Sensors mounted in the block and flow sensor integration.................................... 44

Figure 3.1-11: 3-Cup anemometer mounted on sampling unit...................................................... 44

Figure 3.1-12: 3-D model of sampling unit with components.................................................... 47

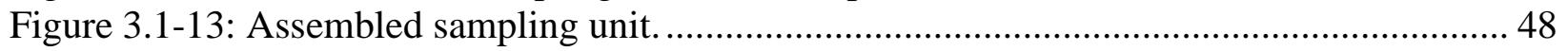

Figure 3.1-14: 3-Cup anemometer mounted on sampling unit ................................................... 48

Figure 3.1-15: CPH closed (left) and open (right)............................................................. 49

Figure 3.1-16: Diagram of "daisy-chain" connection of sampling units...................................... 50

Figure 3.1-17: Two sampling locations at each node configuration............................................ 51

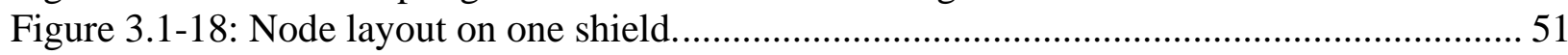

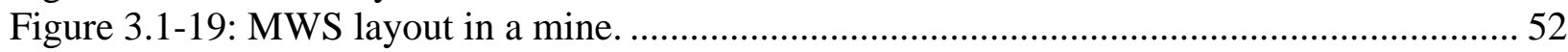

Figure 3.2-1: Three Filters Analyzed for System Filtration ..................................................... 53

Figure 3.3-1: Setup for IRS and MOS calibration and verification............................................. 56

Figure 3.3-2: Image of the Edgetech DewMaster chilled mirror hygrometer [157]...................... 56

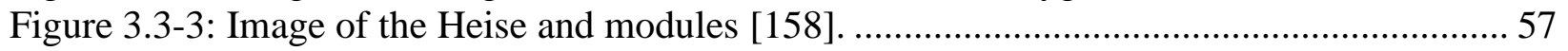

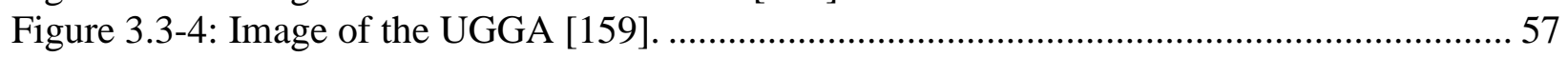

Figure 3.3-5: Calibration performed on the UGGA using a 2.01\% (20,100 ppm) $\mathrm{CH}_{4}$ bottle..... 58

Figure 3.3-6: UGGA calibration verification after external calibration was applied. .................. 59

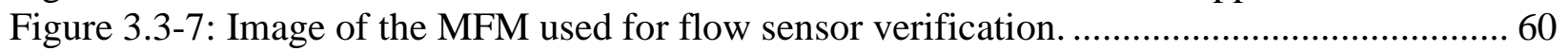

Figure 3.3-8: Image of the WindSonic 2-D ultrasonic anemometer [160] .............................................. 60

Figure 3.3-9: Left - test chamber with equipment, right - inside of test chamber........................ 63

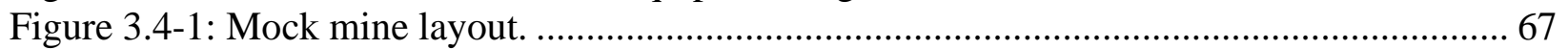

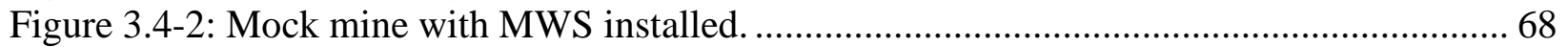

Figure 3.4-3: Cup anemometer mounted on sampling unit at Node 2........................................... 69

Figure 3.4-4: Pump and manifold mounted to the "T" structure. .................................................... 70 


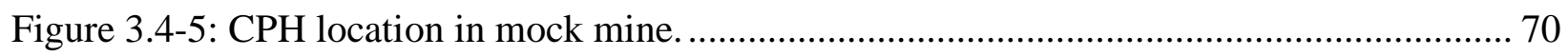

Figure 3.4-6: iBTHX and its location in the mock mine. ................................................... 71 Figure 3.4-7: Valve setup for the supply of methane using a flooded probe approach used in both

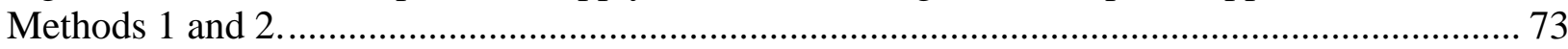

Figure 3.4-8: Example of a sensor's response to help visualize rise and decay times. .............. 74

Figure 3.4-9: Response time testing - Method 2 setup. ................................................... 75

Figure 3.4-10: Use of the FFS system for creation of high volumetric flow rates of lower

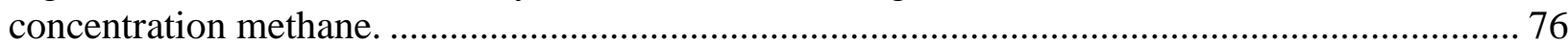

Figure 3.4-11: Location of FFS with respect to Node 1.................................................... 77

Figure 3.4-12: Type 3 FFS Test - Visualization for one sampling location. ............................. 78

Figure 3.4-13: Type 4 FFS Test - Visualization of test setup.......................................... 78

Figure 3.4-14: $\mathrm{CPH}$ interface showing IRS 1 measuring a $\mathrm{CH}_{4}$ concentration above the $1 \%$

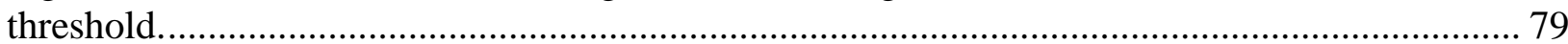

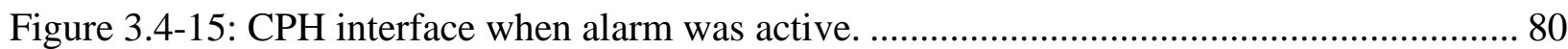

Figure 3.6-1: Ejector efficiency curve. ..................................................................... 84

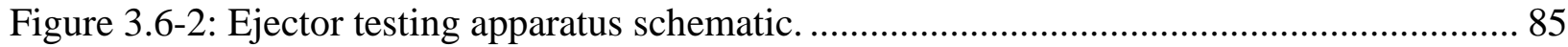

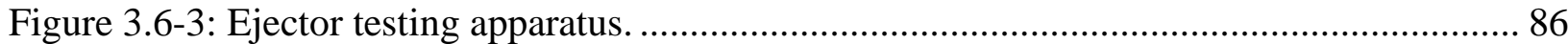

Figure 4.1-1: Effects of flowrate on the pressure drop across filters..................................... 91

Figure 4.1-2: Pressure drop due to coal loading for three filters at 3 SLPM............................ 93

Figure 4.1-3: Pressure drop due to water loading for three filters at 3 SLPM.......................... 94

Figure 4.1-4: Filter 3 selected for use in the MWS....................................................... 95

Figure 4.2-1: Calibration curve for the RH sensors at $23^{\circ} \mathrm{C}$ using the Edgetech as reference for

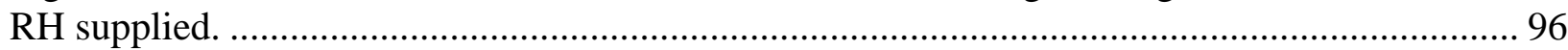

Figure 4.2-2: RH Sensor calibration verified with the Edgetech........................................ 97

Figure 4.2-3: Calibration curve for the pressure sensors using Heise as static pressure reference.

Figure 4.2-4: Pressure sensor calibration verification with Heise. .......................................... 99

Figure 4.2-5: Initial testing to determine temperature effects on the MOS. ............................ 100

Figure 4.2-6: Initial testing to determine temperature effects on the IRS. ............................. 100

Figure 4.2-7: Humidity effects on MOS and IRS raw responses (no $\mathrm{CH}_{4}$ present)................ 101

Figure 4.2-8: Pressure effects on MOS and IRS response with $\sim 1 \% \mathrm{CH}_{4}$ supplied................. 102

Figure 4.2-9: Pressure effects on MOS and IRS response zoomed in to expected minimum

system pressure when in operation. ........................................................................... 102

Figure 4.2-10: Flowrate effects on MOS and IRS raw responses with $\sim 1 \% \mathrm{CH}_{4}$ supplied....... 103

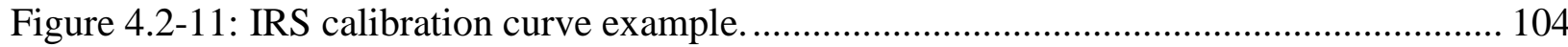

Figure 4.2-12: IRS plot used for humidity calibration corrections....................................... 105

Figure 4.2-13: Example of MOS 20-Point dry calibration curve and equation....................... 106

Figure 4.2-14: MOS plot used for humidity calibration corrections. .................................... 107

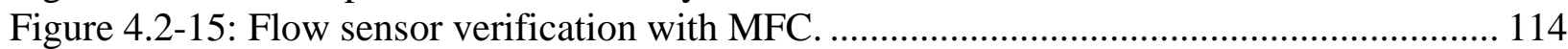

Figure 4.3-1: Temperature, RH, and pressure during a long-term test (test 5).................... 116

Figure 4.3-2: Example of MOS response for sampling locations 1-5 using method 1............. 118

Figure 4.3-3: Type 1 FFS Test - MOS offset raw responses for sampling locations 1-10....... 121

Figure 4.3-4: Type 1 FFS Test - MOS offset raw response zoomed into initial response........ 121

Figure 4.3-5: Type 1 FFS Test - MOS responses for sampling locations 1-10...................... 122

Figure 4.3-6: Type 2 FFS Test - MOS offset raw responses for sampling locations 1-10. ...... 122

Figure 4.3-7: Type 2 FFS Test - MOS offset raw responses zoomed into initial response....... 123 
Figure 4.3-8: Type 2 FFS Test - MOS responses for sampling locations $1-10 \ldots \ldots \ldots \ldots \ldots \ldots \ldots \ldots . . . . . . . .123$

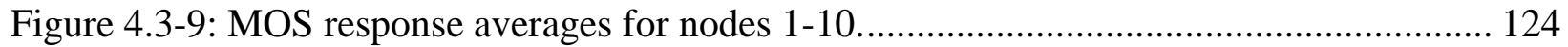

Figure 4.3-10: Type 3 FFS test - IRS responses for sampling locations 1-10 ........................ 125

Figure 4.3-11: Type 3 FFS test - MOS responses for Sampling Locations 1-10.................... 126

Figure 4.3-12: Type 4 FFS test - IRS responses for sampling locations 1-10...................... 127

Figure 4.3-13: Type 4 FFS test - MOS responses for sampling locations 1-10..................... 128

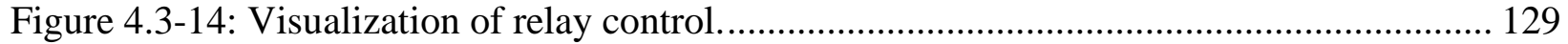

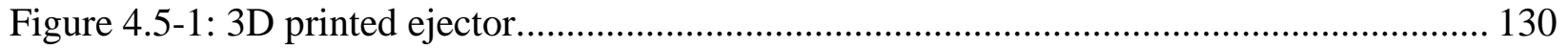

Figure 4.5-2: Ejector performance curves. ................................................................... 132

Figure 4.5-3: Disassembled multi-nozzle ejector CAD model.......................................... 134

Figure 4.5-4: Assembled multi-nozzle ejector CAD model. ............................................... 134

Figure 4.5-5: Disassembled multi-nozzle ejector. ............................................................. 135

Figure 4.5-6: Assembled multi-nozzle ejector.................................................................. 135

Figure 4.5-7: Multi-nozzle ejector test (water pressure $\approx 30 \mathrm{psig}$ ) .................................... 136

Figure 4.5-8: Multi-nozzle ejector test (water pressure $\approx 40$ psig) ...................................... 137

Figure 4.5-9: Multi-nozzle ejector test (water pressure $\approx 45 \mathrm{psig}$ )...................................... 137

Figure 4.5-10: Multi-nozzle ejector test (water pressure $\approx 55 \mathrm{psig}$ )................................... 138

Figure 4.5-11: Multi-nozzle ejector test (water pressure $\approx 65 \mathrm{psig}$ )................................... 138

Figure 4.5-12: Relationship between air flowrate and water pressure.................................. 140

Figure 4.5-13: Relationship between flow ratio and water pressure. ..................................... 140

Figure 4.5-14: Modelled flow ratios compared to experimental. ......................................... 142

Figure 4.5-15: Outlet pressure trend from experimental data.............................................. 143

Figure 4.5-16: Air volume fraction contour....................................................................... 145

Figure 4.5-17: Velocity contour.................................................................................. 145

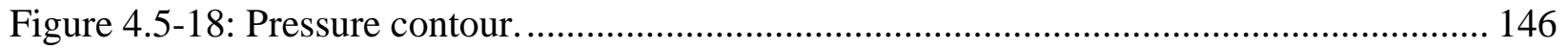




\section{Table of Tables}

Table 2.1-1: Temperature and RH information summary. ................................................... 8

Table 2.1-2: Coal mine dust parameters. ............................................................................ 9

Table 2.1-3: Statistical summary of coal mining disasters in the U.S. [31] .............................. 10

Table 2.1-4: Number of coal mining disasters and worker deaths by casual classification

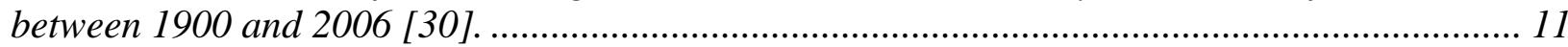

Table 2.1-5: Major underground coal mine explosions around the world occurring after 2000

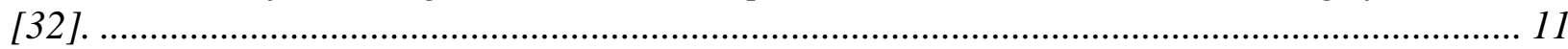

Table 2.1-6: Summary of longwall coal mine dimensions and ventilation data........................ 15

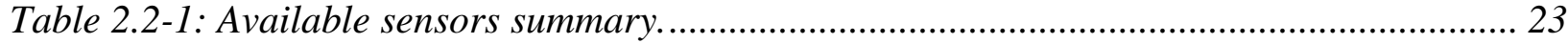

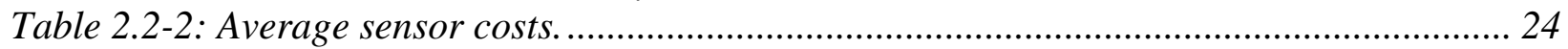

Table 2.3-1: M values summary......................................................................................... 29

Table 2.4-1: Sensor response times summary..................................................................... 31

Table 2.4-2: Comparison of response times for three monitors using two $\mathrm{CH}_{4}$ delivery methods (with dust cap integrated) [133] [97].................................................................................. 32

Table 2.4-3: Comparison of response times for three monitors with and without dust cap (using

"Test Box" delivery method) [97] ....................................................................................... 32

Table 2.4-4: Response times for two IR monitors and one CAT monitor................................... 33

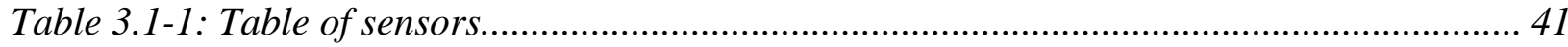

Table 3.1-2: Components housed within each sampling box (node)...................................... 45

Table 3.2-1: Filter Specifications ......................................................................................... 53

Table 3.3-1: Sensors and equipment used in the calibration and verification methods.............. 54

Table 3.3-2: UGGA Calibration Results Verified to GD Corrected Values................................ 59

Table 3.3-3: Table of Reference Analyzers........................................................................ 61

Table 3.6-1: Ratios used for ejector design.......................................................................... 84

Table 3.6-2: Multi-nozzle ejector recommended design parameters........................................ 87

Table 4.1-1: Effects of flowrate on the pressure drop across filters. ....................................... 91

Table 4.1-2: Effects of coal dust loading for filter 1........................................................... 92

Table 4.1-3: Effects of coal dust loading for filter 2........................................................... 92

Table 4.1-4: Effects of coal dust loading for filter 3................................................................. 92

Table 4.1-5: Effects of moisture loading for filter 1............................................................. 93

Table 4.1-6: Effects of moisture loading for filter 2.......................................................... 94

Table 4.1-7: Effects of moisture loading for filter 3.......................................................... 94

Table 4.2-1: RH values reported by RH sensor and compared to the Edgetech...................... 97

Table 4.2-2: Pressure sensor compared to Heise measurements. ............................................. 99

Table 4.2-3: IRS calibration correction factors. ................................................................... 105

Table 4.2-4: MOS calibration correction factors. ................................................................. 107

Table 4.2-5: MOS 1 and IRS 1 compared to the UGGA measurement. ................................. 108

Table 4.2-6: MOS 2 and IRS 2 compared to the UGGA measurement. ................................. 109

Table 4.2-7: MOS 3 and IRS 3 compared to the UGGA measurement. ................................. 109

Table 4.2-8: MOS 4 and IRS 4 compared to the UGGA measurement. .................................. 110

Table 4.2-9: MOS 5 and IRS 5 compared to the UGGA measurement. ................................. 110

Table 4.2-10: MOS 6 and IRS 6 compared to the UGGA measurement. ............................... 111

Table 4.2-11: MOS 7 and IRS 7 compared to the UGGA measurement. ................................ 111

Table 4.2-12: MOS 8 and IRS 8 compared to the UGGA measurement. ................................ 112

Table 4.2-13: MOS 9 and IRS 9 compared to the UGGA measurement. ............................... 112 
Table 4.2-14: MOS 10 and IRS 10 compared to the UGGA measurement. ............................ 113

Table 4.2-15: Flow sensor verification with MFC. ................................................................ 114

Table 4.2-16: 3-Cup anemometer verification with the WindSonic. ....................................... 115

Table 4.3-1: Response time test - Method 2 comparison of response times at different supply

flowrates..................................................................................................................... 117

Table 4.3-2: Rise and decay times for both methods and the difference between them........... 119

Table 4.3-3: Type 3 FFS Test-Percent difference between peak responses (20 s averages) of

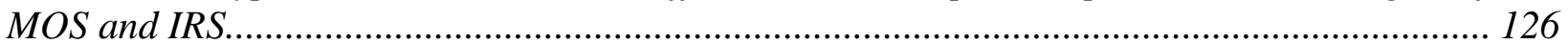

Table 4.3-4: Type 4 FFS Test - Peak responses of MOS and IRS. ....................................... 128

Table 4.4-1: Power Consumption for a Single Unit........................................................... 129

Table 4.5-1: Initial ejector design dimensions. ............................................................... 130

Table 4.5-2: Points of "Low" pressure curve......................................................................... 132

Table 4.5-3: Initial design ejector test with constant air suction pressure. .............................. 133

Table 4.5-4: Multi-Nozzle ejector design dimensions............................................................ 133

Table 4.5-5: Multi-nozzle ejector test with constant air suction pressure ................................. 139

Table 4.5-6: CFD model results for Points 3 through 7..................................................... 141

Table 4.5-7: Comparison of experimental to modeled results................................................ 141

Table 4.5-8: Modelled results for water pressures of 100 and 150 psig................................ 143

Table 4.5-9: CFD model results of the scaled-down design................................................. 144

Table 4.5-10: Scaled-down design dimensions................................................................... 144 
List of Acronyms and Abbreviations

Acronym/Abbreviation

${ }^{\circ} \mathrm{C}$

${ }^{\circ} \mathrm{F}$

A

AI

$\mathrm{AO}$

$\mathrm{C}$

$\mathrm{C}_{2} \mathrm{H}_{6}$

$\mathrm{CAD}$

CAT

CEAS

CFD

cfm

CFR

$\mathrm{CH}_{4}$

$\mathrm{CPH}$

CRDS

$\mathrm{D}$

DAQ

DC

DI

DO

FFS

fpm

$\mathrm{ft}$

$\mathrm{g}$

GD

GPM

$\mathrm{H}_{2} \mathrm{O}$

$\mathrm{HC}$

HG

in

$\mathrm{inH}_{2} \mathrm{O}$

IR

$\mathrm{K}$

$\mathrm{kPa}$

$\mathrm{k} \Omega$

$\mathrm{L}$

$\mathrm{lb}$
Word or Phrase

Degree Celsius

Degree Fahrenheit

Area

Analog Input

Analog Output

Ejector Density Ratio

Ethane

Computer Aided Design

Catalytic Heat of Combustion

Cavity Enhanced Absorption Spectroscopy

Computational Fluid Dynamics

Cubic Feet per Minute

Code of Federal Regulations

Methane

Central Processing Hub

Cavity Ringdown Spectroscopy

Diameter

Data Acquisition

Direct Current

Digital Input

Digital Output

Full Flow Sampling System

Feet per Minute

Foot

Gram

Gas Divider

Gallons per Minute

Water

Hydrocarbon

Headgate

Inch

Inches of Water

Infrared

Ejector Loss Coefficients

Kilopascal

Kilohm

Length

Pound 
LEL

LGR

LPM

$\mathrm{m}$

$\mathrm{M}$

$\mathrm{mA}$

MAF

MFC

MFM

$\mathrm{mm}$

MO

MSHA

MWS

$\mathrm{N}$

NDIR

NPT

NXP

ppm

psia

psig

PTFE

Q

Re

$\mathrm{RH}$

$\mathrm{S}$

scfm

SDF

SLA

SLPM

$\mathrm{SnO}_{2}$

TBS

TG

UEL

UGGA

UZA

$\mathrm{V}$

W

$\rho$

$\omega$

$\eta$

$\dot{\mathrm{m}}$
Lower Explosive Limit

Los Gatos Research

Liters per Minute

Meter

Ejector Flow-ratio

Milliampere

Mass Air Flow

Mass Flow Controller

Mass Flow Meter

Millimeter

Metal-Oxide

Mine Safety and Health Administration

Methane Watchdog System

Ejector Pressure Ratio

Non Dispersive Infrared

National Pipe Thread

Nozzle-Exit Position

Parts per Million

Pounds per Square Inch Absolute

Pounds per Square Inch Gauge

Polytetrafluoroethylene

Volumetric Flowrate

Reynolds Number

Relative Humidity

Seconds

Standard Cubic Feet per Minute

Scale-Down Factor

Stereolithography

Standard Liters per Minute

Tin Dioxide

Tube Bundle System

Tailgate

Upper Explosive Limit

Ultra-Portable Greenhouse Gas Analyzers

Ultra-Zero Air

Volt

Watt

Density

Humidity Ratio

Ejector Efficiency

Mass Flowrate 


\subsection{Introduction}

Longwall mining is one of the most safe and efficient underground coal mining methods used in industry today. The longwall technique has grown in popularity since it began in the U.S. in the 1970s. Between 1983 and 1993, longwall productivity more than doubled and has continued to grow since [1]. It has overtaken room-and-pillar mining as the most productive and efficient form of underground coal mining [1]. A longwall mining operation begins by locating a coalbed and a section, or panel, of desired dimensions is blocked off. Major components of longwall mining operations include mobile roof supports, cutting machines, and a conveyor system. The roof supports, also known as the shields, are crucial to the safety of the miners as they prevent the newly exposed roof from collapsing. The shearer traverses the longwall panel, cutting a prescribed coal thickness at a desired speed. The newly cut coal falls onto a conveyor and is transported out of the mine [1]. The shearer begins cutting at the headgate (HG) of the mine, where ventilation air is being supplied, and progresses towards the tailgate (TG); this represents one cutting pass of the longwall. The length of a pass is herein referred to as the longwall length. The exposed coal after the cutting pass is known as the longwall coal face. After the initial pass, the shearer reverses direction and then cuts from the TG to the HG. As the shearer passes in either direction, the shields advance forward toward the newly exposed coal face allowing the roof behind the shields to collapse. This roof collapse creates an area known as the gob, where methane $\left(\mathrm{CH}_{4}\right)$ accumulation occurs. The shearer continues to make passes in both directions until the entire panel is mined. Figure 1.0-1 shows a diagram of the longwall mining process. Figure 1.0-2 shows a 3-D computer aided design (CAD) rendering of an example longwall geometry. 


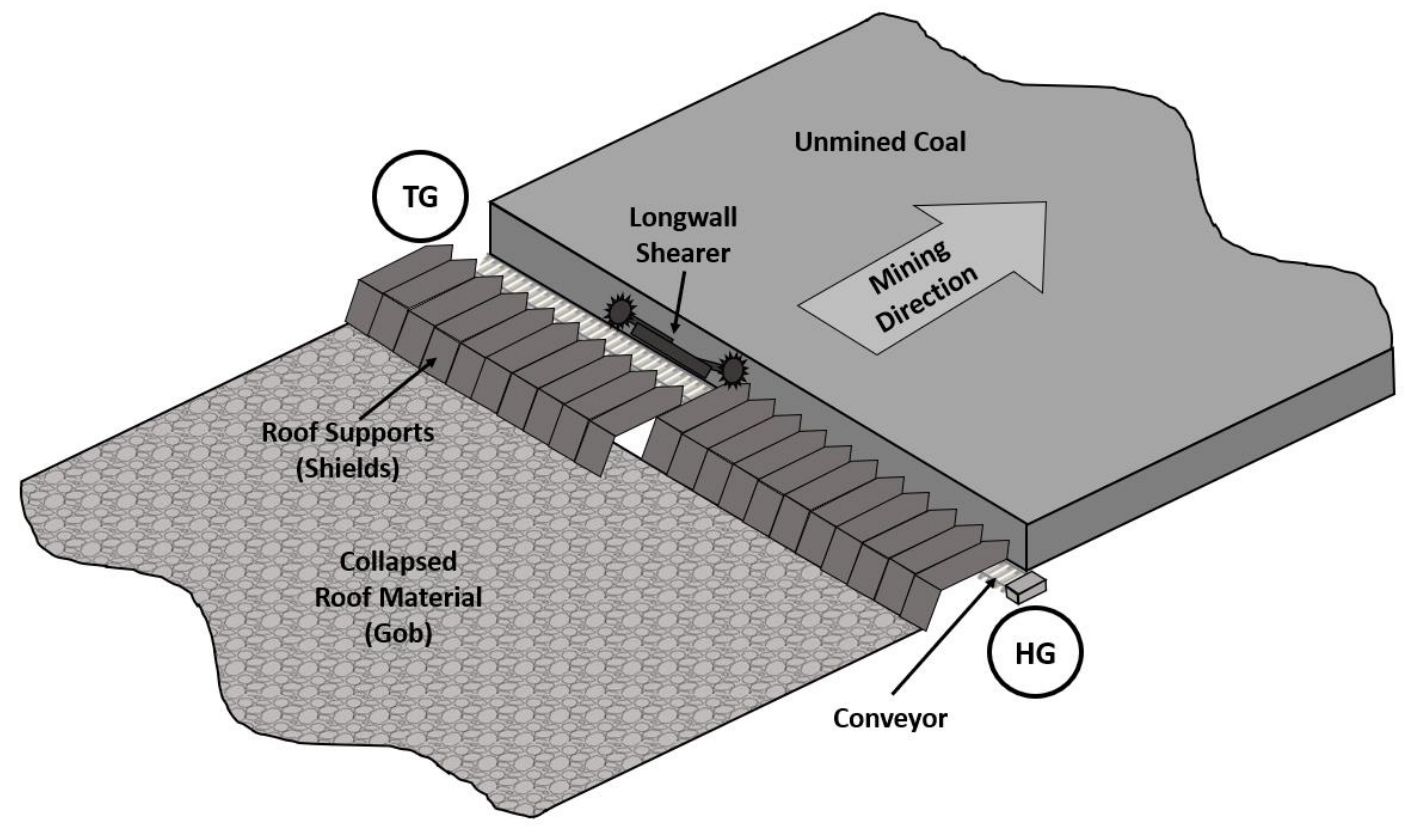

Figure 1.0-1: Generic overview of longwall mining process.

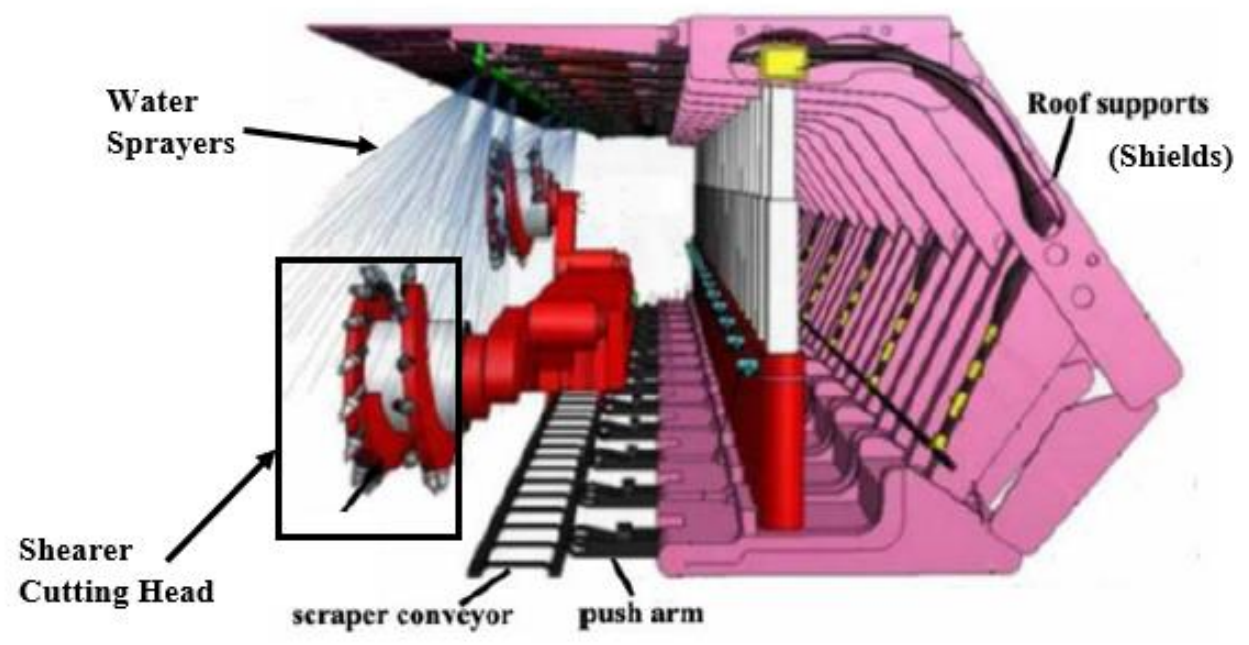

Figure 1.0-2: Example rendering of longwall components at the face [2].

With the growth of the industry, safety and technology improvements have become a major research topic. A principal danger in longwall mining is $\mathrm{CH}_{4}$ related explosions. $\mathrm{A} \mathrm{CH}_{4}$-dry air mixture at atmospheric pressure is explosive between the lower explosive limit (LEL) of $5 \% \mathrm{CH}_{4}$ by volume and the upper explosive limit (UEL) of $15 \%$ by volume; all $\mathrm{CH}_{4}$ concentrations herein are presented on a volume basis [3]. $\mathrm{CH}_{4}$ is trapped in the coal during its formation and is released when the coal is cut during the mining process. As the $\mathrm{CH}_{4}$ is emitted, potentially dangerous $\mathrm{CH}_{4}$ air mixtures can form if not properly mitigated. Ventilation systems are implemented as $\mathrm{CH}_{4}$ 
mitigation strategy in mines. These systems provide dilution air from the surface to the longwall section being mined to prevent elevated levels of $\mathrm{CH}_{4}$ from forming [4]. Areas near the roof are of concern since $\mathrm{CH}_{4}$ is lighter than air and buoyant forces cause it to rise above air, accumulating near the roof without proper ventilation [4] [5]. Due to the hazard of $\mathrm{CH}_{4}$ related explosions, mines have implemented regulations to prevent the dangerous $\mathrm{CH}_{4}$-air mixtures from forming in unwanted areas and to provide a safe work environment for miners.

These regulations include ventilation and dust control, and $\mathrm{CH}_{4}$ monitoring requirements. Ventilation plans are required to, at a minimum, produce an air velocity of $0.3 \mathrm{~m} / \mathrm{s}$ (60 fpm) at defined locations. However, depending on the mine dimensions and production rates, a greater velocity is sometimes required to mitigate elevated $\mathrm{CH}_{4}$ concentrations [3]. Dust control is also an important component to the longwall mining process because coal dust particles are also flammable [6]. Coal dust may increase the intensity of an explosion caused by a $\mathrm{CH}_{4}$-air mixture ignition. In April of 2010, a $\mathrm{CH}_{4}$-air mixture ignited at the Upper Big Branch mine causing one of the most recent longwall mining disasters in the US. The explosion was intensified by coal dust and 29 miners lost their lives [7]. Mines deploy dust control methods, such as water sprayers integrated into the shields and shearer (presented in Figure 2.1-2), to meet regulations.

Due to the dangers associated with $\mathrm{CH}_{4}$ in a longwall mining process, $\mathrm{CH}_{4}$ monitoring is crucial to the safety of the working environment. Industry has typically defaulted to the use of catalytic heat of combustion (CAT) sensors because they are relatively low cost and robust. However, they are generally used in combination with an oxygen sensor since CAT sensors require a certain oxygen concentration for accurate measurements. Some research suggests that infrared (IR) sensors are suitable for use in a longwall mining operation [8]. Further research investigating the potential use of IR and other sensors in industry will be beneficial for the growth of $\mathrm{CH}_{4}$ monitoring technologies.

Title 30 Code of Federal Regulations (CFR) Part 75.342 (30 CFR §75.342) requires the mounting of $\mathrm{CH}_{4}$ monitors on the coal cutting machine, also referred to as the shearer [3]. The monitor is mounted as close to the face as possible (without likely cause of physical damage), because $\mathrm{CH}_{4}$ concentrations tend to be high near the shearer. Miners must also take measurements with portable monitors periodically throughout the process, typically at least once per shift (more frequently for some locations). Portable monitor measurements are made in locations where $\mathrm{CH}_{4}$ accumulation is likely, such as near the roof, at the longwall face, and at the back of the shields, near the gob. 
These locations are determined prior to the start of the mining process and can alter during the process if deemed necessary by a qualified person. Time increments for $\mathrm{CH}_{4}$ measurements taken at these locations are regulated and set forth by 30 CFR $\$ 75.336$ and 30 CFR $\$ 75.362$ [9] [10]. Taking measurements in these dangerous locations may place the miner at risk of physical harm, either by the potential for $\mathrm{CH}_{4}$-air mixture ignition or by "pinch" points at the back of the shields near the gob. Federal regulations require a warning signal be given if any monitor measures $1 \%$ $\mathrm{CH}_{4}$. All electrical equipment must be deenergized (production stoppage) if any monitor measures $2 \% \mathrm{CH}_{4}$. These concentration regulations were developed based on research concluding that if $\mathrm{CH}_{4}$ concentrations at the measurement locations were maintained below these limits, $\mathrm{CH}_{4}$ concentrations at the face should not exceed the LEL [11]. Thus, this method relies on indirect assumptions based on limited empirical data. De-energization of equipment prevents the shearer from entering and possibly igniting a dangerous $\mathrm{CH}_{4}$-air mixture. Since production stoppages hinder the efficiency of production, it is ideal to limit the number of these scenarios.

Monitors typically operate by using either a passive (diffusion) or active sampling method. Passive sampling monitors are placed directly in the sampling location and the sample passes by the monitor via an external source, such as ventilation flow, movement of the shearer, or movement of the miner [12]. Some portable monitors utilize an active sampling method and are equipped with an electric pump. The pump actively draws the sample into the monitor, decreasing the time the sample has to pass over the sensors [12]. This ultimately decreases the monitor response time, which is a critical component to $\mathrm{CH}_{4}$ monitoring. The sensor type, housing, and sampling method all effect the response time of the monitor. An active sampling method also allows the attachment of a sealed conduit (i.e. a tube) to the monitor, traveling from the monitor to a dangerous sampling location. If used on a portable monitor, this allows the miner to stand at a safer distance from the sampling location or take measurements in restricted areas not easily accessible [12]. For response time improvement, the transit time (time for the sample to travel from the sampling location to the sensor) should be minimized. While the use of a pump as an active sampling is an improvement to passive sampling, there are still downfalls to this method. Pumps are electric, making them a potential ignition source, so they must be intrinsically safe for mine use in the working area [13]. Pumps also consist of moving components which require maintenance. Another downfall of pumps utilized in portable monitors, is that they require operation by a miner and periodic charging of the battery. 
Due to the limited number and locations of monitors used in the longwall mining process, there are gaps, spatially and temporally, where a dangerous $\mathrm{CH}_{4}$-air mixture could form and not be detected. This poses the risk of the shearer entering the location and potentially igniting it, resulting in an explosion. This is one reason why response times of the monitors are crucial to these time sensitive measurements. The development of a multi-nodal $\mathrm{CH}_{4}$ monitoring system will benefit the longwall mining industry. A multi-nodal system, spanning the entire longwall, will decrease the spatial and temporal measurement gaps by increasing the number of measurement locations and by increasing the continuity of the measurements at these locations. It will also diminish the need for portable monitor measurements by placing sampling locations directly in the dangerous areas. This will reduce the risk to miners and eliminate the need for estimations of dangerous $\mathrm{CH}_{4}$ concentrations at the measurement locations, as used for regulations. The use of a non-electric, low-maintenance sampling method, such as an ejector, is ideal. A multi-nodal system will ultimately provide the ability to predict $\mathrm{CH}_{4}$ concentrations during the mining process, resulting in less production stoppages and an overall safer work environment.

Based on its potential for improved efficiency and safety, West Virginia University (WVU) was funded by the Alpha Foundation to design and develop the Methane Watchdog System (MWS). The Alpha Foundation is an organization which supports research related to the improvement of mine safety and health [14]. The MWS is a multi-nodal system that can easily be integrated into a mining process by utilizing the low-voltage direct current (DC) power source already provided to the shields. It was necessary that the development of the system involve the investigation of cost-effective $\mathrm{CH}_{4}$ sensors with the potential to replace the traditional CAT sensors. The MWS needed the capability to take accurate $\mathrm{CH}_{4}$ measurements from locations along the entire longwall, using a non-electric, low maintenance sampling method. Through the MWS development, it was necessary that Mining Safety and Health Administration (MSHA) regulations be considered; many monitor related regulations are set forth in 30 CFR Part 22 and Part 75. 


\section{Research Tasks}

As part of the research team and based on the goals of the research I completed the following research tasks as outline in five key areas presented below. A key component which led to the success of the research was the literature review. This directed the research to focus on important items such as sensor review, MSHA requirements, and sampling methods.

a.) Conduct literature review on...

- mine conditions, dimensions, and ventilation

- Current underground mining regulations related to the development of the MWS

- $\mathrm{CH}_{4}$ sensors currently implemented in monitors (including T90 response times)

- Current monitor sampling methods

- Power sources along the longwall

b.) Integrate alternative sensor types and conduct research to assess and compare advantages and disadvantages of each, including...

- Climate effects on responses

- Response ranges

- Response times

c.) Develop an inherently MSHA safe and compliant sampling method - water ejector

- Design an ejector based on system requirements

- Produce a prototype and test in laboratory

- Verify ejector capabilities

d.) Assess the basic requirements of such a system regarding federal regulation requirements and those set forth in the project including...

- power requirements

- cost efficiency

- alarm and de-energization requirements

e.) Construct and deploy the MWS for initial verification 


\subsection{Review of Literature}

To better understand the requirements and constraints necessary to design and assess the MWS, a thorough literature review was conducted. This review focused on longwall mine conditions, the inherent dangers of $\mathrm{CH}_{4}$ in a coal mine, regulations related to $\mathrm{CH}_{4}$ monitoring and monitoring systems, and detection devices and methods currently used in the mining industry.

\subsection{Background}

\section{Mining Conditions}

\section{Climate}

Due to the continuous flow of ventilation air, which is supplied to the mine from above ground via large intake or exhaust fans, the temperature within the mine is partially dictated by above ground weather conditions. Other factors that contribute to a temperature increase in a mine include auto compression in adiabatic conditions, radiant heat from equipment, and radiant heat from coal oxidation [15]. To ensure miner health and safety related to heat, mines implement temperature regulations. For example, the MSHA requires the apparent temperature of an occupied refuge alternative (a sealed area used to protect and sustain the lives of miners inside in the event of an emergency where they cannot exit the mine [16]) not exceed $35^{\circ} \mathrm{C}\left(95^{\circ} \mathrm{F}\right)$ as stated in Title $30 \mathrm{CFR}$ Part 7.504 [17]. Note that the apparent temperature (heat index) is an estimate of the temperature's effect on a person's body at a relative humidity $(\mathrm{RH})$ of around $20 \%$ and is calculated based on the actual temperature and RH [18].

For this research, mine climate conditions at $\mathrm{CH}_{4}$ measurement locations were of most concern. Yantek et al. conducted a study to validate a thermal simulation model of a refuge alternative. The temperature of the mine atmosphere varied between 10 and $21.1^{\circ} \mathrm{C}\left(50\right.$ and $\left.70^{\circ} \mathrm{F}\right)$ [19]. Yantek et al. assumed a relative humidity of $90 \%$ for the models [19]. Klein et al. also investigated refuge alternative environments and their effect on human core temperature and moisture levels with varying temperature/humidity combinations. For all scenarios, the relative humidity remained constant at 95\% [20]. The author of an early article in Scientific America evaluated temperatures at various depths in a coal mine. This article was published in 1869 and investigated temperatures at three coal mines in England. The author stated that the temperature range of the mine atmosphere was approximately 15.6 to $26.7^{\circ} \mathrm{C}\left(60\right.$ to $\left.80^{\circ} \mathrm{F}\right)$ for a variety of measurements throughout the year 
[21]. Ozdeniz et al. investigated spontaneous combustion of coal in an underground mine located in Tepebaşı region, Turkey using a data set based on ventilation exhaust temperatures. The results showed that the ventilation exhaust temperatures ranged from around 16.1 to $23.9^{\circ} \mathrm{C}\left(61\right.$ to $\left.75^{\circ} \mathrm{F}\right)$ between March $18^{\text {th }}$ and July $10^{\text {th }}$ in 2012 [22]. Khanal and McPhee investigated temperature and $\mathrm{RH}$ monitoring systems for use in underground mines. During their experiments, temperature varied between a range of approximately 20 to $25^{\circ} \mathrm{C}\left(68\right.$ to $\left.77^{\circ} \mathrm{F}\right)$ and $\mathrm{RH}$ varied between a range of approximately 25 to $95 \%$ RH [23]. Table 2.1-1 presents a summary of the temperature and RH information found in literature.

Table 2.1-1: Temperature and RH information summary.

\begin{tabular}{|c|c|c|}
\hline Source & $\begin{array}{c}\text { Temperature } \\
{\left[{ }^{\circ} \mathbf{C}\left({ }^{\circ} \mathbf{F}\right)\right]}\end{array}$ & $\begin{array}{c}\text { RH } \\
{[\%]}\end{array}$ \\
\hline$[19]$ & $10-21.1(50-70)$ & 90 \\
\hline$[20]$ & - & 95 \\
\hline$[21]$ & $15.6-26.7(60-80)$ & - \\
\hline$[22]$ & $16.1-23.9(61-75)$ & - \\
\hline$[23]$ & $20-25(68-77)$ & $25-95$ \\
\hline
\end{tabular}

Khanal et al. conducted a study to investigate the use of temperature and humidity monitoring systems used in underground coal mines. The authors obtained information from 18 persons in the Australian coal mine industry via a questionnaire. The results indicated that there was, at the time, no real-time monitoring system for temperature and humidity in any of the Queensland mines. Measurements were typically made during each shift in an area of greater concern for higher temperatures and where persons were working. They also determined that one issue with temperature and humidity measurements was the risk of human error when interpreting measurements, since manual thermometers were still used in many mines. Another issue with measurements taken by miners included that the proximity to the miner's body could introduce additional heat, affecting the measurement. The persons who completed the questionnaire believed that devices with digital readouts provided more accurate measurements without the need for interpretations/calculations. However, digital readout instruments were not intrinsically safe and could not be used. Most persons who completed the questionnaire also indicated that if real-time monitoring systems were available, they were interested in deploying them at their mine site [24]. 


\section{Particle Matter}

During the coal cutting process, respirable particles of coal dust are suspended in the air. Peng et al. examined respirable dust control and presented data on sources and size distribution [25]. The National Institute for Occupational Safety and Health (NIOSH) reported on the coal dust sizes from 47 coal mines and presented results for mesh size and median diameter [26]. The mesh size corresponds to the size of the openings in a screen or filter and the size of the particles which can pass through it. It is the number of openings in one linear inch of the screen [27]. They also examined the breakdown of samples with a focus on rock dust, which was required for bituminous mining since the application of rock dust assists in explosion prevention [28]. Particulate matter data for a mine atmosphere are of interest for this research as the coal and rock dust can cause damage to a $\mathrm{CH}_{4}$ monitoring system if not adequately protected or filtered. Data from literature were analyzed and are presented in Table 2.1-2.

Table 2.1-2: Coal mine dust parameters.

\begin{tabular}{|c|c|c|c|}
\hline & Average & Minimum & Maximum \\
\hline Dust Loading $\left(\mathbf{m g} / \mathbf{m}^{\mathbf{3}}\right)$ & 1.5 & $<1.5$ & $<2.0$ \\
\hline Dust Diameter $(\boldsymbol{\mu m})$ & $116-169$ & 98 & 197 \\
\hline Dust by Size (70 Mesh) $\mathbf{( \% )}$ & $59-77$ & 53 & 83 \\
\hline Dust by Size (200 Mesh) $\mathbf{( \% )}$ & $28-39$ & 25 & 43 \\
\hline
\end{tabular}

\section{Dangers Related to $\mathrm{CH}_{4}$ in Longwall Mining}

\section{$\mathrm{CH}_{4}$ Related Explosions}

$\mathrm{CH}_{4}$ is a colorless and odorless gas that, when mixed with air, can create a potentially explosive $\mathrm{CH}_{4}$-air mixture. $\mathrm{CH}_{4}$-air mixtures are explosive between $5 \%$ and $15 \% \mathrm{CH}_{4}$. It should be noted that the explosive limits of $5 \%$ and $15 \%$ are for $\mathrm{CH}_{4}$ mixed with dry air at atmospheric pressure; moisture, inert gasses, coal dust, other hydrocarbons (HCs) can narrow or expand the range. These limits are referred to as the lower explosive limit (LEL) and upper explosive limit (UEL), respectively. Mixtures in this explosive range have an ignition potential and can cause devastating accidents. This is especially dangerous in underground coal mining because $\mathrm{CH}_{4}$ is released from various sources during the mining process. Recently cut coal at the face and roof material that collapses behind the shields as they progress, creating the gob, emit $\mathrm{CH}_{4} \cdot \mathrm{CH}_{4}$ explosions in coal mines have caused serious injuries and deaths of numerous coal miners. One $\mathrm{CH}_{4}$ explosion that was related to gob gas occurred at the Willow Creek mine in Carbon City, Utah in 2000, killing 
two miners [29]. Another, more recent, accident occurred in the Upper Big Branch mine, located in Charleston, WV. Ignition of an area with an elevated concentration of $\mathrm{CH}_{4}$ caused an explosion which then ignited coal dust, increasing the severity. This explosion resulted in the death of 29 men [7]. According to Zipf et al., "Between 1976 and 2010, at least 25 explosions involving $\mathrm{CH}_{4}$ and coal dust occurred in the active areas of coal mines, resulting in at least 1 and up to 29 fatalities in each explosion" [30]. These explosions in U.S. mines resulted in at least 185 fatalities and many more seriously injured [30]. Table 2.1-3 presents a summary of U.S. coal mining disasters over recent decades. Most of these disasters were caused by explosions. However, it should be noted that the number of disasters has decreased over the last three decades, while longwall mining production increased. Table 2.1-4 presents a summary of the number of disasters and fatalities associated with the disaster classification between 1900 and 2006. The explosion classification accounted for around $82 \%$ of the total number of disasters and around $90 \%$ of the total number of deaths. In addition to the U.S., many countries around the world use underground mines to produce coal for energy use. Table 2.1-5 presents a summary of the major underground coal mine explosions from around the world. Fourteen of those major disasters occurred after 2000.

Table 2.1-3: Statistical summary of coal mining disasters in the U.S. [31].

\begin{tabular}{|c|c|}
\hline Historic Period & \# of Coal Mining Disasters in the U.S. \\
\hline Through 1875 & 21 \\
\hline $1876-1900$ & 105 \\
\hline $1901-1925$ & 308 \\
\hline $1926-1950$ & 149 \\
\hline $1951-1975$ & 36 \\
\hline $1976-2000$ & 14 \\
\hline $2001-$ present & 5 \\
\hline Total & $\mathbf{6 3 8}$ \\
\hline
\end{tabular}


Table 2.1-4: Number of coal mining disasters and worker deaths by casual classification between 1900 and 2006 [30].

\begin{tabular}{|c|c|c|}
\hline Casual Classification & $\begin{array}{c}\text { \# of Coal Mining } \\
\text { Disasters in the U.S. }\end{array}$ & \# of Deaths \\
\hline Explosion & 420 & 10,390 \\
\hline Fire & 35 & 727 \\
\hline Haulage* & 21 & 145 \\
\hline Ground fall/Bump** & 13 & 83 \\
\hline Inundation*** & 7 & 62 \\
\hline Other & 17 & 199 \\
\hline Total & $\mathbf{5 1 3}$ & $\mathbf{1 1 , 6 0 6}$ \\
\hline
\end{tabular}

*Transportation of personnel, material, or equipment

**Fall of roof rock or outward bursting of walls in an underground work area.

***Usually an inrush of toxic gasses or water from old mine working

Table 2.1-5: Major underground coal mine explosions around the world occurring after 2000 [32].

\begin{tabular}{|c|c|c|c|}
\hline Country & Date & Coal Mine & Fatalities \\
\hline China & February 14, 2005 & Sunjiawan, Haizhou Shaft, Fuxin & 214 \\
\hline USA & June 2, 2006 & Sago, West Virginia & 12 \\
\hline Poland & November 21, 2006 & KWK Halemba, Ruda Slaska & 19 \\
\hline Kazakhstan & September 20, 2006 & Lenina, Karaganda & 43 \\
\hline Russia & March 19, 2007 & Ulyanovskaya, Kemerovo & 108 \\
\hline Ukraine & November 19, 2007 & Zasyadko, Donetzk & 80 \\
\hline Poland & September 18, 2009 & KWK Wujek, Ruda Slaska & 20 \\
\hline USA & April 5, 2010 & Upper Big Branch, West Virginia & 29 \\
\hline Russia & May 8, 2010 & Raspadskaya, Kemerovo Oblast & 66 \\
\hline Turkey & May 17, 2010 & Karadon, Zonguldak & 30 \\
\hline New Zealand & November 19, 2010 & Pike River Mine & 29 \\
\hline Turkey & May 13, 2014 & Soma, Turkey & 301 \\
\hline Ukraine & March 4, 2015 & Zasyadko, Donetzk & 33 \\
\hline China & October 30, 2016 & Jinshangou, Chongqing & 33 \\
\hline
\end{tabular}




\section{Sources of Ignition}

$\mathrm{CH}_{4}$ related accidents are of high concern, partially because of the vast amount of ignition sources in underground mines. A "hot" solid, such as a piece of equipment with a temperature as low as $630{ }^{\circ} \mathrm{C}$ has the potential to ignite combustible gas mixtures and equipment with temperatures as low as $160{ }^{\circ} \mathrm{C}$ have the potential to ignite a coal dust layer [33]. Other potential sources of ignition are sparks created by a light metal alloy striking a piece of rusty steel or the friction from rocks and/or steel sliding against one another. Ignition can also be caused by the adiabatic compression of a collapsing roof [33]. There are many regulations involving electrical equipment in mines, however, electrical arcs are not a common source of ignition. In the 1960s and 1970s, about 40\% of coal mine fires could be traced back to an electrical source. However, from 1970 to 1977, only about 5\% of $\mathrm{CH}_{4}$ ignitions resulted from an electrical source; $85 \%$ of the total ignitions were frictional ignitions [34].

Longwall operations tend to have more frictional ignitions than other coal mining methods, such as room-and-pillar. Certain pieces of mining equipment are more likely to cause a frictional ignition than others. The continuous miner and longwall shearer are the two types of mining equipment that cause most frictional ignitions. Figure 2.1-1 presents a breakdown of the percent of total number of frictional ignitions cause by various pieces of mining equipment from 1983 to 2005 [33]. 


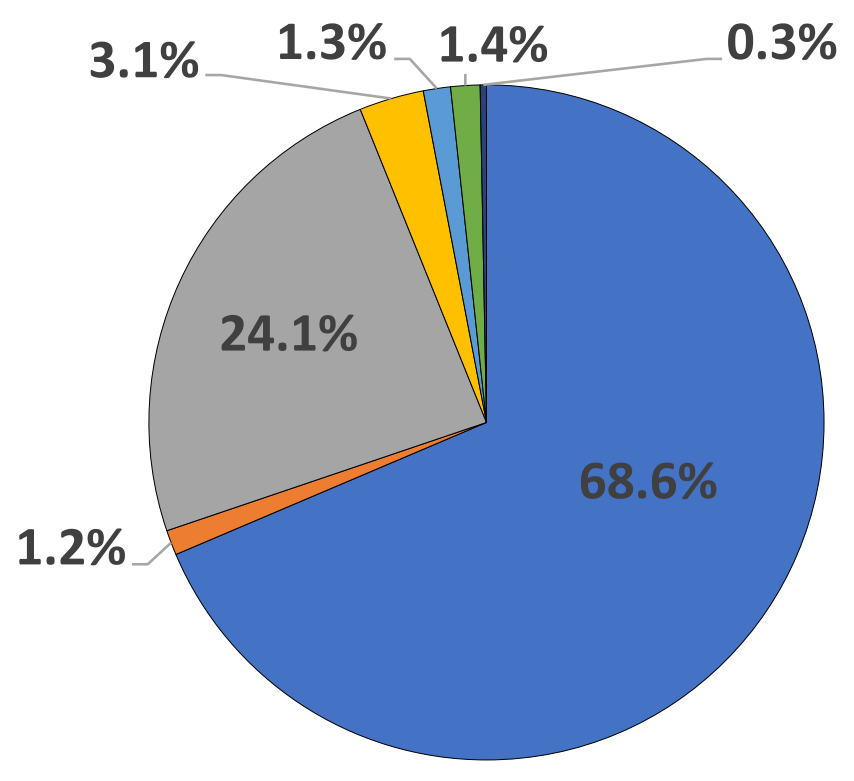

$\square$ Continuous Miner

$\square$ Cutting Machines

$\square$ Longwall Shearer

$\square$ Roof Bolter

$\square$ Unknown Equipment

Other Equipment

Ground Fall

Figure 2.1-1: Percent of total frictional ignitions based on machine type (data from 19832005) [33].

\section{Ventilation and Longwall Dimensions}

Since the density of $\mathrm{CH}_{4}$ is about half the density of air, buoyant forces cause $\mathrm{CH}_{4}$ to rise above air when the gases are stagnant [5]. This can cause $\mathrm{CH}_{4}$ to build up near the roof of the mine. When this occurs, it is referred to as a " $\mathrm{CH}_{4}$ roof layer" and becomes a safety concern. Ventilation plans are implemented in attempts to mitigate risks of explosion caused by these $\mathrm{CH}_{4}$ roof layers by providing fresh air to the face. Ventilation assists in the mixing of the air and $\mathrm{CH}_{4}$ to prevent the formation of the roof layers. Although regulations require a minimum ventilation speed of 0.30 $\mathrm{m} / \mathrm{s}$ (60 feet per minute (fpm) ), Kissell concluded that a ventilation velocity of at least $0.51 \mathrm{~m} / \mathrm{s}$ (100 fpm) is typically adequate to prevent the formation of $\mathrm{CH}_{4}$ layers at the roof [4]. The ventilation flows in the HG to TG direction. The ventilation air velocity can be increased as needed to help prevent layers from forming and/or dissipate layers that have already began forming; this ultimately reduces the risk of ignition [4]. Figure 2.1-2 shows an example of a ventilation network for visualization of flow directions. 


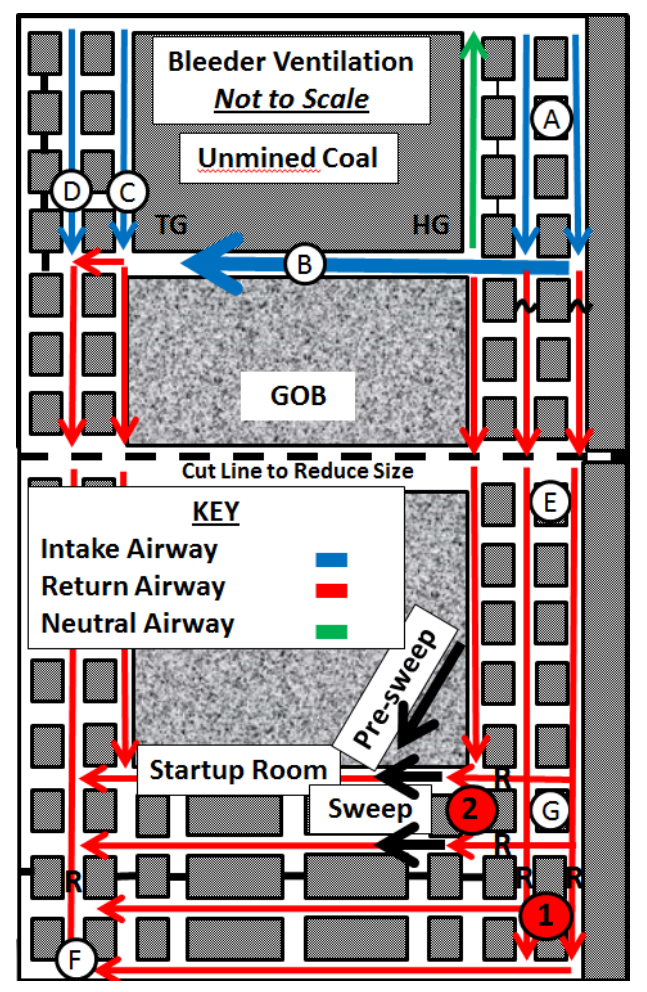

Figure 2.1-2: Mine ventilation network example [35].

Since the ventilation velocity is derived from the volumetric flowrate of fresh air and the crosssectional area of the longwall, an adequate ventilation system is highly dependent on the longwall dimensions. Increasing longwall length generally causes an increase in $\mathrm{CH}_{4}$ concentrations at the TG, therefore a greater air flow ventilation system is needed [36]. A Pittsburgh Coalbed had a longwall length of $315 \mathrm{~m}(1032 \mathrm{ft})$, a width of $4.8 \mathrm{~m}(16 \mathrm{ft})$, and a coal thickness ranging from 2.0 - $2.4 \mathrm{~m}(6.5-8.0 \mathrm{ft})$ [36]. The Pocahontas No.3 VP-1 and VP-3 mines had longwall lengths of $229 \mathrm{~m}(750 \mathrm{ft})$ and $305 \mathrm{~m}(1000 \mathrm{ft})$, widths of $4.8 \mathrm{~m}(16 \mathrm{ft})$ and $4.8 \mathrm{~m}(16 \mathrm{ft})$, and coal thicknesses ranging from $1.5-1.9 \mathrm{~m}(5.0-6.5 \mathrm{ft})$ and $1.7-2.0 \mathrm{~m}(5.5-6.5 \mathrm{ft})$, respectively [37]. The Lower Kittanning mine had a longwall length of $178 \mathrm{~m}(585 \mathrm{ft})$, a width of $4.8 \mathrm{~m}(16 \mathrm{ft})$, and a coal thickness of $1.4 \mathrm{~m}(4.5 \mathrm{ft})$ [38].

Ventilation data were collected for three different longwall mines. In a western longwall coal mine with a working face of $300 \mathrm{~m}$ (984 ft), ventilation air velocities were measured at two locations; one at shield 57 (nearer the HG) and one at shield 165 (nearer the TG). The ventilation velocities for these two locations were $3.03 \mathrm{~m} / \mathrm{s}(596 \mathrm{fpm})$ at and $2.20 \mathrm{~m} / \mathrm{s}(433 \mathrm{fpm})$, respectively [39]. In the Lower Kittanning study, air velocity measurements were recorded and averaged in two different mining sections; the first section average air velocity was $2.51 \mathrm{~m} / \mathrm{s}$ (495 fpm) and the 
second section average air velocity was $2.31 \mathrm{~m} / \mathrm{s}$ (454 fpm). These two sections had cross-sectional areas of $6.13 \mathrm{~m}^{2}\left(66 \mathrm{ft}^{2}\right)$ and $7.71 \mathrm{~m}^{2}\left(83 \mathrm{ft}^{2}\right)$, respectively [38]. A volumetric flowrate was also estimated by industry from a Pennsylvania mining operation to be 50,000 cfm of air along the face, where a velocity of $2.4 \mathrm{~m} / \mathrm{s}$ (500 fpm) at shield 20 and $2.03 \mathrm{~m} / \mathrm{s} \mathrm{(400} \mathrm{fpm)} \mathrm{at} \mathrm{shield} 270$ must be maintained to assure areas of elevated $\mathrm{CH}_{4}$ concentration did not form. Table 2.1-6 presents a summary of ventilation and longwall dimension data reviewed and calculated.

Table 2.1-6: Summary of longwall coal mine dimensions and ventilation data.

\begin{tabular}{|c|c|c|c|c|}
\hline \multirow[t]{2}{*}{ Mine } & $\begin{array}{l}\text { Longwall } \\
\text { Length }\end{array}$ & $\begin{array}{c}\text { Average } \\
\text { Cross-Sectional } \\
\text { Area }\end{array}$ & $\begin{array}{c}\text { Velocity } \\
\text { HG and TG }\end{array}$ & $\begin{array}{c}\text { Average } \\
\text { Volumetric } \\
\text { Flowrate }\end{array}$ \\
\hline & m (ft) & $\mathbf{m}^{2}\left(\mathbf{f t}^{2}\right)$ & $\mathbf{m} / \mathbf{s}(\mathbf{f p m})$ & cfm \\
\hline $\begin{array}{l}\text { Pittsburgh } \\
\text { Coalbed }\end{array}$ & 315 (1032) & $10.56(113.67)$ & --- & --- \\
\hline $\begin{array}{l}\text { Pocahontas } \\
\text { No.3 VP-1 }\end{array}$ & $229(750)$ & $11.76(126.58)$ & --- & --- \\
\hline $\begin{array}{l}\text { Pocahontas } \\
\text { No.3 VP-3 }\end{array}$ & 305 (1000) & $8.88(95.58)$ & --- & --- \\
\hline $\begin{array}{c}\text { Western } \\
\text { longwall }\end{array}$ & $300(984)$ & --- & $\begin{array}{c}3.03(596) \text { and } \\
2.20(433)\end{array}$ & 105,000 \\
\hline $\begin{array}{c}\text { Lower } \\
\text { Kittanning }\end{array}$ & $178(585)$ & $6.92(75)$ & $\begin{array}{c}2.50(495) \text { and } \\
2.31(454) \\
\end{array}$ & 35,176 \\
\hline $\begin{array}{c}\text { Pennsylvania } \\
\text { mine }\end{array}$ & --- & $10.45(112.5)$ & $\begin{array}{l}2.54(500) \text { and } \\
2.03(400)\end{array}$ & 50,000 \\
\hline Average & $265.4(870.73)$ & $9.71(104.52)$ & $\begin{array}{c}2.69(530) \text { and } \\
2.18(429)\end{array}$ & 63,392 \\
\hline
\end{tabular}

In addition to the ventilation velocities being dependent on longwall dimensions, they are also variable depending on the location within the mine. While maintaining adequate ventilation along the longwall face is crucial, ventilation speeds reduce in areas where ventilation air is lost to other areas, such as behind the shields in the gob. Wang et al. analyzed the effect of a change in ventilation air speeds along the longwall face. They developed a model, which was validated with ventilation survey data. The model predicted ventilation speeds along the entire longwall face. Figure 2.1-3 shows the results of the model for a HG-TG pass; note the data were obtained by digitalizing a figure from literature [32]. Notice that the fluctuations in the velocity diminish 
around $60 \mathrm{~m}(196.9 \mathrm{ft})$ and remain relatively constant until about $15-20 \mathrm{~m}(49.2-65.6 \mathrm{ft})$ away from the TG (180-190 m (590.6-623.4 ft)), where they begin to drop dramatically. This poor ventilation is one reason the $\mathrm{TG}$ is an area of main concern for high $\mathrm{CH}_{4}$ concentrations.

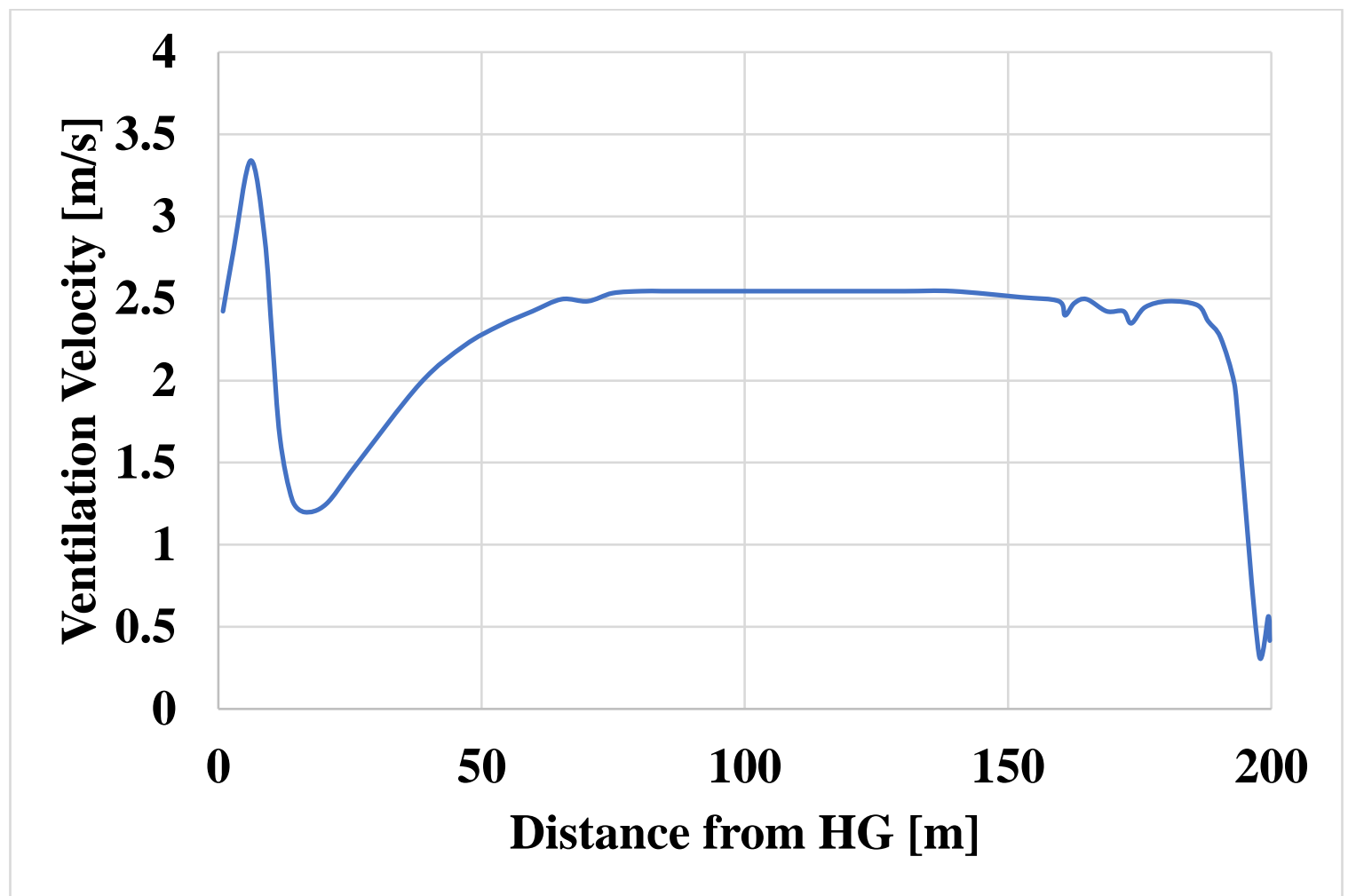

Figure 2.1-3: Ventilation velocities along longwall face for a HG-TG pass [32].

$\mathrm{CH}_{4}$ and Dust Control Regulations

To help ensure the safety of the miners in the longwall industry, there are many regulations to help alleviate the risks of $\mathrm{CH}_{4}$ related accidents in longwall coal mining. These include ventilation requirements, coal dust concentration requirements, and $\mathrm{CH}_{4}$ monitoring requirements. These regulations are listed in the 30 CFR Part 75. States and individual mines may use additional regulations to improve safety. Since this research was performed at WVU, some regulations found in the West Virginia (WV) Administrative Code Agency 36 are also mentioned and apply to WV mines.

\section{Ventilation Requirements (\$75.326)}

One or more main mine fans provide ventilation air to the working area. Regulations require that the, "mean entry air velocity shall be at least $0.30 \mathrm{~m} / \mathrm{s}(60 \mathrm{fpm})$ reaching each working face where coal is being cut, mined, drilled for blasting, or loaded, and to any other working places as required 
in the approved ventilation plan" [3]. While this is a minimum regulation, a greater velocity may be required to maintain $\mathrm{CH}_{4}$ concentrations under statutory limits. For example, a larger than average mine or a gassier mine requires a larger amount of ventilation then an average mine. If monitors detect elevated concentrations of $\mathrm{CH}_{4}$, miners may adjust the ventilation system as necessary to mitigate the elevated concentration [3].

\section{Dust Control (\$70.100 and $\$ 75.401)$}

Respirable coal dust that is a product of cutting coal is not only a health hazard for miners, it is also flammable. Coal dust could be ignited by a $\mathrm{CH}_{4}$ ignition, resulting in a more catastrophic explosion. Federal regulations require that respirable coal dust average concentration be maintained, by the operator, at or below $1.5 \mathrm{mg} / \mathrm{m}^{3}\left(9.36 \times 10^{-8} \mathrm{lb} / \mathrm{ft}^{3}\right)$ of air at the active working area and at or below $0.5 \mathrm{mg} / \mathrm{m}^{3}\left(3.12 \times 10^{-8} \mathrm{lb} / \mathrm{ft}^{3}\right)$ of air within $61 \mathrm{~m}(200 \mathrm{ft})$ of the working faces of each section in the intake airways [40]. To minimize explosion hazards and severity, regulations require the application of water to coal dust on the ribs, roof, and floor within $12.2 \mathrm{~m} \mathrm{(40} \mathrm{ft)} \mathrm{from}$ the face [41]. The implementation of water sprayers into the shearer and recently into the shields provide a key dust control method. Water sprayers on the shields spray in various directions, mostly towards the working face, during the cutting process [42] [43]. Shield sprayers use nozzles and pressurized water around $689.5-1379.0 \mathrm{kPa}(100-200 \mathrm{psig})$ to disperse water to aid in dust control and dust layer formation on equipment. Reed et al. conducted research to analyze the effectiveness of underside shield sprays to create a travelling water curtain. This water curtain was desirable as it helped prevent dust cloud formations from entering the walkway [44].

\section{$\mathrm{CH}_{4}$ Monitoring Requirements (\$75.342)}

All $\mathrm{CH}_{4}$ monitors implemented in a mining operation must obtain MSHA approval. The development of $\mathrm{CH}_{4}$ monitoring technologies over the past decades were a key component to the improved safety of longwall mining. Regulations require monitors be mounted on all mechanized equipment used to extract or load coal, such as the shearer in a longwall mine. These machinemounted monitors continuously measure $\mathrm{CH}_{4}$ concentrations at the mounting location on the shearer. Since $\mathrm{CH}_{4}$ concentrations around the shearer are likely to be highest at the face, the location of the machine-mounted monitor is also regulated; unless otherwise approved, regulations require the monitor be mounted as close to the cutting head as practicable, downwind of the lead cutting head. Machine-mounted monitors are robustly designed to withstand the mining 
environment, including coal dust accumulation and water sprayed at the shearer. Figure 2.1-4 shows an example of a machine mounted monitor used in industry.

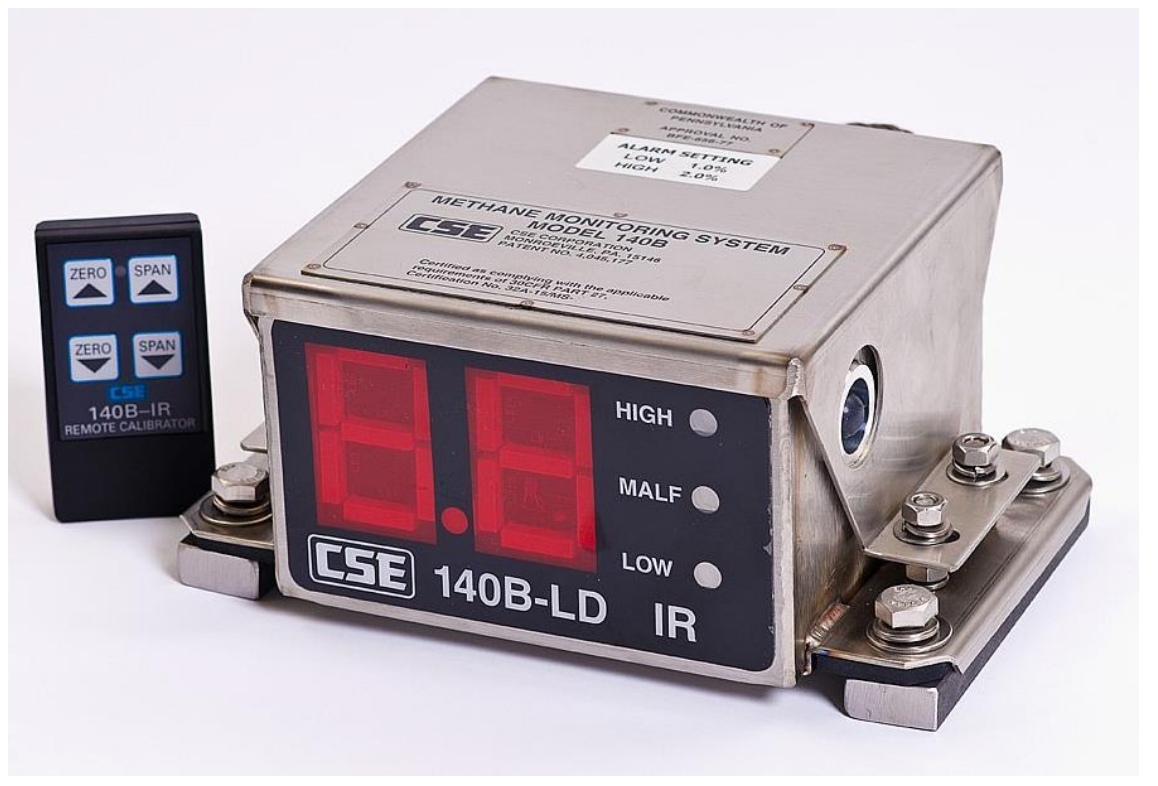

Figure 2.1-4: Machine mounted $\mathrm{CH}_{4}$ monitor [45].

Since $\mathrm{CH}_{4}$ accumulation also occurs in areas unmeasurable by the machine-mounted monitor, regulations also require the use of portable $\mathrm{CH}_{4}$ monitors. A qualified person must take portable monitor measurements periodically throughout the mining process. Measurements are made near the mine roof, in areas of poor ventilation (i.e. near the TG), and in areas near a potential $\mathrm{CH}_{4}$ source (i.e. near the face and gob). MSHA approval requires that these portable detectors "give indications of gas at $0.25 \% \mathrm{CH}_{4}$ and must have an accuracy of at least $\pm 20 \%$ over most of the applicable range" [12]. Many of these detectors can measure $\mathrm{CH}_{4}$ as well as other combustible gasses. Figure 2.1-5 shows an example of an MSHA approved portable monitor. In addition to $\mathrm{CH}_{4}$, it can also detect carbon monoxide $(\mathrm{CO})$, oxygen $\left(\mathrm{O}_{2}\right)$, and nitrogen dioxide $\left(\mathrm{NO}_{2}\right)$ [46]. Some states regulate the location of portable monitor measurements. For example, WV requires portable monitor measurements be taken no less than $203.2 \mathrm{~mm}$ (8 in) away from the longwall face or the roof [47]. 


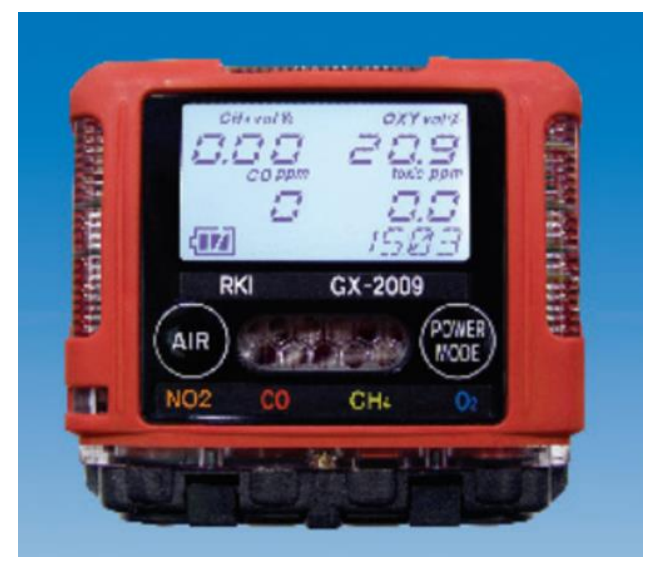

Figure 2.1-5: Portable gas monitor from RKI instruments [46].

Since continuous measurements directly at the face are not currently obtainable by the machinemounted monitor based on the mounting location, dangerous $\mathrm{CH}_{4}$ concentration limits at the monitoring location were estimated and used for regulations. Based on research, these concentration regulations were implemented with intentions to maintain the $\mathrm{CH}_{4}$ concentration at the longwall face below 5\%, the $\mathrm{LEL}$ of $\mathrm{CH}_{4}$. The lower concentration regulation which gives a warning signal is around $20 \%$ of the LEL and the higher concentration regulation where equipment is deenergized is $40-60 \%$ of the LEL [11]. For $\mathrm{CH}_{4}, 1 \% \mathrm{CH}_{4}$ is $20 \%$ of the $\mathrm{LEL}$ and $2 \% \mathrm{CH}_{4}$ is $40 \%$ of the LEL. Therefore, federal regulations require a warning signal be given if any of the $\mathrm{CH}_{4}$ monitors measure a concentration of $1 \% \mathrm{CH}_{4}$ and all equipment be deenergized if any monitor measures $2 \%$ or if any monitor is not operating properly. However, regulations for WV mines, as stated in the WV Administrative Code \$36-54-4, require all electrical equipment in an area where a $1 \%$ or greater $\mathrm{CH}_{4}$ concentration is measured be deenergized and other mechanized equipment shut-off. If $1.5 \% \mathrm{CH}_{4}$ is measured, all electrical equipment is disconnected from the power source and all persons except those permitted to stay by section $\S 22 \mathrm{~A}-2-43$ must leave the area. Work in the affected area stops until the elevated $\mathrm{CH}_{4}$ concentration decreases to less than $1 \%$ [48].

Calibration regulations are also established to ensure all $\mathrm{CH}_{4}$ monitors are in operable condition. Regulations require the calibration of monitors at least once every 31 days with a known mixture concentration and all calibrations be documented and kept for at least one year from the calibration date. To ensure proper operation of monitors, a "bump" test is often performed by a miner. To conduct a "bump" test, the monitor is exposed to a known $\mathrm{CH}_{4}$ concentration that is high enough to set off the alarm. If the alarm goes off, it is assumed to be working adequately [12]. Maintaining 
$\mathrm{CH}_{4}$ monitor calibrations and ensuring that they are working properly is critical in maintaining a safe work environment [3].

\section{$2.2 \mathrm{CH}_{4}$ Sensors}

\section{Catalytic Heat of Combustion (CAT) Sensors}

Most, if not all, $\mathrm{CH}_{4}$ monitors used in the longwall mining industry today utilize CAT sensors. The detection of combustible gases has utilized CAT sensors for over 50 years [49]. According to Taylor et al., as of 2008, machine mounted $\mathrm{CH}_{4}$ monitors only utilized CAT sensors [50]. CAT sensors consist of one active catalytic bead and one inactive bead, which is used as a reference. A catalyst material, generally a platinum- or palladium-based material, coats the active bead [51]. It is ideal that the reference bead be formed the same as the active bead, except for the catalytic properties. There are various methods to prevent combustion from occurring on the reference bead, such as operation at lower temperatures, chemical treatment, or the addition of a non-catalytic material coating. The most common method, however, being the elimination of the coating of the catalyst material in the formation process of the bead [49]. The beads are made of a ceramic or porous alumina material. The material coats coils of fine platinum wire which are wired into a Wheatstone Bridge electrical circuit. Heat is required for oxidation to occur; therefore, a voltage is applied across the two beads to heat them, typically up to $500^{\circ} \mathrm{C}$ [52]. When a $\mathrm{CH}_{4}$ concentration is present, it oxidizes catalytically on the active bead causing it to heat up further, resulting in an increase in voltage. This voltage increase can be correlated to a $\mathrm{CH}_{4}$ concentration [52]. Power consumption for the operation of the sensor (heating the beads) directly correlates to the battery life of the monitor [51]. Therefore, this is necessary for consideration when a battery powered monitor is required, like for handheld monitors.

CAT sensors typically measure $0-100 \%$ of the LEL of the target gas, which is adequate for $\mathrm{CH}_{4}$ monitoring in mines based on regulations [51]. For $\mathrm{CH}_{4}$, when the temperature is within the operational range, the sensor responds linearly up to the LEL. The response then peaks at $10 \%$ $\mathrm{CH}_{4}$, increasing rapidly between the stoichiometric value of $9 \%$ and the peak [49]. CAT sensors are relatively cheap and robust, which makes them suitable for the application. They are also relatively simple in design and easy to manufacture [49]. CAT sensors have a life expectancy of 3 to 5 years, sometimes longer [50] [53] [54].

For proper operation of the CAT sensors, the methane concentration must be below $8 \%$ and the oxygen level must be above $10 \%$, therefore, oxygen sensors are often used in conjunction with the 
CAT sensors where oxygen level may be an issue, such as in confined spaces [55]. CAT sensors are susceptible to sensor poisoning and inhibitors. Certain chemicals, such as substances containing silicon or sulfur, will poison the sensor. Sensor poisoning results in the loss of sensitivity. Other chemicals, such as halogen compounds, temporarily inhibit the sensors functionality [49]. The performance is also affected by exposure to elevated concentrations of combustible gases or prolonged exposure to lower concentrations of combustible gases, affecting the zero and span setting of the sensor. This deterioration is known as sensor cracking [49]. These sensors often lose sensitivity to $\mathrm{CH}_{4}$ first when poisoning occurs [51]. This is of high concern in the mining industry and the reason monitor calibrations are regularly conducted [51]. CAT sensor measurements are also inhibited by combustible gases that are not of interest. For example, if measurements target $\mathrm{CH}_{4}$ concentrations, the presence of other hydrocarbons (HCs), like ethane $\left(\mathrm{C}_{2} \mathrm{H}_{6}\right)$, will alter the measurement. If the sensor is calibrated to $\mathrm{CH}_{4}$, measurements of the other HCs would be a fraction of their actual concentration based on the heat of combustion for that substance compared to the heat of combustion of $\mathrm{CH}_{4}$ [51]. Measurements are based on the total heating effects of the combustible gasses surrounding the sensor [51]. Factors changing the thermal conductivity of the atmosphere surrounding the sensor, like $\mathrm{RH}$, affects the measurement. This is typically compensated for by zeroing the sensor once it stabilizes in its environment [53]. However, climate conditions are highly variable in a mine depending on the location of measurement, for example, the RH increases for measurement locations near water sprayers.

\section{Infrared (IR) Sensors}

While CAT sensors have been used and unchanged over the past decades, improvements in mine safety technologies have promoted research to determine if other sensor types could be more appropriate for industry use. Specifically, infrared (IR) sensors may serve as a replacement of the CAT sensors. IR sensors operate by using IR absorption to quantify the concentration of a target gas. IR radiation passes through the sensor at specific wavelengths and the absorption of this radiation corresponds to a gas concentration. Most HCs absorb IR radiation at wavelengths of around 3.4 $\mu \mathrm{m}$ [54]. Detection of a specific hydrocarbon, like $\mathrm{CH}_{4}$, requires special IR filtration if other HCs are likely to be presence. Taylor et al. investigated the effects of other HCs on measurements targeting $\mathrm{CH}_{4}$ for multiple IR sensors. Measurements taken by one of the IR sensors were overestimated by $50 \%$ in the presence of ethane while the other was un-affected [50]. 
Since IR sensors are not susceptible to poisoning, they generally have a longer life expectancy than the CAT sensors. The life expectancy of IR sensors is typically 5 to 10 years, sometimes longer [53] [54]. IR sensor measurements are unaffected by a wide range of climate conditions, unlike the CAT sensors [53]. This makes them desirable for applications of highly varying temperature and humidity conditions. In addition, IR sensors do not require oxygen for measurements [55]. IR sensors are typically more expensive than CAT sensors initially, although, they have lower maintenance costs [54].

Metal-Oxide (MO) Sensors

MO sensors are similar to CAT sensors as they both utilize thermodynamic reactions for operation. In a $\mathrm{MO}$ sensor, a sensing (metal-oxide) material, such as $\mathrm{SnO}_{2}$ for $\mathrm{CH}_{4}$ detection, undergoes oxidation or reduction when it contacts the target gas [53]. Typically, trapped atmospheric oxygen on the surface of the sensing material reduces by the target gas, resulting in a resistance drop [56]. This creates an increase in the output voltage. This change in voltage corresponds to the gas concentration [53]. The sensing material creates a layer by coating a separate component, such as an electrode structure. This connects the sensing layer to the electrical circuit used to output the sensor's signal [56]. Porous structures (thicker layer) are often used in the sensing layer to increase the interaction area of the target gas and sensitive material, enhancing sensitivity of the sensor [57]. However, thinner films result in faster response and recovery times [56].

The operational principle of MO sensors allows for faster response times than other sensing methods. Also, due to the robustness and simplicity of these sensors, they have a relatively long life expectancy of 10 or more years and they are relatively low cost depending on the components in the specific sensor. Earlier versions of the $\mathrm{MO}$ sensors were only developed with $\mathrm{SnO}_{2}$ as the sensitive material. However, while $\mathrm{SnO}_{2}$ is still commonly used, many types of metal oxides are used in sensors developed today. Development of new sensor technologies allow for improvements in new sensors, such as lessened humidity influence, lower sensitivity to interfering gases, and decreased drift over time [58].

Optimization of sensor performance partially depends on the operational temperature of the sensor, typically between 200 and $400^{\circ} \mathrm{C}$. A micro heater within the sensor controls this temperature [56]. However, the implementation of a heating element results in relatively high power requirements. Like the CAT sensors, climate changes affect the sensor performance [53]. Humidity decreases the sensitivity and negatively affects the repeatability of the sensor [57]. Generally, MO sensors 
require a "break-in" time of up to 50 hours before usable measurements are taken [58]. This can be a hinderance depending on the application.

Table 2.2-1 presents a summary of CAT, IR, and MO sensors on the market today, including the costs of each sensor. Table 2.2-2 provides the average cost for each type of sensor of the sensors found readily available on the market.

Table 2.2-1: Available sensors summary.

\begin{tabular}{|c|c|c|c|c|c|c|}
\hline Type & Manufacturer & Part \# & $\begin{array}{c}\text { Cost } \\
{[\$]}\end{array}$ & $\begin{array}{c}\text { Life } \\
\text { Expectancy } \\
\text { [years] }\end{array}$ & $\begin{array}{c}\text { CH4 } \\
\text { Detection } \\
\text { Range } \\
\text { [\% by vol.] }\end{array}$ & $\begin{array}{c}\text { References } \\
\text { (Webpage/ } \\
\text { Manual) }\end{array}$ \\
\hline CAT & MSA & MSA10106722 & 385.00 & $>4$ & $0-5$ & {$[59] /[60]$} \\
\hline CAT & Dräger & 6812950 & 263.00 & & $0-5$ & {$[61] /[62]$} \\
\hline CAT & Industrial Scientific & $17155304-M$ & 347.00 & & $0-5$ & {$[63] /[64]$} \\
\hline CAT & GfG & 1460710 & 323.00 & 3 & $0-5$ & {$[65] /[66]$} \\
\hline CAT & AimSafety & PM-400 & 115.50 & $>5$ & $0-5$ & {$[67] /[68]$} \\
\hline CAT & GfG & 2800750 & 744.00 & 3 to 5 & $0-5$ & {$[69] /[70]$} \\
\hline CAT & SGX Sensortech & VQ21TSB & 43.50 & & $0.1-5$ & {$[71] /[72]$} \\
\hline CAT & SGX Sensortech & VQ23TB & 72.50 & & $>0.1$ & {$[73] /[74]$} \\
\hline IR & Winsen & MH-440D & 246.80 & $>5$ & $0-100$ & {$[75] /[76]$} \\
\hline IR & Industrial Scientific & $17155304-N$ & 859.00 & & $0-5$ & {$[77] /[64]$} \\
\hline IR & SGX Sensortech & IR32BC & 192.67 & $>10$ & $0-100$ & {$[78] /[79]$} \\
\hline IR & Industrial Scientific & $17124975-N$ & 768.00 & & $0-100$ & {$[80] /[81]$} \\
\hline IR & Dynament & MSH2ia-LS & 156.56 & $>5$ & $0-100$ & {$[82] /[83]$} \\
\hline MO & SGX Sensortech & MiCS-5524 & 8.95 & & $>0.1$ & {$[84] /[85]$} \\
\hline MO & SGX Sensortech & MICS-4514 & 9.72 & & $>0.1$ & {$[86] /[87]$} \\
\hline MO & Winsen & MP-4 & 2.88 & 10 & $0.03-1$ & {$[88] /[89]$} \\
\hline MO & Winsen & MQ-4 & 4.95 & & $0.02-1$ & {$[90] /[91]$} \\
\hline MO & FIGARO & TGS813 & 24.49 & $8-10$ & $0.05-1$ & {$[92] /[93]$} \\
\hline
\end{tabular}


Table 2.2-2: Average sensor costs.

\begin{tabular}{|c|c|}
\hline Type & $\begin{array}{c}\text { Average Cost } \\
{[\$]}\end{array}$ \\
\hline CAT & 286.69 \\
\hline IR & 444.61 \\
\hline MO & 10.20 \\
\hline
\end{tabular}

\section{Advanced Methods}

In addition to the CAT, IR, and MO sensor technologies, other methods exist that are typically more advanced, such as laser spectroscopy techniques. However, analyzers that utilize more advanced methods are more costly. Ultra-portable greenhouse gas analyzers (UGGAs) manufactured by Los Gatos Research (LGR) utilize cavity enhanced absorption spectroscopy (CEAS) for gas quantification. The UGGA gas quantification technique allows for the analyzer to correct for water dilution, or humidity, in the sample without post-processing. The CEAS technique also allows for species specific measurements, meaning other gases (i.e. other HCs for $\mathrm{CH}_{4}$ measurements) do not interfere with measurements [94]. Many UGGAs available by LGR have a detection range of approximately 0 to $0.01 \%$, however they offer an extended range option which can detect up to $10 \% \mathrm{CH}_{4}$ [94]. CEAS, like a technique known as cavity ringdown spectroscopy (CRDS), quantifies gas concentrations by measuring the signal decay that results from absorbing species. To do this, a laser pulse is reflected between two mirrors and the decay correlates to the amount of light absorbed. CRDS typically applies the measurement of small molecules while CEAS applies to larger molecules with broader spectra [95]. In 2014, an LGR UGGA cost approximately $\$ 30,000$. The addition of a Mulitport Inlet Unit (extra $\$ 6000$ ) provided 16 inlet ports which allowed for 16 sampling locations [96]. Therefore, each sampling location cost around \$2250; this is more than four times the average cost of the IR sensors. This would, however, require sample tubing to travel from the analyzer to each sampling location which would extend sample transport times and require additional signal processing. 


\subsection{Sampling Methods}

\section{Passive}

There are various sampling methods that can be used for methane detection in longwall mining. Devices which use a passive sampling method depend on the flow of the sample past the sensor via an external source and the diffusion of the target gas through the sensor. For passive sampling, the sensor is place directly in the monitoring area (sampling location) and the sample, which could be a potentially hazardous concentration of methane, passes by it via the mine ventilation or by the movement of the machine on which it is mounted. Many machine-mounted methane monitors use the diffusion sampling method as they are located at the sampling location. The $\mathrm{CH}_{4}$ sensors are enclosed in the monitor to prevent direct physical damage by water or coal debris. They are also protected by a dust cap and include a flame arrestor [97]. However, this protection results in an increased response time of the sensor when using the passive sampling method, which is later discussed in more detail. The portable monitor produced by RKI Instruments (Figure 2.1-5) often operates using the diffusion sampling method, however the addition of a hand aspirator or motorized pump is optional; if one of these were added, it would then be using an active sampling principle [98].

\section{Active}

Since the passive sampling method places the sensor directly at the sampling location, which risks physical damage to a sensor without proper protection, an active sampling method may alleviate this risk. An active sampling method allows the sensor be placed at a remote location, away from physical hazards, where the sample is actively transported from the sampling location to the sensor. Various sampling systems (samplers) facilitate the transportation of the sample.

Active sampling allows the placement of the sampler at any location with a sealed conduit, such as a PTFE (polytetrafluoroethylene) tube, connecting the sampler to the sensor location. Another tube can attach at the sensor location and lead to the sampling location. This benefits sampling in restricted areas that are un-accessible to miners, areas at risk of elevated $\mathrm{CH}_{4}$ concentrations, or sampling in locations containing physical hazards that may cause sensor damage. An active sampling method has potential to decrease response time by decreasing the time of the sample to pass through the protection surrounding sensor and contact the sensor. However, it also adds a transit time for the sample to travel from the sampling location to the sensor. This contributes to 
the response time of the system. To provide time sensitive measurements, the minimization of this transit time is crucial.

\section{Pumps}

One type of active sampler that could be used to pull the sample is the use of one or multiple air pumps, like the addition to the RKI monitor mentioned previously [12]. The Eagle (shown in Figure 2.3-1), also manufactured by RKI Instruments, utilizes a pump for active sampling. Filtration and a sampling tube are attached, and the pump can draw samples from up to $38.1 \mathrm{~m}$ (125 ft) away [99]. While pumps used for active sampling provide an improved sampling method compared to passive sampling, there are downfalls with the use of a pump in the mining industry. Since pumps (other than hand-pumps) are electric, they require MSHA approval for mine use. Pumps also contain moving components which increase the risk of malfunction and need for maintenance.

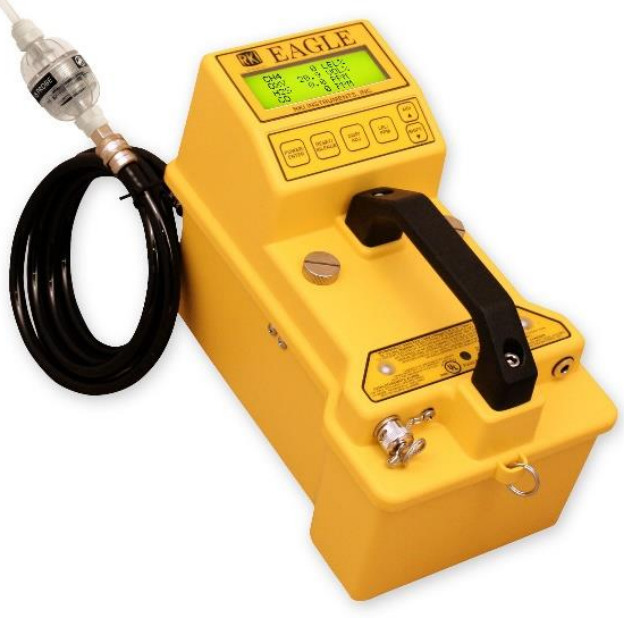

Figure 2.3-1: Eagle portable gas monitor [99].

\section{Ejectors}

Another type of active sampler that could be used is an ejector which can be powered by various fluids including compressed air or pressurized water. An ejector does not require electricity to 
operate and has no moving parts. They would not pose an ignition risk and are low maintenance [100]. An ejector operates using the Bernoulli Principle [101]. Simple, single-stage ejectors consist of four main components, a nozzle, suction chamber, mixing section, and a diffuser. As the motive, or primary, pressurized fluid passes through the nozzle, its velocity increases, creating a vacuum in the suction chamber. This motive fluid can be a gas or liquid. The low-pressure region in the suction chamber causes the suction, or secondary, fluid to be pulled into the suction chamber. The secondary fluid then mixes with the primary fluid as it enters the diffuser, from which the mixture exits the ejector [100]. In the application of using an ejector as a sampler for $\mathrm{CH}_{4}$ detection, the secondary fluid would be the sample. Figure 2.3-2 shows a sketch of a basic single-stage ejector with the main components labelled.

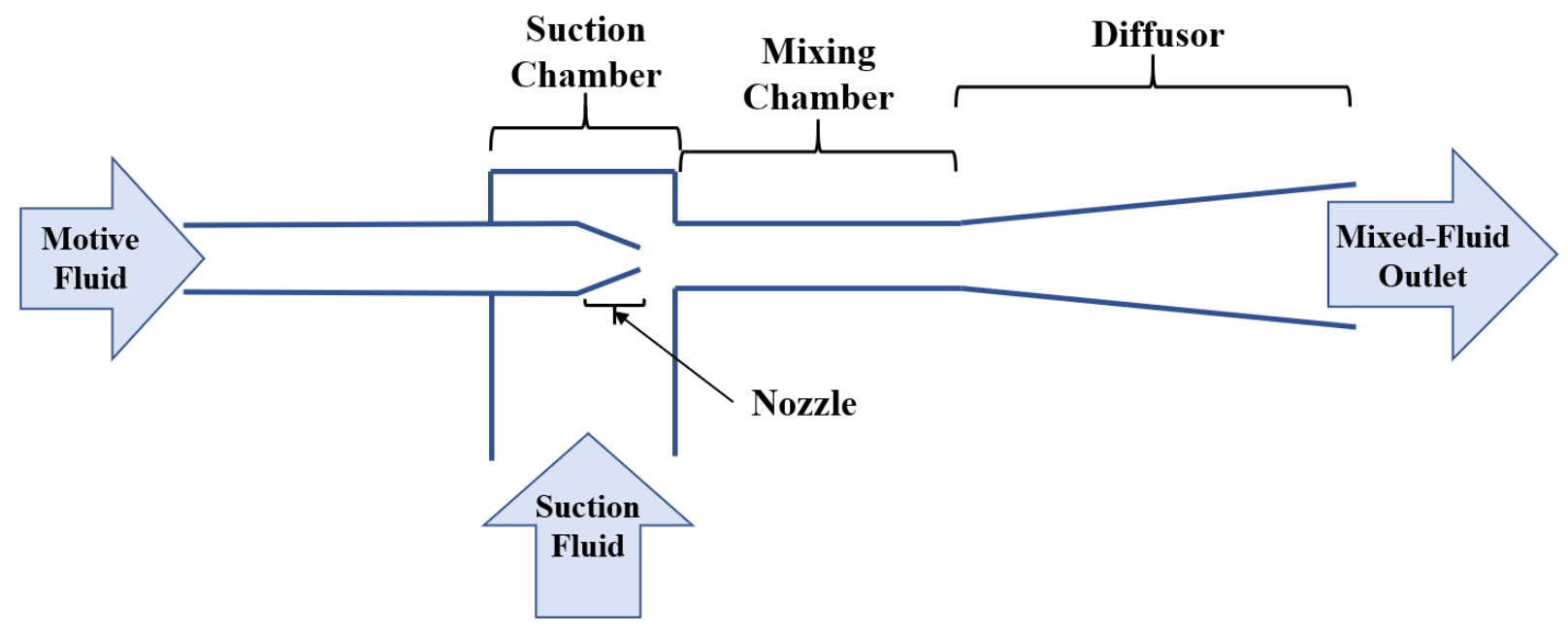

Figure 2.3-2: Main components of a single-stage ejector.

While ejectors are not yet used in the mining industry, they are used in various other applications. The ejector refrigeration system utilizes an ejector for the mixing of the high-pressure fluid from a generator and the low-pressure fluid from an evaporator, where the motive fluid is typically a refrigerant [102]. Figure 2.3-3 shows a diagram of the ejector refrigeration system for visualization. 

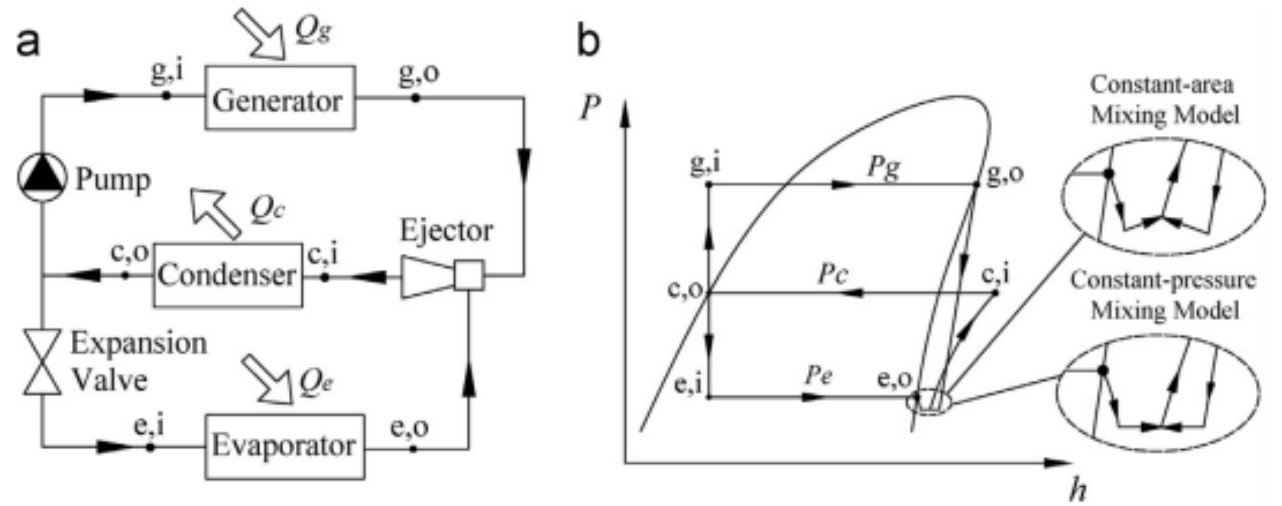

Figure 2.3-3: Ejector refrigeration system (a) with corresponding P-h diagram (b) [102].

Ejectors are also used for operations such as water treatment. Song et al. analyzed the use of an ejector for ship ballast water treatment, where ozone gas is introduced as the suction fluid to kill unwanted microorganisms in the water [103]. Some emissions measurement systems utilize ejectors to dilute the sample, often referred to as ejector dilutors. Ejector dilutors mix the emission sample with dilution air before the mixture is sent to the measurement location [104]. Pressurized air acts as the motive fluid and the emissions sample is the suction fluid. Björkstrand's master's thesis focused of the design of an ejector dilutor for a particulate matter (PM) emission measurement system [105]. Giechaskiel et al. conducted research to analyze a prototype dilution system for on-board vehicle PM measurements which utilized three ejectors [106]. Known flowrates of each fluid are especially important in ejectors designed to dilute samples for emissions measurements.

The performance of an ejector is often characterized by three parameters, the flow ratio (M), the pressure ratio $(\mathrm{N})$, and the efficiency $(\eta)$. These parameters are represented in Eq. 2.3.1, Eq. 2.3.2, and Eq. 2.3.3, respectively, where subscript "p" represents the motive (primary) fluid inlet, subscript "s" represents the suction fluid inlet, and subscript "o" represents the ejector outlet.

$$
\begin{gathered}
M=\frac{Q_{s}}{Q_{p}} \\
N=\frac{P_{o}-P_{s}}{P_{p}-P_{o}} \\
\eta=M \times N
\end{gathered}
$$

An optimal performance ejector is designed based on the operating conditions such as the motive and suction fluids, the boundary conditions of the ejector, and the application. In $\mathrm{CH}_{4}$ detection, the important operational parameters of an ejector are its ability to create a vacuum to overcome 
pressure losses through the monitoring system, relatively high volumetric flowrates to reduce delay times, and minimizing the usage of the motive fluid (water in the case of this research). The minimization of water consumption corresponds to the maximization of M. Since this thesis focuses on a water-air ejector design, investigations pertaining to liquid-gas ejectors were primarily researched. Flow ratios ( $\mathrm{M}$ values) for liquid-gas ejectors were obtained from various sources; Table 2.3-1 presents a summary of these $\mathrm{M}$ values. Note that the motive fluid for all ejector investigations from which data were obtained was water and the suction fluid was air.

Table 2.3-1: $M$ values summary.

\begin{tabular}{|c|c|c|c|}
\hline $\begin{array}{c}\mathbf{Q}_{\mathbf{s}} \\
{\left[\mathbf{m}^{\mathbf{3}} / \mathbf{s}\right]}\end{array}$ & $\begin{array}{c}\mathbf{Q}_{\mathbf{p}} \\
{\left[\mathbf{m}^{\mathbf{3}} / \mathbf{s}\right]}\end{array}$ & $\mathbf{M}$ & Author \\
\hline 0.0013 & 0.0007 & 1.97 & {$[107]$} \\
\hline 0.0050 & 0.0020 & 2.52 & {$[108]$} \\
\hline 0.0045 & 0.0018 & 2.49 & {$[109]$} \\
\hline 0.0010 & 0.0007 & 1.50 & {$[110]$} \\
\hline 0.0077 & 0.0018 & 4.28 & {$[111]$} \\
\hline 0.0032 & 0.0028 & 1.14 & {$[112]$} \\
\hline 0.0024 & 0.0008 & 3.00 & {$[113]$} \\
\hline 0.0070 & 0.0020 & 3.50 & {$[114]$} \\
\hline 0.0034 & 0.0022 & 1.51 & {$[115]$} \\
\hline 0.0051 & 0.0020 & 2.55 & {$[116]$} \\
\hline--- & --- & 1.50 & {$[117]$} \\
\hline 0.00002 & 0.00003 & 0.69 & {$[118]$} \\
\hline 0.0016 & 0.0003 & 0.60 & {$[119]$} \\
\hline--- & --- & 0.89 & {$[120]$} \\
\hline--- & --- & 1.20 & {$[121]$} \\
\hline--- & --- & 1.57 & {$[122]$} \\
\hline & Average & $\mathbf{1 . 9 3}$ & \\
\hline
\end{tabular}

The effects of varying geometric parameters on the ejector performance are common research topics among ejector optimization. Some geometry parameters that are deemed important to ejector design performance are nozzle to mixing chamber diameter ratio $\left(\mathrm{D}_{\mathrm{n}} / \mathrm{D}_{\mathrm{m}}\right)$, mixing chamber length to diameter ratio $\left(\mathrm{L}_{\mathrm{m}} / \mathrm{D}_{\mathrm{m}}\right)$, nozzle converging angle $\left(\theta_{\mathrm{n}}\right)$, nozzle exit position relative to the mixing chamber inlet (NXP), diffuser outlet to inlet area ratio $\left(\mathrm{A}_{d} / \mathrm{A}_{\mathrm{m}}\right)$, and diffuser diverging angle $\left(\theta_{\mathrm{d}}\right)$. According to Yan et al., the nozzle to mixing chamber diameter or area ratio and the 
NXP are two of the most important geometries in ejector design [123]. Zhang et al. concluded that the diffuser length was an important ejector design parameter [124]. Figure 2.3-4 shows a general ejector diagram to show a visualization of the ejector components and geometry parameters.

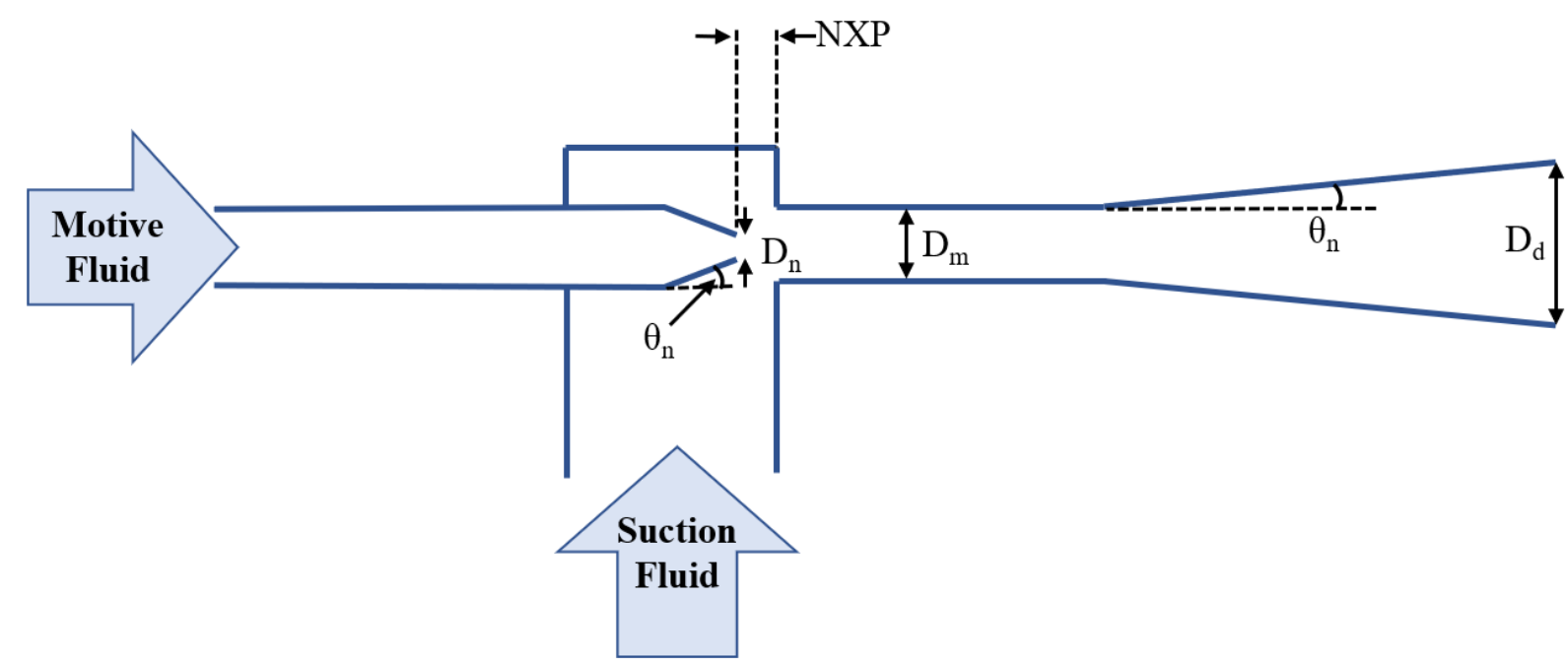

Figure 2.3-4: Ejector diagram with labelled geometries [125].

Numerous studies have been conducted related to optimization of the geometries of an ejector, however, general conclusions are difficult to make due to the variety of applications and configurations of an ejector. For example, optimal geometric parameters are different for a singlephase ejector than for a multi-phase ejector. Zhang et al. conducted a study evaluating an ejector used for an air conditioning system using R236fa as the motive fluid. In this study, the $\theta_{\mathrm{n}}$ and NXP were varied to three values and it was concluded that the lowest value for each parameter resulted in the best performance [124]. In a study to investigate the entrainment behavior of gas-liquid (gas as the motive fluid) ejectors, it was concluded that the optimum mixing tube length to diameter ratio was 1 to 2 which differed greatly from the optimal ratio for a single phase gas ejector which was between 5 and 7 [126]. Almutairi analyzed a liquid-gas ejector with the motive fluid being water and the suction fluid being air. It was determined that the maximum efficiency was achieved with a diffuser angle of $5^{\circ}$, the largest $L_{m}$, and the largest $D_{n} / D_{m}$. The largest $L_{m}$ was in the case where $\mathrm{L}_{m} / \mathrm{D}_{\mathrm{m}}$ was 6 ; the mixing tube diameter was held constant for every mixing tube length analyzer. The largest $\mathrm{D}_{\mathrm{n}} / \mathrm{D}_{\mathrm{m}}$ was 0.35 [122]. Cramers and Beenackers also concluded that a similar $\mathrm{D}_{\mathrm{n}} / \mathrm{D}_{\mathrm{m}}$ of 0.4 to be optimal for the liquid-gas ejector investigated [117]. Alshebani et al. suggested that the optimal NXP is equal to the $D_{m}[127]$. Zhang et al. concluded that a diffuser length to 
mixing chamber diameter ratio $\left(\mathrm{L}_{\mathrm{d}} / \mathrm{D}_{\mathrm{m}}\right)$ of 6 showed the best performance, while Yuan et al. utilized a $\mathrm{L}_{\mathrm{d}} / \mathrm{D}_{\mathrm{m}}$ of 8 [124] [128]. In Engineering Sciences Data Unit (ESDU)'s ejector design document, the recommended $\mathrm{L}_{\mathrm{m}} / \mathrm{D}_{\mathrm{m}}$ was 5-10, the recommended $\theta_{\mathrm{n}}$ was $16-20^{\circ}$, the recommended NXP was equal to $D_{n}$, the recommended $\theta_{d}$ was less than $14^{\circ}$, and the recommended diffuser exit area to mixing chamber area ratio $\left(\mathrm{A}_{\mathrm{d}} / \mathrm{A}_{\mathrm{m}}\right)$ was less than 5 [129].

\subsection{Measurement Response Times}

Response times are an important parameter of the sensors in machine mounted methane monitors. However, federal regulations do not include monitor response time or response time measurement technique requirements [130]. Detection of an area of elevated $\mathrm{CH}_{4}$ concentration before the shearer cuts in that area is critical to preventing a frictional ignition. Some manufacturers provided response times for the readily available sensors found online. Table 2.4-1 presents a summary of the sensors found online and the corresponding response times. Due to the lack of information available for MO sensor response times, only one MO sensor response time is presented. It should be noted that the response time is generally represented as T90 which denotes the time it takes for the sensor to reach $90 \%$ of its total response; T50 is the time it takes to reach $50 \%$ of its total response.

Table 2.4-1: Sensor response times summary.

\begin{tabular}{|c|c|c|c|c|}
\hline Type & Manufacturer & Part \# & $\begin{array}{c}\text { CH4 } \\
\text { Response } \\
\text { Time (T90) } \\
{[\mathbf{~}]}\end{array}$ & $\begin{array}{c}\text { References } \\
\text { Webpage/Manual) }\end{array}$ \\
\hline CAT & MSA & MSA10106722 & $<10$ & {$[59] /[60]$} \\
\hline CAT & Industrial Scientific & $17155304-M$ & $<10$ & {$[63] /[64]$} \\
\hline CAT & GfG Instrumentation & 1460710 & $<30$ & {$[65] /[66]$} \\
\hline CAT & GfG Instrumentation & 2800750 & $<10$ & {$[69] /[70]$} \\
\hline CAT & SGX Sensortech & VQ21TSB & T50=2 & {$[71] /[72]$} \\
\hline CAT & SGX Sensortech & VQ23TB & T50=2 & {$[73] /[74]$} \\
\hline IR & Winsen & MH-440D & $<30$ & {$[75] /[76]$} \\
\hline IR & Industrial Scientific & $17155304-N$ & $<25$ & {$[77] /[64]$} \\
\hline IR & SGX Sensortech & IR32BC & $<20$ & {$[78] /[79]$} \\
\hline IR & Industrial Scientific & $17124975-N$ & $<25$ & {$[80] /[81]$} \\
\hline IR & Cubic & SFH-5 & $<25$ & {$[131] /[132]$} \\
\hline IR & Dynament & MSH2ia-LS & $<30$ & {$[82] /[83]$} \\
\hline MO & SGX Sensortech & MiCS-5524 & $<10$ & {$[84] /[85]$} \\
\hline
\end{tabular}


Taylor et al. conducted a study which investigated the effects of measurement technique on the response times of three $\mathrm{CH}_{4}$ monitors. The monitors were obtained by three different manufacturers. All three of the monitors used a CAT sensor for $\mathrm{CH}_{4}$ measurements. A calibration cup was used to deliver gas to the sensor head [133]. However, since the calibration cup alters the flow around and through the sensor head, another study was conducted by Taylor et al. which used a different sample delivery method. The same three monitors were used as in the previous study. The delivery method for this study was a test box consisting of two fans and the $\mathrm{CH}_{4}$ was injected into the box using a syringe. The recorded response times using the box method were less than those using the calibration cup for all three monitors [97]. Table 2.4-2 presents the T90 response times of all three monitors for each method. Note for both tests, all three monitors contain a dust cap. During the study where the test box was used the effect of the dust cap integrated into the monitors was also investigated. The authors performed tests with and without the dust cap using the "Test Box" delivery method. Table 2.4-3 presents the T90 response time results of these tests. The response time was nearly doubled for Monitor A and more than doubled for Monitor B and Monitor $\mathrm{C}$ when the dust cap was on versus when it was removed.

Table 2.4-2: Comparison of response times for three monitors using two $\mathrm{CH}_{4}$ delivery methods (with dust cap integrated) [133] [97].

\begin{tabular}{|c|c|c|c|}
\hline \multirow{2}{*}{ Method } & \multicolumn{3}{|c|}{ Response Time (T90) } \\
& \multicolumn{3}{|c|}{ [s] } \\
\cline { 2 - 4 } & Monitor A & Monitor B & Monitor C \\
\hline Calibration Cup & 29 & 40 & 36 \\
\hline Test Box & 23 & 25 & 29 \\
\hline
\end{tabular}

Table 2.4-3: Comparison of response times for three monitors with and without dust cap (using “Test Box" delivery method) [97].

\begin{tabular}{|c|c|c|c|}
\hline \multirow{2}{*}{$\begin{array}{c}\text { Dust Cap } \\
\text { (On or Off) }\end{array}$} & \multicolumn{3}{|c|}{ Response Time (T90) } \\
& \multicolumn{3}{|c|}{ [s] } \\
\cline { 2 - 4 } & Monitor A & Monitor B & Monitor C \\
\hline Off & 12 & 4 & 14 \\
\hline On & 23 & 25 & 29 \\
\hline Percent Increase [\%] & 91.7 & 525.0 & 107.1 \\
\hline
\end{tabular}

Another study conducted by Taylor et al. investigated the response times of three monitors, two containing an IR sensor and one containing a CAT sensor. One of the monitors with an IR sensor 
had a faster response time than the monitor with the CAT sensor and the other had a slower response time. Response time of IR sensors was heavily dependent on the sensor housing, which protects it from hazardous environmental conditions [50]. Table 2.4-4 provides the response times for all three monitors [50].

Table 2.4-4: Response times for two IR monitors and one CAT monitor.

\begin{tabular}{|c|c|}
\hline Monitor & $\begin{array}{c}\text { Response Times (T90) } \\
\text { [s] }\end{array}$ \\
\hline IR 1 & 9.75 \\
\hline IR 2 & 32.5 \\
\hline CAT & 18.5 \\
\hline
\end{tabular}

The response times of $\mathrm{CH}_{4}$ detection systems are also dependent on transit times for the sample to reach the monitor. For example, if an active sampling method is used, a sample can be drawn from a sampling location away from the monitor, transporting the sample via a tube. The time it takes for the sample to travel from the sampling location to the sensor is known as the transit time. The system response time is the sum of the transit time and the response time of the sensor. It is ideal that this transit time be nearly negligible compared to the response time of the sensor for the response time of the system to be minimized. One form of a non-time sensitive $\mathrm{CH}_{4}$ sampling system in a mine consists of a network of tubes used to draw samples from various locations in a mine. A vacuum pump draws the samples from the sampling location to an external location, typically above ground. This system is known as a tube bundle system (TBS) [134]. Mines implement the TBS to measure the mine atmosphere. Australian mines often deploy this system with 30 to 40 sampling locations throughout the mine. The systems measure various gases, such as $\mathrm{CH}_{4}$, oxygen, carbon dioxide, and carbon monoxide. Due to their transit times, TBSs are not a suitable $\mathrm{CH}_{4}$ detection systems to meet regulations, however, they provide data useful to a mine disaster investigation [134]. Krog conducted studies to analyze longwall ventilation systems and to understand the movement of $\mathrm{CH}_{4}$ through a mine using a bleeder system. He deployed a TBS and analyzed transit times through the tubes. The pumps were mounted in an area of fresh air, where they were not at risk of causing an ignition. The longest sampling tube was $2290 \mathrm{~m}$ (7500 $\mathrm{ft})$ and resulted in the highest transit time of 63 minutes. The pump flowrate was 3.1 LPM $(0.12$ $\mathrm{ft}^{3} / \mathrm{min}$ ) [135]. While this excessive transit time was not an issue for Krog's study, it would be a major issue for a time sensitive $\mathrm{CH}_{4}$ detection system. Belle compared the use of "real-time" 
monitors, like a machine mounted monitor, to the TBSs used in Australian mines. The real-time monitor contained a CAT sensor and the TBS contained an IR sensor. Measurements were typically made in 30 second increments for the real-time monitor and 50 min increments for the TBS. On average, results showed that the TBS recorded $\mathrm{CH}_{4}$ measurements were $8 \%$ higher than measurements made by the real-time monitor. It was concluded that the average measurement difference was due to the infrequency of TBS measurements [136].

\section{$2.5 \mathrm{CH}_{4}$ Monitoring System Integration}

Additional MSHA Regulations

Electrical Equipment (\$75.506)

Since $\mathrm{CH}_{4}$ monitoring systems are electrical devices, electrical equipment regulations apply. Only permissible electrical devices may be used in return airways [13]. Any electrical devices (i.e. portable monitors) used in a mine are required to obtain MSHA approval [3]. MSHA approval requires the circuits in electrical equipment to be intrinsically safe. According to MSHA, "Intrinsically safe circuits shall be incapable of releasing enough electrical or thermal energy in normal operation and with up to two independent fault conditions to cause ignition of a flammable mixture of methane and air of the most easily ignitable composition" [13].

\section{$\mathrm{CH}_{4}$ Monitoring System Construction and Design}

Title 30 Part 27 Subpart B of the CFR provide federal regulations related specifically to the construction and design of $\mathrm{CH}_{4}$ monitoring systems. These regulations include the explosion proof requirement of the $\mathrm{CH}_{4}$ monitor enclosure, which must contain a lock, seal, or other MSHA acceptable equivalent. The external surface temperature of the system shall never exceed $150^{\circ} \mathrm{C}$ $\left(302{ }^{\circ} \mathrm{F}\right)$. Regulations also require the capability of the monitoring system to automatically send a warning signal or de-energize if it measures the corresponding regulated concentration. The system may monitor at multiple locations if MSHA deems the sampling frequency at each location acceptable [137].

\section{$\mathrm{CH}_{4}$ Monitoring System Testing}

Title 30 Part 27 Subpart $\mathrm{C}$ of the CFR provides federal regulations related specifically to the testing of $\mathrm{CH}_{4}$ monitoring systems to determine MSHA approval. Tests are conducted to confirm items such as the performance, explosion-proof characteristics, intrinsic safety characteristics, and robustness of the system. For example, regulations require tests to determine resistance to 
vibration, resistance to dust, and resistance to moisture. Since the humidity in a mining environment is likely high, the atmosphere for humidity tests is around $80 \% \mathrm{RH}$ and $65-75^{\circ} \mathrm{F}$. The monitor must continuously sample in the atmosphere for 4 hours [138].

\section{Filtration}

Federal regulations require the integration of an adequate filter in the $\mathrm{CH}_{4}$ monitoring system at the sample intake [137]. For MSHA approval, the $\mathrm{CH}_{4}$ monitoring system must withstand dust resistance tests. During dust tests, the atmosphere consists of an average dust concentration of 50 million -40 micron particles per $\mathrm{ft}^{3}$ and the monitor must continuously sample in the atmosphere for 4 hours, where the "-40" relates to the mesh size required for filtering the particles [138].

\section{Shield Integration}

Shields today are generally 1.5 to $2 \mathrm{~m}$ wide and the number of shields used varies from one mine to another [139]. A Komatsu employee stated that shields generally cost around \$250,000 [140]. Enough shields, typically around 200 based on the average panel dimensions and shield width, are used to span the length of the longwall face. Shield control systems use a low-voltage DC power for operation. More specifically, a lead longwall mining equipment manufacturer, Komatsu, integrated the Faceboss RS20S control system which requires 12-volt (V) DC power supply [141]. Each shield has an integrated 12 VDC 2.5-amp (A) power supply, which is intrinsically safe, to power the control system and other shield components [141]. Note that the intrinsically safe power supply is powered by a high voltage alternating current (AC) power located at each shield. Longwall shields today also contain integrated water sprayers for dust control [142]. The water supplied to these sprayers is generally between 689.5 and $1378 \mathrm{kPa}$ (100 and $200 \mathrm{psi}$ ) [143] [44]. This water can provide water to power an ejector sampler. 


\subsection{Methodology}

\subsection{System Design}

Since it was initially thought that the power supply at each shield was 24 VDC, it was necessary that all components were powered by either 24 VDC or 5VDC (attained with a power converter). It was also essential that most (if not all) electrical components be enclosed in an intrinsically safe container.

Sensor Selection

MQ-4 Sensor (MOS)

One methane $\left(\mathrm{CH}_{4}\right)$ sensor proposed for use in the Methane Watchdog System (MWS) was the MQ-4, shown in Figure 3.1-1. The MQ-4 was a low-cost metal-oxide sensor (MOS) ( \$5). The MQ-4 sensors, herein referred to as the MOS, are semiconductors and operate by using tin dioxide $\left(\mathrm{SnO}_{2}\right)$ as the sensitive material. When $\mathrm{CH}_{4}$ was present, it reacted with the $\mathrm{SnO}_{2}$ and caused the conductivity of the sensor to rise; this rise in conductivity was correlated to the sensors output voltage which was then used to calibrate the sensor to the acceptable $\mathrm{CH}_{4}$ concentration range. These sensors were used in conjunction with a breakout board $(\sim 1)$ designed specifically for the MOS to help ease the wiring process. Figure 3.1-1 shows an image of a MOS, the breakout board, and the two in conjunction. The input voltage required to power the sensor was 5 VDC and the output voltage, which is between 0 and $5 \mathrm{~V}$, was sent as an analog input signal to the data acquisition (DAQ) device. The manufacturers also recommended a load resistor of $4.7 \mathrm{k} \Omega$ be placed between the ground and signal wire. Upon further development of calibration strategies, the $4.7 \mathrm{k} \Omega$ resistor was replaced with an $8.77 \mathrm{k} \Omega$. This load resistance helped vary the high and low detection limits of the sensor which allowed for more accuracy within these regions. The 8.77 $\mathrm{k} \Omega$ was selected to extend the upper limit of the sensor's response range to $2 \% \mathrm{CH}_{4}$ for calibrations. Figure 3.1-2 shows a wiring example for the MOS. Sensor specifications and dimensions are found in Appendix A. 


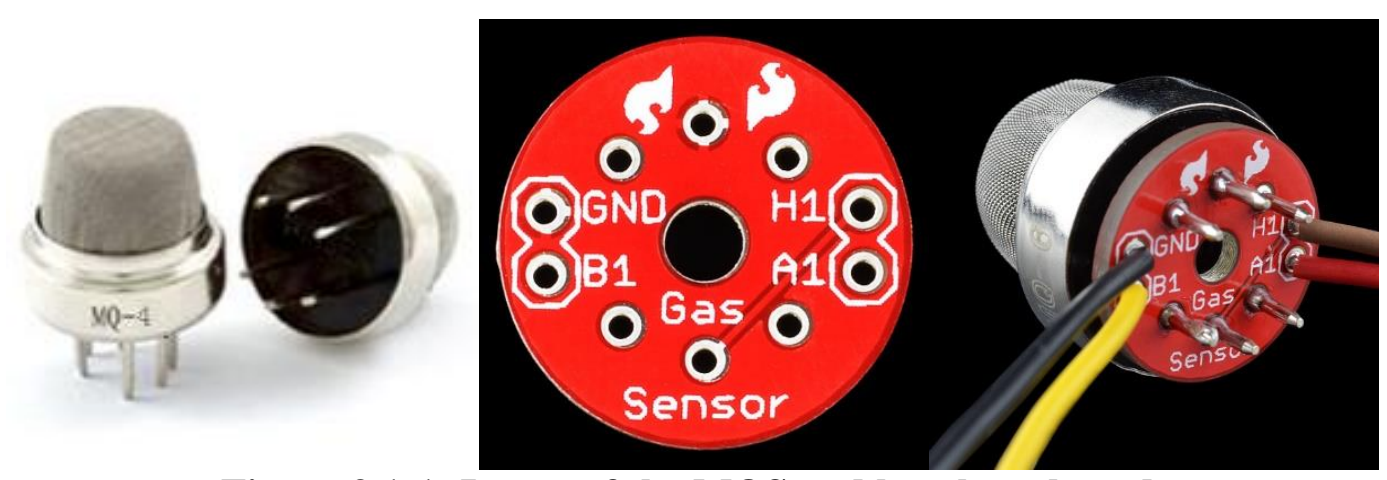

Figure 3.1-1: Image of the MOS and breakout board.
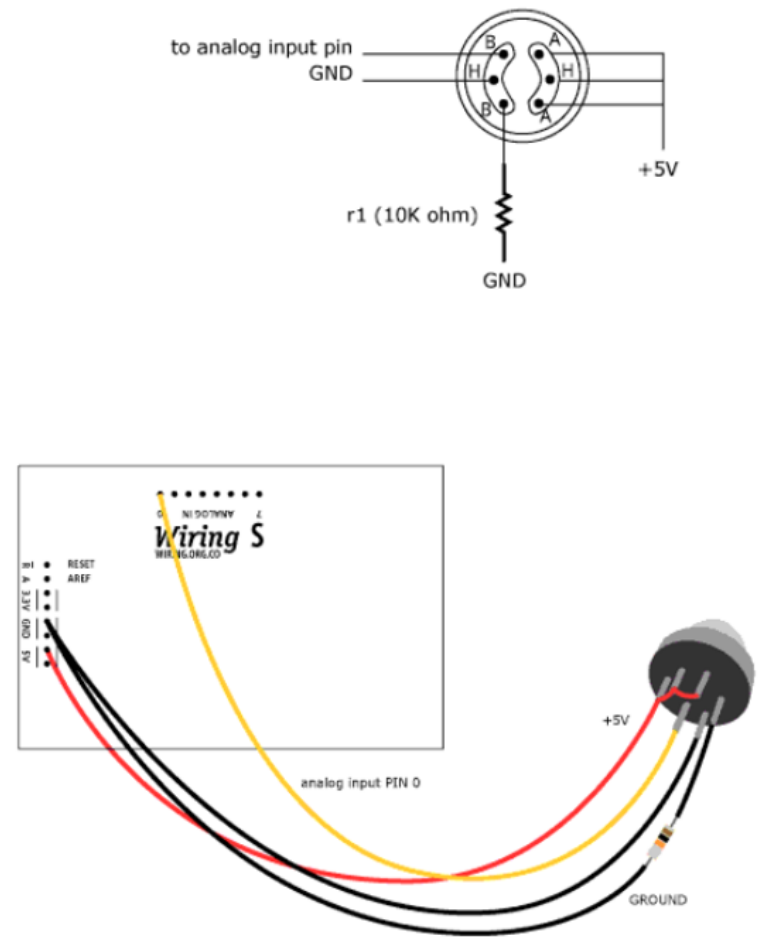

Figure 3.1-2: MOS wiring example.

\section{Dynament Sensor (IRS)}

Due to their operating principle, the MOS were impacted by external factors such as humidity and temperature, therefore, another sensor was implemented along with the MOS. The second $\mathrm{CH}_{4}$ sensor integrated into the system was a Dynament infrared sensor, herein referred to as the IRS. The IRS used infrared technology for $\mathrm{CH}_{4}$ detection. Although the IRS was more expensive than the MOS at around \$150, it was still considered a low-cost option for this application. Figure 3.13 shows the IRS. The IRS had the same power requirements as the MOS (5 VDC) and the output voltage is sent to the DAQ device as an analog input signal between 0.2 and $2.4 \mathrm{~V}$. Appendix B contains the specifications and dimensions of the sensor. 


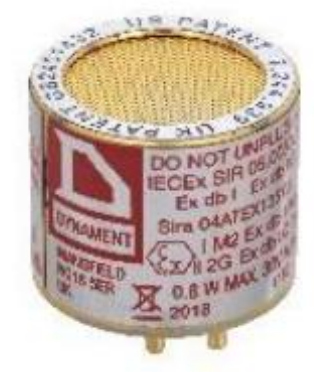

Figure 3.1-3: Image of the IRS.

\section{Climate Sensors}

During initial testing of the MOS and IRS, RH, and temperature were found to substantially impact the MOS and slightly impact the IRS responses. Therefore, a RH sensor and thermocouple were included in each sampling unit along with the $\mathrm{CH}_{4}$ sensors. This enabled application of both $\mathrm{RH}$ and temperature corrections. The addition of these sensors also allowed for continuous measurement of these parameters that would be useful in a mine. It would eliminate the need for a miner to record measurements in certain locations and the associated human error. As previously mentioned, researchers surveyed various miners where they expressed their interest in a continuous monitoring system for temperature and $\mathrm{RH}$ [24]. A pressure sensor was also added into the sampling unit to determine when the filter needed changed; as the coal debris caked onto the filter, the absolute pressure would drop at the sampling block, before the motive force and after the filter. Figure 3.1-4 shows the three climate sensors (RH, temperature, and pressure). The temperature sensor was a Type-T thermocouple with a $7.62 \mathrm{~cm}$ (3 in) probe. The pressure sensor already had an O-ring and mounting holes which were taken advantage of in the design. The RH and pressure sensors had an output signal of 0-5 V which was interpreted by the DAQ system through their connection as analog inputs. A transmitter was required to convert the thermocouple signal to a current of 4-20 mA, which could then be recorded by the DAQ system. 

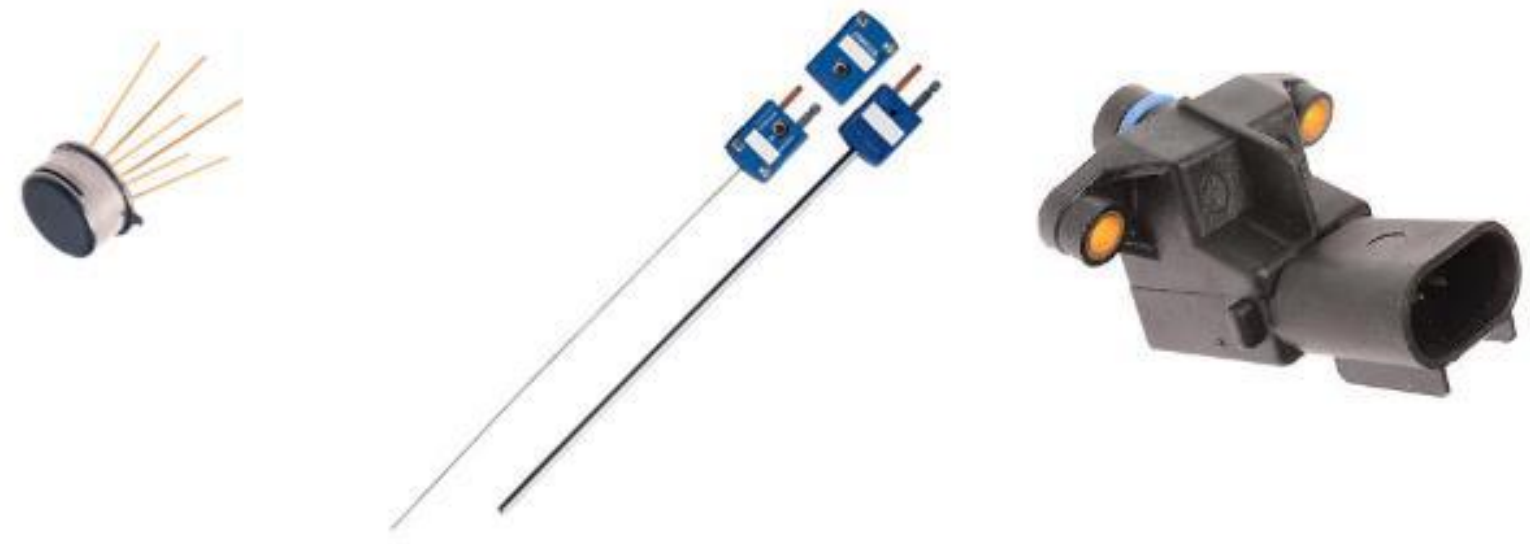

Figure 3.1-4: RH sensor (left), temperature sensor (middle), and pressure sensor (right)

[144] [145] [146].

\section{Additional Sensors (Flow and Air Velocity)}

Since a goal of the proposed system was to ultimately be integrated for possible control of shearer and ventilation speeds, an anemometer was needed to measure wind speed for the semi-full-scale testing and demonstrations. Note that continuous wind measurements would improve mine safety and enable estimates of $\mathrm{CH}_{4}$ flow rates. A 3-cup anemometer was selected primarily for their low cost. Two were obtained with intentions to mount them on the sampling units at the second and second to last (near HG and near TG) nodes of the system. Mounting them on the units near the roof may serve to replace periodic measurements taken with handheld anemometers for the velocity requirements to prevent $\mathrm{CH}_{4}$ layering.

A flow sensor was also integrated into each unit to assure similar sampling flowrates were maintained through each unit. Both the anemometer and flow sensors, were powered by the 5 VDC power supply and were connected to an analog input channel in their respective sampling unit so the signals were measured, recorded, and interpreted at the $\mathrm{CPH}$. The 3-cup anemometer and flow sensor can be seen in Figures 3.1-5 and 3.1-6, respectively. 


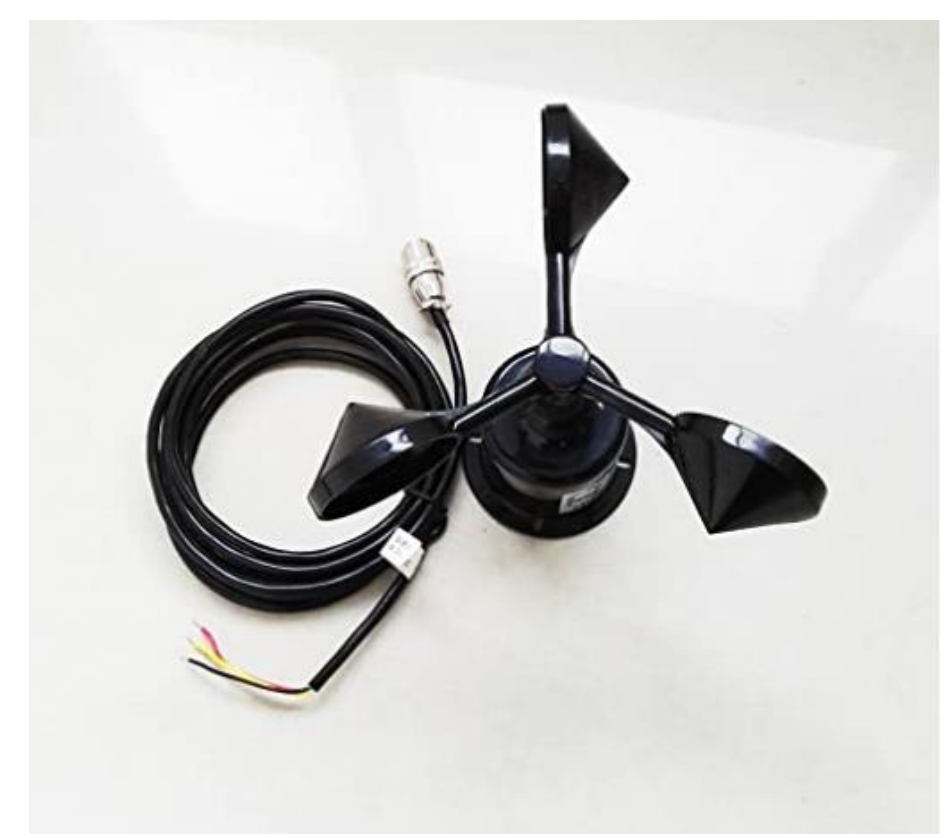

Figure 3.1-5: 3-Cup anemometer used to measure ventilation/wind speeds [147].

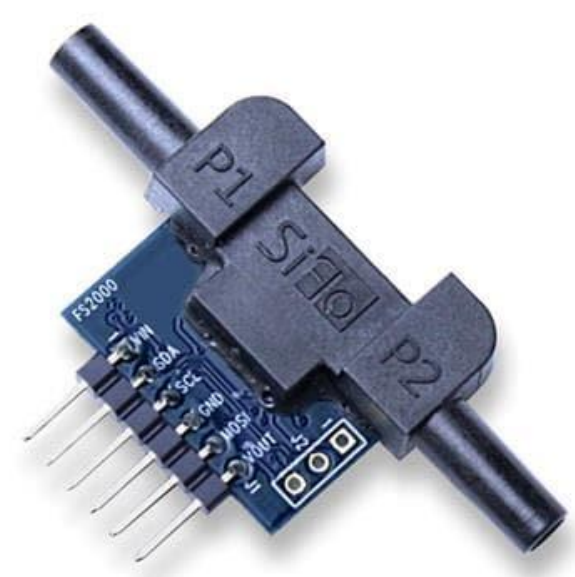

Figure 3.1-6: Flow sensor used in unit for measuring sample flowrate [148]. 


\section{Table of Sensors}

Table 3.1-1 presents a list of sensors integrated into each unit, including the measurement range, input voltage and output voltage range for each.

Table 3.1-1: Table of sensors.

\begin{tabular}{|c|c|c|c|c|c|c|c|}
\hline & Make & Model & $\begin{array}{l}\text { Manufacturer } \\
\text { Location }\end{array}$ & Range & $\begin{array}{c}\text { Supply } \\
\text { Voltage } \\
\text { [V] }\end{array}$ & $\begin{array}{c}\text { Output } \\
\text { Voltage } \\
\text { [V] }\end{array}$ & $\begin{array}{l}\text { Website/ } \\
\text { Manual }\end{array}$ \\
\hline MOS & Winson & MQ-4 & $\begin{array}{l}\text { Zhengzhou, } \\
\text { China }\end{array}$ & $\begin{array}{c}0.03 \text { to } \\
1 \% \mathrm{CH}_{4}\end{array}$ & 5 & $0-5$ & [90]/ [91] \\
\hline IRS & Dynament & $\begin{array}{l}\text { MSH2ia- } \\
\text { LS/HC/5 } \\
\text { /V/P }\end{array}$ & Mansfield, UK & $\begin{array}{l}0 \text { to } 5 \% \\
\mathrm{CH}_{4}\end{array}$ & 5 & $0.2-2.5$ & {$[82] /[83]$} \\
\hline $\begin{array}{c}\text { Temperature } \\
\text { Sensor }\end{array}$ & Omega & $\begin{array}{l}\text { TMQSS- } \\
062 U-3\end{array}$ & $\begin{array}{c}\text { Norwalk, CT, } \\
\text { USA }\end{array}$ & $\begin{array}{l}-454 \text { to } \\
752^{\circ} \mathrm{F}\end{array}$ & N/A & N/A & $\begin{array}{l}{[145] /} \\
{[149]}\end{array}$ \\
\hline RH Sensor & Honeywell & $\begin{array}{c}\text { HIH- } \\
\text { 4602-L- } \\
\text { CP }\end{array}$ & $\begin{array}{l}\text { Minneapolis, } \\
\text { MN, USA }\end{array}$ & $\begin{array}{c}0 \text { to } \\
100 \% \\
\text { RH }\end{array}$ & 5 & $0.8-3.9$ & $\begin{array}{l}{[144] /} \\
{[150]}\end{array}$ \\
\hline $\begin{array}{l}\text { Pressure } \\
\text { Sensor }\end{array}$ & $\begin{array}{c}\text { Borg } \\
\text { Warner }\end{array}$ & EC7034 & $\begin{array}{c}\text { Long Island } \\
\text { City, NY,USA }\end{array}$ & & 5 & & {$[146]$} \\
\hline Flow Sensor & $\begin{array}{c}\text { Renesas } \\
\text { Electronics }\end{array}$ & $\begin{array}{l}\text { FS2012- } \\
1100-N G\end{array}$ & Tokyo, Japan & $\begin{array}{l}0 \text { to } 10 \\
\text { SLPM }\end{array}$ & 5 & $0-5$ & $\begin{array}{l}{[148] /} \\
{[151]}\end{array}$ \\
\hline $\begin{array}{c}\text { 3-Cup } \\
\text { Anemometer }\end{array}$ & CALT & YGC-FS & $\begin{array}{l}\text { Shanghai, } \\
\text { China }\end{array}$ & $\begin{array}{c}0.5 \text { to } 45 \\
\mathrm{~m} / \mathrm{s}\end{array}$ & 5 & $0-5$ & $\begin{array}{l}{[147] /} \\
{[152]}\end{array}$ \\
\hline
\end{tabular}

\section{Additional Components for Sensor Mounting}

Some components were designed and machined for the MOS and IRS mounting. A custom mounting unit was constructed for the IRS using a plastic block. A wiring harness was integrated into the block so that the IRS could easily be plugged in and out of the unit. Four holes were drilled in the corners of the block for the placement of screws for mounting the unit into the aluminum sensor block, discussed in the next section. Once mounted, the unit pressed onto an O-ring placed around the sensor, creating a seal. A metal housing was also made to ease the mounting process of the MOS. This housing was made with a $25.4 \mathrm{~mm}$ ( 1 in) diameter aluminum cylinder where two different diameter holes were bored. One was large enough for the entire sensor to be recessed into the housing and one was just large enough for the sensor head to fit through the bottom of the housing. Once the sensor was placed in the housing, electronics potting epoxy was used to seal the sensor into the housing itself. An O-ring was also used between the MOS housing and the O-ring surface created in the aluminum sensor block to seal and prevent leaks. A metal plate was used to press down onto the MOS and created the seal. The MOS housing allowed for the plate to apply 
pressure to the housing instead of on the sensor itself, preventing damage to the sensor. Figures 3.1-7 and 3.1-8 show the components used for mounting the IRS and MOS, respectively.

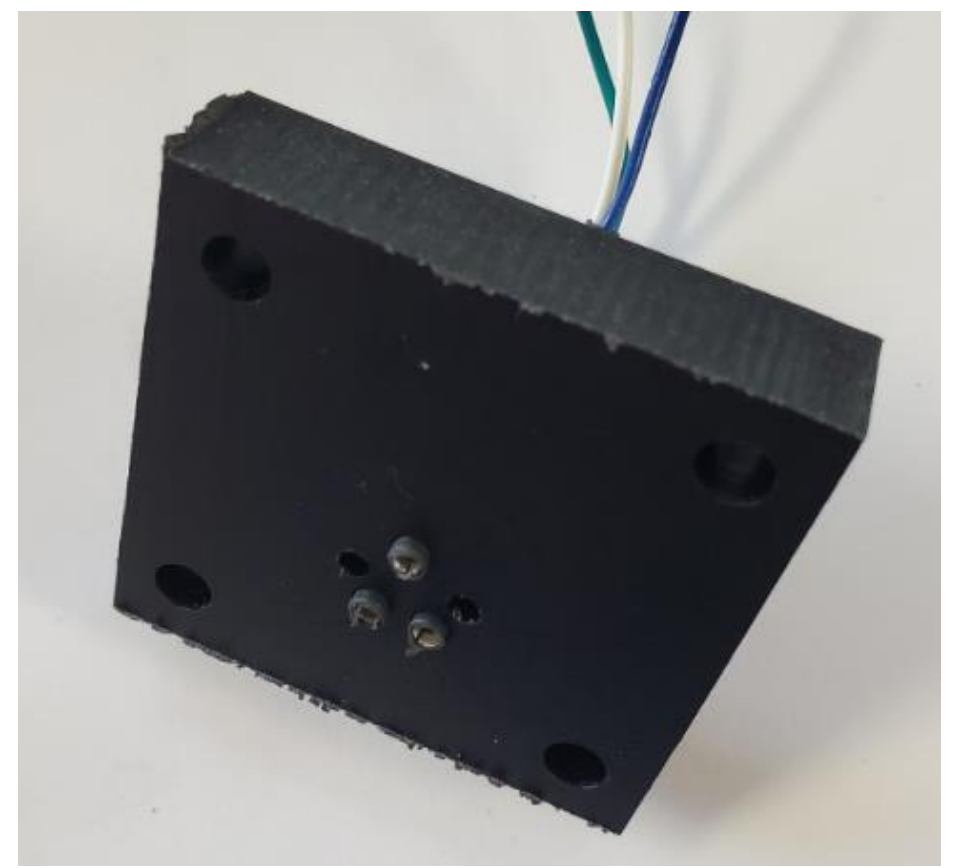

Figure 3.1-7: Plastic mounting unit for IRS.

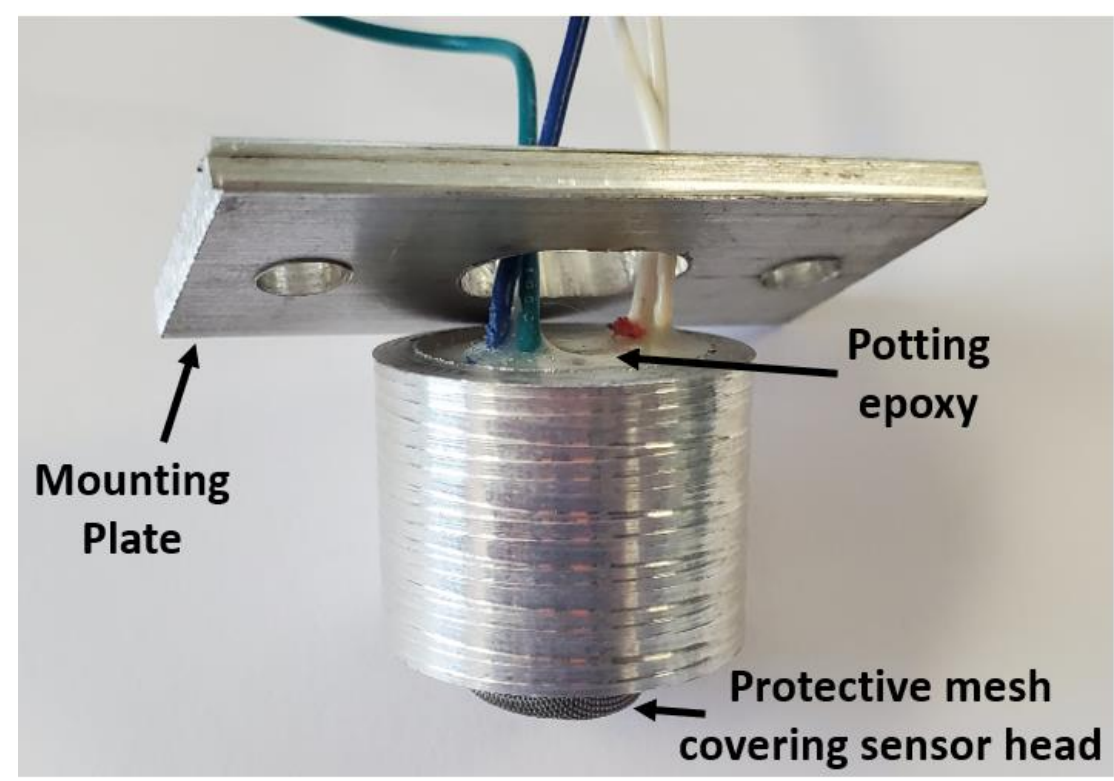

Figure 3.1-8: Metal housing and plate for MOS mounting.

\section{Aluminum Sensor Block Design}

An aluminum sensor block was designed and machined to house all five sensors (RH sensor, temperature sensor, pressure sensor, and MOS, and IRS). Figure 3.1-9 shows a 3-D model of the sensor block. The holes for the mounting locations of the MOS and IRS were milled to a specific 
diameter to accommodate for the MOS housing and IRS diameter. A recess was also integrated into the mounting locations for the MOS and IRS to create a surface for the O-ring to rest on and create a seal. The hole for the mounting of the pressure sensor was also designed to a specific diameter in order to utilize the O-ring that was already integrated on the pressure sensor. The inlet and outlet holes as well as the holes for mounting the RH sensor and thermocouple were designed to accommodate $6.35 \mathrm{~mm}(1 / 4 \mathrm{in})$ National Pipe Thread (NPT) fittings.

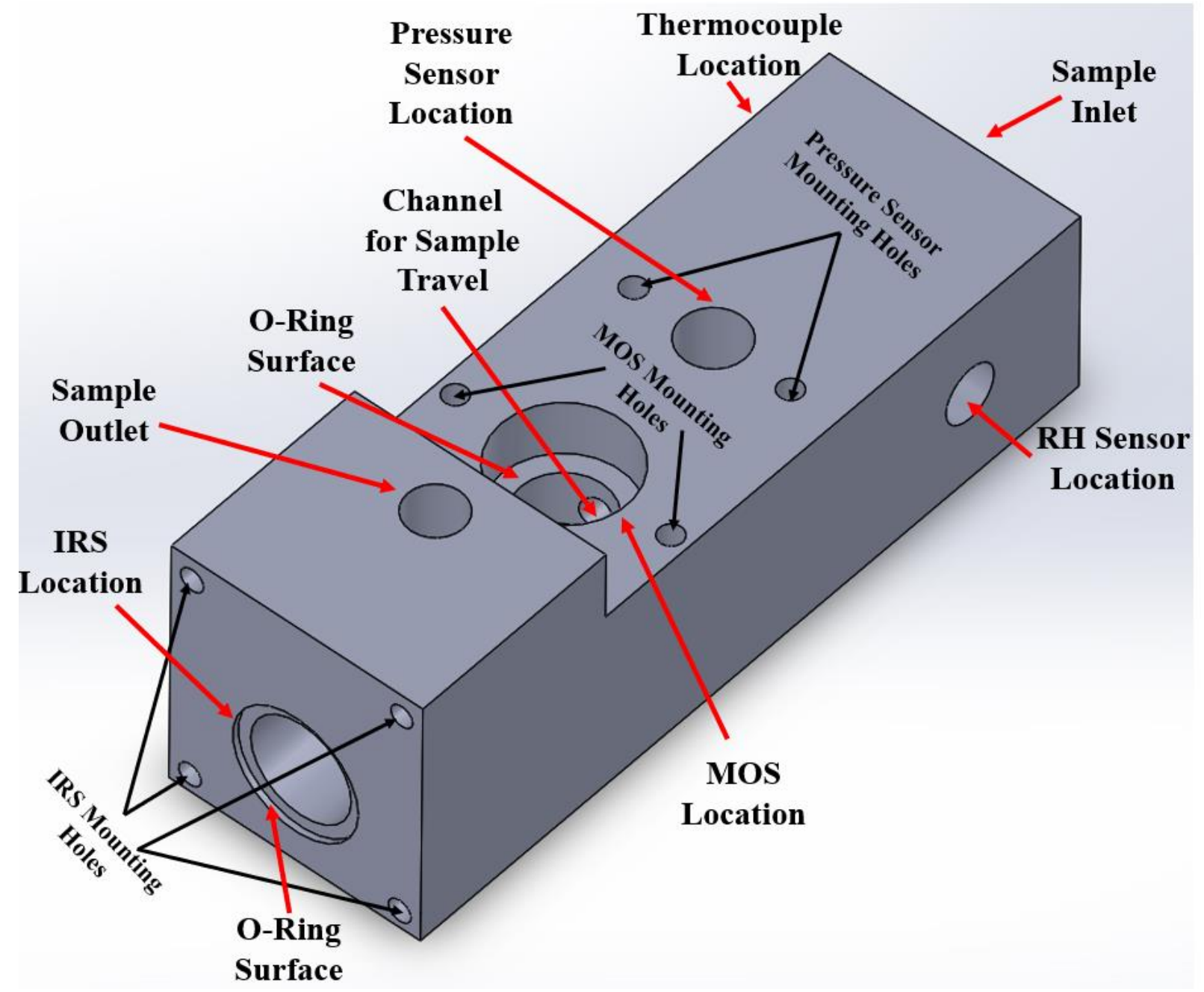

Figure 3.1-9: 3-D model of aluminum sensor block.

\section{Integration of Components into the "Sampling Box"}

\section{Mounting of Sensors}

Figure 3.1-10 shows the sensor block with all five sensors mounted along with the flow sensor attached to the outlet of the block. Figure 3.1-11 shows one of the 3-cup anemometers mounted onto one of the sampling units. 


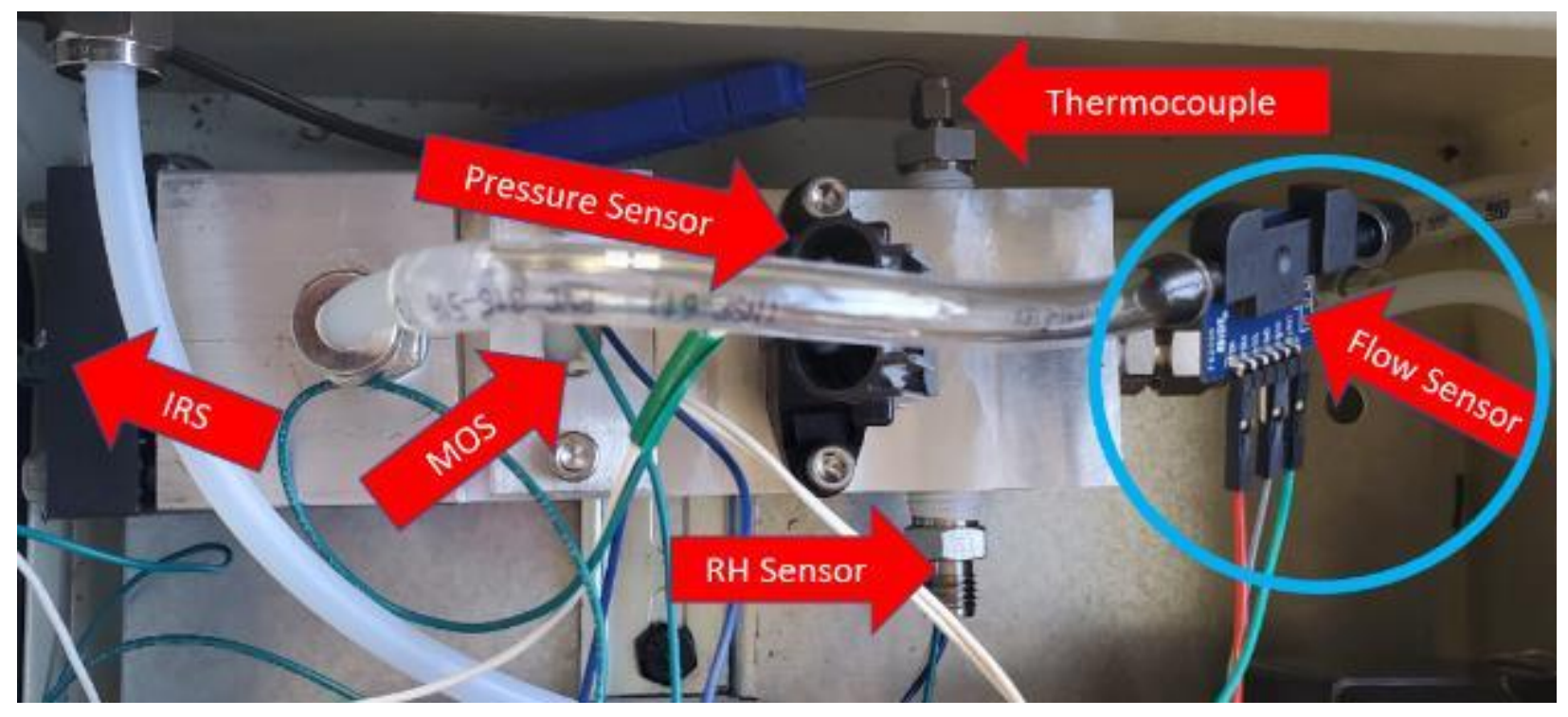

Figure 3.1-10: Sensors mounted in the block and flow sensor integration.

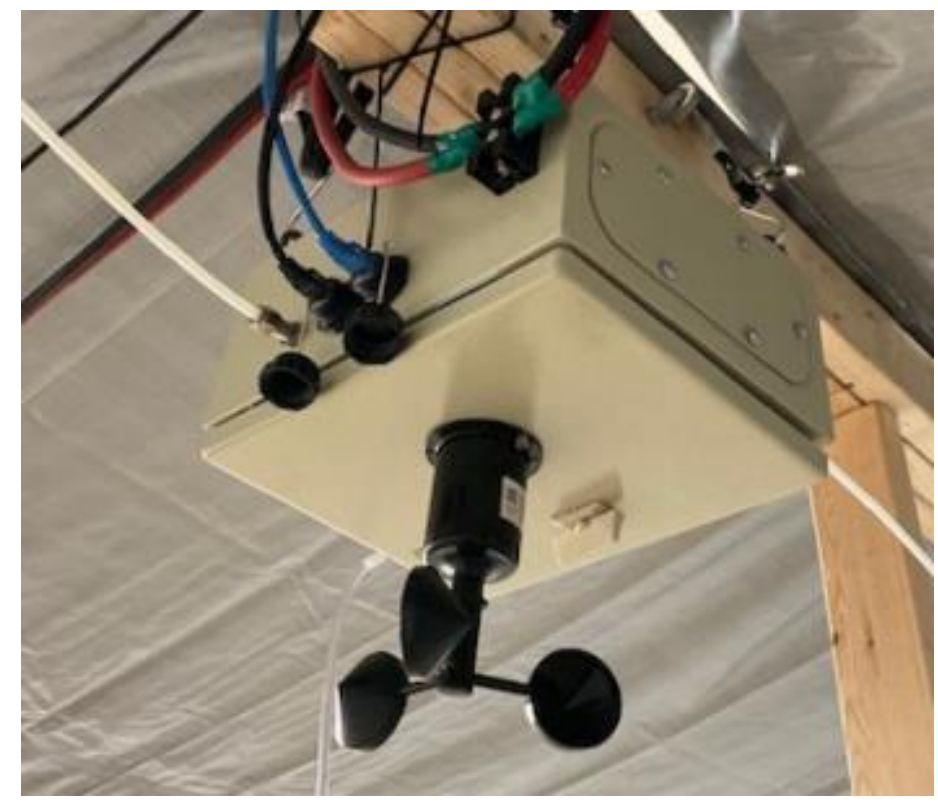

Figure 3.1-11: 3-Cup anemometer mounted on sampling unit.

\section{Sampling Unit Design}

Each sampling unit consisted of a steel box which housed the aluminum sensor block containing the five sensors as well as other components for power, data collection, and communication with the CPH. Table 3.1-2 contains a list of all components inside the sampling unit. 
Table 3.1-2: Components housed within each sampling box (node).

\begin{tabular}{|c|c|c|}
\hline Item & Picture of Component & Description \\
\hline Sensor Block & & $\begin{array}{l}\text { The aluminum sensor block houses the IRS, } \\
\text { MOS, RH sensor, thermocouple, and pressure } \\
\text { sensor and has one inlet and one outlet which are } \\
\text { connected to the sampling tubes; this allows the } \\
\text { sample to flow through the sensor block, past all } \\
\text { five sensors. }\end{array}$ \\
\hline 3-Way Valve & [153] & $\begin{array}{l}\text { The 3-way valve is a direct acting solenoid valve } \\
\text { and controls the location that the sample is being } \\
\text { pulled from Inlet } 1 \text { or Inlet } 2 \text {, either from the face } \\
\text { or from the gob. (see the "Two Sampling } \\
\text { Locations per Node" section) The valve is } \\
\text { powered by the } 24 \text { VDC power supply. }\end{array}$ \\
\hline $\begin{array}{l}\text { 24VDC to } \\
\text { 5VDC Power } \\
\text { Converter }\end{array}$ & & $\begin{array}{l}\text { The converter has an input of } 24 \mathrm{VDC} \text {, from the } \\
\text { external power source, and an output of } 5 \mathrm{VDC} \text {, } \\
\text { which is needed to power most sensors in the unit. }\end{array}$ \\
\hline $\begin{array}{l}\text { Terminal } \\
\text { Blocks } \\
\text { (one } 24 \text { VDC } \\
\text { and one } \\
\text { 5VDC) }\end{array}$ & & $\begin{array}{l}\text { The terminal blocks are bridged in a way that one } \\
\text { can supply } 24 \mathrm{VDC} \text { power and one can supply } \\
5 \mathrm{VDC} \text { power. All components that require power } \\
\text { in the unit are connected to the terminal block } \\
\text { corresponding to their power input specification. } \\
\text { The } 24 \mathrm{VDC} \text { terminal block is powered directly } \\
\text { from the external power source and the } 5 \mathrm{VDC} \\
\text { power strip is powered by the output of the } \\
\text { converter. }\end{array}$ \\
\hline ICP CON & [154] & $\begin{array}{l}\text { The ICP CON is a DAQ unit by ICP DAS. It has } \\
8 \text { analog input (AI) channels and } 4 \text { digital output } \\
\text { (DO) channels and is powered by the } 24 \mathrm{VDC} \\
\text { power supply. All sensors are connected to the AI } \\
\text { channels and the valve is connected to a relay and } \\
\text { is controlled through a DI channel. The ICP CON } \\
\text { sends the sensors' signals to the computer where } \\
\text { they can be post processed and the computer } \\
\text { sends signals to the ICP CON to control the valve } \\
\text { via ethernet. }\end{array}$ \\
\hline Relay & 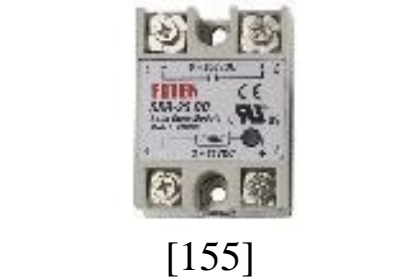 & $\begin{array}{l}\text { The relay receives the DI signal from the ICP } \\
\text { CON and controls the power supplied to the } \\
\text { valve. }\end{array}$ \\
\hline
\end{tabular}




\begin{tabular}{|c|l|l|}
\hline $\begin{array}{c}\text { Temperature } \\
\text { Transmitter }\end{array}$ & $\begin{array}{l}\text { Since the ICP CON being used does not have a } \\
\text { thermocouple input, a transmitter is needed which } \\
\text { converts the thermocouple signal into signal of 4- } \\
\text { 20mA. This transmitter is powered by the 24VDC } \\
\text { power supply. }\end{array}$ \\
$\begin{array}{c}\text { Sampling } \\
\text { Tubes }\end{array}$ & $\begin{array}{l}\text { Sampling tubes (0.25in PTFE Tubing) are } \\
\text { connected to inlet and outlet locations throughout } \\
\text { the box. They are connected from each of the unit } \\
\text { inlets to the corresponding valve inlet, from the } \\
\text { valve outlet to the sensor block inlet, and from the } \\
\text { sensor block outlet to the outlet of the unit. }\end{array}$ \\
\hline $\begin{array}{c}\text { Ethernet } \\
\text { Connection } \\
\text { Ports }\end{array}$ & $\begin{array}{l}\text { Two ethernet connection ports were mounted } \\
\text { through the back side of the unit. The ICP CON } \\
\text { "in" and "out" ethernet ports are connected to the } \\
\text { respective connection port. The ethernet "in" and } \\
\text { "out" connection ports allow the units to be } \\
\text { "Daisy-Chained" together where only the first } \\
\text { unit is directly connected to the computer. }\end{array}$ \\
$\begin{array}{c}\text { Through } \\
\text { Panel } \\
\text { Block }\end{array}$ & $\begin{array}{l}\text { The through panel terminal block is mounted } \\
\text { through the back side of the unit. The external } \\
24 \mathrm{VDC} \text { power source is connected to the side of } \\
\text { the terminal on the outside of the unit. The } \\
\text { 24VDC power strip is connected to the side of the } \\
\text { terminal on the inside of the unit; all components } \\
\text { in the unit can then be powered }\end{array}$ \\
\hline
\end{tabular}

Figure 3.1-12 shows a 3-D model, made in SOLIDWORKS ${ }^{\mathrm{TM}}$, of the sampling unit with the location of each of the components as well as the direction of the sample flow through the unit; the sampling tubes and direction of flow are represented by the curved blue arrows and the greendashed lines represent the ethernet cables. Figure 3.1-13 shows one of the 10 sampling units assembled with the components. While the box itself would likely not be approved for use in the mine, it was selected to be comparable in size to a final product. It should be metallic, sealable, and as small as possible to reduce issues associated with installation in a real mine, as regulations require that $\mathrm{CH}_{4}$ monitoring systems contain an explosion proof enclosure which is sealable (with a lock) and robust [137]. Figure 3.1-14 shows one of the 3-cup anemometers mounted onto one of the sampling units. A material cost analysis (shown in Appendix C-1) was performed to calculate the total cost of the 10-node MWS prototype, which was around $\$ 14,000$. That total was then divided by 10 to calculate the approximate cost of sampling at a single node, which was around $\$ 1400$. However, a few changes would be made for industry use. For example, the metal box will 
be changed to an MSHA approved, explosion proof enclosure and the cable used for powering the units of the prototype would not be necessary. Instead, an additional power supply would be integrated with each unit. Because of this, an estimated cost of the system for use in industry was also calculated, considering the cost of an explosion proof container, the additional power supply, and the additional components necessary for ejector integration and operation. The estimated cost per sampling node for the final design to be used in industry was around $\$ 4550$. The summary of the estimated cost modifications is shown in Appendix C-2). The significant increase in price was mainly contributed to the upgrade of the metal box to an explosion proof enclosure. While this cost may seem high, if a unit is integrated into the Komatsu shield costing around $\$ 250,000$, the shield cost increases by only $1.82 \%$. Future research will focus on verifying the estimated cost analysis.

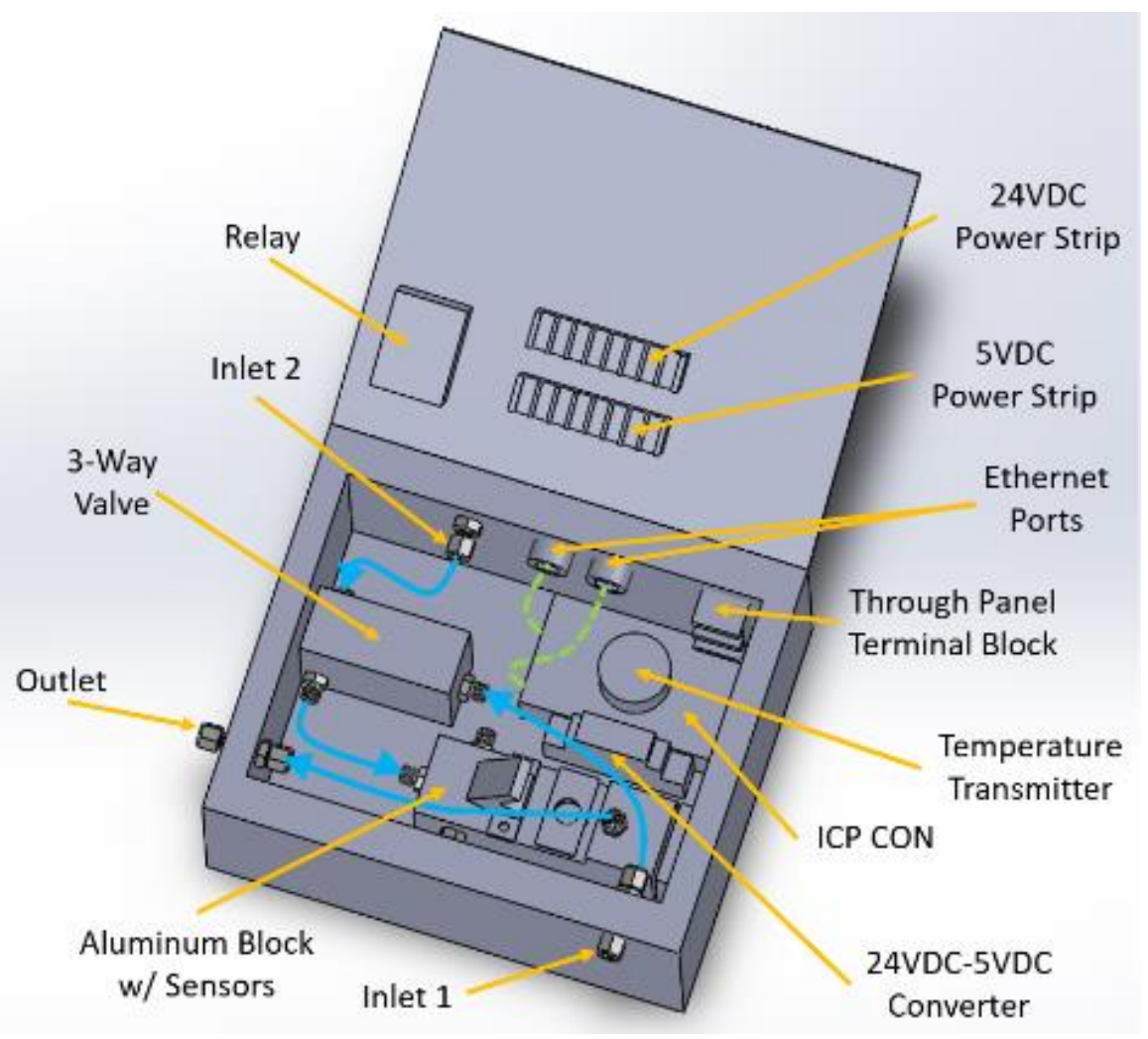

Figure 3.1-12: 3-D model of sampling unit with components. 


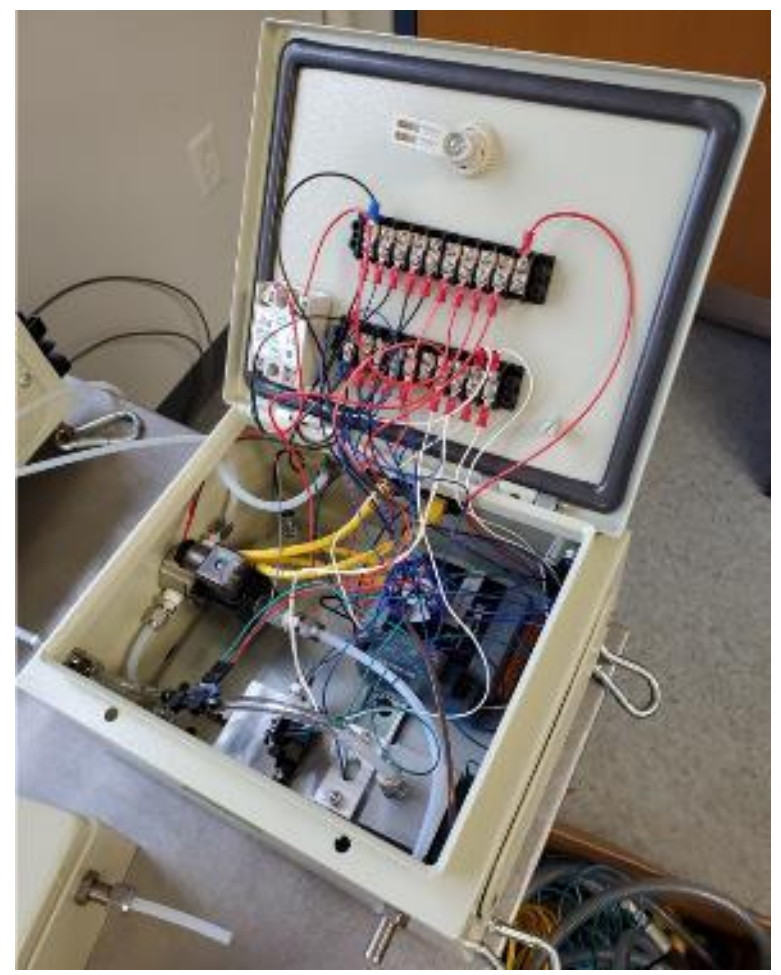

Figure 3.1-13: Assembled sampling unit.

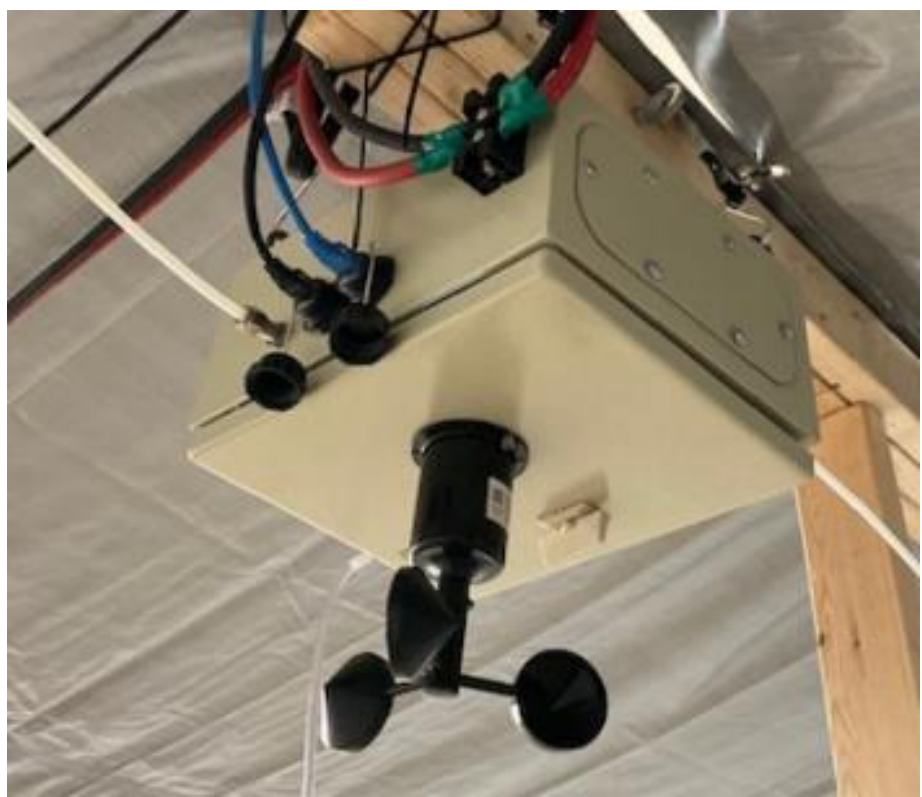

Figure 3.1-14: 3-Cup anemometer mounted on sampling unit. 


\section{The Network}

\section{Central Processing $\mathrm{Hub}(\mathrm{CPH})$}

The CPH was an industrial computer housed in a steel box, along with the 24 VDC power supply used to power the entire MWS. The industrial computer was a panel PC by ICP DAS (model \#: iPPC-6731-WES7) which was also powered by the 24 VDC power supply. Appendix D contains the specifications for the industrial computer. The $\mathrm{CPH}$ had the ability to process input analog signals and display desired parameters on a user interface (such as $\mathrm{CH}_{4}$ concentrations at each node) as well as send and receive digital signals to control the 3-way valves in each unit and the relay which controlled the alarm. Figure 3.1-15 shows the $\mathrm{CPH}$.
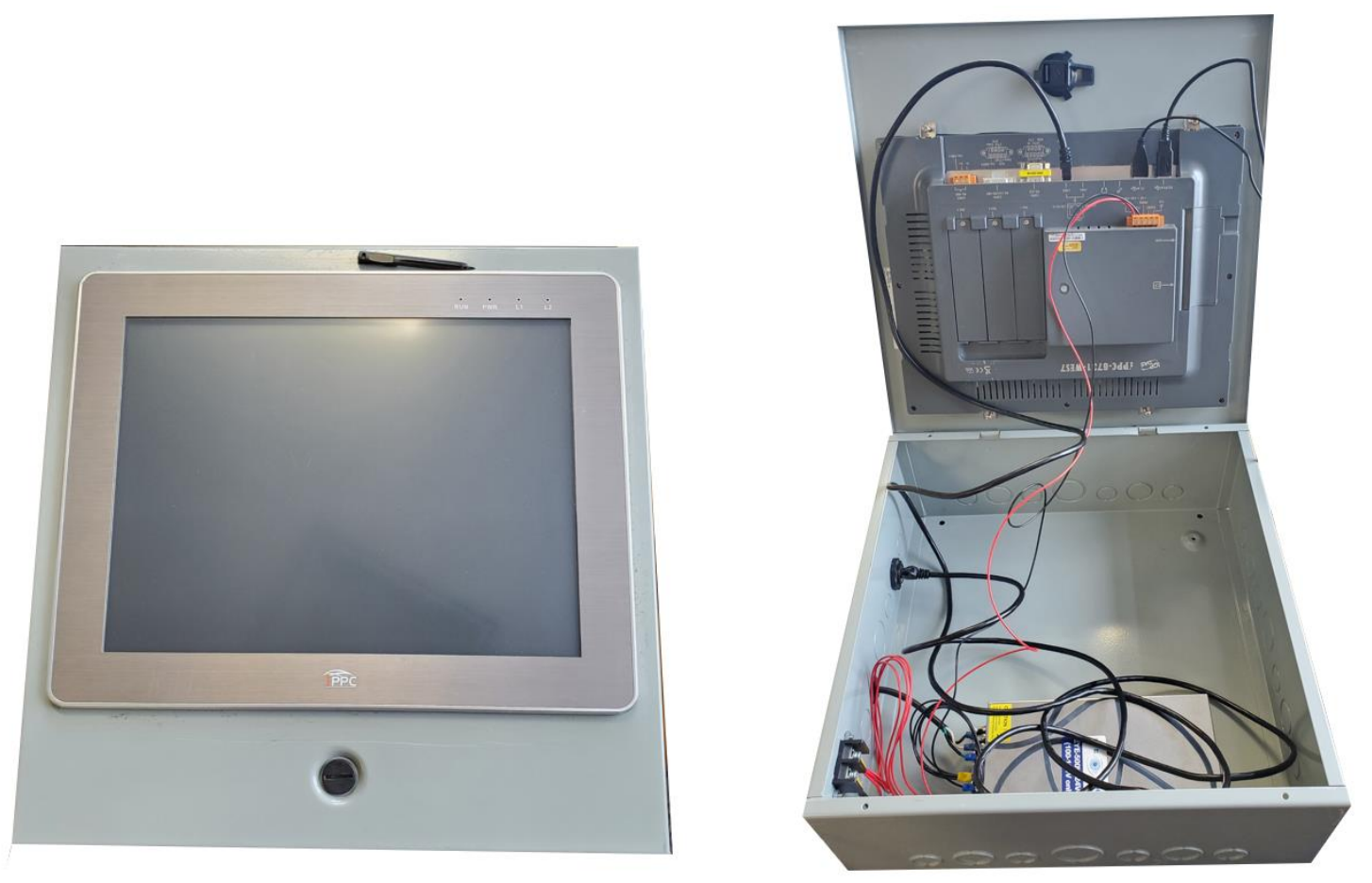

Figure 3.1-15: CPH closed (left) and open (right).

\section{Communication/Power Connections}

All ten sampling units were connected in series ("daisy-chained") with ethernet cables, where only the first unit was directly connected to the computer in the $\mathrm{CPH}$. The power supply was connected in the same manor using 2-gauge wire. It should be noted that in an actual mine, the power supply would already be integrated for shield control. Figure 3.1-16 shows a diagram of this set up where the yellow lines represent the ethernet cables, the red lines represent the positive wire of the power 
supply, and the black lines represent the ground wires. Note that the diagram only shows an example with five sampling units; all ten units were connected this way.

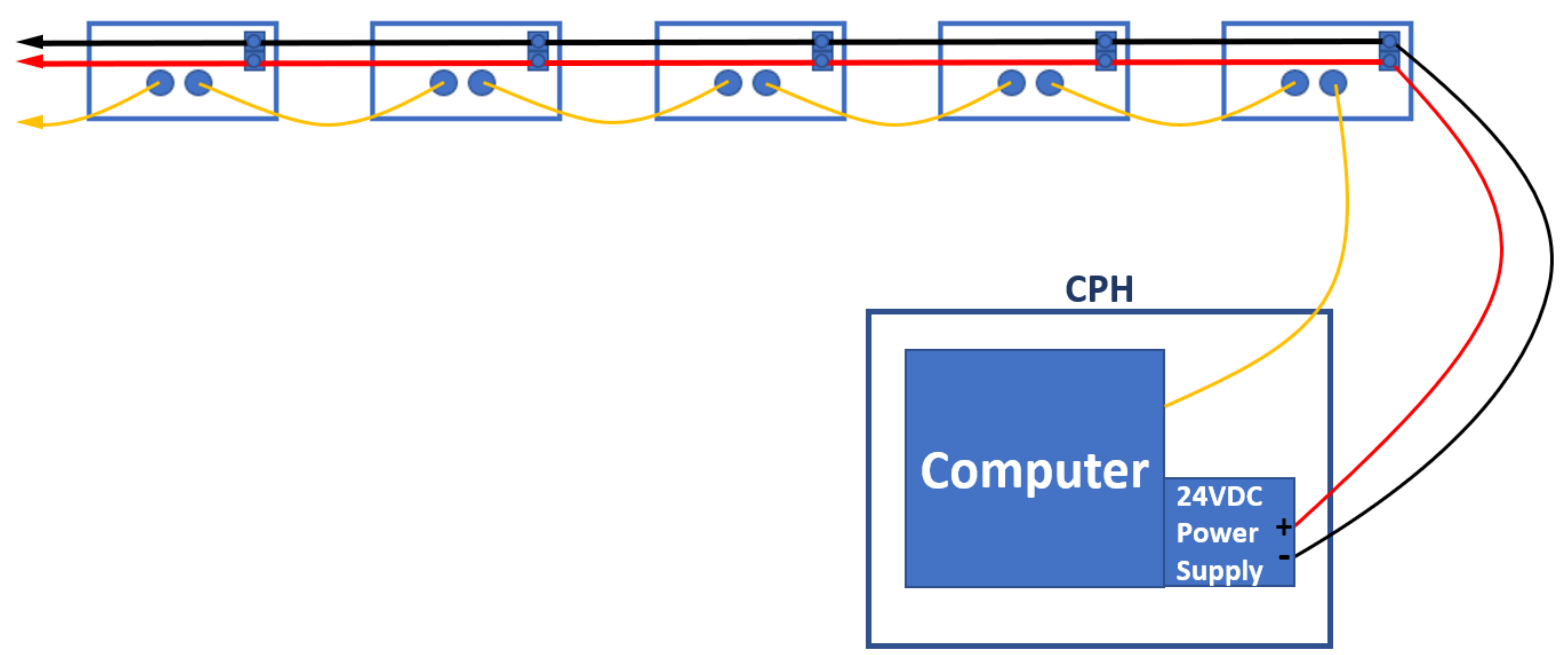

Figure 3.1-16: Diagram of "daisy-chain" connection of sampling units.

\section{Dual Location Sampling per Node}

After initial testing, it was determined that each node should consist of two sampling locations, one near the face (shield tip) and one near the gob. Having two sampling locations for each node allowed for a greater number of sampling locations without increasing the number of sampling units; this helped make the system more cost effective. The sampling node alternated sampling between the two locations at a prescribed time interval and was controlled by a three-way valve. When the valve was energized, the node sampled from the gob and when it was deenergized, the node sampled from the face. It was assumed that a default status at the mining face would be beneficial for enhanced safety even in the case of a disabled valve. The sample traveled through a $2.1 \mathrm{~m}(7 \mathrm{ft})$ tube from the sampling location to the sampling unit. This distance was determined based on the intentions to place the sampling unit at the center of the shield (around 14-16 ft from face to gob). The end of each tube at the sampling locations was connected to an enclosed filter to protect against coal dust and water droplets. Figure 3.1-17 shows the two sampling locations per node configuration. Figure 3.1-18 shows an example of a node layout, including the sampling unit and sampling locations. 


\section{Node}
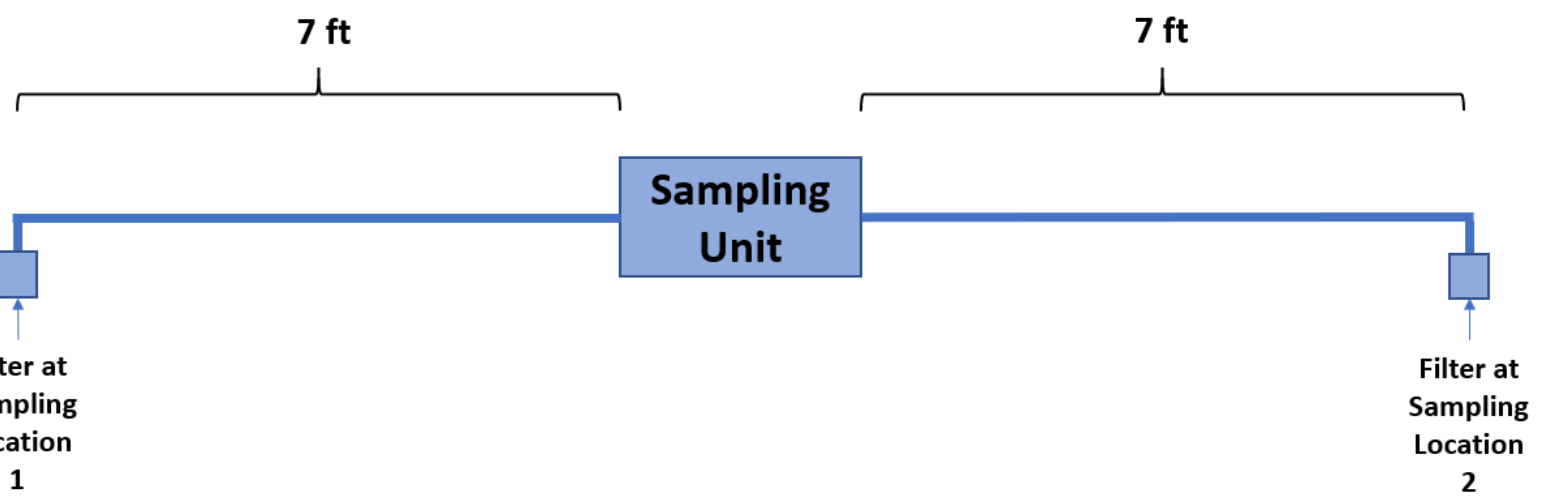

Figure 3.1-17: Two sampling locations at each node configuration.

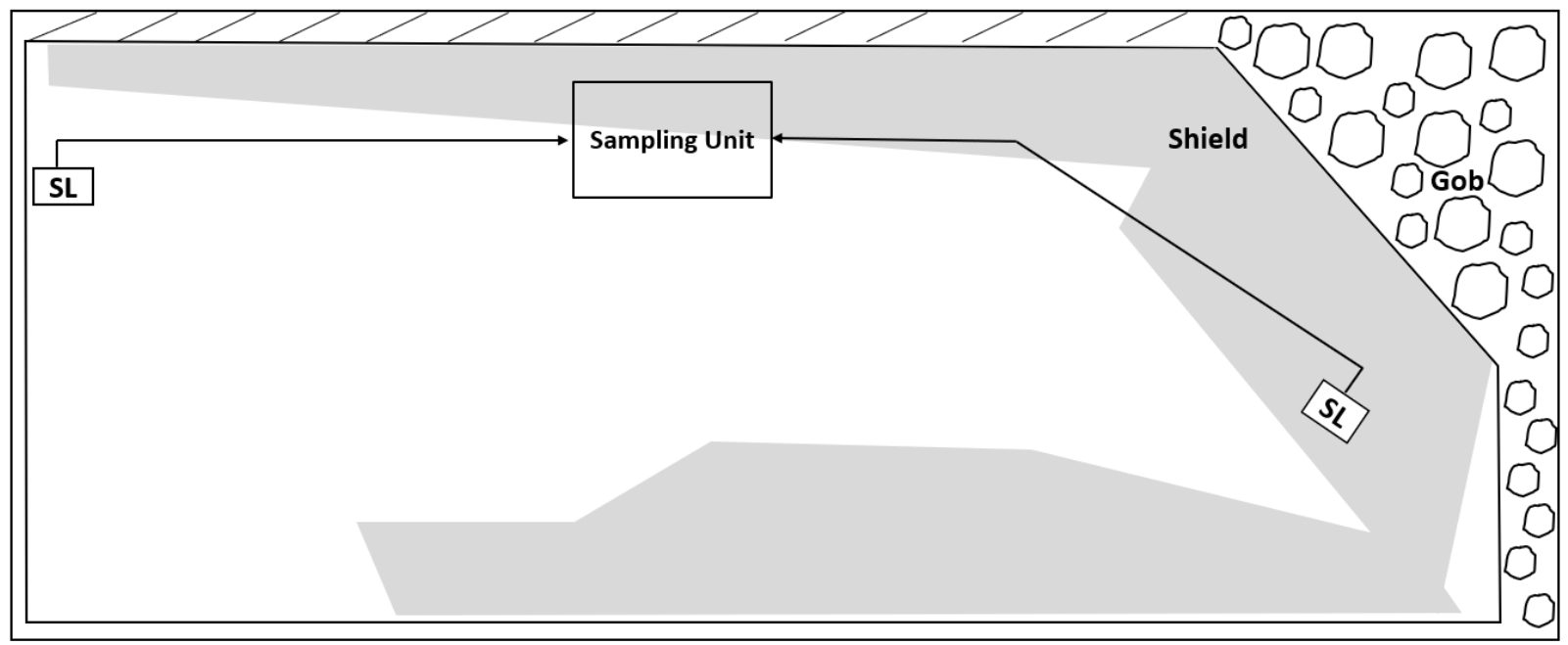

Note: SL = Sampling Location

Figure 3.1-18: Node layout on one shield.

\section{MWS Mine Layout}

Figure 3.1-19 shows the proposed layout of the MWS in a longwall mine. As an elevated $\mathrm{CH}_{4}$ concentration plume traverses the longwall, the unit at the plume location detects it and the signal is sent to the $\mathrm{CPH}$. The data acquisition software interprets the signal and activates the alarm/relay to alert miners and de-energize equipment when necessary. 

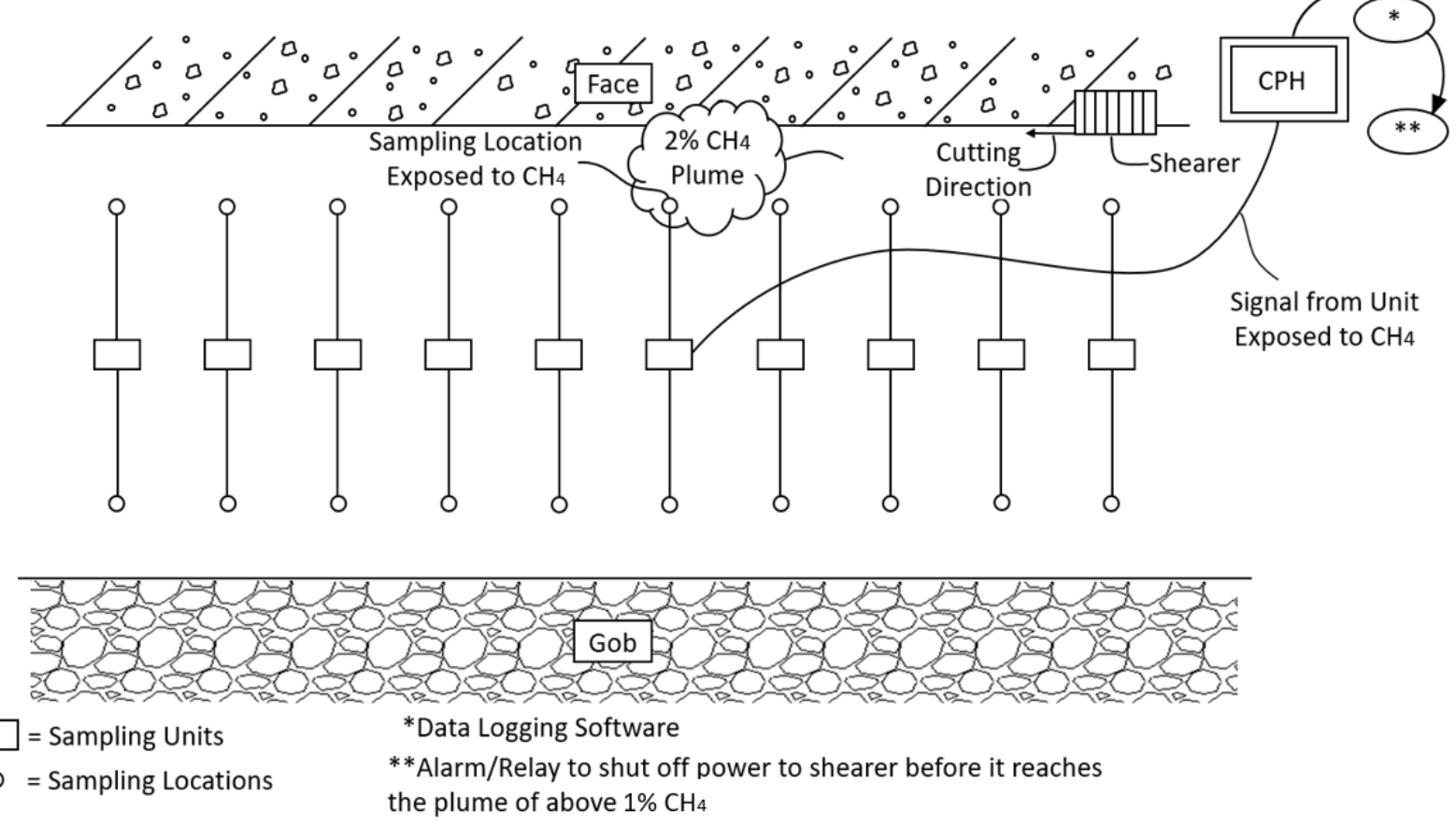

Figure 3.1-19: MWS layout in a mine.

\subsection{Filtration}

Three different filters were analyzed during the filter selection process. These efforts were led by Mr. Brian Capellini. The three filters are shown in Figure 3.2-1 and are referred to as Filter 1, Filter 2, and Filter 3 from left to right in the figure. It should be noted that Filter 3 came with a metal housing which was also used during testing. Table 3.2-1 shows the geometry and filtration area for each filter. Initial tests on the filters analyzed the effects of flowrate on the pressure drop caused by the filter. Since coal dust and moisture are two main physical characteristics of a mining atmosphere and could pose risk of harm to sensors, multiple experiments were performed to analyze the effects of coal dust and moisture loading on the pressure drop to assure they would be acceptable for this application. The differential pressure across the filters (pressure drop) was measured by a pressure calibration unit (Heise) which is further discussed in a later section. Heise Module 2 was used for the filtration selection process (see Table 3.3-3). 

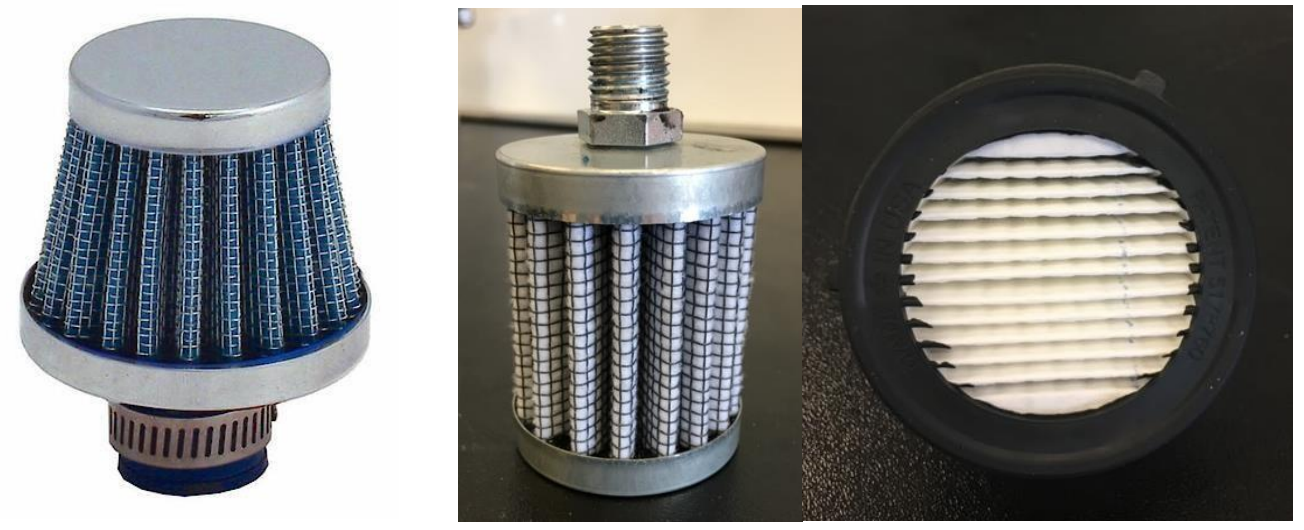

Figure 3.2-1: Three Filters Analyzed for System Filtration

Table 3.2-1: Filter Specifications

\begin{tabular}{|c|c|c|}
\hline Filter \# & Geometry & Effective Filtration Area $\left[\mathbf{m}^{\mathbf{2}}\right]$ \\
\hline $\mathbf{1}$ & Conical & 0.0102 \\
\hline $\mathbf{2}$ & Cylindrical & 0.0147 \\
\hline $\mathbf{3}$ & Flat & 0.0185 \\
\hline
\end{tabular}

\section{Flowrate Effects}

Each of the filters were attached to a tube which was then connected to the inlet of a positive displacement pump. The flowrate was controlled by a valve connected at the outlet of the pump. Four flowrates were achieved, and the pressure drop was measured for each.

\section{Coal Dust Loading}

Coal dust cake formation (accumulation of coal dust) on a filter can be a major concern in filtration since this could cause restriction in the sample flow. The effects of cake formation on the filters were analyzed by adding coal dust to the filters and then measuring the pressure drop. In attempts to accurately represent the coal dust loading in a mine, an average daily coal dust loading was calculated to be approximately 1 gram per week (g/week). In order to know the amount of coal added to the filter during testing, the filter was weighed with no coal dust added and then weighed again after each incremental amount of coal dust had been added. The difference in these values was the amount of coal dust that had been added. Five dust loading points were achieved that corresponded to 1 day, 1 week, 2 weeks, 3 weeks, and 4 weeks of coal dust added. 


\section{Moisture (Water) Loading}

After the coal dust loading results were concluded, water was added, incrementally to the filters to determine the effects of moisture on the pressure drop across the filter. It should be noted that any coal dust that could not be taken off the filter from the previous set of tests remained on the filter.

\subsection{Sensor Calibrations}

As previously discussed, there were multiple sensors housed within the sensor block of each sampling unit. Each of the sensors were either calibrated or verified with additional laboratory equipment. Table 3.3-1 includes a summary of all sensors implemented at each sampling node and the respective reference device. Figure 3.1-10, in a previous section, presents an overview of the sampling block housed within the sealed sampling unit.

Table 3.3-1: Sensors and equipment used in the calibration and verification methods.

\begin{tabular}{|c|c|c|}
\hline Measurement Type & Sensor in Sampling Unit & Verification Analyzers/Equipment \\
\hline CH$_{4}$ (Primary) & Dynament Infrared Sensor (IRS) & UGGA (OA-ICOS) \\
\hline CH$_{4}$ (Secondary) & $\begin{array}{c}\text { MQ-4 Metal-Oxide Sensor } \\
\text { (MOS) }\end{array}$ & UGGA (OA-ICOS) \\
\hline $\begin{array}{c}\text { Relative Humidity } \\
\text { of Sample }\end{array}$ & Honeywell HIH-4602-L Series & $\begin{array}{c}\text { Edgetech DewMaster (Chilled } \\
\text { Mirror Hygrometer) }\end{array}$ \\
\hline $\begin{array}{c}\text { Sampling } \\
\text { Temperature }\end{array}$ & Thermocouple (K-type) & Omega iBTHX \\
\hline $\begin{array}{c}\text { Absolute Sampling } \\
\text { Pressure }\end{array}$ & Manifold Air Pressure (MAP) & Heise \\
\hline $\begin{array}{c}\text { Sample Flow Rate } \\
\text { Desired CH4 } \\
\text { Concentration } \\
\text { Mine Ventilation } \\
\text { Flow }\end{array}$ & Anemometer (3-cup transducer) & WindSonic 2-D Ultrasonic \\
\hline
\end{tabular}




\section{Laboratory Set-Up for Calibration Procedures}

\section{Humidity Control}

Two HORIBA, Ltd. gas dividers (GDs) were used to control both methane $\left(\mathrm{CH}_{4}\right)$ and humidity in the sample for sensor verifications. Both GDs operated on the same source of Ultra Zero Air (UZA) as the dilution gas, and a specified concentration of $\mathrm{CH}_{4}$ (from a calibration gas cylinder) as the component gas. One GD was used to control the $\mathrm{CH}_{4}$ concentration of a dry sample and the other GD controlled the $\mathrm{CH}_{4}$ of a wet sample. Both samples (dry and wet) were joined at a 4-way flooded junction. One GD connected the dry sample directly to the flooded junction, while the other was connected to the bubbler, where humidity was added (wet sample). A mass flow controller (MFC) was connected to the outlet of each gas divider to independently control the flow rates of the dry sample and the gas sent to the inlet of the bubbler. The humidity was controlled by adjusting each of the GDs flowrates with the two MFC's to the setpoints corresponding to the desired humidity.

\section{Sample Delivery}

The GDs directed the samples to the flooded junction where the positive pressure was vented to atmosphere through an open junction end. The remaining junction port was connected to the sampling box. The primary flow of the sample was driven by a positive displacement pump and manifold system connected to all the sampling boxes. The pump created a negative pressure and pulled the controlled mixture through the 4-way flooded intersection. The sum of the two flowrates from the GDs were set higher than the flow of the pump to ensure no atmospheric air entered the sample. An Ultraportable Greenhouse Gas Analyzer (UGGA) was then connected to the exit of the sampling box on a T-fitting. The UGGA contained an internal pump by which it pulled in its own sample at a flowrate of about $0.5 \mathrm{SLPM}(0.018 \mathrm{scfm})$. The UGGA was used to verify methane concentrations upstream. Figure 3.3-1 shows a schematic of the humidity control and sampling system setup. 


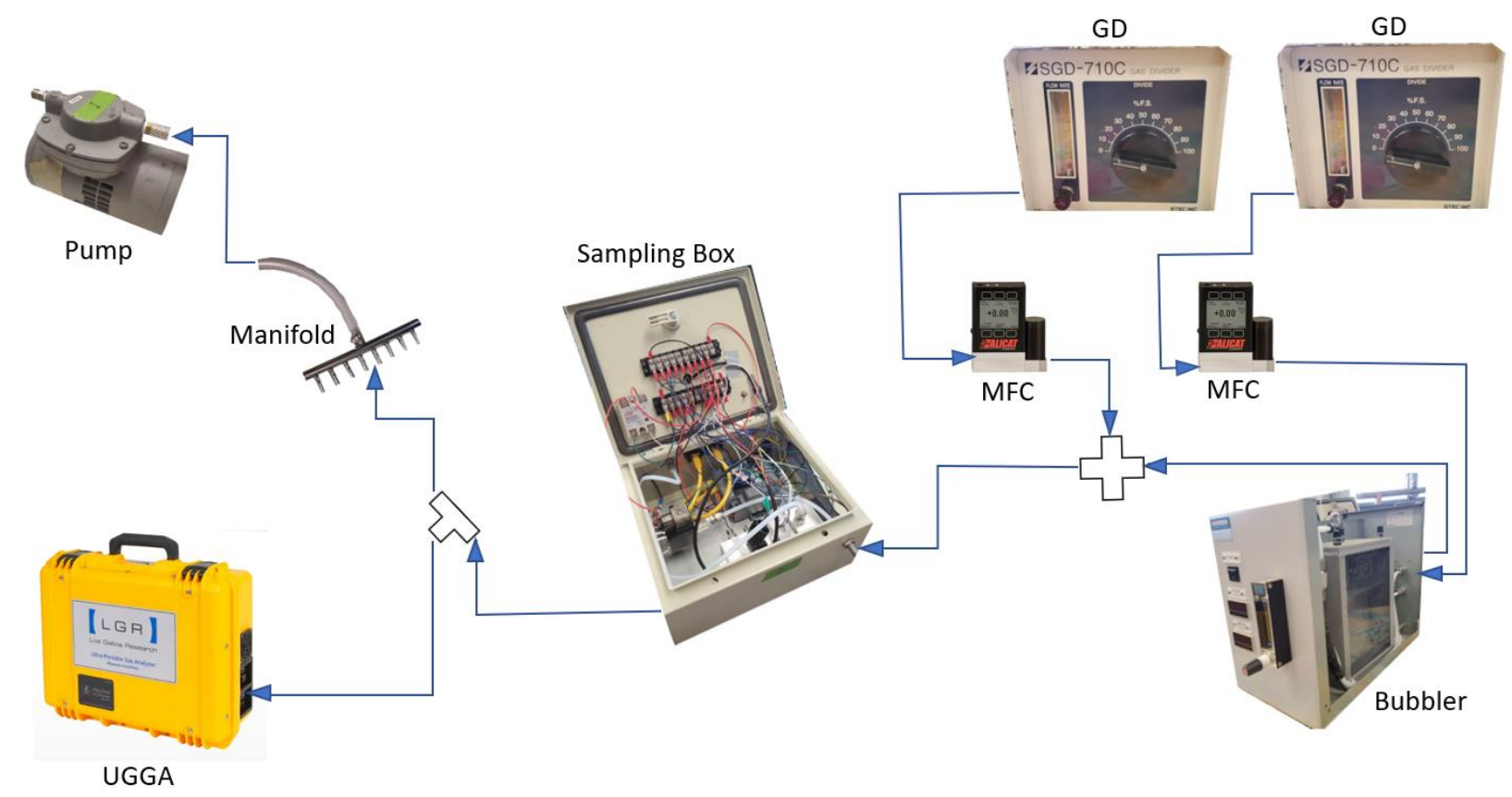

Figure 3.3-1: Setup for IRS and MOS calibration and verification.

Reference Analyzers

Edgetech DewMaster (RH Sensors)

Relative humidity (RH) sensors in the sampling box were verified and calibrated against an Edgetech DewMaster chilled mirror hygrometer, see Figure 3.3-2. The Edgetech measured three parameters as set by the user. For the calibrations performed for the RH sensors in the sampling box and the UGGA, the Edgetech was set to measure either $\mathrm{RH}$, temperature, and pressure or $\mathrm{H}_{2} \mathrm{O}$ concentration in parts per million (ppm), temperature, and pressure.

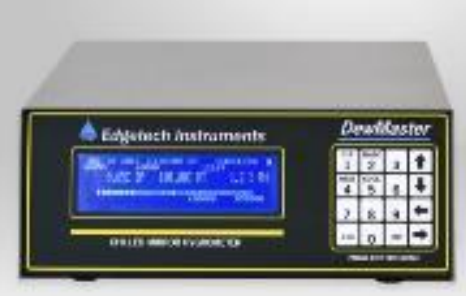

Figure 3.3-2: Image of the Edgetech DewMaster chilled mirror hygrometer [157]. 


\section{Heise (Pressure Sensors)}

Leak tests were performed, and pressure sensors were verified and calibrated with a pressure calibrator unit (Heise), utilizing a specific module (Module 1 in Table 3.3-3) for absolute pressure. The Heise is pictured in Figure 3.3-3.

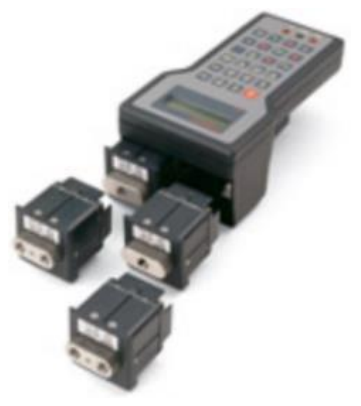

Figure 3.3-3: Image of the Heise and modules [158].

\section{UGGA (MOS and IRS)}

For $\mathrm{CH}_{4}$ sensor verifications, the UGGA (shown in Figure 3.3-4) was used as the reference source for the sample exiting the sensor box.

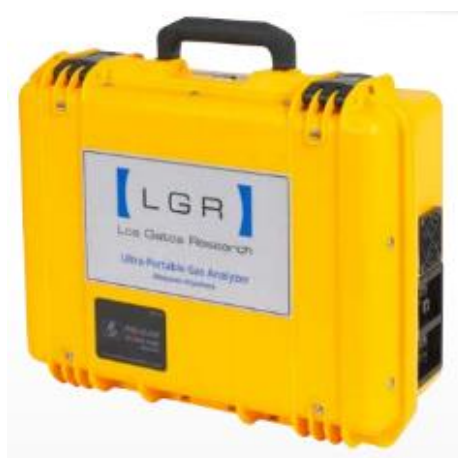

Figure 3.3-4: Image of the UGGA [159].

Since higher $\mathrm{H}_{2} \mathrm{O}$ concentrations (up to $90-95 \% \mathrm{RH}$ ) were likely in the mines, an internal and external calibration of the UGGA was conducted at a known methane $\left(\mathrm{CH}_{4}\right)$ concentration of $20,100$ parts per million ( $\mathrm{ppm})$ as well as a known water $\left(\mathrm{H}_{2} \mathrm{O}\right)$ concentration of $24,000 \mathrm{ppm}$. Humidity was added to the sample by means of the methods listed above. The external calibration was applied to $\mathrm{CH}_{4}$ measurements greater than $1500 \mathrm{ppm}$; it was determined that the external calibration was not necessary at lower concentrations (less than 1500 ppm). For this calibration, as well as any other calibration performed where the GDs were used, the GD corrected values were calculated. These values were calculated to compensate for viscosity differences from the dilution gas to the component gas, since the operational principle of the GD is a pressure/flow driven mechanism. The composition gas inlet pressure to the divider was set to $144.8 \mathrm{kPa}(21 \mathrm{psig}$ ) at the 
$100 \%$ cut point and the dilution gas inlet pressure set to $117.2 \mathrm{kPa}(17 \mathrm{psig})$ at the $0 \%$ cut point, pursuant to manufacturers guidelines. Since $\mathrm{H}_{2} \mathrm{O}$ was added to the sample, the GD corrected values were subsequently corrected based on the amount of $\mathrm{H}_{2} \mathrm{O}$ present; this correction was performed using Eq. 3.3.1 where the GD corrected value (in ppm) is the known $\mathrm{CH}_{4}$ concentration directed through the GDs based on the component gas used and the $\mathrm{H}_{2} \mathrm{O}$ concentration (in ppm) was determined by the Edgetech.

$$
\text { Actual } \mathrm{CH}_{4} \text { Concentration }=\text { GD Corrected Value } *\left(1-\frac{\mathrm{H}_{2} \text { O Concentration }}{1000000}\right) \text { Eq. 3.3.1 }
$$

Figure 3.3-5 shows the results of the calibration test performed on the UGGA from which the external calibration equation was obtained.

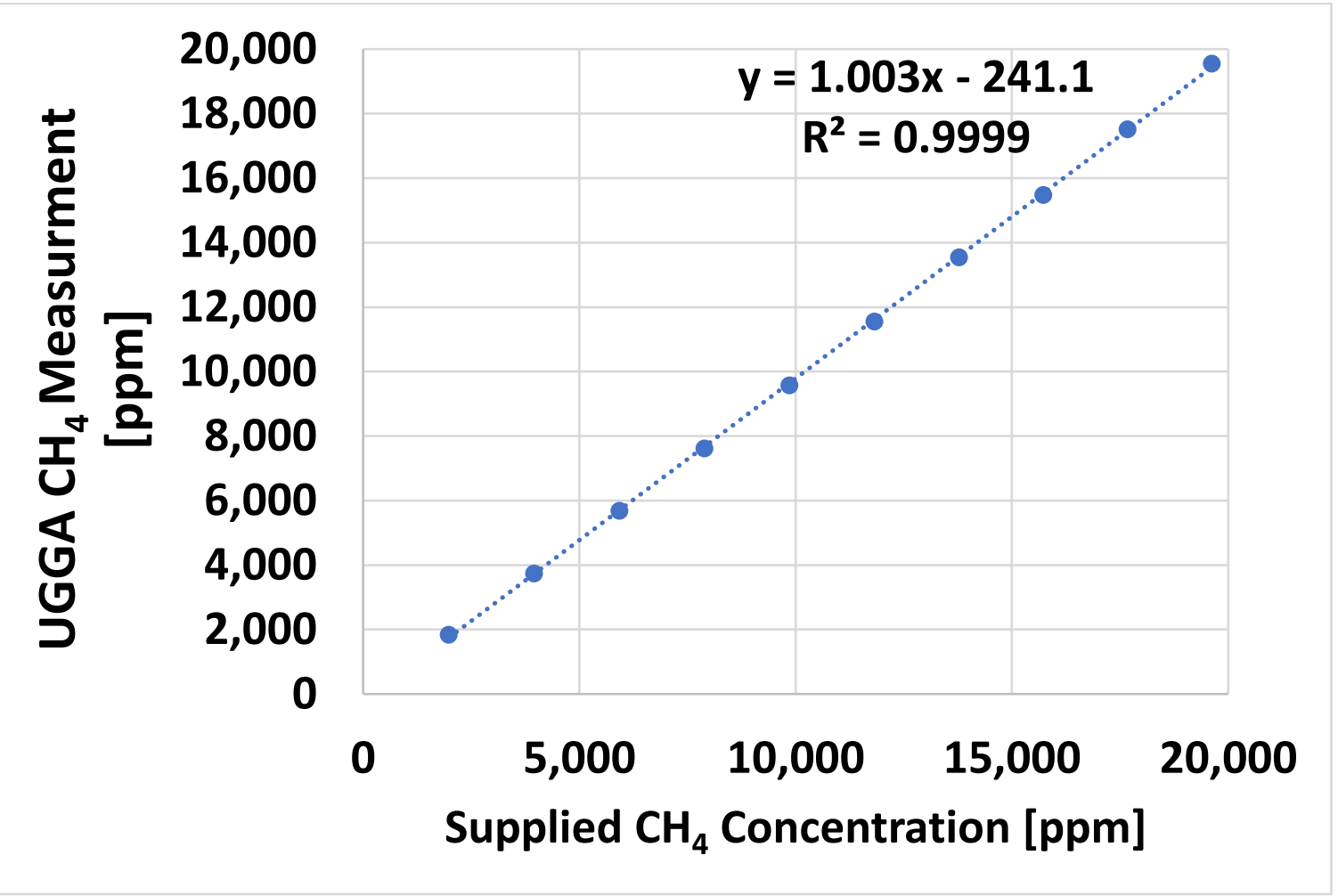

Figure 3.3-5: Calibration performed on the UGGA using a $2.01 \%(20,100 \mathrm{ppm}) \mathrm{CH}_{4}$ bottle.

Figure 3.3-6 and Table 3.3-2 show the verification of the UGGA calibration by comparing the UGGA measured values to the supplied $\mathrm{CH}_{4}$ concentration (GD corrected values). 


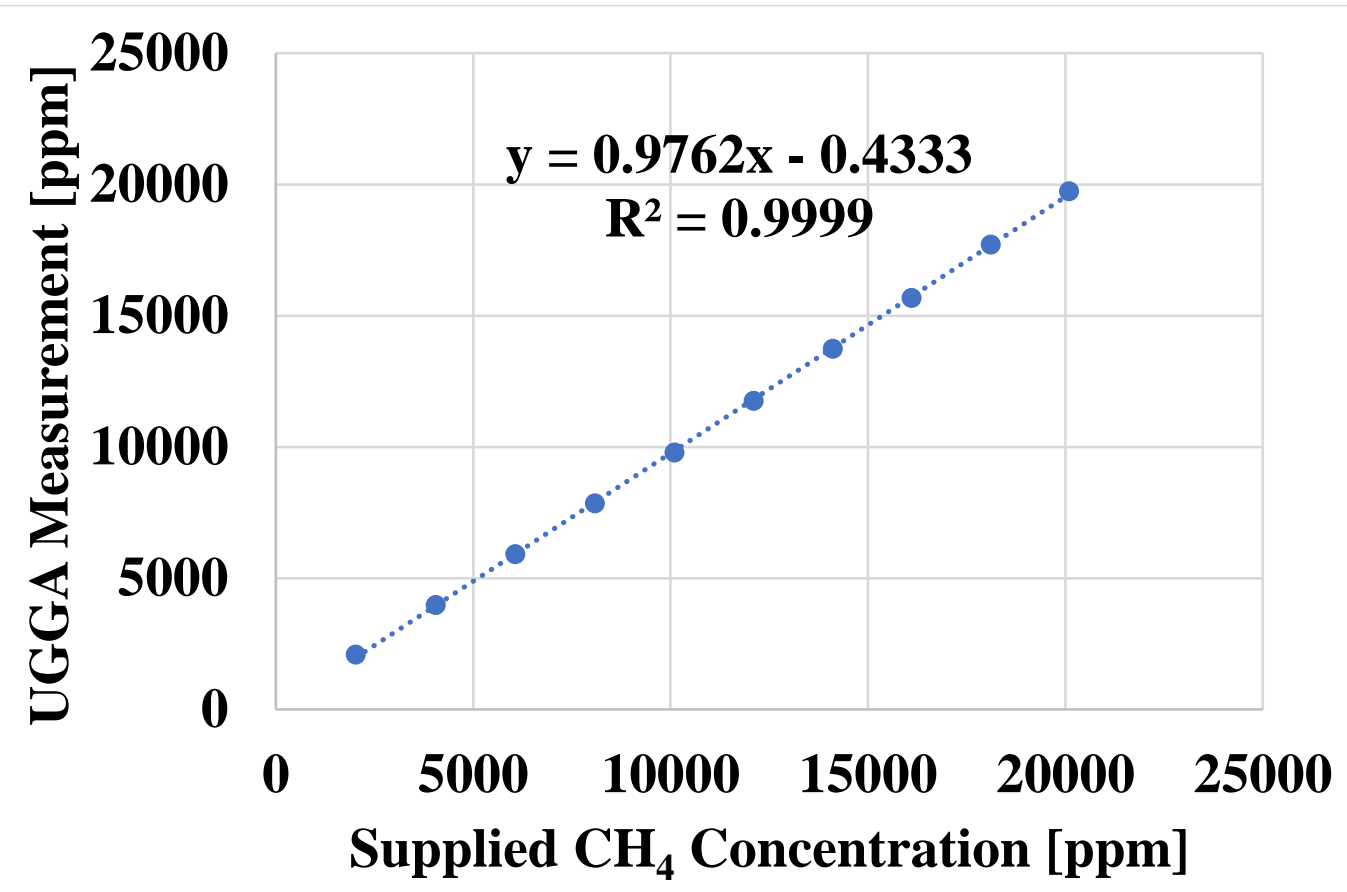

Figure 3.3-6: UGGA calibration verification after external calibration was applied. Table 3.3-2: UGGA Calibration Results Verified to GD Corrected Values.

\begin{tabular}{|c|c|c|}
\hline $\begin{array}{c}\text { UGGA CH} \\
{[\mathbf{p p m}]}\end{array}$ & $\begin{array}{c}\text { Supplied } \mathbf{C H}_{\mathbf{4}} \\
\text { Concentration [ppm] }\end{array}$ & Error [\%] \\
\hline $\mathbf{2 0 3 2}$ & 2027 & 0.233 \\
\hline $\mathbf{4 0 5 9}$ & 4051 & 0.213 \\
\hline $\mathbf{6 1 0 2}$ & 6070 & 0.520 \\
\hline $\mathbf{8 1 3 2}$ & 8086 & 0.572 \\
\hline $\mathbf{1 0 , 1 6 1}$ & 10,098 & 0.627 \\
\hline $\mathbf{1 2 , 1 5 8}$ & 12,106 & 0.426 \\
\hline $\mathbf{1 4 , 1 7 8}$ & 14,110 & 0.484 \\
\hline $\mathbf{1 6 , 1 9 6}$ & 16,111 & 0.531 \\
\hline $\mathbf{1 8 , 1 9 3}$ & 18,107 & 0.473 \\
\hline $\mathbf{2 0 , 2 2 1}$ & 20,100 & 0.603 \\
\hline
\end{tabular}

\section{Alicat MFC (Flow Sensors)}

Calibrations of the flow sensors in each box were verified using an Alicat mass flow meter (MFM), specifically the 50 SLPM MFM (see Table 3.3-3). Figure 3.3-7 shows the MFM. 


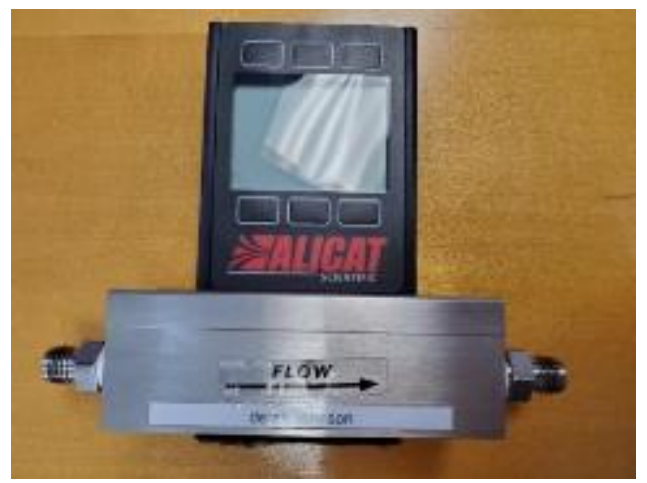

Figure 3.3-7: Image of the MFM used for flow sensor verification.

\section{WindSonic (3-Cup Anemometers)}

Measured wind speeds were collected with the WindSonic 2-D ultrasonic anemometer, herein referred to as the WindSonic (shown in Figure 3.3-8) and used as reference for the two 3-cup anemometers mounted to the sampling boxes 2 and 9 .

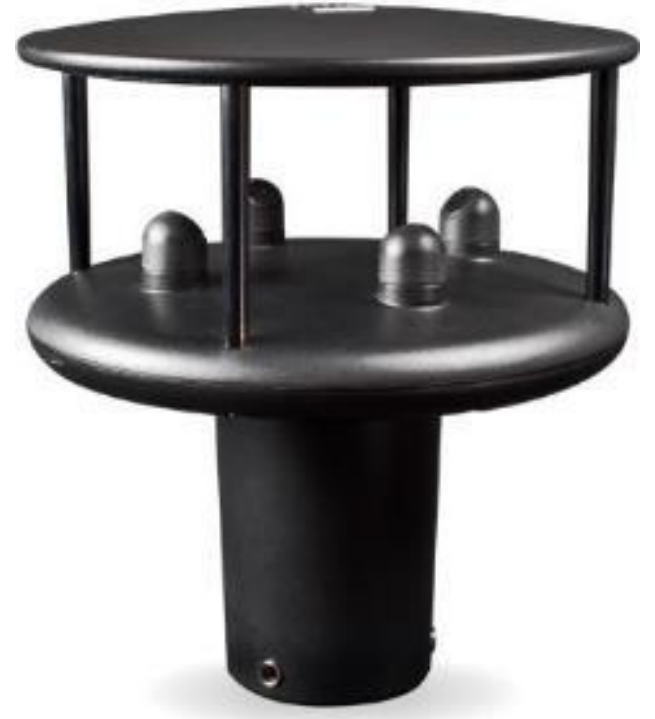

Figure 3.3-8: Image of the WindSonic 2-D ultrasonic anemometer [160]. 
Table 3.3-3: Table of Reference Analyzers

\begin{tabular}{|c|c|c|c|c|c|}
\hline & Make & Model & $\begin{array}{c}\text { Manufacturer } \\
\text { Location }\end{array}$ & Range & Website/Manual \\
\hline $\begin{array}{c}\text { Edgetech Chilled Mirror } \\
\text { Hygrometer }\end{array}$ & $\begin{array}{l}\text { Edgetech } \\
\text { Instruments }\end{array}$ & DewMaster & $\begin{array}{l}\text { Hudson, MA, } \\
\text { USA }\end{array}$ & $\begin{array}{c}0-100 \% \mathrm{RH} \\
\text { (non-condensing) }\end{array}$ & {$[157] /[161]$} \\
\hline $\begin{array}{l}\text { Heise Module } 1 \\
\text { Heise Module } 2 \\
\end{array}$ & Heise & $\begin{array}{l}\text { PTE-1 - Module: HQS-22041 } \\
\text { PTE-1 - Module: HQS-14134 }\end{array}$ & $\begin{array}{c}\text { Stratford, CT, } \\
\text { USA }\end{array}$ & $\begin{array}{c}0-30 \mathrm{psia}^{-} \\
0-25 \mathrm{inH}_{2} \mathrm{O}\end{array}$ & {$[158] /[162]$} \\
\hline UGGA & $\begin{array}{l}\text { Los Gatos } \\
\text { Research }\end{array}$ & $915-0011$ & $\begin{array}{l}\text { Mountain } \\
\text { View, CA, } \\
\text { USA }\end{array}$ & $0-10 \% \mathrm{CH}_{4}$ & [159]/ [163] \\
\hline $\begin{array}{c}\text { Alicat MFC (5 SLPM) } \\
\text { Alicat MFC (20 SLPM) } \\
\text { Alicat MFC (50 SLPM) } \\
\text { Alicat MFM (50 SLPM } \\
\text { no controller) }\end{array}$ & $\begin{array}{c}\text { Alicat } \\
\text { Scientific }\end{array}$ & $\begin{array}{c}\text { MC-5SLPM-D/5M } \\
\text { MCQ-20SLPM-D-PCV30/5M } \\
\text { MCP-50SLPM-D/5M } \\
\text { M-50SLPM-D/5M }\end{array}$ & $\begin{array}{c}\text { Tucson, AZ, } \\
\text { USA }\end{array}$ & $\begin{array}{c}\text { 0-5 SLPM } \\
\text { 0-20 SLPM } \\
0-50 \text { SLPM } \\
\text { 0-50 SLPM }\end{array}$ & $\begin{array}{c}{[164] /[165]} \\
{[166]} \\
{[167]} \\
{[168]}\end{array}$ \\
\hline WindSonic & $\begin{array}{c}\text { Gill } \\
\text { Instruments }\end{array}$ & Windsonic 60 & $\begin{array}{l}\text { Lymington, } \\
\text { Hampshire, } \\
\text { UK }\end{array}$ & $0-60 \mathrm{~m} / \mathrm{s}$ & [157]/ [169] \\
\hline
\end{tabular}




\section{RH Sensors}

The RH sensors used in the sampling boxes were calibrated using the two GDs and bubbler set up as described above to control humidity and with the Edgetech as the reference analyzer. The Edgetech measured a $\mathrm{RH}$ value that was then converted to an $\mathrm{H}_{2} \mathrm{O}$ concentration in ppm based on the temperature and pressure, which were also measured by the Edgetech (Eq. 3.3.2 - 3.3.4). The ppm values for $\mathrm{H}_{2} \mathrm{O}$ concentration were then used to calculate the expected $\mathrm{RH}$ values for the sensors based on the temperature and pressure measurements within the sensor block (Eq. 3.3.5 3.3.7); the RH sensors were calibrated with respect to these values. It should also be noted that the calibration occurred at $23^{\circ} \mathrm{C}\left(73.4^{\circ} \mathrm{F}\right)$ while the manufacturer's calibration and temperature compensation were at $25^{\circ} \mathrm{C}\left(77.0^{\circ} \mathrm{F}\right)$, therefore the calibration was offset by two so that the temperature compensation equation given by the manufacturer was used.

$$
\begin{gathered}
P_{g_{E}}=0.00014 T_{E}{ }^{2}-0.00686 T_{E}+0.17603 \\
P_{v_{E}}=\left(\frac{R H_{E}}{100}\right) * P_{g_{E}} \\
P P M v_{E}=\frac{P v_{E}}{P_{E}} * 1000000 \\
P g_{R H S}=0.00014 T_{T}^{2}-0.00686 T_{T}+0.17603 \\
P v_{R H S}=\frac{P P M_{E}}{P_{R H S}} \\
R H_{S}=\frac{P_{v_{S}}}{P_{g_{S}}} * 100
\end{gathered}
$$

The subscripts "E", "RHS", and "T" denote the Edgetech, RH sensor in the sampling box, and the thermocouple in the sampling box, respectively, $\mathrm{P}_{\mathrm{g}}$ is the saturation pressure (psia), $\mathrm{P}_{\mathrm{v}}$ is the partial pressure of water vapor (psia), $\mathrm{T}$ is the sample dry bulb temperature $\left({ }^{\circ} \mathrm{F}\right), \mathrm{PPMv}$ is the humidity (PPM), and RH is the relative humidity.

\section{Pressure Sensors}

The pressure sensors were calibrated using a hand pump to control pressure, and the Heise Module 1 was used as the reference. 


\section{$\mathrm{CH}_{4}$ Sensors}

\section{Climate and Flowrate Effects}

In order to calibrate the MOS and IRS, the effects of climate (temperature, RH, and pressure) and flowrate of the sample on the sensors were analyzed. To initially test the climate effects on the sensors, a testing apparatus consisting of a test chamber where climate could be modified was used. Climate was changed by using an air conditioner to either heat or cool the test chamber volume and various methods were used to vary the humidity. A MOS and an IRS were both mounted in a metal tube along with a thermocouple to measure temperature near the sensor locations. The section of the tube containing the open end and all the sensors were placed inside the test chamber. The rest of the tube extended through a hole in the test chamber, where it was connected to a pump which pulled the sample through the tube. An Omega iBTHX was also placed in the testing apparatus to measure temperature, $\mathrm{RH}$, and pressure of the test chamber volume. The testing apparatus set-up can be seen in Figure 3.3-9.
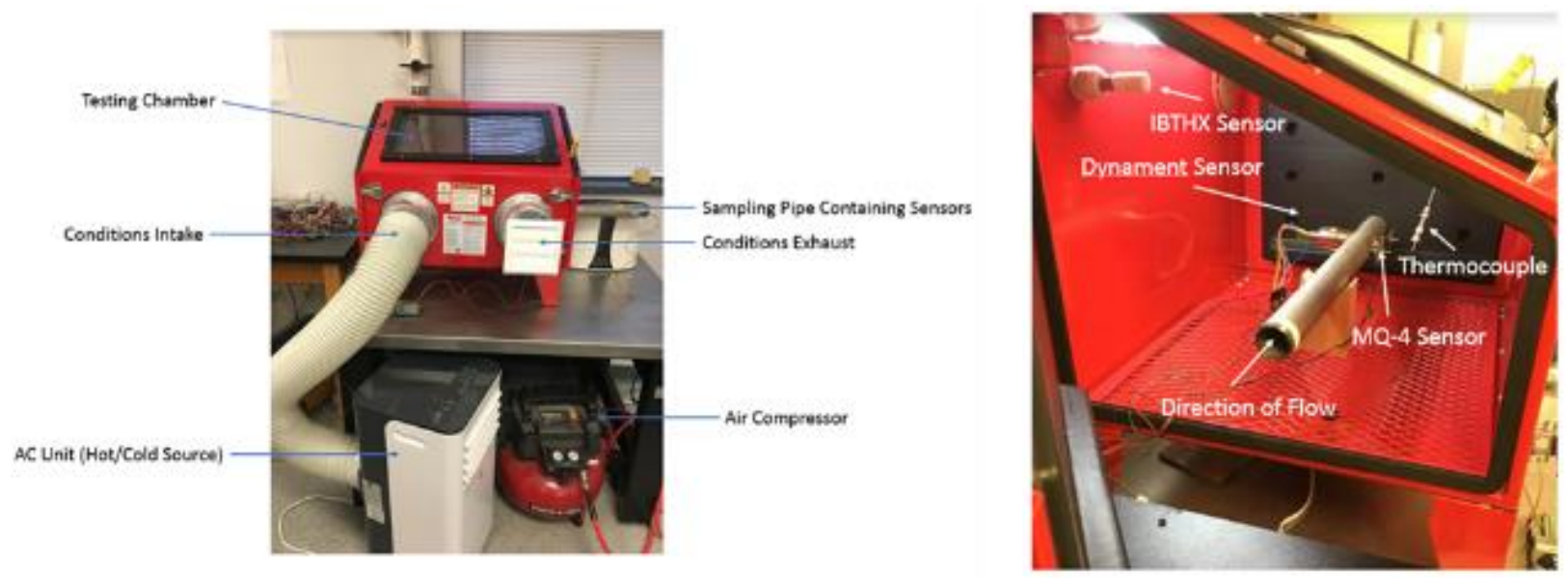

Figure 3.3-9: Left - test chamber with equipment, right - inside of test chamber.

Initial tests were completed to determine if temperature had a significant effect on the sensors' responses. Three tests were performed at three different temperature ranges. It should be noted that the temperature range represented the variation of temperature over the span of the test. An air conditioning (AC) unit was used to vary the temperature in the chamber. A $2.01 \% \mathrm{CH}_{4}$ calibration gas bottle and a GD were used to supply methane at the tube inlet at ten different $\mathrm{CH}_{4}$ concentrations. In these three tests, the conditions in the box were not directly being sampled, however the temperature variations in the test chamber also caused a change in temperature in the 
sample over the time it took for the sample to reach the sensors. The thermocouple located in the tube near the MOS and IRS was the temperature reference for these tests.

An initial test to analyze effects of humidity on the MOS and IRS was also performed in the test chamber. One MOS and one IRS were suspended in the test chamber and the humidity in the chamber was continuously increased over the duration of the test using a humidifier. It should be noted that this test was at room temperature and there was no $\mathrm{CH}_{4}$ added.

To test the effects of sample flowrate on the MOS and IRS, a $2.02 \% \mathrm{CH}_{4}$ calibration gas bottle and a GD were used to flow 1\% methane through the aluminum sensor block which housed the sensors. The flowrate of the sample was increased in increments of approximately 0.5 SLPM $(0.018 \mathrm{scfm})$ from $1 \mathrm{SLPM}(0.035 \mathrm{scfm})$ up to $3.5 \mathrm{SLPM}(0.124 \mathrm{scfm})$ over the duration of the test.

\section{IRS Calibrations}

An initial, "dry", 20-point calibration was performed utilizing a $2.01 \% \mathrm{CH}_{4}$ bottle for the first ten points and a $0.2475 \% \mathrm{CH}_{4}$ bottle for the second ten points; both bottles were divided with UZA using the GD to obtain the 20 calibration points. This calibration contained no humidity in the sample. An additional correction calibration was performed to ensure acceptable error at all humidity conditions. To derive the correction factors, the previous dry calibration was conducted with the addition of humidity by means of the two GDs combining a wet and dry sample to a desired relative humidity (setup shown in Figure 3.3-1). Three different correction factors were calculated for different ranges of IRS raw response. A set of correction factors was calculated using one IRS and then applied to all ten IRS. These corrections used absolute humidity ratio to account for RH, temperature, and pressure. The equations used to calculate the absolute humidity ratio are shown in Eq. 3.3.5, 3.3.8, and 3.3.9. The calibrated RH sensor, temperature sensor, and pressure sensor in the sampling box were referenced for these calculations and a corrected methane concentration value was computed from the base calibration.

$$
\begin{gathered}
P_{v_{R H S}}=\left(\frac{R H_{R H S}}{100}\right) * P_{g_{R H S}} \\
\omega=\frac{0.622 * P_{v_{R H S}}}{P_{p s}-P_{v_{R H S}}}
\end{gathered}
$$


Where Pg, Pv, T, RH, and the subscripts "RHS" and "T" are the same as in Eqs. 3.3.2 to 3.3.7, the subscript "ps" denotes the pressure sensor in the sampling box, P is the absolute pressure (psia), and $\omega$ is the absolute humidity ratio (lb/lbdryair).

\section{MOS Calibrations}

The non-linear response of the MOS caused calibration of these sensors to be more challenging than for the IRS. An initial 20-point calibration was performed for each MOS with dry $\mathrm{CH}_{4}$ concentrated gas out of two calibration gas bottles as was completed for the IRS. In attempts to calibrate the sensors above their recommended range of operation (up to $1 \% \mathrm{CH}_{4}$ ) two exponential calibration equations were found for each sensor, one for lower concentrations (less than 1\%) and one for higher concentrations (greater than 1\%).

Tests where humidity was added to the sample were also performed the same way as for the IRS. It was found that different humidity correction factors were required for different ranges of humidity as well as for different ranges of $\mathrm{CH}_{4}$ concentration. One set of humidity correction factors for the different humidity and $\mathrm{CH}_{4}$ concentrations ranges was found using one MOS and then it was applied to all ten MOS.

\section{Verifications}

To verify that all IRS and MOS were reporting accurately at various $\mathrm{CH}_{4}$ and $\mathrm{H}_{2} \mathrm{O}$ concentrations, each sensor was exposed to three different $\mathrm{H}_{2} \mathrm{O}$ concentrations and four different $\mathrm{CH}_{4}$ concentrations measured in ppm. Since the UGGA was the reference device when testing transitions to a scale demonstration, the IRS as well as the MOS measurements were compared to the UGGA measurements by calculating the percent difference. The percent difference values were found using Eq. 3.3.10, where the "measured1" value was either the IRS or MOS and the "measured2" value was the UGGA.

$$
\% \text { Difference }=\left(\frac{\text { measured } 1-\text { measured } 2}{\frac{\text { measured } 1+\text { measured } 2}{2}}\right) * 100
$$

Flow Sensors

The calibration for the flow sensors was given in the data sheet. This calibration is shown in Eq. 3.3.11 where the flowrate is in SLPM and V is the raw response voltage of the sensor.

$$
\text { Flowrate }=2 * V
$$

Eq. 3.3.11

The calibration for the flow sensors was verified by testing one of the ten sensors at various flowrates and comparing it to the MFC. A positive displacement pump was used to provide the 
flow and a valve was attached at the outlet of the pump to throttle it down in order to supply different flowrates.

\section{3-Cup Anemometers}

The calibration used for the 3-cup anemometers was the original calibration given by the manufacturer based on the specific sensor parameters. The equation for this calibration can be seen in Eq. 3.3.12, where $\mathrm{V}$ is the raw sensor response voltage and "wind speed" is in meters per second $(\mathrm{m} / \mathrm{s})$. It should be noted that the starting/minimum wind speed for the operation of these anemometers is $0.5 \mathrm{~m} / \mathrm{s}(98.4 \mathrm{fpm})$.

$$
\text { wind speed }=9 \mathrm{~V}
$$

Eq. 3.3.12

The manufacturers calibration for the 3-cup anemometers was verified using the WindSonic as reference. During the verification tests, the WindSonic was aligned with one of the 3-Cup anemometers and both sensors were enclosed in a cardboard tunnel (one inlet and one outlet). Air flow was supplied at four different velocities to the tunnel inlet using the air conditioning unit, which was throttled to obtain various velocities.

\section{4 "Mock" Mine Verification of System}

\section{"Mock" Mine Set-Up}

WVU's research wind tunnel was utilized for a scaled demonstration and evaluation of the newly developed multi-nodal MWS. The tunnel was used as a "mock" mine in attempts to model possible longwall mining scenarios that mimicked methane release and dispersion. Based on the federal regulations for de-energization of equipment at certain $\mathrm{CH}_{4}$ concentrations, $\mathrm{CH}_{4}$ concentrations in the range of $1-2 \%$ would occupy the sampling regions in the mock mine to ensure the system is working properly within the operational and required limits [8]. It should be noted that all $\mathrm{CH}_{4}$ concentrations were on a volume basis.

To more accurately represent the dimensions of a typical longwall mine, the wind tunnel was sectioned by placing a 30.5 by $6.1 \mathrm{~m}$ (100 by $20 \mathrm{ft})$ piece of plastic $2.4 \mathrm{~m}(8 \mathrm{ft})$ from the ground to act as the roof of the mine. The height of the roof was determined based on the maximum and minimum height of a shield, fully extended and fully collapsed, respectively. The dimensions for one type of shield typically used in industry were obtained from Swanson Industries. The maximum height of the fully extended shield was $3.0 \mathrm{~m} \mathrm{(10} \mathrm{ft)}$ and the minimum height, fully 


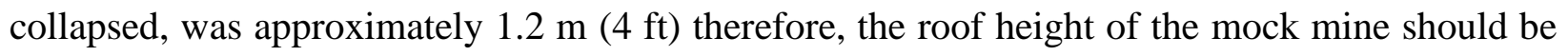
between 1.2 and $3.0 \mathrm{~m}$ ( 4 and $10 \mathrm{ft}$ ). The roof height was also limited by the wind tunnel entry door. For these reasons, a mock mine roof height of $2.4 \mathrm{~m}(8 \mathrm{ft})$ was used. The plastic laid across ten " $T$ " structures that were constructed by various lengths of 50.8 by $101.6 \mathrm{~mm}$ (2 in by 4 in) pieces of wood (shown in Figure 3.4-2). The cross-sectional area of the mock mine was approximately 4.9 by $2.4 \mathrm{~m}$ (16 by $8 \mathrm{ft}$ ), making the experimental volume approximately $373.8 \mathrm{~m}^{3}$ $\left(13,200 \mathrm{ft}^{3}\right)$. The prototype MWS was installed in the mock mine. The ten sampling units were evenly spaced along the $30.5 \mathrm{~m}$ (100 ft) wind tunnel (one at each node and mounted near the roof, $2.4(8 \mathrm{ft})$ from the ground, at the center of the cross section. Node 1 was located nearest the HG and Node 10 was located nearest the TG. Each node had the ability to sample from both the face and gob sides (not simultaneously) 2.1 ( $7 \mathrm{ft}$ ) from each side of the node, perpendicular to the flow. Two fans (one at the HG and one at the TG) to assist ventilation flow through the mock mine. Figure 3.4-1 shows the layout of the mock mine. Figure 3.4-2 shows a couple views of the mock mine with the MWS installed.

$\underline{\text { HG }}$

$\underline{\text { TG }}$

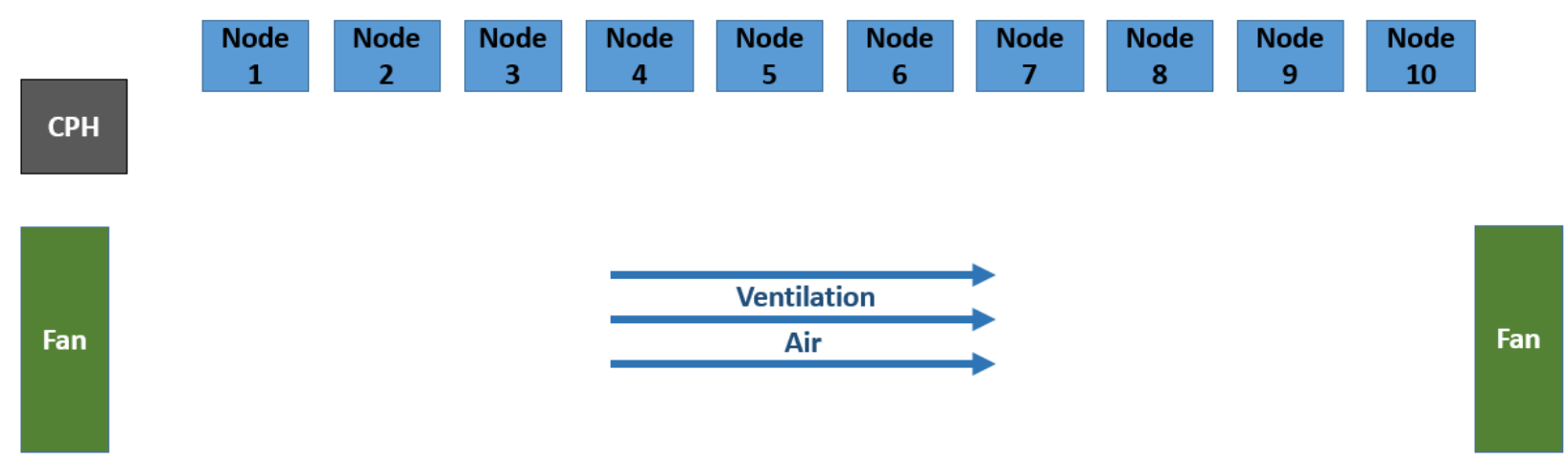

Figure 3.4-1: Mock mine layout. 


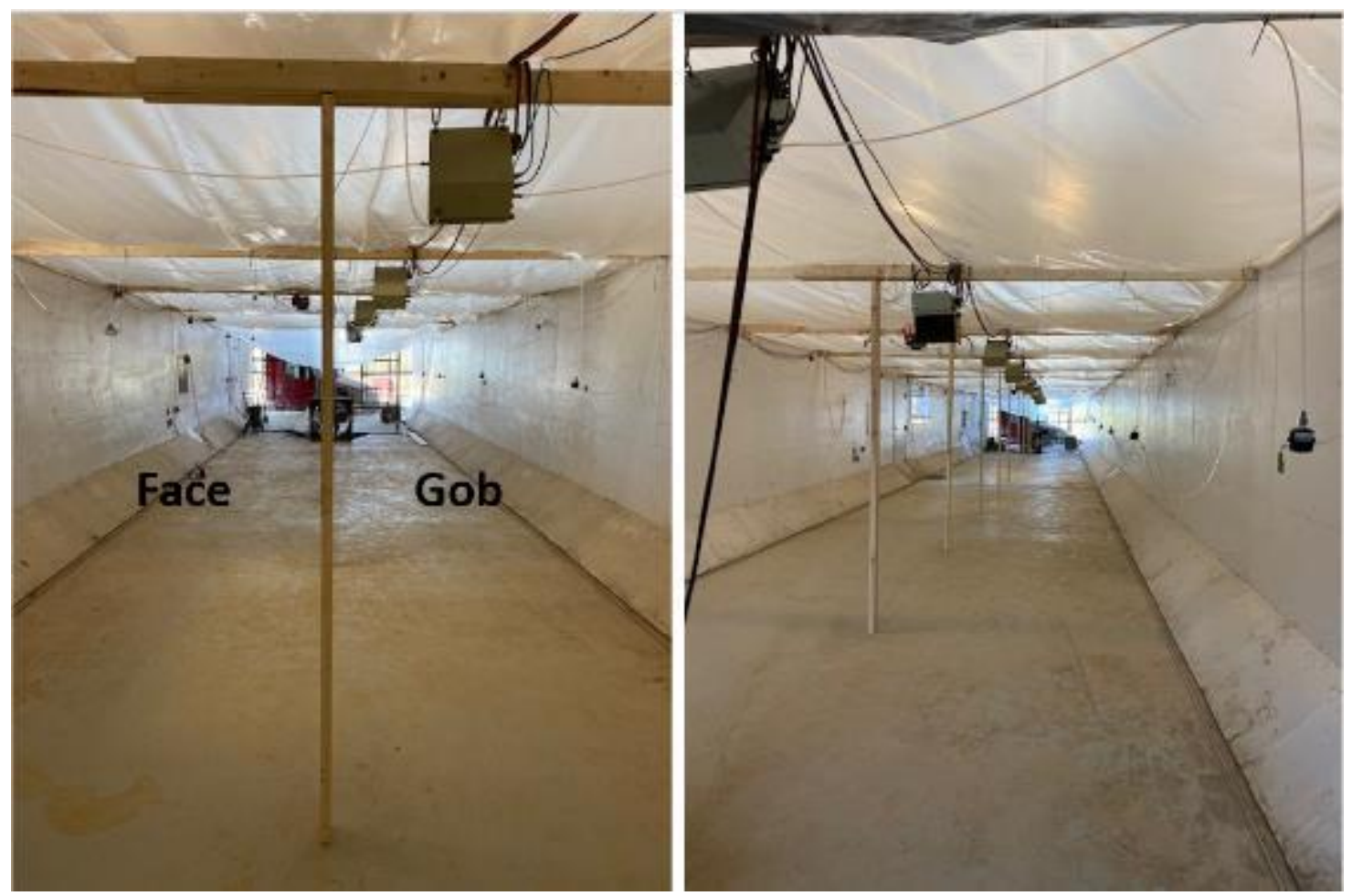

Figure 3.4-2: Mock mine with MWS installed.

Ultimately, the integration of monitoring atmospheric flow rates in the coal mine (longwall face) would be beneficial in the case of the proposed system. Issues with accurately measuring wind speed among the everyday operations of an underground coal mine may be difficult due to spatial limitations and structural integrity. For system demonstrations and data collection, two 3-cup anemometers were implemented into the design of sampling units two and nine to measure wind velocities near the beginning (HG) and exit (TG) of the mock mine. Figure 3.4-3 shows the anemometer mounted at Node 2. The measurements of these 3-cup anemometers were referenced to the standard (WindSonic) which was placed in-line with the 3-cup anemometers and at the center of the wind tunnel for various tests. Due to poor circulation of air throughout the mock mine from the fans and natural causes beyond our control (i.e. gusts of wind), wind speeds were generally below the minimum operational wind speeds and were inconsistent. Since the 3-cup anemometers operated on a momentum driven principle, consistent and sufficient wind speeds were required for more practicality. 


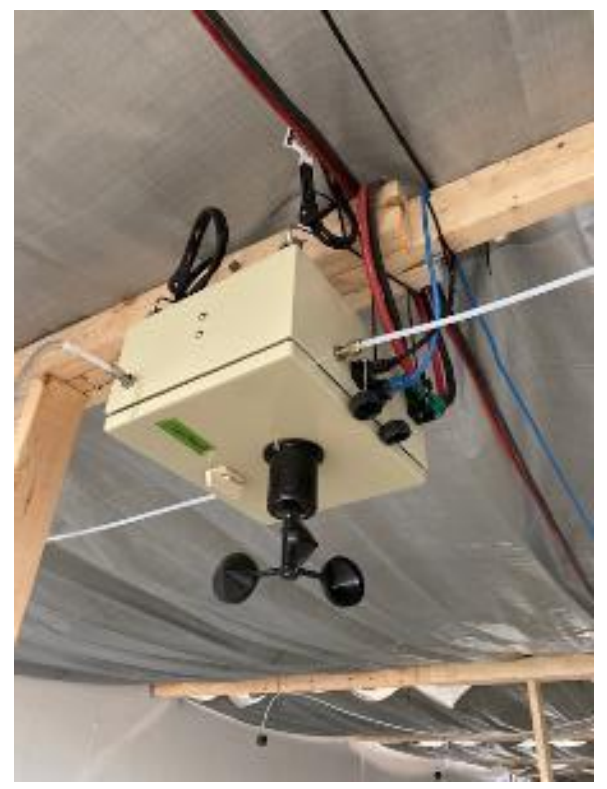

Figure 3.4-3: Cup anemometer mounted on sampling unit at Node 2.

While the proposed sampling method for the system was the use of water ejectors, due to the lack of water access at the mock site, two positive displacement diaphragm pumps were used in conjunction with two manifolds to induce sample flows. Each pump controlled the flow through five sampling units. The sampling flowrates for each node were controlled to approximately 2 SLPM $(0.071 \mathrm{scfm})$ by adjusting the valves on the manifolds and by throttling the pump with a valve that was placed at the outlet. The pumps and manifolds were then mounted on the " $T$ " structure of Nodes 3 and 8, as shown in Figure 3.4-4. 


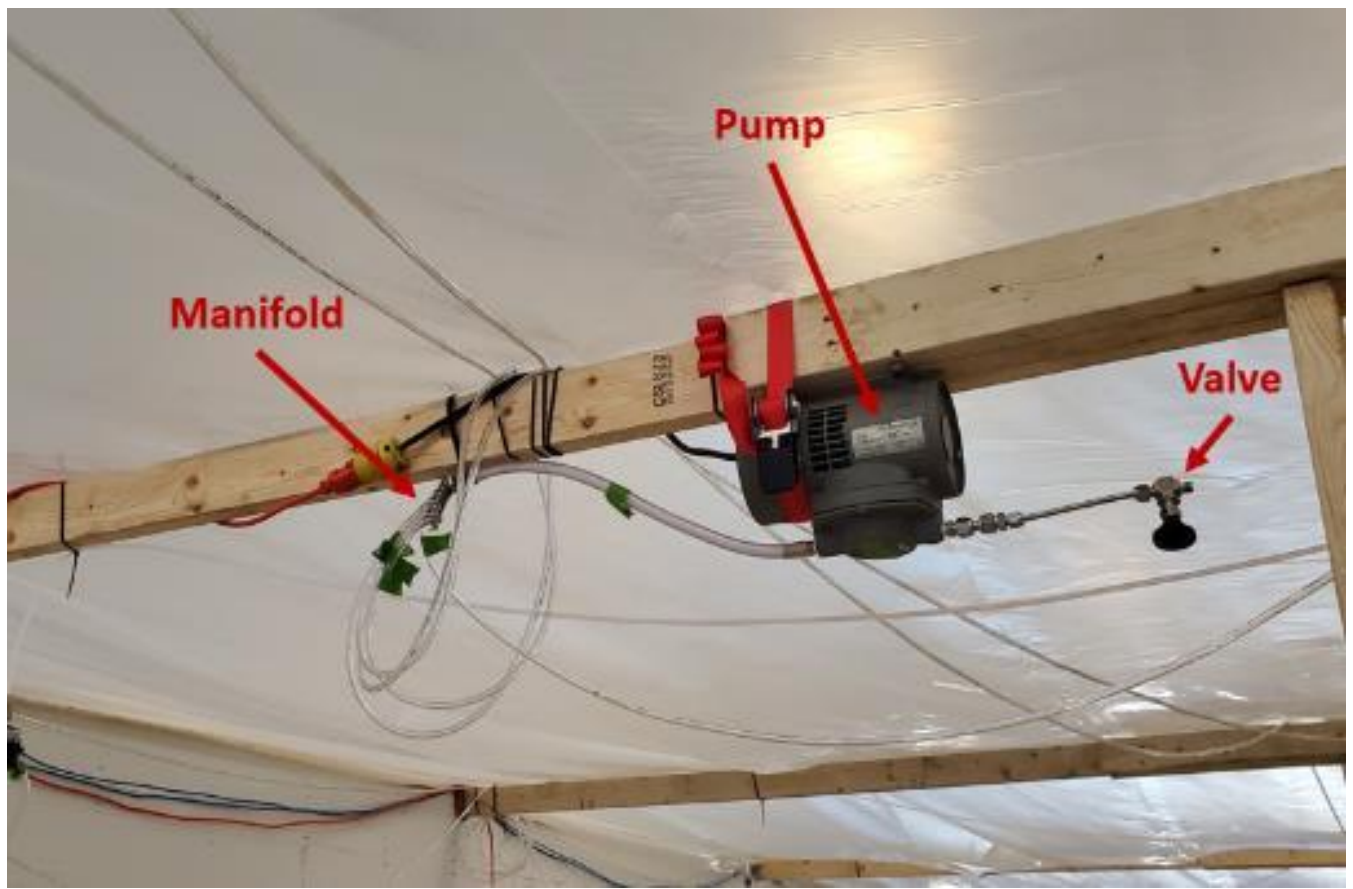

Figure 3.4-4: Pump and manifold mounted to the "T" structure.

Figure 3.4-5 shows the $\mathrm{CPH}$ and its placement in the mock mine.

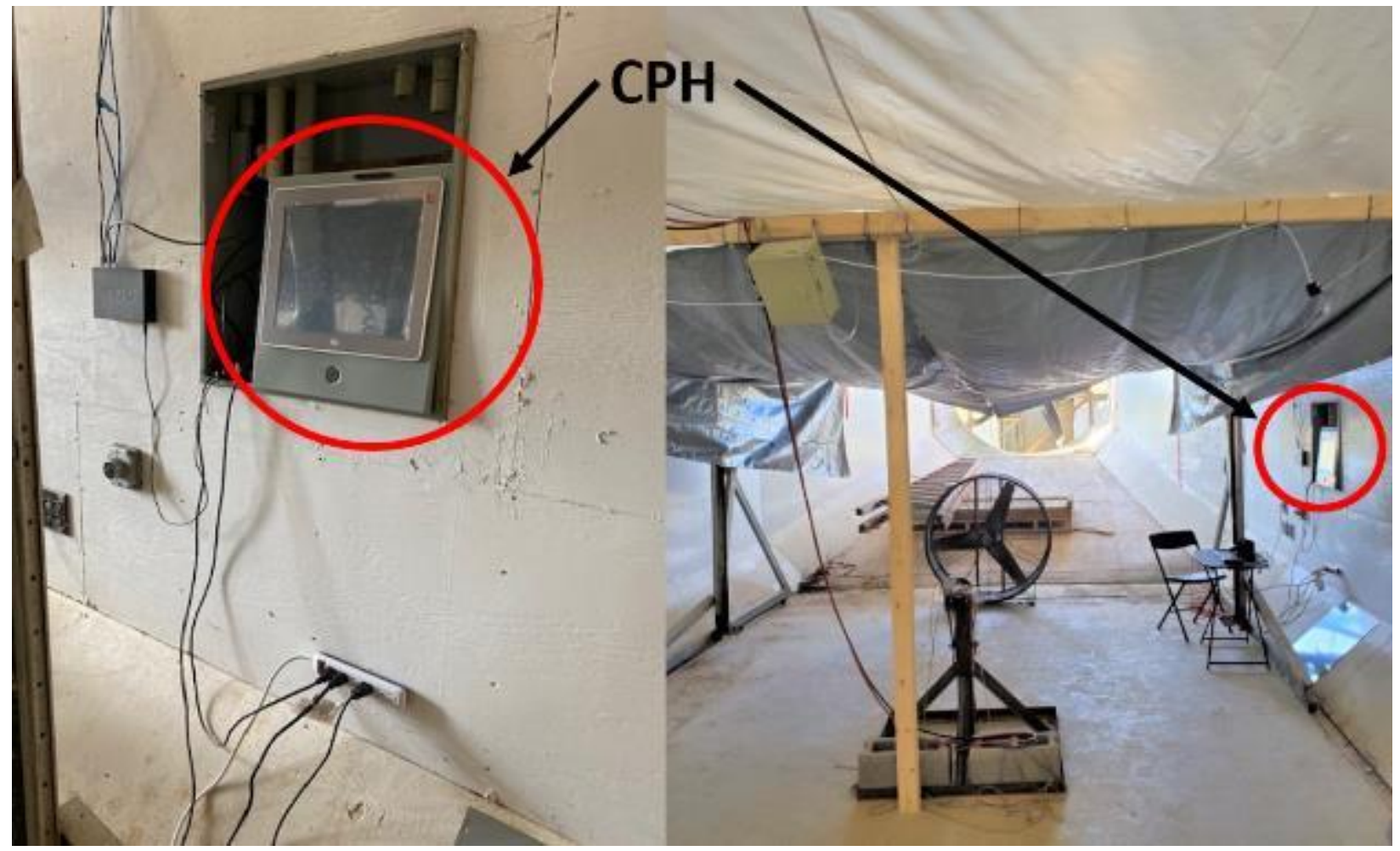

Figure 3.4-5: CPH location in mock mine. 
Ambient/Baseline Tests (Temperature, RH, Pressure)

To attain measurements of ambient conditions, baseline tests were completed without the presence of $\mathrm{CH}_{4}$; these tests measured temperature, $\mathrm{RH}$, and pressure in the mock mine. Many of these tests were recorded overnight or over the period of 2-3 days. Also, all tests that involved the presence of $\mathrm{CH}_{4}$ were recorded for a period long enough to obtain baseline conditions before $\mathrm{CH}_{4}$ was introduced. Temperature, $\mathrm{RH}$, and pressure were measured in each of the ten sampling units as well as by an Omega iBTHX which was placed on the face side at the middle of the mock mine (at the door) near the roof. Figure 3.4-6 shows a picture of the iBTHX (left) and its location in the mock mine (right).

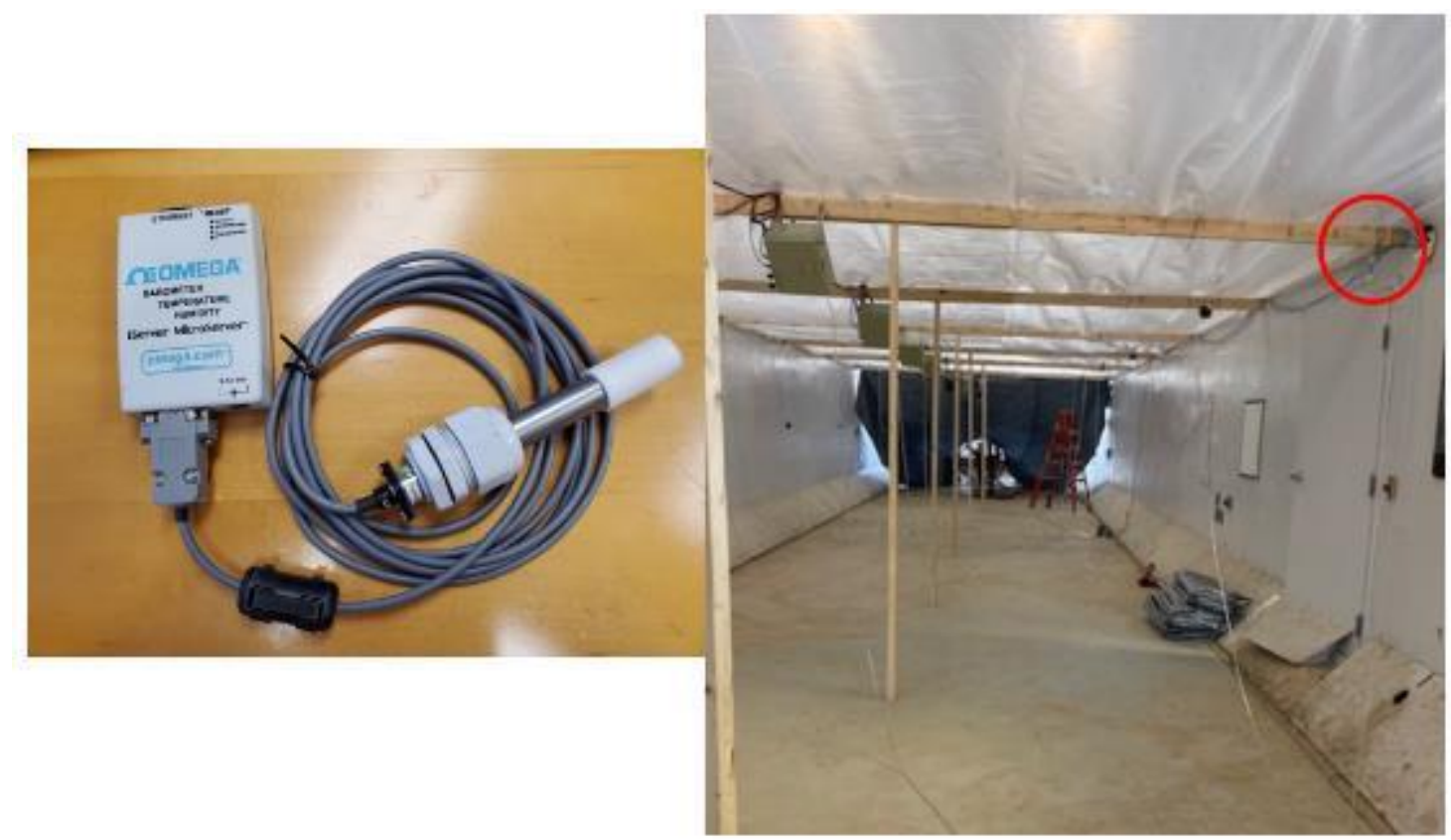

Figure 3.4-6: iBTHX and its location in the mock mine.

\section{System Response Times in the Presence of $\mathrm{CH}_{4}$}

Two methods were used to analyze system response times when exposed to $\mathrm{CH}_{4}$. The rise and decay times of the system were found for each test using both the metal-oxide sensor (MOS) and infrared sensor (IRS) responses as reference. During these tests, $\mathrm{CH}_{4}$ at a known concentration of 2.03\% (from a calibration gas bottle) was supplied to the desired sampling location(s). Method 1 
supplied $\mathrm{CH}_{4}$ to five sampling locations at a time through a tubing network, while Method 2 examined a single sampling location.

\section{Method 1}

Method 1 consisted of a network of tubing which supplied $\mathrm{CH}_{4}$ to one of four groups of sampling locations at a time; each group consisted of five sampling locations. Figure 3.4-7 shows the placement of these sampling locations (face or gob). This system consisted of four manifolds, each with a single inlet and five outlets, for a total of 20 supplied sampling locations. The first manifold supplied $\mathrm{CH}_{4}$ to sampling locations $1-5$, the second to sampling locations 6-10, the third to sampling locations 11-15, and the last to sampling locations 16-20. The $\mathrm{CH}_{4}$ supply was directed to one manifold at a time (five sampling locations); this action was controlled by a system of three 3-way valves, see Figure 3.4-7. The "true" and "false" at each valve represented the direction of the flow when the valve was powered on and off, respectively. For example, if all valves were powered off, sampling locations 11-15 received the sample of $\mathrm{CH}_{4}$. The length of the tubing that the $\mathrm{CH}_{4}$ was supplied through was approximately $19.8 \mathrm{~m}(65 \mathrm{ft})$ from the 3-way valve system to the sampling location of interest. Before the test began, the $\mathrm{CH}_{4}$ supply was turned on to purge the tubing to ensure it was flooded with methane; the tubing was then placed into the filters of the respective sampling locations. It should be noted that the outer diameter of the tube was less than the inner diameter of the filter inlet, thus it was served as a flooded probe to ensure the system was not over pressurized - which would have impacted the response time. The recording of the test was started before the supply of $\mathrm{CH}_{4}$ was initiated to record background conditions before supplying the $\mathrm{CH}_{4}$. The $\mathrm{CH}_{4}$ was then supplied to each sampling location at a flowrate lower than the sampling flowrates of each box to alleviate the chance of effecting the response time due to the $\mathrm{CH}_{4}$ supply rate; the remaining portion of the sample was pulled from ambient. The flowrate of the $\mathrm{CH}_{4}$ was regulated by a MFC that was connected directly to a pressure regulator on the $\mathrm{CH}_{4}$ gas bottle. The time in which the $\mathrm{CH}_{4}$ supply was initiated (start time, $\mathrm{t}_{\text {start }}$ ) and the time at which the $\mathrm{CH}_{4}$ supply was ceased (stop time, $\mathrm{t}_{\text {stop }}$ ) were either controlled and referenced by the MFC or by the 3-way valve system. There were two tests performed where the MFC was referenced for start and stop times and two tests where the valves were referenced. Note that there was no noticeable difference between either method, therefore they have been grouped together to form one set of four tests for assessment of the rise and decay times. 


\section{Face}

Gob

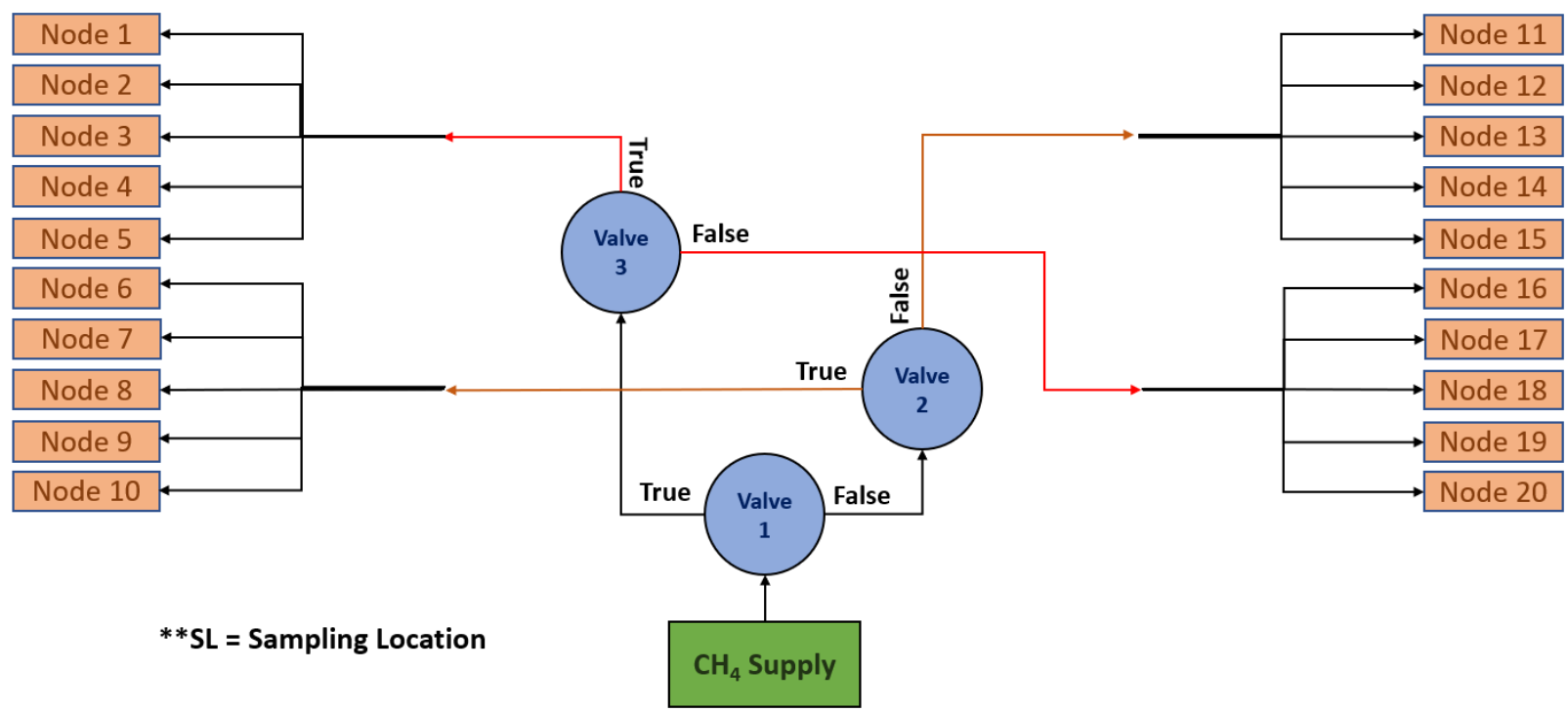

Figure 3.4-7: Valve setup for the supply of methane using a flooded probe approach used in both Methods 1 and 2.

The rise and decay times of the system were determined based on the responses of both the MOS and IRS. The rise time was characterized as the time it took a sensor (MOS or IRS) to reach $90 \%$ of its total steady response once the $\mathrm{CH}_{4}$ supply was initiated ( $\mathrm{t}_{\text {start }}$ ). Taylor et al. and Zhang et al. conducted research that analyzed response times of sensors and both studies used $90 \%$ of the response when calculating the rise times of the sensors. The total response was determined by taking an average (60-100 seconds) of the peak sensor response while $\mathrm{CH}_{4}$ was supplied. The total response was then multiplied by 0.9 to determine $90 \%$ of the total response. The decay time was characterized as the time, once the $\mathrm{CH}_{4}$ supply is stopped ( $\left.\mathrm{t}_{\text {stop}}\right)$, to drop within $+10 \%$ of the background response; the background response was determined by averaging (60-100 seconds) a "flat" segment of the sensors response where no $\mathrm{CH}_{4}$ was being supplied. The flat response after the start time and before the response begins to rise was the transit time associated with the sample travelling from the filter to the sensors. Figure 3.4-8 shows an example of the of a sensor's response to help visualize how the rise and decay times were calculated. 


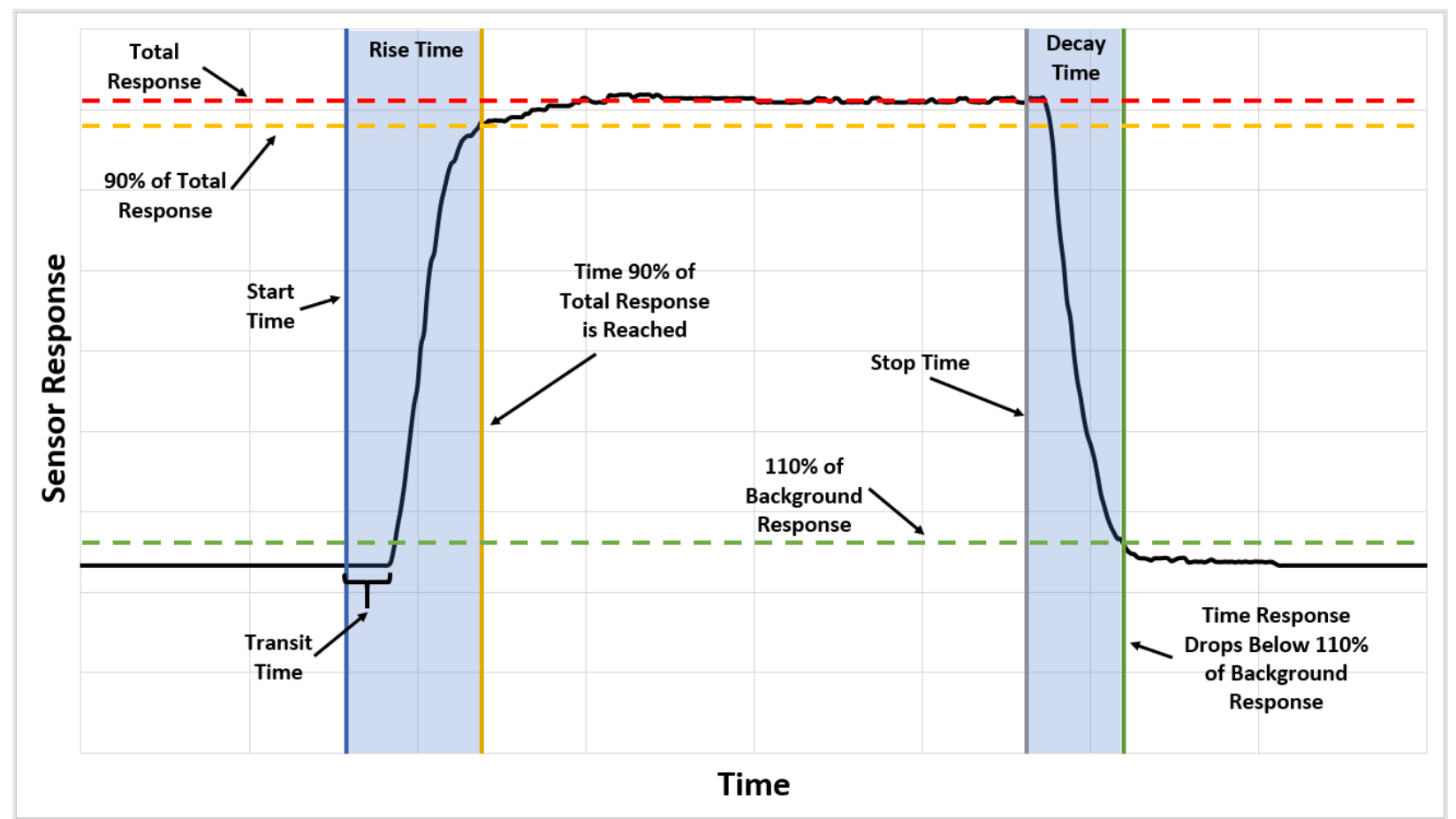

Figure 3.4-8: Example of a sensor's response to help visualize rise and decay times.

After the rise and decay times for each test were found, the results for both the MOS and IRS were averaged to calculate an average rise time and an average decay time for each sensor. It was originally thought that the $\mathrm{CH}_{4}$ supply tube was flooded prior to the start of the test (i.e. no diffusion) and the filter was filled with ambient air; meaning that at the start time the $\mathrm{CH}_{4}$ supply immediately began to flood the filter, replacing the ambient air with the $\mathrm{CH}_{4}$ concentrated gas. However, after initially viewing the results, it was determined this was likely not the case; discussed in more detail in the "Results and Discussion" section. To further analyze the accuracy of these results, the results of Method 2 were used for comparison.

\section{Method 2}

Method 2 was performed where the MFC was placed directly at the filter of sampling location 5. A tube of approximately $0.3 \mathrm{~m}(1 \mathrm{ft})$ was attached to the MFC and inserted into the filter; Figure 3.4-9 shows this setup. It should be noted that the outer diameter of the tube was less than the inner diameter of the filter inlet, thus it acted as a flooded probe to ensure the system was not over pressurized - which would have impacted the response time. This method was repeated four times with four different supply flowrates: $3,1.4,1.3$, and 1.2 SLPM $(0.106,0.049,0.046$, and 0.042 scfm). 
This method was used to ensure the $\mathrm{CH}_{4}$ was being supplied to the filter as soon as the MFC was turned on; this was assumed because the $0.3 \mathrm{~m}(1 \mathrm{ft}) \mathrm{CH}_{4}$ supply tube was considered negligible

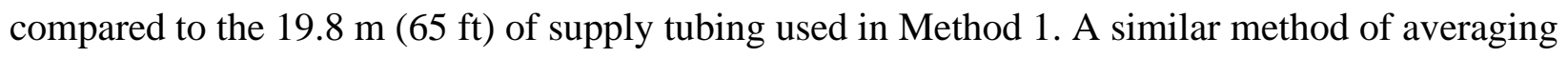
(as for Method 1) was used to calculate the rise and decay times.

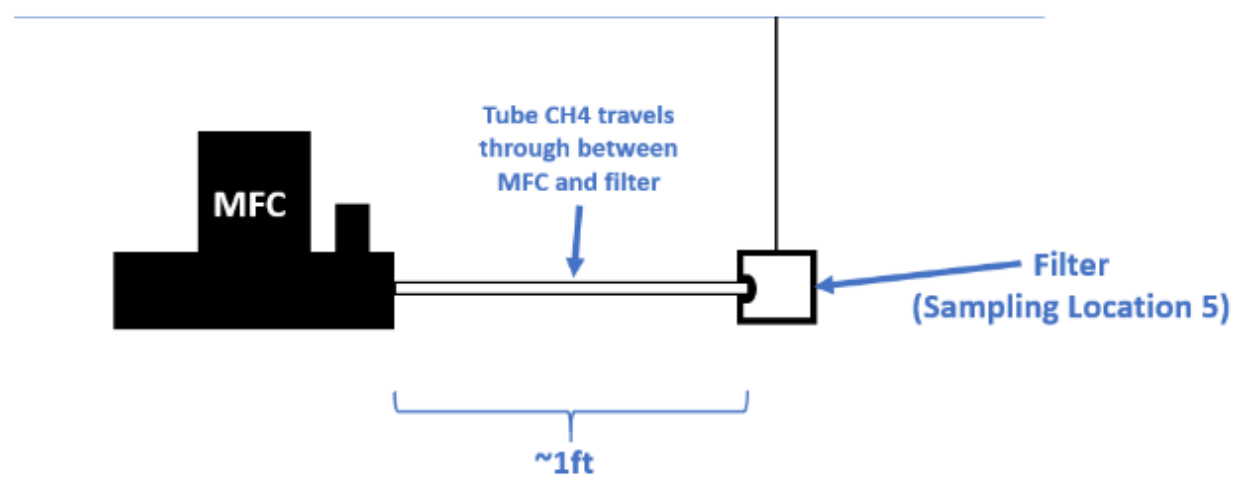

Figure 3.4-9: Response time testing - Method 2 setup.

\section{Tests Conducted Using the FFS}

Initial attempts were made to locally increase the presence of $\mathrm{CH}_{4}$ to the desired limits by leaking $2 \%$ calibration gas $\left(\mathrm{CH}_{4}\right)$ at various flow rates and release points. It was determined a proximity of a few inches was necessary to overcome dilution of the gas within the test section. Therefore, we used WVU's full flow sampling system (FFS), pictured in Figure 3.4-10, operating in reverse to deliver dilute $\mathrm{CH}_{4}$ plumes directly near the filter inlet at the sampling location as well as to increase the concentration of $\mathrm{CH}_{4}$ and its flowrate. The system utilized a blower that coupled a dilute flow measurement section containing a mass air flow (MAF) sensor, temperature sensor, and the UGGA used for varying $\mathrm{CH}_{4}$ emissions into the mock mine. Corrugated tubing of about

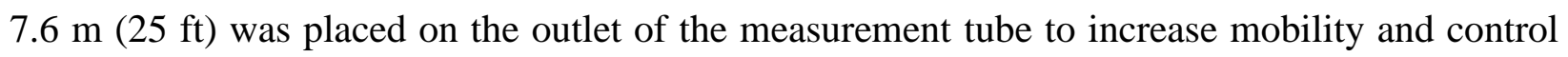
the position of the $\mathrm{CH}_{4}$ leak. About $30.5 \mathrm{~m}$ (100 ft) of tubing was placed on the inlet of the blower to allow dilution air to be pulled from outside of the test section to avoid recirculation. The FFS system allowed for an elevated level of $\mathrm{CH}_{4}$ to enter the system at a controlled flow rate; for which it was then diluted to the desired concentration and was discharged at a greater volumetric flow rate to test section. 


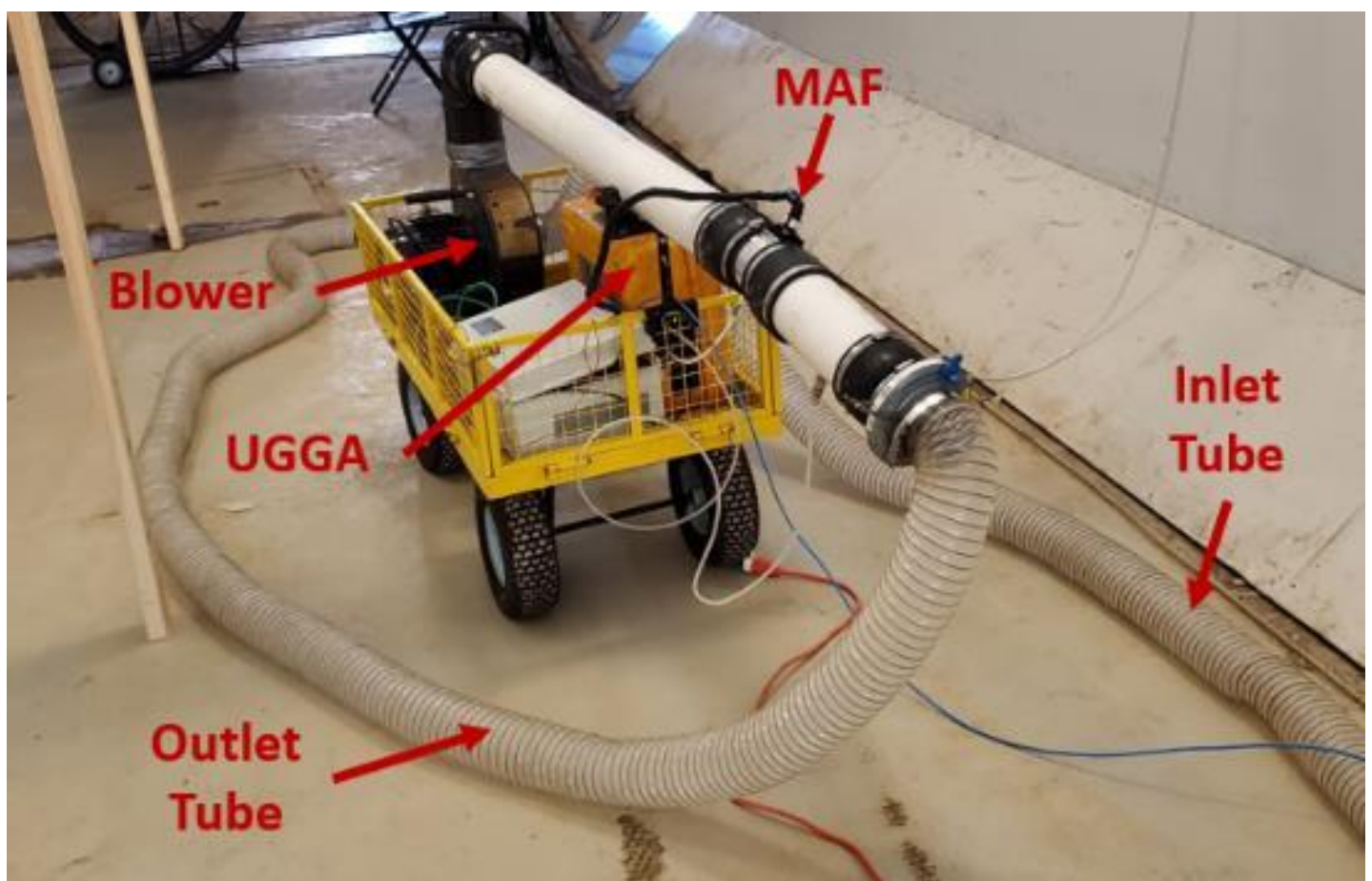

Figure 3.4-10: Use of the FFS system for creation of high volumetric flow rates of lower concentration methane.

\section{Type 1 - Constant Immobilized Leak with Low Ventilation}

For this test, only the fan located at the TG of the test section was on to help direct and pull flow through the wind tunnel. It should be noted that any outside variables to the test section, such as weather, were directly associated with the conditions inside the test section and may have contributed to variances to the ideal scenarios throughout the tests being described. The FFS was then placed at the HG with its flow directed down the test section, parallel to the face of the longwall. The release point is fixed $2.1 \mathrm{~m}(7 \mathrm{ft})$ before Node 1 at a height of $0.9 \mathrm{~m}(3 \mathrm{ft})$ from the ground, as shown in Figure 3.4-11. After collecting background responses of the system (prior to the presence of $\left.\mathrm{CH}_{4}\right), \mathrm{CH}_{4}$ from the pure bottle was injected into the intake flow of the FFS at a setpoint which corresponded to a desired diluted concentration. Most of these tests consisted of a $2 \% \mathrm{CH}_{4}$ leak into the test section at a flow rate of 2832 SLPM (100 scfm)). A higher concentration of $6 \% \mathrm{CH}_{4}$ was also used to conducted tests. The $2 \%$ leak described above was left constant for the remaining duration of the tests. 


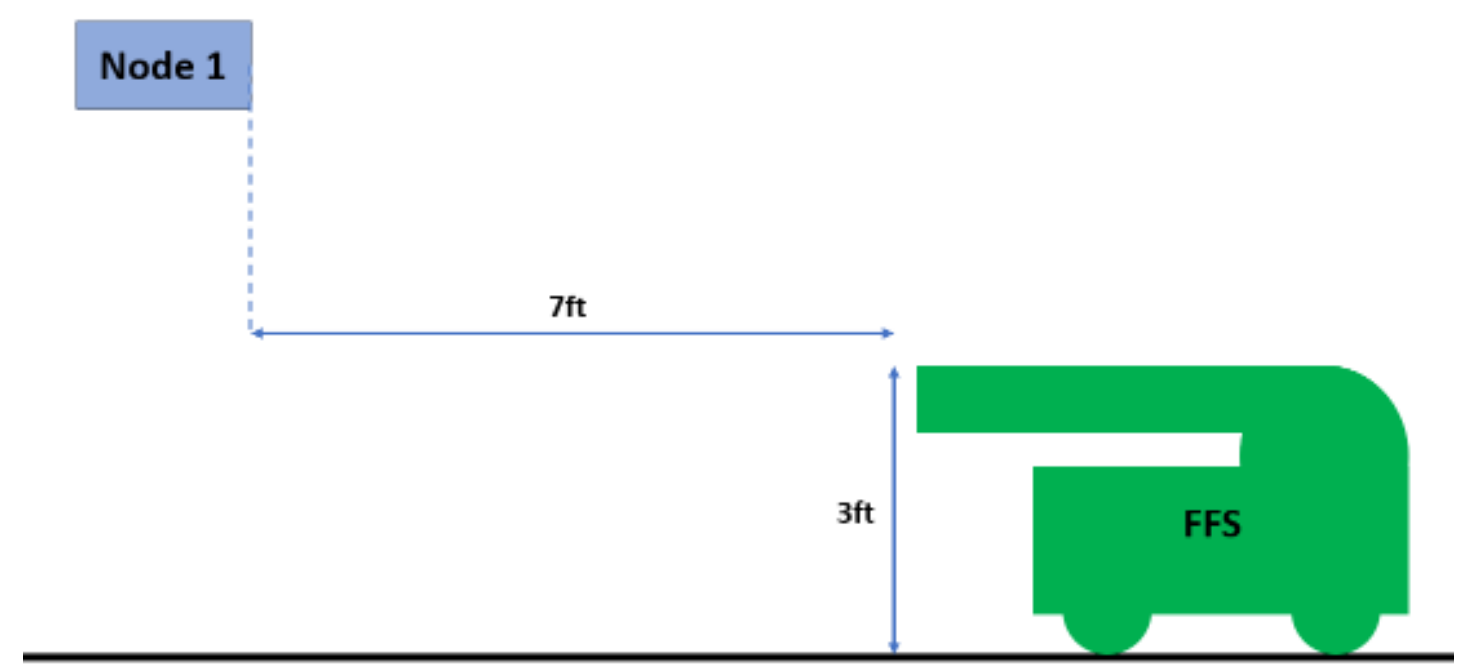

Figure 3.4-11: Location of FFS with respect to Node 1.

\section{Type 2 - Constant Immobilized Leak with Increased Ventilation}

These tests were conducted similarly as the ones in the previous section with the addition of a fan at the HG. The additional fan was implemented in attempts to increase and better control the flow through the mock mine section. Once again, the FFS was used to release a known concentration of $\mathrm{CH}_{4}$ to the test section at the $\mathrm{HG}$.

\section{Type 3 - Methane Released Directly Near the Sampling Locations (Filters)}

Due to the detection limits of the infrared sensor (IRS), a local, detectable, methane concentration was unable to be achieved with the immobilized leak methods mentioned above. To evaluate the sensors responses within their operational range, the FFS was placed directly near each individual filter at the sampling location to ensure the desired concentration was present. The FFS flow containing the $\mathrm{CH}_{4}$ was held approximately a $0.3 \mathrm{~m}(1 \mathrm{ft})$ from each filter for around a minute, allowing the sensor to reach a full response. These tests were conducted with $2 \% \mathrm{CH}_{4}$ by volume from the FFS as referenced by the UGGA. In proper operating conditions, the UGGA measured with an uncertainty of around $+/-5 \%$. Figure 3.4-12 shows a visualization for the setup of a Type 3 test for one sampling location. 


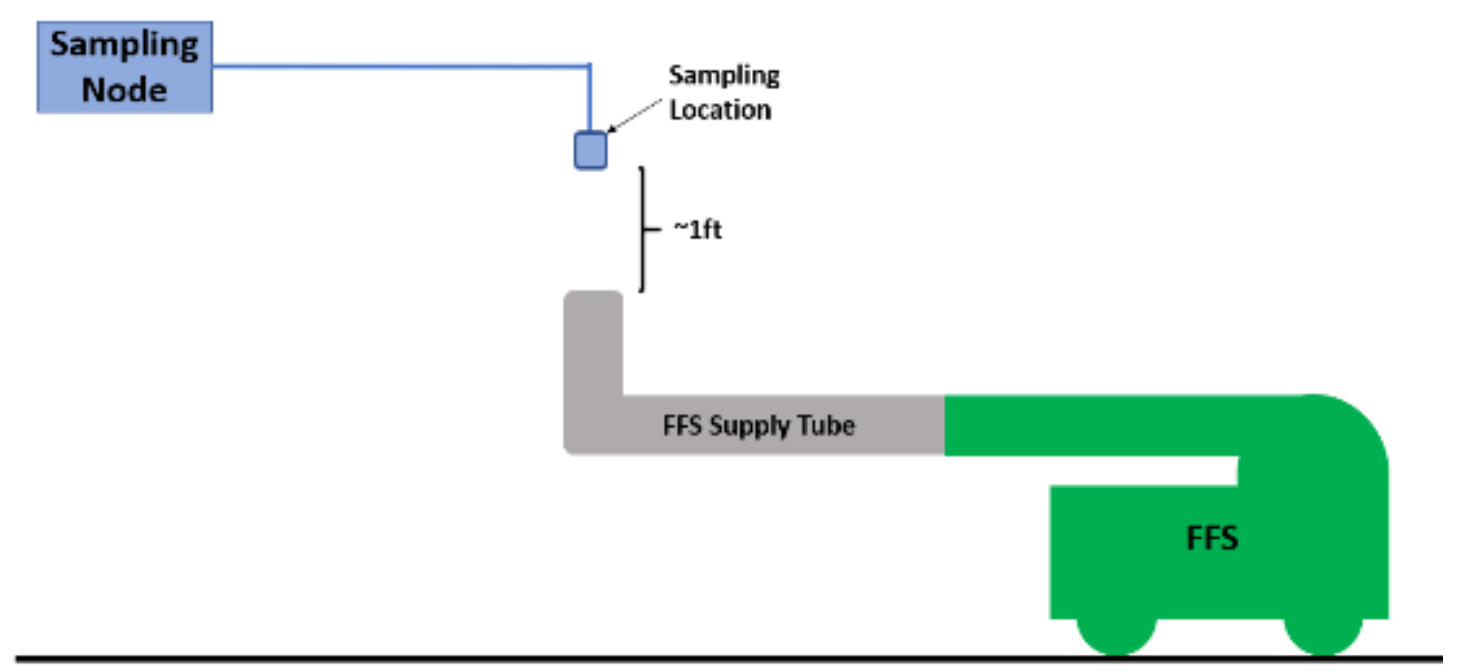

Figure 3.4-12: Type 3 FFS Test - Visualization for one sampling location.

Type 4 - Methane Released Directly Near the Sampling Locations (Filters) and Continuously

\section{Moving}

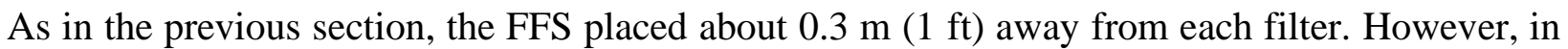
these tests, the FFS was continuously moving past each sampling location at a slow walking speed; it was never stationary at a sampling location for an extended period. A diagram showing this test can be seen in Figure 3.4-13.

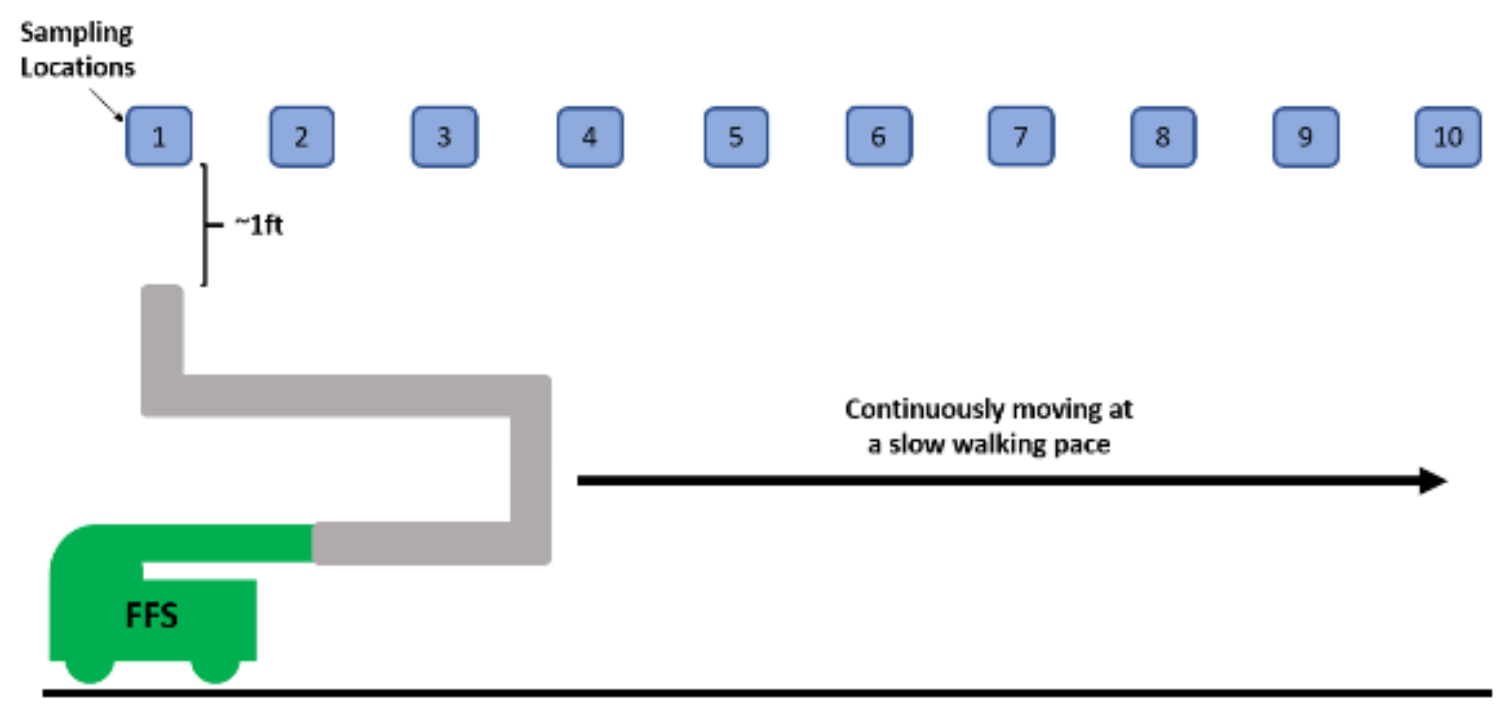

Figure 3.4-13: Type 4 FFS Test - Visualization of test setup. 


\section{Relay/Alarm Control}

A major objective was to improve mine safety by including the ability to deenergize equipment.

Physical disconnections would be through notification of operators and through software control.

The MWS included both an audible and visual alarm to notify operators, and the capabilities to control isolated relays. To test that the relay control worked properly, a program was written that turned a relay on and off and set an alarm whenever any of the IRS measured over $1 \% \mathrm{CH}_{4}$ concentration. Figure 3.4-14 shows a scenario when an IRS sensor exceeded the $1 \%$ threshold. In this example, IRS 1 ("Dynament 1" in the picture) was exposed to a $\mathrm{CH}_{4}$ concentration above $1 \%$ to set the alarm. Figure 3.4-15 shows an example of what the interface looks like when an alarm is set; when an alarm is triggered, the "Gauge" block in the "Alarm" group turns red (shown in the red circle) and the message box displays which node triggered the alarm (shown in the blue rectangle). In this example, "Dynament 1 " represents Node 1.

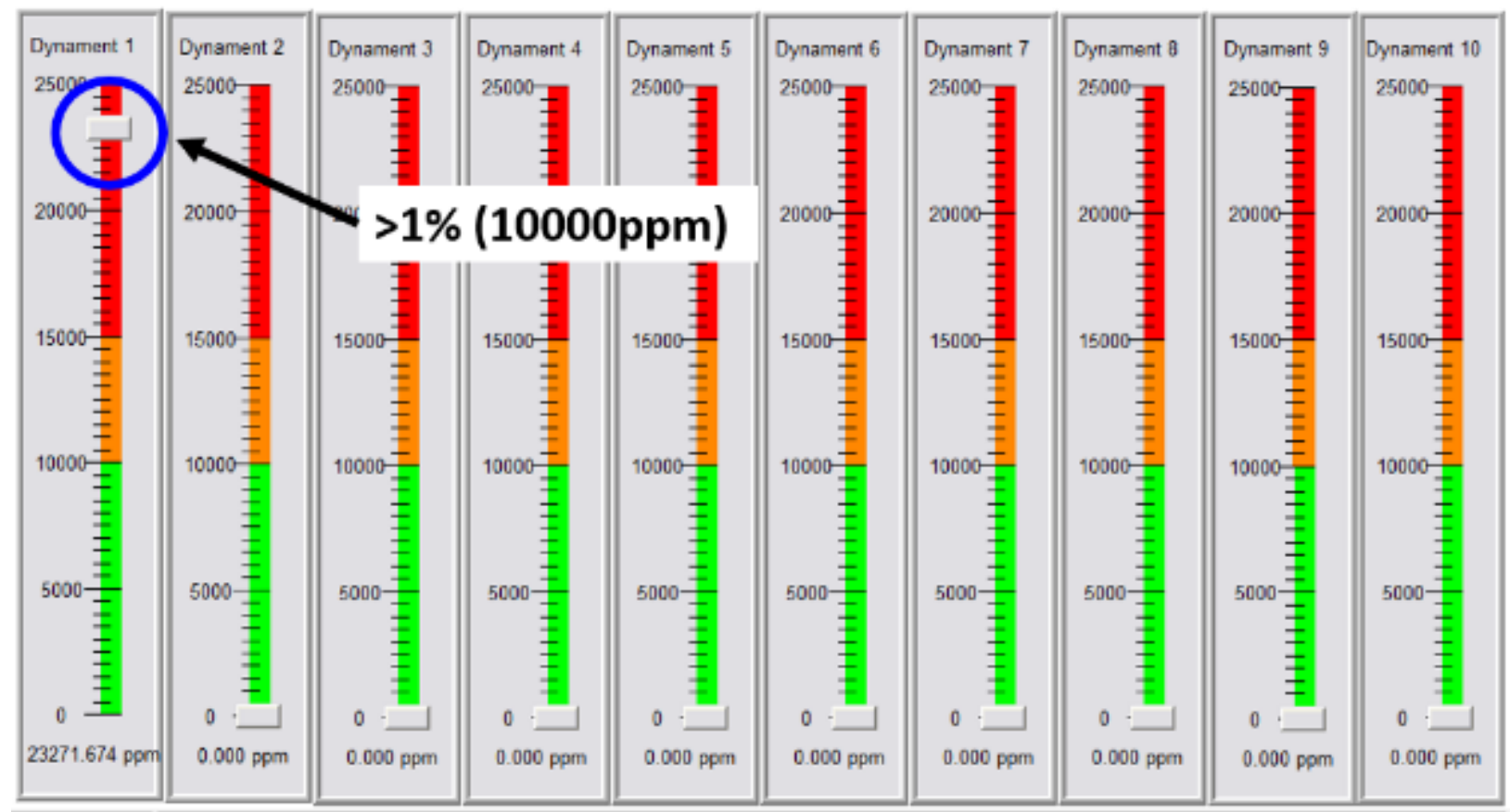

Figure 3.4-14: CPH interface showing IRS 1 measuring a $\mathrm{CH}_{4}$ concentration above the $1 \%$ threshold. 


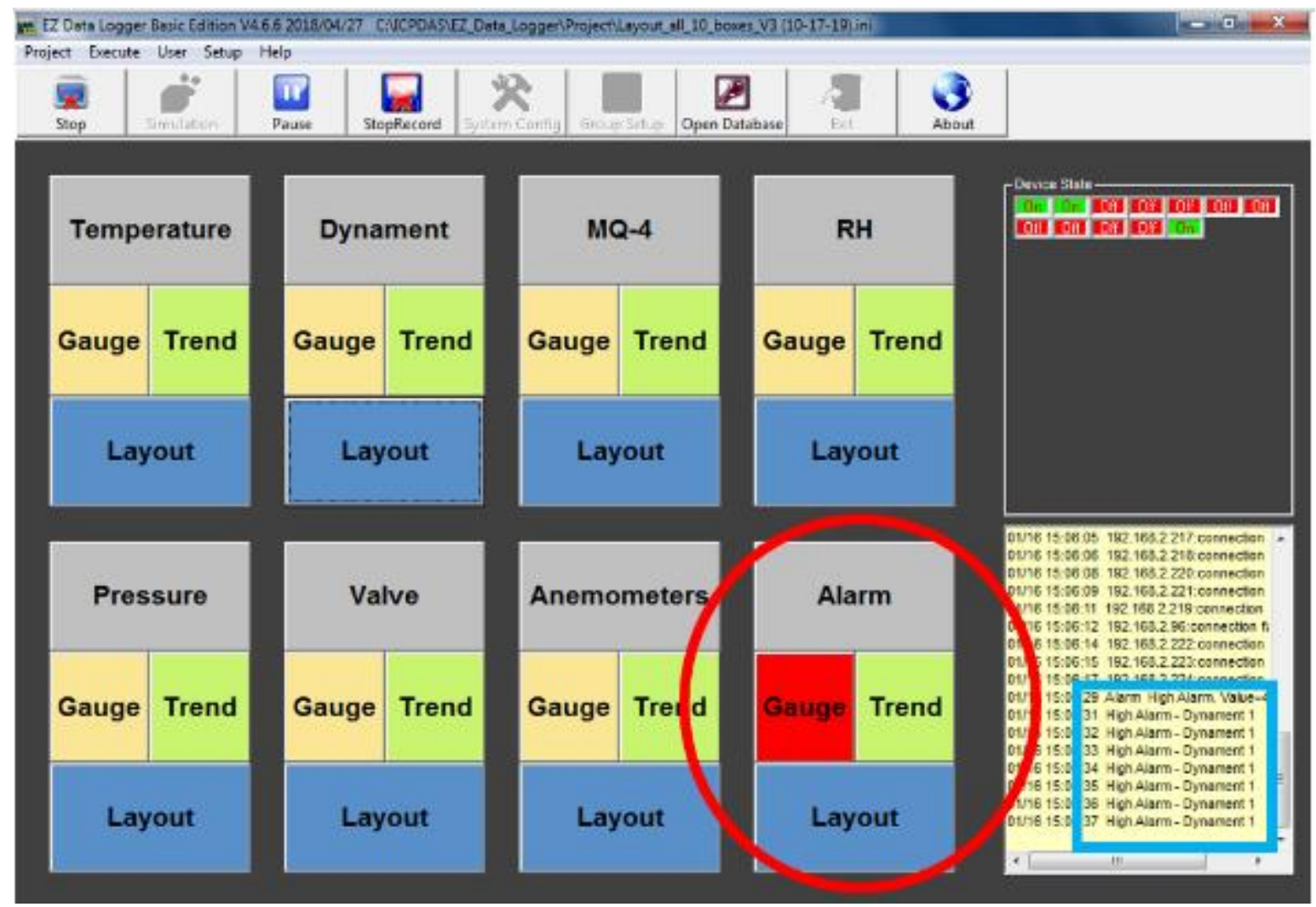

Figure 3.4-15: CPH interface when alarm was active.

In this test, the FFS was used to supply $\mathrm{CH}_{4}$ to each sampling location on the gob side. One sampling location was supplied with approximately $2 \% \mathrm{CH}_{4}$ until the sensor measured high enough to turn on the relay and set off the alarm. The supply was then taken away until the sensor's response decayed to below $1 \%$ and the relay was turned off; this was completed for all ten nodes.

\subsection{Power Consumption}

Since the system was proposed to utilize the power supply currently implemented into the shields, a test was performed to analyze the power consumption of a single sampling unit. One sampling unit was connected to a 24 VDC power supply. A Hantek CC-65 AC/DC current clamp measured the current drawn by the unit by clamping it around the positive wire connecting the power supply to the unit [170]. The current was recorded while the valve was turned off and while the valve was turned on to obtain an estimate of the minimum and maximum power consumption of the unit. Eq. 3.5.1 was used to calculate the power consumption, where $P$ is the power in watts $(W), I$ is the measured current in amps (A), and V is the power supply voltage in volts (V).

$$
P=I \times V
$$




\subsection{Proposed Sampling Method (Water Ejector)}

An ejector was designed to provide an active sampling method for the MWS. It was determined that compressed air was not readily available, and that passive sampling would be plagued with variable flow rates, water sprays, and particulate matter. However, during initial discussion with industry workers, it was determined that water upwards of $689.5 \mathrm{kPa}$ (100 psig) was available throughout mines. In order to reduce moving components, use available resources, and to use a mine safe method, my research focused on development of a water powered ejector.

\section{Requirements}

The ejector for the proposed system was designed based on the assumption that water supply systems currently implemented in longwall mines could be used to provide water as the primary fluid of the ejector. The ejector would be placed downstream of a node's sampling system and the low-pressure port would serve as the motive force though the sensor block and components. It was originally thought that the water pressure being supplied to each shield, where the ejectors would also be supplied from, was around $689.5 \mathrm{kPa}$ (100 psig), which was a design parameter used. The ejector was designed where the $\mathrm{CH}_{4}$-air mixture is the secondary fluid; the sample fluid being pulled into the ejector. Note that since the sample in a mine would predominately be air, the experimental work performed for the ejector research only used air as the suction fluid. The ejector was designed to minimize water consumption and maximize suction pressure. The goal was maintaining an air flowrate of around 2 SLPM $(0.071 \mathrm{scfm})$ at the estimated pressure drop due to the sampling system (including a filter and coal dust caking to the filter). The pressure drop was determined experimental measured at a flowrate of 2 SLPM $(0.071 \mathrm{scfm})$, the maximum pressure drop due to the system for one sampling box was approximately $1.4 \mathrm{kPa}\left(0.2 \mathrm{psig}, 5.55 \mathrm{inH}_{2} \mathrm{O}\right)$, which corresponded to the suction pressure required to produce the expected flowrate.

\section{Initial Design}

An ejector was designed from calculations and recommendations from "Ejectors and Jet Pumps Design and Performance for Incompressible Liquid Flow" [129]. The ejector design was based primarily around the flow ratio to ensure the ejector was capable of facilitating sampling at the desired flowrate. The nozzle to mixing chamber area ratio, $\mathrm{R}$, was calculated using Eq. 3.6.1 to 3.6.5, where $\mathrm{N}$ is the pressure ratio, $\mathrm{M}$ is the flow ratio, $\mathrm{C}$ is the density ratio, and $\mathrm{K}_{\mathrm{p}}, \mathrm{K}_{\mathrm{s}}, \mathrm{K}_{\mathrm{m}}$, and $\mathrm{K}_{\mathrm{d}}$ are loss coefficients for the primary nozzle, secondary flow inlet, mixing chamber, and diffuser, 
respectively. Note that subscript "a" denotes "air inlet", subscript "w" denotes "water inlet", and subscript "o" denotes "outlet". Calculations and iterations were performed using MATLAB ${ }^{\circledR}$. The code used for these can be found in Appendix E.

$$
\begin{gathered}
N=\frac{P_{o}-P_{a}}{P_{w}-P_{o}} \\
M=\frac{Q_{a}}{Q_{w}} \\
C=\frac{\rho_{a}}{\rho_{w}} \\
R^{4} a_{1}(N+1)+2 R^{3}\left[(N+1)\left(C M^{2}-a_{1}-1\right)\right] \\
-R^{2}\left[(N+1)\left(2 C M^{2}-a_{1}-4\right)-C M^{2}\left(1+K_{s}\right)-N\left(1+K_{p}\right)\right] \\
-2 R\left[(N+1)+N\left(1+K_{p}\right)\right]+N\left(1+K_{p}\right)=0
\end{gathered}
$$

Where,

$$
a_{1}=(1+C M)(1+M)\left(1+K_{m}+K_{d}\right)
$$

For the initial calculations, $\mathrm{K}_{\mathrm{p}}, \mathrm{K}_{\mathrm{s}}, \mathrm{K}_{\mathrm{m}}$, and $\mathrm{K}_{\mathrm{d}}$ were set to $0.05,0.1,0.19$, and 0.12 , respectively. For latter iterations, these loss coefficients were estimated by plots provided in the "Ejectors and Jet Pumps - Design and Performance for Incompressible Liquid Flow" appendices using the Reynold's Numbers $(R e)$ calculated at the end of each iteration [129].

The nozzle cross-sectional area $\left(A_{n}\right)$ and diameter $\left(D_{n}\right)$ were calculated using Eq. 3.6.6 and 3.6.7. The mixing chamber diameter was then calculated using Eq. 3.3.8 and 3.6.9.

$$
\begin{gathered}
A_{n}=Q_{w}\left[\frac{\left(1+K_{p}\right)-C\left(1+K_{s}\right)\left(\frac{M R}{1-R}\right)^{2}}{\left(P_{w}-P_{a}\right) /\left(0.5 \rho_{w}\right)}\right]^{0.5} \\
D_{n}=\sqrt{\frac{4 A_{n}}{\pi}} \\
A_{m}=\frac{A_{n}}{R} \\
D_{m}=\sqrt{\frac{4 A_{m}}{\pi}}
\end{gathered}
$$

The $R e$ for the water and air were calculated using Eq. 3.6.10 and Eq. 3.6.11, where $v$ was the kinematic viscosity of the corresponding fluid. 


$$
\begin{gathered}
R e_{w}=\frac{Q_{w} D_{n}}{A_{n} v_{w}} \\
R e_{a}=\frac{Q_{s}\left(D_{m}-D_{n}\right)}{\left(A_{m}-A_{n}\right) v_{a}}
\end{gathered}
$$

If $\mathrm{N}$ and $\mathrm{M}$ were varied, the values at which the characteristic curve crosses the axes $\left(\mathrm{N}_{0}\right.$ and $\left.\mathrm{M}_{0}\right)$ were calculated using Eqs. 3.6.12 to 3.6.13c, where $\mathrm{N}_{0}$ was when $\mathrm{M}=0$ and $\mathrm{M}_{0}$ was when $\mathrm{N}=0$.

$$
\begin{gathered}
N_{0}=\frac{2 R-R^{2}\left(1+K_{m}+K_{d}\right)}{\left(1+K_{p}\right)-2 R+R^{2}\left(1+K_{m}+K_{d}\right)} \\
M_{0}=\frac{-b-\sqrt{b^{2}-4 a c}}{2 a}
\end{gathered}
$$

where

$$
\begin{gathered}
a=\frac{2 C R^{2}}{1-R}-C R^{2}\left(1+K_{m}+K_{d}\right)-C\left(\frac{R}{1-R}\right)^{2}\left(1+K_{s}\right), \\
b=-R^{2}(1+C)\left(1+K_{m}+K_{d}\right),
\end{gathered}
$$

and

$$
c=2 R-R^{2}\left(1+K_{m}+K_{d}\right)
$$

The efficiency varies with changing flow ratio, M, and was also calculated using Eq.3.6.14.

$$
\eta=M N_{0}-\left(\frac{N_{0}}{M_{0}}\right) M^{2}
$$

The two points, $\left(0, \mathrm{~N}_{0}\right)$ and $\left(\mathrm{M}_{0}, 0\right)$, were plotted along on top of the efficiency curve. Figure 3.6-1 shows this plot, where the maximum efficiency occurred where $\mathrm{M}$ was 2.2. 


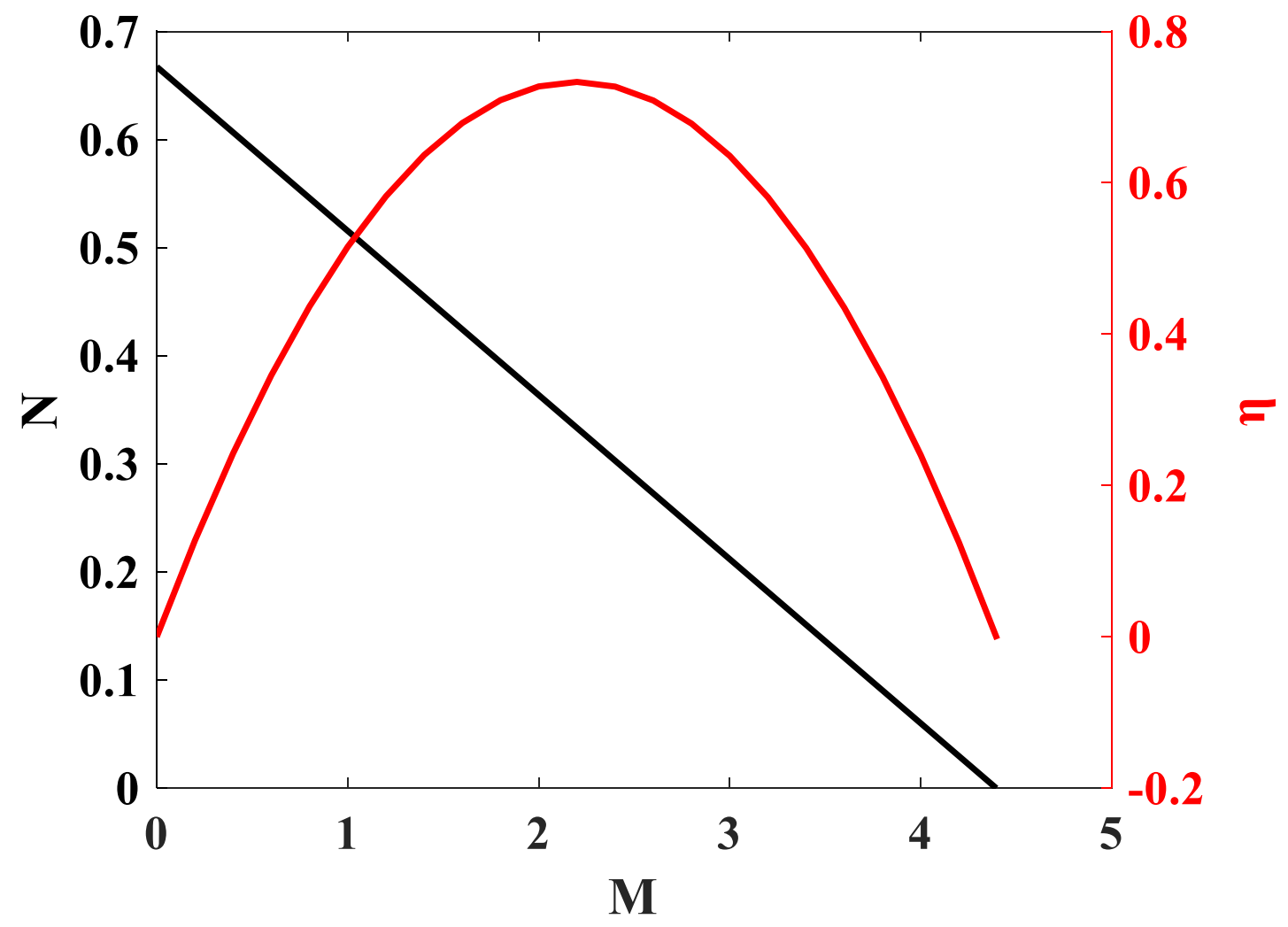

Figure 3.6-1: Ejector efficiency curve.

Multiple iterations were performed where the loss coefficients were re-evaluated, and subsequent calculations performed for each iteration. The final $D_{n}$, along with recommendations found in literature, other design parameters were calculated. Table 3.6-1 presents a summary of the recommended ratios that were used for the design.

Table 3.6-1: Ratios used for ejector design.

\begin{tabular}{|c|c|}
\hline $\begin{array}{c}\text { Nozzle to Mixing Chamber Diameter } \\
\text { Ratio }\end{array}$ & $\frac{D_{n}}{D_{m}}=0.5$ \\
\hline $\begin{array}{c}\text { Mixing Chamber Length to } \\
\text { Diameter Ratio }\end{array}$ & $\frac{L_{m}}{D_{m}}=10$ \\
\hline $\begin{array}{c}\text { Diffuser Length to Mixing Chamber } \\
\text { Diameter Ratio }\end{array}$ & $\frac{A_{d}}{A_{m}}<5$ \\
\hline
\end{tabular}




\section{Laboratory Testing}

Once final dimensions were calculated, a 3D model of the ejector was formed using SOLIDWORKS ${ }^{\mathrm{TM}}$. The ejector model was then 3D-printed using a Formslab Form 3 Stereolithography (SLA) 3D printer [171]. The 3D printed ejector was tested in the laboratory where the water supply was regulated to $482.6 \mathrm{kPa}(70 \mathrm{psig})$. The water flowrate, $\mathrm{Q}_{\mathrm{w}}$, was measured with a water flow meter, the air mass flowrate, $\dot{m}_{a}$, temperature, $\mathrm{T}_{\mathrm{a}}$, and pressure, $\mathrm{P}_{\mathrm{a}}$, were measured with an MFR, and the water pressure and outlet pressure were measured with pressure sensors. The air/suction pressure was varied using a valve at the air inlet. Figure 3.6-2 shows a schematic of the testing apparatus design with components labeled and Figure 3.6-3 shows a photograph of the constructed apparatus with the ejector hooked-up. Since the water supply in the laboratory was a relatively low pressure and highly variable, a booster pump, bladder water tank, and a pressure regulator to allow for a steady water stream at a nearly constant pressure.

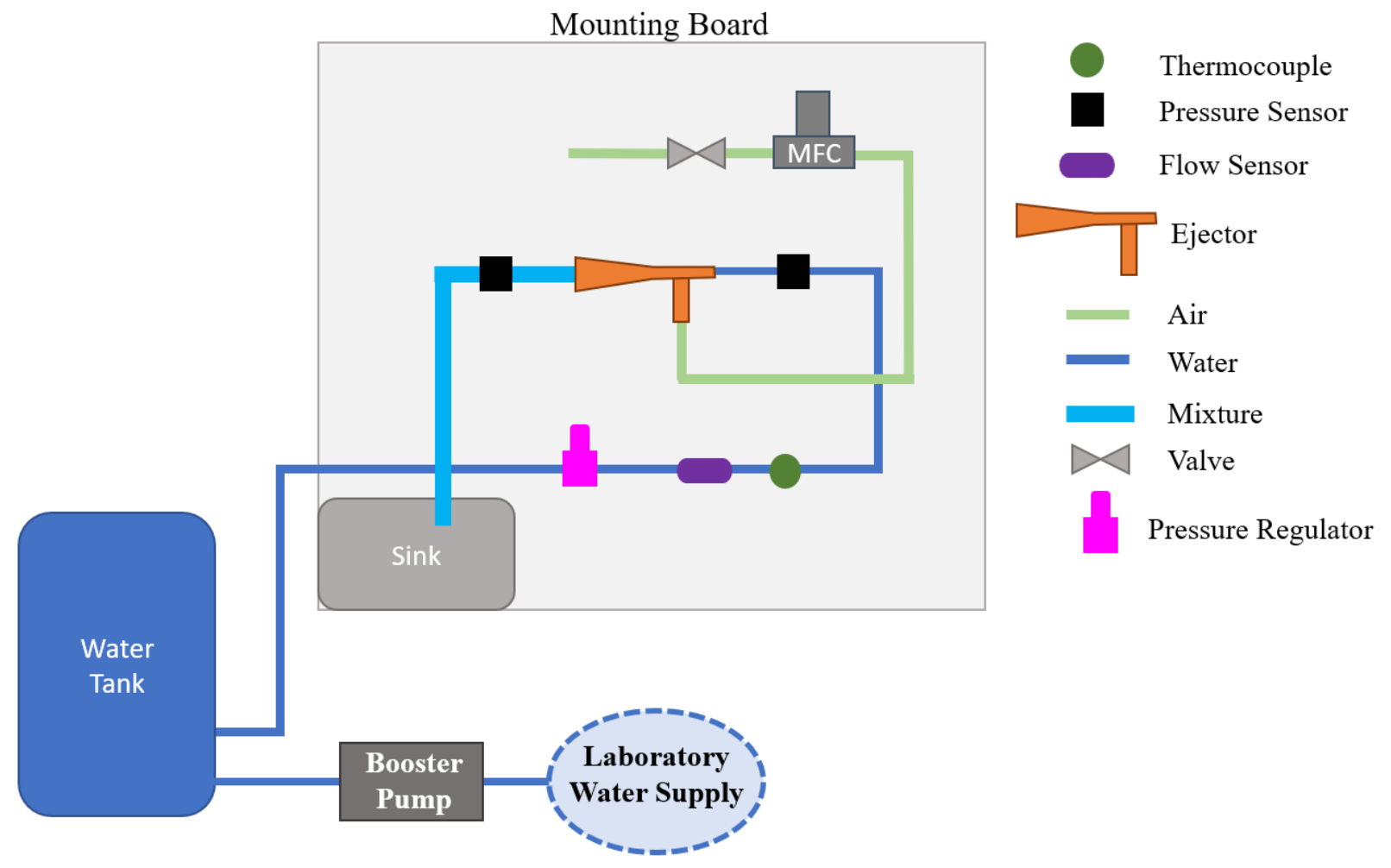

Figure 3.6-2: Ejector testing apparatus schematic. 


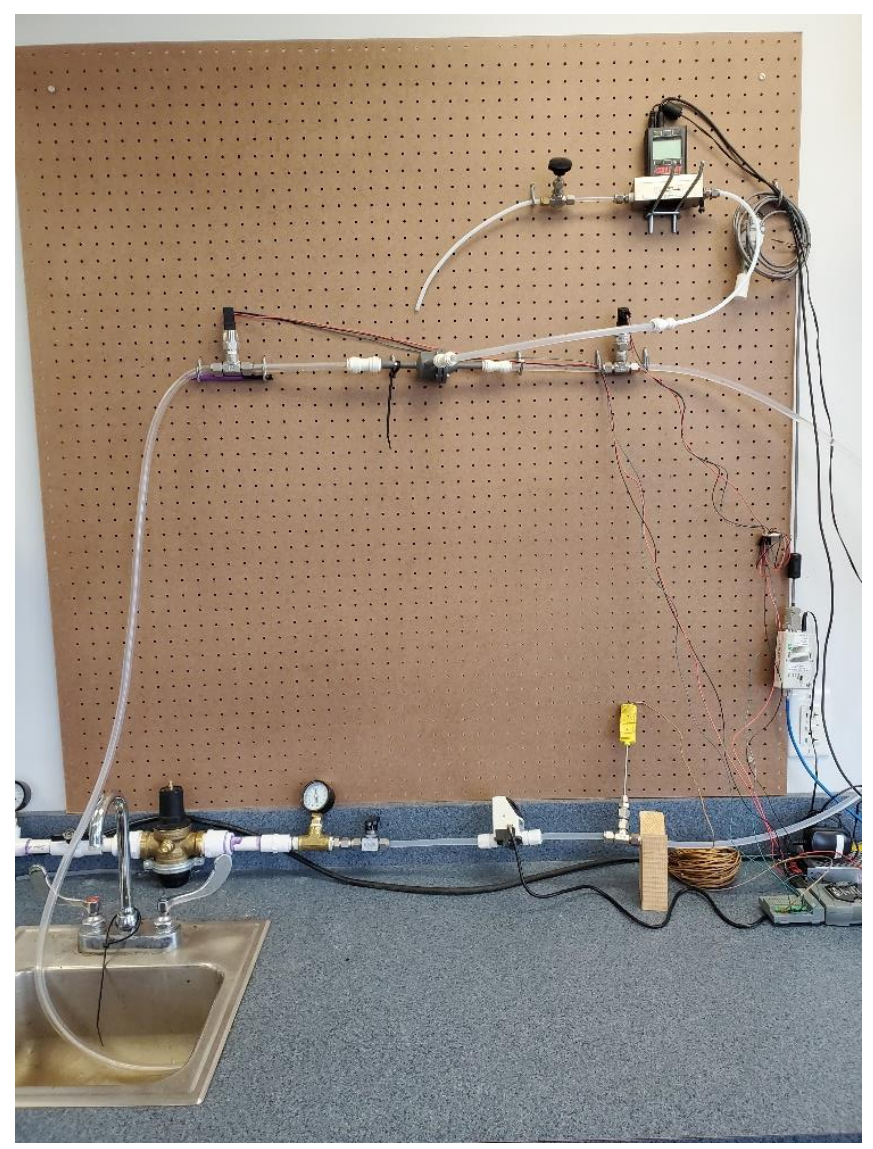

Figure 3.6-3: Ejector testing apparatus.

Multiple suction pressure points were achieved, and the parameters were recorded for each. The mass flowrate, temperature and pressure of the air were used to calculate the volumetric flowrate of the air using Eq. 3.6.15.

$$
Q_{a}[L P M]=\dot{m}_{a}[S L P M] \times\left(\frac{T_{a}}{294.26}\right) \times\left(\frac{14.696}{P_{a}}\right)
$$

After the initial test where water pressure remained constant and suction pressure was varied, a different test was conducted where the suction pressure remained constant and the water pressure was varied. The water pressure was increased from around 276 to $483 \mathrm{kPa}$ (40 to $70 \mathrm{psig}$ ) in increments of $69 \mathrm{kPa}$ (10 psig). The air suction pressure for this test was set at an absolute pressure of around $76 \mathrm{kPa}(11 \mathrm{psia})$ to allow operation on the "low" pressure (greater performance) curve at each water pressure point. 


\section{Multi-Nozzle Design}

Once testing and verification of the initial design concluded, further research was conducted to improve the ejector performance. Aissa investigated the performance of multi-nozzle ejectors in comparison with single nozzle ejectors and concluded that, overall, multi-nozzle ejectors typically have greater flow ratios and efficiencies [172]. Utilizing multiple nozzles improves the contact between the motive and suction fluids [173]. Therefore, a multi-nozzle ejector was designed to improve the ejector's performance. The new design utilized six nozzles, all the same diameter. The same nozzle area (An) of the initial design was used to calculate the nozzle diameters for the new design. Eq. 3.6.17 and 3.6.18 show the calculated for the new nozzle diameters.

$$
\begin{gathered}
A_{n_{\text {new }}}=\frac{A_{n_{\text {initial }}}}{\# \text { nozzles }} \\
D_{n_{\text {new }}}=\sqrt{\frac{A_{n_{\text {new }} * 4}}{\pi}}
\end{gathered}
$$

The new $D_{m}$ was set at $4 \mathrm{~mm}(0.157$ in) to ensure streams from all nozzles would enter the chamber without interference. Other parameters, such as $\mathrm{L}_{\mathrm{m}}, \mathrm{L}_{\mathrm{d}}$, and $\theta_{\mathrm{d}}$ were then calculated based on recommendations found in literature [122] [124] [126] [129]. These recommendations that were used for the new multi-nozzle design are summarized in Table 3.6-2. The water and air inlets were designed to accommodate $9.5 \mathrm{~mm}$ (3/8 in) PTFE tubing.

Table 3.6-2: Multi-nozzle ejector recommended design parameters.

\begin{tabular}{|c|c|}
\hline Included Diffuser Angle & $\theta_{d}<14^{\circ}$ \\
\hline Included Nozzle Angle & $20^{\circ} \leq \theta_{n} \leq 16^{\circ}$ \\
\hline $\begin{array}{c}\text { Mixing Chamber Length to } \\
\text { Diameter Ratio }\end{array}$ & $\frac{L_{m}}{D_{m}}=6$ \\
\hline $\begin{array}{c}\text { Diffuser Length to Mixing Chamber } \\
\text { Diameter Ratio }\end{array}$ & $\frac{A_{d}}{A_{m}}<5$ \\
\hline
\end{tabular}

\section{Laboratory Testing}

A 3D model of the multi-nozzle ejector was drawn in SOLIDWORKS ${ }^{\mathrm{TM}}$. However, unlike the initial design, it was drawn as three different components (nozzle, water inlet, and air inlet/mixing 
chamber/diffuser). All three components were printed using the same 3D printer as for the initial design and then assembled.

Five experimental tests were conducted where the water pressure was held constant at around 207, $276,310,379$, and $448 \mathrm{kPa}(30,40,45,55$, and $65 \mathrm{psig})$ for the respective tests. The air suction pressure was controlled, similarly to the testing of the initial design, using a valve at the air inlet. The air volumetric flowrate was calculated using Eq. 3.6.15. The same test conducted for the initial ejector design, where the suction pressure remained constant and the water pressure was varied, was then conducted with the multi-nozzle ejector. However, for this test, the water pressure was increased from around 69 to $483 \mathrm{kPa}$ (10 to $70 \mathrm{psig}$ ) in increments of $69 \mathrm{kPa}$ (10 psig).

\section{CFD Modelling}

The multi-nozzle ejector was also modelled in the computational fluid dynamic (CFD) software, ANSYS $^{\circledR}$ FLUENT $^{\circledR}$. The operational points of interest achieved in the laboratory testing were modeled and the air mass flowrate and water volumetric flowrate were calculated and recorded for each point. The air and water temperatures and pressures were used as input parameters for the model boundary conditions. The model utilized the Volume of Fluid (VOF) Multiphase model. The VOF model calculates and tracks the volume fraction of the two fluids throughout the domain using Eq. 3.6.18. The volume fraction equation was solved for the secondary phase (air) and the primary phase was calculated based on the constraint shown as Eq. 3.6.19. The Implicit Scheme (Eq. 3.6.20) was used to for time discretization. Eq. 3.6.21 shows the momentum equation solved throughout the domain for the VOF model. The Interface Modelling option corresponding to the VOF model was set to "Sharp/Dispersed" as this option was found to give results most similar to experimental results. These VOF equations as well as other equations and information related to the VOF model can be found in section 16.3 of the ANSYS $^{\circledR}$ FLUENT $^{\circledR}$ Theory Guide [174].

$$
\frac{1}{\rho_{q}}\left[\frac{\partial}{\partial t}\left(\alpha_{q} \rho_{q}+\nabla \cdot\left(\alpha_{q} \rho_{q} \vec{v}_{q}\right)=\sum_{p=1}^{n}\left(\dot{m}_{p q}-\dot{m}_{q p}\right)\right)\right]
$$

Where $\dot{m}_{q p}$ is the mass transfer from phase $q$ to phase $p$ and $\dot{m}_{p q}$ is the mass transfer from phase $p$ to phase $q$, and $\alpha$ is the volume fraction in the cell.

$$
\begin{gathered}
\sum_{q=1}^{n} \alpha_{q}=1 \\
\frac{\alpha_{q}^{n+1} \rho_{q}^{n+1}-\alpha_{q}^{n} \rho_{q}^{n}}{\Delta t} V+\sum_{f}\left(\rho_{q}^{n+1} U_{f}^{n+1} \alpha_{q, f}^{n+1}\right)=\left[\sum_{p=1}^{n}\left(\dot{m}_{p q}-\dot{m}_{q p}\right)\right] V
\end{gathered}
$$


Where $\alpha_{q, f}$ is the face value of the $q^{\text {th }}$ volume fraction, $V$ is the volume of the cell, and $U_{f}$ is the volume flux through the face.

$$
\frac{\partial}{\partial t}(\rho \vec{v})+\nabla \cdot(\rho \vec{v} \vec{v})=-\nabla p+\nabla \cdot\left[\mu\left(\nabla \vec{v}+\nabla \vec{v}^{T}\right]+\rho \vec{g}+\vec{F}\right.
$$

The Realizable k-epsilon turbulence model was used for turbulence modelling [175]. The transport equations utilized in the Realizable k-epsilon model are shown in Eqs. 3.6.21 and 3.6.22. More information this turbulence model can be found in section 4.3.3 of the ANSYS ${ }^{\circledR}$ FLUENT $^{\circledR}$ Theory $^{\circ}$ Guide [174].

$$
\begin{gathered}
\frac{\partial}{\partial t}(\rho k)+\frac{\partial}{\partial x_{j}}\left(\rho k u_{j}\right)=\frac{\partial}{\partial x_{j}}\left[\left(\mu+\frac{\mu_{t}}{\sigma_{k}}\right) \frac{\partial k}{\partial x_{j}}\right]+G_{k}+G_{b}-\rho \epsilon-Y_{M}+S_{k} \quad \text { Eq. 3.6.22 } \\
\frac{\partial}{\partial t}(\rho \epsilon)+\frac{\partial}{\partial x_{j}}\left(\rho \epsilon u_{j}\right)=\frac{\partial}{\partial x_{j}}\left[\left(\mu+\frac{\mu_{t}}{\sigma_{\epsilon}}\right) \frac{\partial \epsilon}{\partial x_{j}}\right]+\rho C_{1} S_{\epsilon}+\rho C_{2} \frac{\epsilon^{2}}{k+\sqrt{v \epsilon}}+C_{1 \epsilon} \frac{\epsilon}{k} C_{3 \epsilon} G_{b}+S_{\epsilon} \text { Eq. 3.6.23 } \\
\text { where, } C_{1}=\max \left[0.43, \frac{\eta}{\eta+5}\right], \eta=S \frac{k}{\epsilon}, \quad S=\sqrt{2 S_{i j} S_{i j}}
\end{gathered}
$$

Where $G_{k}$ is the turbulence kinetic energy due to the mean velocity gradients, $G_{b}$ is the generation of turbulence kinetic energy due to buoyancy, $Y_{M}$ is the contribution of the fluctuating dilatation in compressible turbulence to the overall dissipation rate, $\sigma_{k}$ and $\sigma_{\epsilon}$ are the turbulent Prandtl numbers for $k$ and $\epsilon$, respectively, $C_{2}$ and $C_{l \epsilon}$ are constants, and $S_{k}$ and $S \epsilon$ are user defined source terms.

The pressure-based solver was used in a segregated manner using the SIMPLE Algorithm, which is discussed in section 18.4.3 of the ANSYS ${ }^{\circledR}$ FLUENT $^{\circledR}$ Theory Guide [174].

The CFD model was used to simulate multiple experimental points. The experimental results were then used to validate the model. The flow ratio, $\mathrm{M}$, was calculated for both the experimental results and the modelled results. The air volumetric flowrate was also calculated using Eq. 3.6.15. The flow ratios along with the air mass and volumetric flowrates were used for comparison of the experimental results to the model, using Eq. 3.6.24.

$$
\% \text { Difference }=\frac{M_{\text {experimental }}-M_{\text {model }}}{\left(M_{\text {experimental }}+M_{\text {model }}\right) / 2} \times 100
$$

Once the model was verified, it was used to calculate the air mass flowrate and water volumetric flowrate when the water pressure was set to $689.5 \mathrm{kPa}$ (100 psig) and $1034.2 \mathrm{kPa}(150 \mathrm{psig})$. Since 
the results showed that the ejector was capable of sampling air at a flowrate greater than the required flowrate, a scale-down factor was calculated based on the results from the model with the water pressure set to $689.5 \mathrm{kPa}(100 \mathrm{psig})$, using the flow ratio $(\mathrm{M})$, water flowrate $\left(\mathrm{Q}_{\mathrm{w}}\right)$, required air volumetric flowrate $\left(Q_{a_{\text {required }}}\right)$, and nozzle diameter $\left(D_{n}\right)$. Scaling down the ejector geometry was intended to allow for an air flowrate closer to the required flowrate with less water consumption. Eq. 3.6.25 through Eq. 3.6.28 were used for these calculations, where $A_{n}$ was the total area of all six nozzles in the current design, $\mathrm{Q}_{w_{n e w}}, A_{n_{n e w}}$, and $D_{n_{n e w}}$ were the new water flowrate, nozzle area, and nozzle diameter after the ejector was scaled down, respectively, SDF was the scale down factor, and $\mathrm{D}_{\mathrm{n}}$ was the nozzle diameter of the current design.

$$
\begin{gathered}
Q_{w_{\text {new }}}=\frac{Q_{a_{\text {required }}}}{M} \\
A_{n_{\text {new }}}=A_{\text {total }} * \frac{Q_{w_{\text {new }}}}{Q_{w}} \\
D_{n_{\text {new }}}=\sqrt{\frac{4 * \frac{A_{n_{\text {new }}}}{6}}{\pi}} \\
S D F=\frac{D_{n_{\text {new }}}}{D_{n}}
\end{gathered}
$$

The SDF was applied to the geometry of the current design and then the CFD model was used to calculate results for the new scaled-down geometry. 


\subsection{Results and Discussion}

\subsection{Filtration}

Flowrate Effects

Table 4.1-1 and Figure 4.1-1 show the effects of flowrate on the pressure drop across all three filters. The effect of flowrate on Filter 1 is greater than for Filters 2 and 3 as shown by the greater slope of the trendline.

Table 4.1-1: Effects of flowrate on the pressure drop across filters.

\begin{tabular}{|c|c|c|c|c|}
\hline \multirow{2}{*}{ Filter \# } & \multicolumn{4}{|c|}{ Pressure Drop at Various Flowrates [in $\left.\mathrm{H}_{2} \mathrm{O}\right]$} \\
\cline { 2 - 5 } & 4 SLPM & 3 SLPM & 2 SLPM & 1 SLPM \\
\hline $\mathbf{1}$ & 1.041 & 0.655 & 0.341 & 0.126 \\
\hline $\mathbf{2}$ & 0.012 & 0.008 & 0.006 & 0.004 \\
\hline $\mathbf{3}$ & 0.032 & 0.022 & 0.015 & 0.008 \\
\hline
\end{tabular}

*Note 1 in $\mathrm{H}_{2} \mathrm{O}=0.03609$ psi

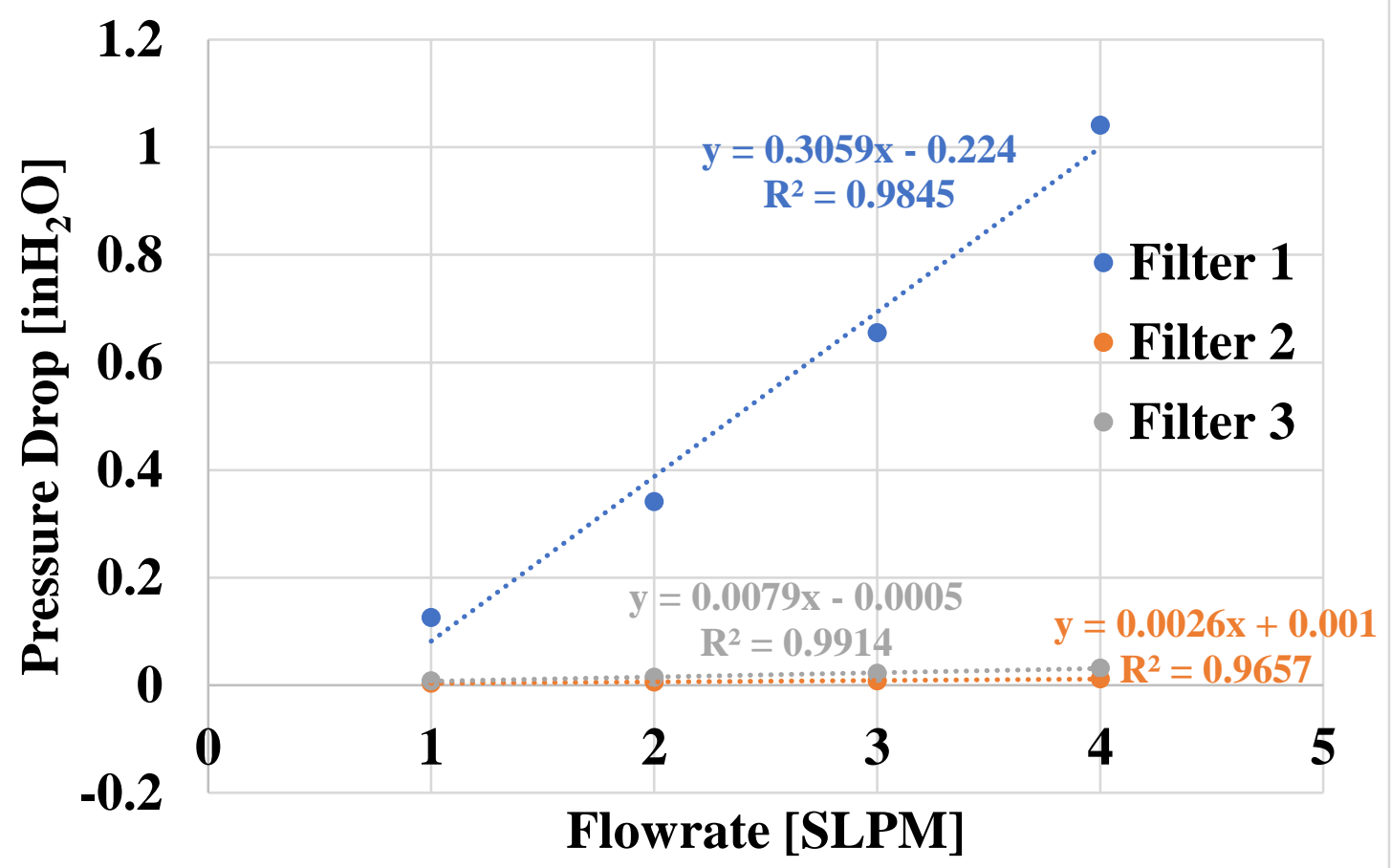

Figure 4.1-1: Effects of flowrate on the pressure drop across filters.

Coal Dust Loading

Tables 4.1-2 to 4.1-4 present the results from the coal dust loading tests for all three filters, respectively. Figure 4.1-2 shows the effects of coal loading on the pressure drop across all three filters at a flowrate of 3 SLPM. The coal loading effects were greater for Filter 1 than for Filters 2 
and 3 based on the greater slope, however, the pressure drop was primarily dependent on the flowrate. Therefore, the coal loading effects were considered negligible for all filters.

Table 4.1-2: Effects of coal dust loading for filter 1.

\begin{tabular}{|c|c|c|c|c|c|}
\hline Time & $\begin{array}{l}\text { Loading } \\
\quad[\mathrm{g}]\end{array}$ & $\begin{array}{c}\text { Pressure } \\
\text { @3.5 SLPM } \\
{\left[\mathrm{inH}_{2} \mathrm{O}\right]} \\
\end{array}$ & $\begin{array}{c}\text { Pressure } \\
\text { @ } 3 \text { SLPM } \\
{\left[\text { inH }_{2} \mathrm{O}\right]}\end{array}$ & $\begin{array}{c}\text { Pressure } \\
\text { @ } 2 \text { SLPM } \\
{\left[\mathrm{inH}_{2} \mathrm{O}\right]}\end{array}$ & $\begin{array}{c}\text { Pressure } \\
\text { @ 1 SLPM } \\
{\left[\mathrm{inH}_{2} \mathrm{O}\right]}\end{array}$ \\
\hline 1 day & 0.1 & 1.560 & 1.218 & 0.652 & 0.240 \\
\hline 1 week & 1 & 1.605 & 1.224 & 0.626 & 0.202 \\
\hline 2 weeks & 2 & 1.592 & 1.240 & 0.639 & 0.211 \\
\hline 3 weeks & 3 & 1.625 & 1.267 & 0.670 & 0.222 \\
\hline 4 weeks & 4 & 1.707 & 1.348 & 0.721 & 0.249 \\
\hline
\end{tabular}

Table 4.1-3: Effects of coal dust loading for filter 2.

\begin{tabular}{|c|c|c|c|c|c|}
\hline Time & $\begin{array}{c}\text { Loading } \\
{[\mathrm{g}]}\end{array}$ & $\begin{array}{c}\text { Pressure } \\
\text { @3.5 SLPM } \\
{\left[\mathrm{inH} \mathrm{H}_{2} \mathrm{O}\right]} \\
\end{array}$ & $\begin{array}{c}\text { Pressure } \\
\text { @ } 3 \text { SLPM } \\
{\left[\mathrm{inH}_{2} \mathrm{O}\right]} \\
\end{array}$ & $\begin{array}{c}\text { Pressure } \\
\text { @2 SLPM } \\
{\left[\mathrm{in} \mathrm{H}_{2} \mathrm{O}\right]}\end{array}$ & $\begin{array}{c}\text { Pressure } \\
\text { @ 1 SLPM } \\
{\left[\mathrm{inH}_{2} \mathrm{O}\right]} \\
\end{array}$ \\
\hline 1 day & 0.1 & 0.010 & 0.008 & 0.005 & 0.003 \\
\hline 1 week & 1 & 0.012 & 0.010 & 0.006 & 0.003 \\
\hline 2 weeks & 2 & 0.013 & 0.011 & 0.007 & 0.003 \\
\hline 3 weeks & 3 & 0.027 & 0.023 & 0.015 & 0.007 \\
\hline 4 weeks & 4 & 0.037 & 0.031 & 0.020 & 0.010 \\
\hline
\end{tabular}

Table 4.1-4: Effects of coal dust loading for filter 3.

\begin{tabular}{|c|c|c|c|c|c|}
\hline Time & $\begin{array}{l}\text { Loading } \\
\text { [g] }\end{array}$ & $\begin{array}{c}\text { Pressure } \\
\text { @3.5 SLPM } \\
{\left[\mathrm{inH}_{2} \mathrm{O}\right]} \\
\end{array}$ & $\begin{array}{c}\text { Pressure } \\
\text { @3 SLPM } \\
{\left[\mathrm{inH}_{2} \mathrm{O}\right]} \\
\end{array}$ & $\begin{array}{c}\text { Pressure } \\
\text { @ } 2 \text { SLPM } \\
{\left[\mathrm{in} \mathrm{H}_{2} \mathrm{O}\right]}\end{array}$ & $\begin{array}{c}\text { Pressure } \\
\text { @ } 1 \mathrm{SLPM} \\
{\left[\mathrm{inH}_{2} \mathrm{O}\right]} \\
\end{array}$ \\
\hline 1 day & 0.1 & 0.028 & 0.022 & 0.014 & 0.006 \\
\hline 1 week & 1 & 0.043 & 0.035 & 0.022 & 0.010 \\
\hline 2 weeks & 2 & 0.052 & 0.043 & 0.027 & 0.013 \\
\hline 3 weeks & 3 & 0.082 & 0.067 & 0.043 & 0.020 \\
\hline 4 weeks & 4 & 0.138 & 0.115 & 0.074 & 0.036 \\
\hline
\end{tabular}




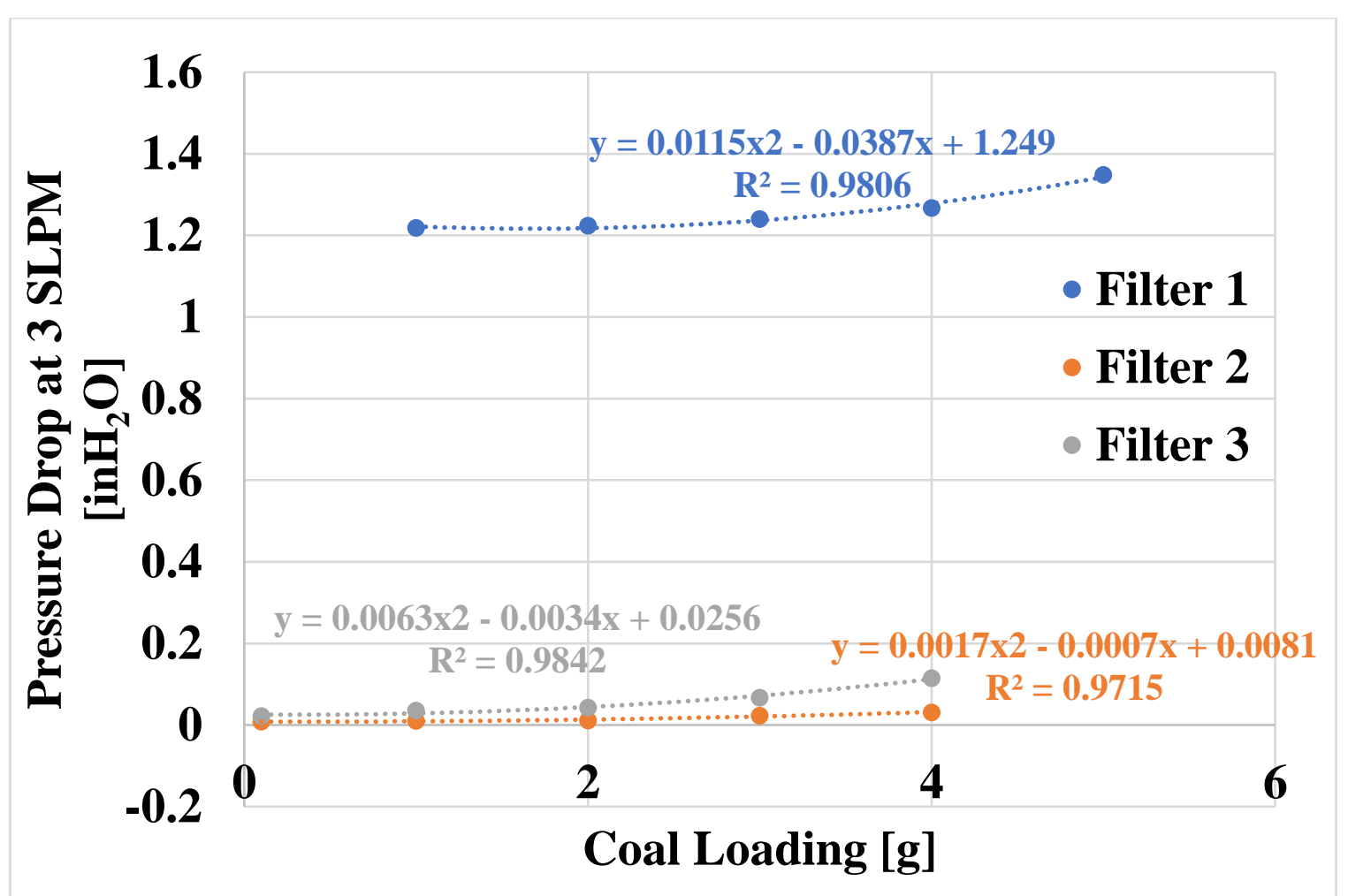

Figure 4.1-2: Pressure drop due to coal loading for three filters at 3 SLPM.

Moisture (Water) Loading

Tables 4.1-5 to 4.1-7 present the results of the water loading tests for all three filters, respectively.

Figure 4.1-3 shows the effects of water loading on the pressure drop across all three filters at a flowrate of 3 SLPM. Like for the coal loading scenarios, the water loading effects were greater for Filter 1 than for Filters 2 and 3 based on the greater slope, however, all water loading effects were considered negligible.

Table 4.1-5: Effects of moisture loading for filter 1.

\begin{tabular}{|c|c|c|c|c|}
\hline $\begin{array}{c}\text { Loading } \\
\text { [g] }\end{array}$ & $\begin{array}{c}\text { Pressure } \\
\text { @ 3.5 SLPM } \\
{\left[\mathbf{i n H}_{2} \mathbf{O}\right]}\end{array}$ & $\begin{array}{c}\text { Pressure } \\
\text { @ 3 SLPM } \\
{\left[\mathbf{i n H}_{\mathbf{2}} \mathbf{O}\right]}\end{array}$ & $\begin{array}{c}\text { Pressure } \\
\text { @ 2 SLPM } \\
{\left[\mathbf{i n H}_{2} \mathbf{O}\right]}\end{array}$ & $\begin{array}{c}\text { Pressure } \\
\text { @ 1 SLPM } \\
{\left[\mathbf{i n H}_{\mathbf{2}} \mathbf{O}\right]}\end{array}$ \\
\hline $\mathbf{0}$ (dry) & 1.543 & 1.218 & 0.624 & 0.196 \\
\hline $\mathbf{0 . 1}$ & 1.607 & 1.216 & 0.644 & 0.199 \\
\hline $\mathbf{0 . 4}$ & 1.616 & 1.219 & 0.633 & 0.208 \\
\hline $\mathbf{1 . 8}$ & 1.643 & 1.231 & 0.639 & 0.206 \\
\hline
\end{tabular}


Table 4.1-6: Effects of moisture loading for filter 2.

\begin{tabular}{|c|c|c|c|c|}
\hline $\begin{array}{c}\text { Loading } \\
\text { [g] }\end{array}$ & $\begin{array}{c}\text { Pressure } \\
\text { @3.5 SLPM } \\
{[\text { inH } \mathbf{2} \text { ] }]}\end{array}$ & $\begin{array}{c}\text { Pressure } \\
\text { @3 3LPM } \\
{\left[\text { inH }_{\mathbf{2}} \mathbf{O}\right]}\end{array}$ & $\begin{array}{c}\text { Pressure } \\
\text { @2 SLPM } \\
{\left[\mathbf{i n H}_{2} \mathbf{O}\right]}\end{array}$ & $\begin{array}{c}\text { Pressure } \\
\text { @ 1 SLPM } \\
{\left[\mathbf{i n H}_{2} \mathbf{O}\right]}\end{array}$ \\
\hline $\mathbf{0}$ (dry) & 0.010 & 0.008 & 0.005 & 0.002 \\
\hline $\mathbf{0 . 1}$ & 0.010 & 0.008 & 0.005 & 0.002 \\
\hline $\mathbf{0 . 5}$ & 0.010 & 0.008 & 0.005 & 0.002 \\
\hline $\mathbf{1 . 8}$ & 0.011 & 0.009 & 0.006 & 0.002 \\
\hline
\end{tabular}

Table 4.1-7: Effects of moisture loading for filter 3.

\begin{tabular}{|c|c|c|c|c|}
\hline $\begin{array}{c}\text { Loading } \\
{[\mathrm{g}]}\end{array}$ & $\begin{array}{c}\text { Pressure } \\
\text { @ 3.5 SLPM } \\
{[\text { inH } \mathbf{O} \text { ] }}\end{array}$ & $\begin{array}{c}\text { Pressure } \\
\text { @ 3 SLPM } \\
{\left[\mathbf{i n H}_{\mathbf{2}} \mathbf{O}\right]}\end{array}$ & $\begin{array}{c}\text { Pressure } \\
\text { @ 2 SLPM } \\
{\left[\mathbf{i n H}_{2} \mathbf{O}\right]}\end{array}$ & $\begin{array}{c}\text { Pressure } \\
\text { @ 1 SLPM } \\
{\left[\mathbf{i n H}_{\mathbf{2}} \mathbf{O}\right]}\end{array}$ \\
\hline $\mathbf{0}(\mathbf{d r y})$ & 0.057 & 0.047 & 0.030 & 0.014 \\
\hline $\mathbf{0 . 1}$ & 0.056 & 0.046 & 0.029 & 0.013 \\
\hline $\mathbf{0 . 4}$ & 0.055 & 0.046 & 0.030 & 0.014 \\
\hline $\mathbf{1 . 8}$ & 0.068 & 0.056 & 0.036 & 0.017 \\
\hline
\end{tabular}

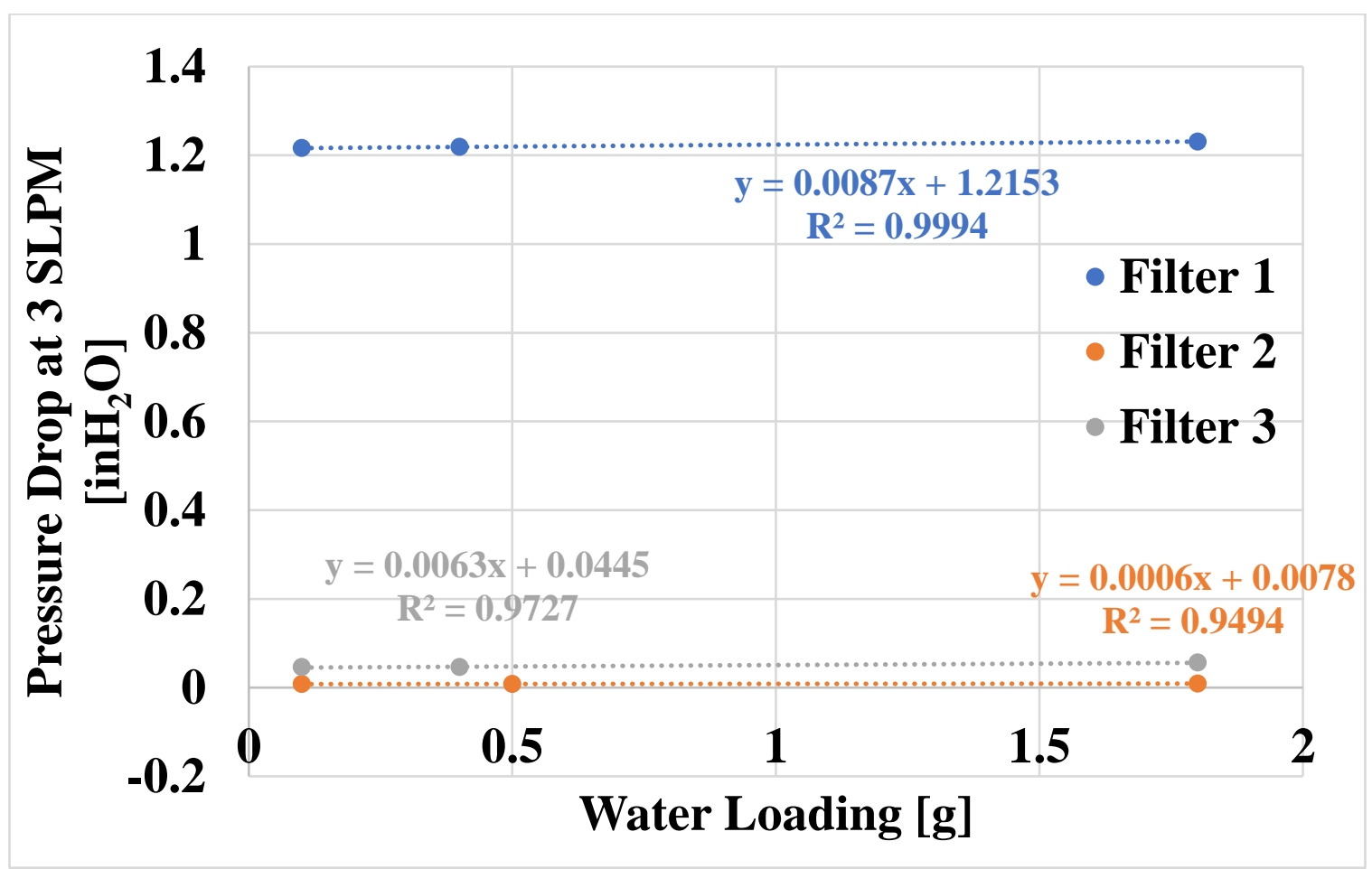

Figure 4.1-3: Pressure drop due to water loading for three filters at 3 SLPM 


\section{Filter Selection}

Overall, there seemed to be no significant coal dust loading, or moisture loading on the pressure drop across any of the three filters. The pressure drop was primarily dictated by the flowrate. Ultimately, Filter 3 was selected to be utilized in the MWS since it already came equipped in a metal housing which could protect the filter from direct impact of coal debris where coal is being cut and water from the sprayers on the shields. Figure 4.1-4 shows two images of Filter 3 with its housing.

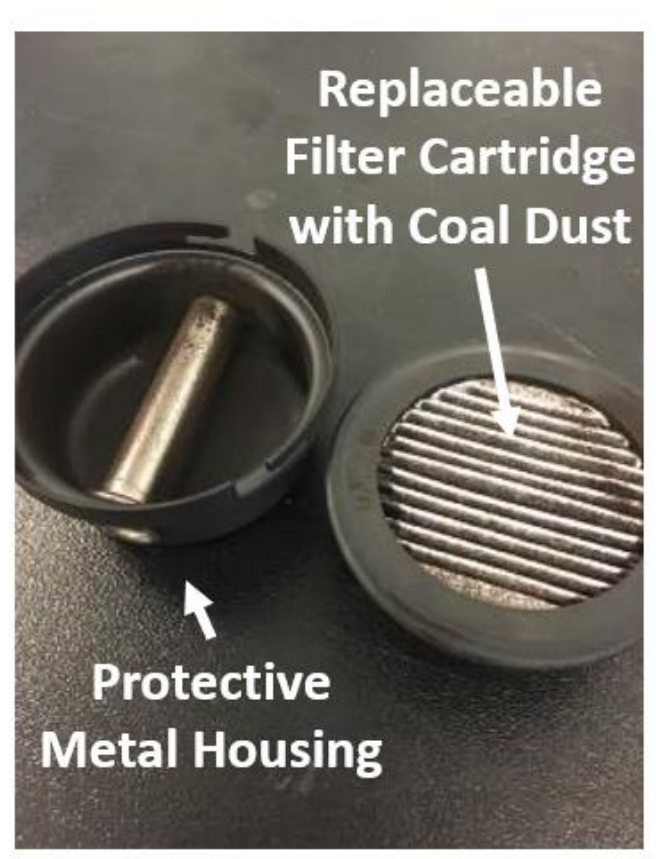

\section{Protective} Metal Housing

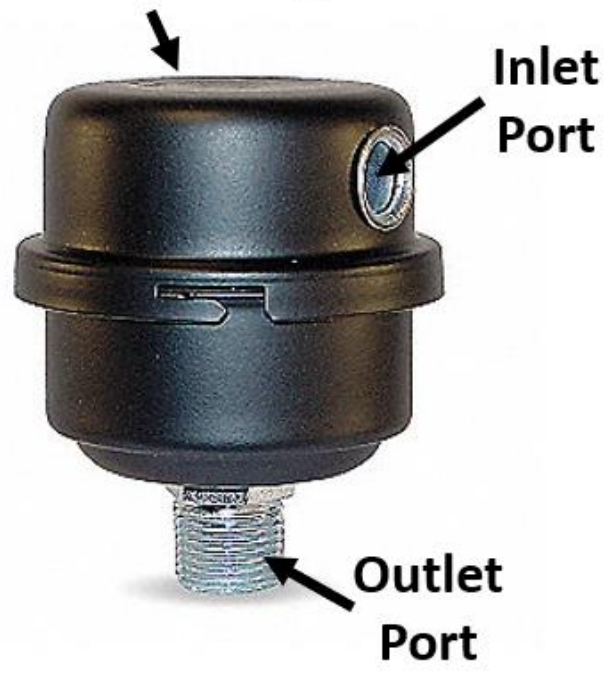

Figure 4.1-4: Filter 3 selected for use in the MWS.

\subsection{Sensor Calibrations and Verifications}

\section{Defining Error}

The equation used to calculate the percent error is shown in Eq. 4.2.1. For the UGGA and IRS, the "actual" value was the calculated $\mathrm{CH}_{4}$ concentration based on GD corrected values and the humidity corrections, and the "measured" value is the measured $\mathrm{CH}_{4}$ concentration. The "actual" values were the measurements taken by the Edgetech and Heise for the RH and pressure sensors, respectively. The "measured" values for the RH and pressure sensors were their respective measurements.

$$
\% \text { Error }=\left(\frac{\text { measured-actual }}{\text { actual }}\right) * 100
$$




\section{RH Sensors}

Figure 4.2-1 shows the results of the calibration test performed for the RH sensors from which the calibration equation was obtained. Calibration equations for all calibrations are shown in a red rectangle in the calibration plot.

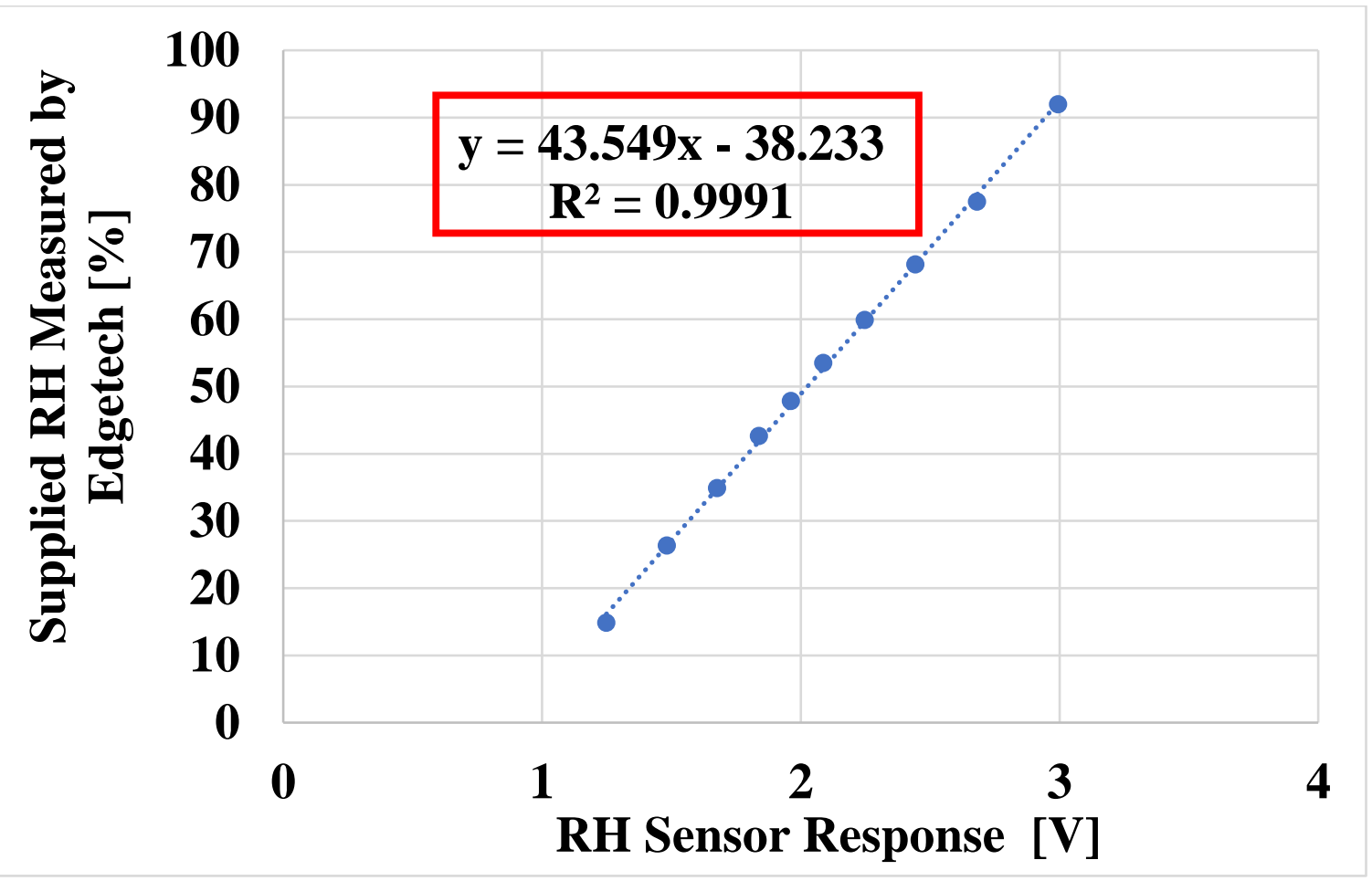

Figure 4.2-1: Calibration curve for the $\mathrm{RH}$ sensors at $23^{\circ} \mathrm{C}$ using the Edgetech as reference for RH supplied.

Figure 4.2-2 and Table 4.2-1 show the verification of the RH sensor calibration by comparing the measured values of the RH sensor to the measured values of the Edgetech. Percent error values are in Table 4.2-1. The average error was $2.7 \%$. The most significant error was at the lowest calibration point, which was not of great concern given the tendency of the mines to have higher RH due to water sprays. 


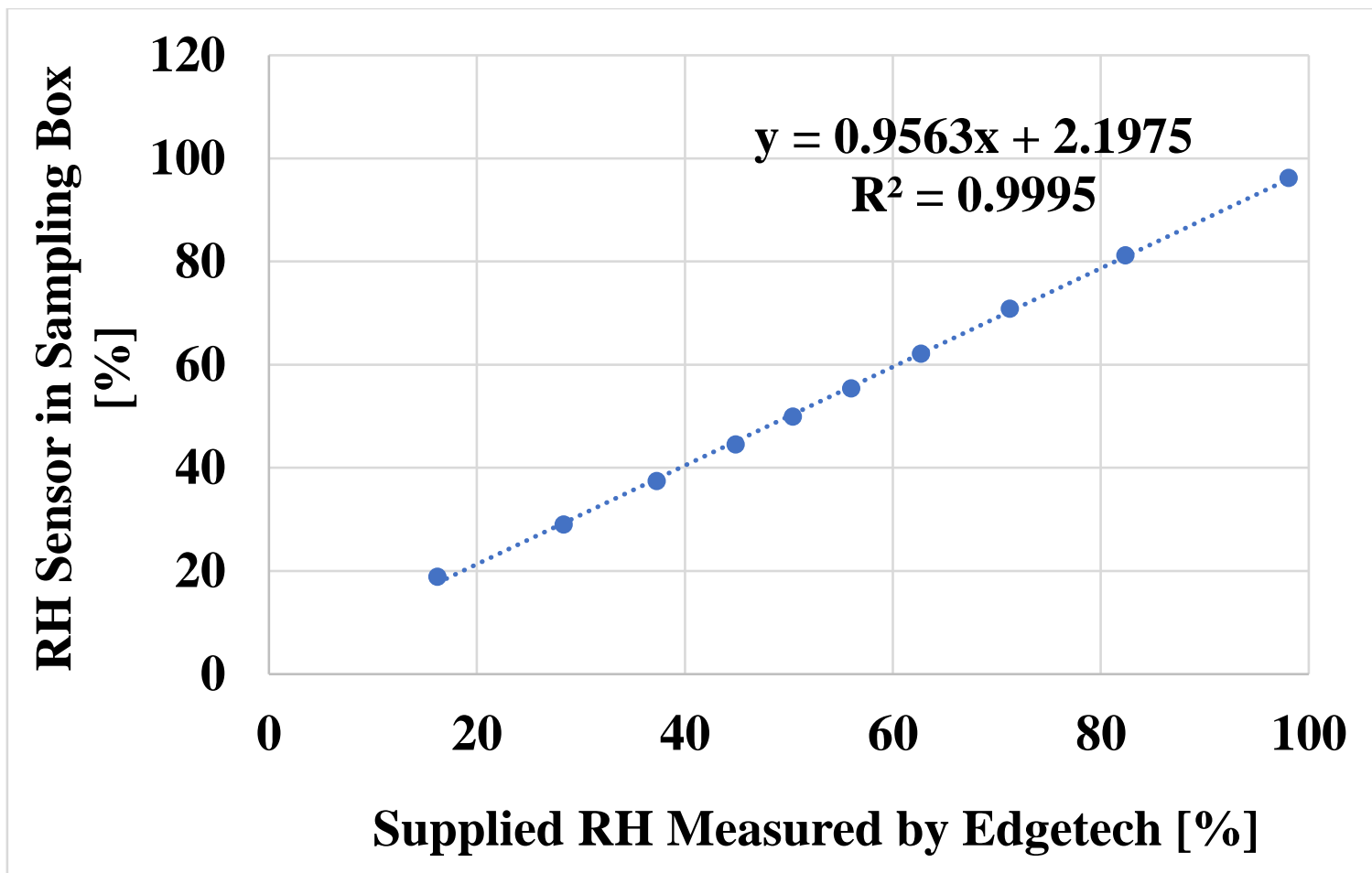

Figure 4.2-2: RH Sensor calibration verified with the Edgetech.

Table 4.2-1: $R H$ values reported by $R H$ sensor and compared to the Edgetech.

\begin{tabular}{|c|c|c|}
\hline RH Sensor [\%] & Edgetech RH [\%] & Error [\%] \\
\hline $\mathbf{1 8 . 9}$ & 16.2 & 16.6 \\
\hline $\mathbf{2 9 . 0}$ & 28.3 & 2.33 \\
\hline $\mathbf{3 7 . 4}$ & 37.3 & 0.353 \\
\hline $\mathbf{4 4 . 6}$ & 44.9 & 0.751 \\
\hline $\mathbf{4 9 . 9}$ & 50.4 & 0.955 \\
\hline $\mathbf{5 5 . 4}$ & 56.0 & 1.07 \\
\hline $\mathbf{6 2 . 1}$ & 62.7 & 0.910 \\
\hline $\mathbf{7 0 . 8}$ & 71.3 & 0.615 \\
\hline $\mathbf{8 1 . 2}$ & 82.4 & 1.40 \\
\hline $\mathbf{9 6 . 2}$ & 98.1 & 1.92 \\
\hline
\end{tabular}

\section{Pressure Sensors}

Figure 4.2-3 shows the results of the calibration test performed for the pressure sensors from which the calibration equation was obtained. 


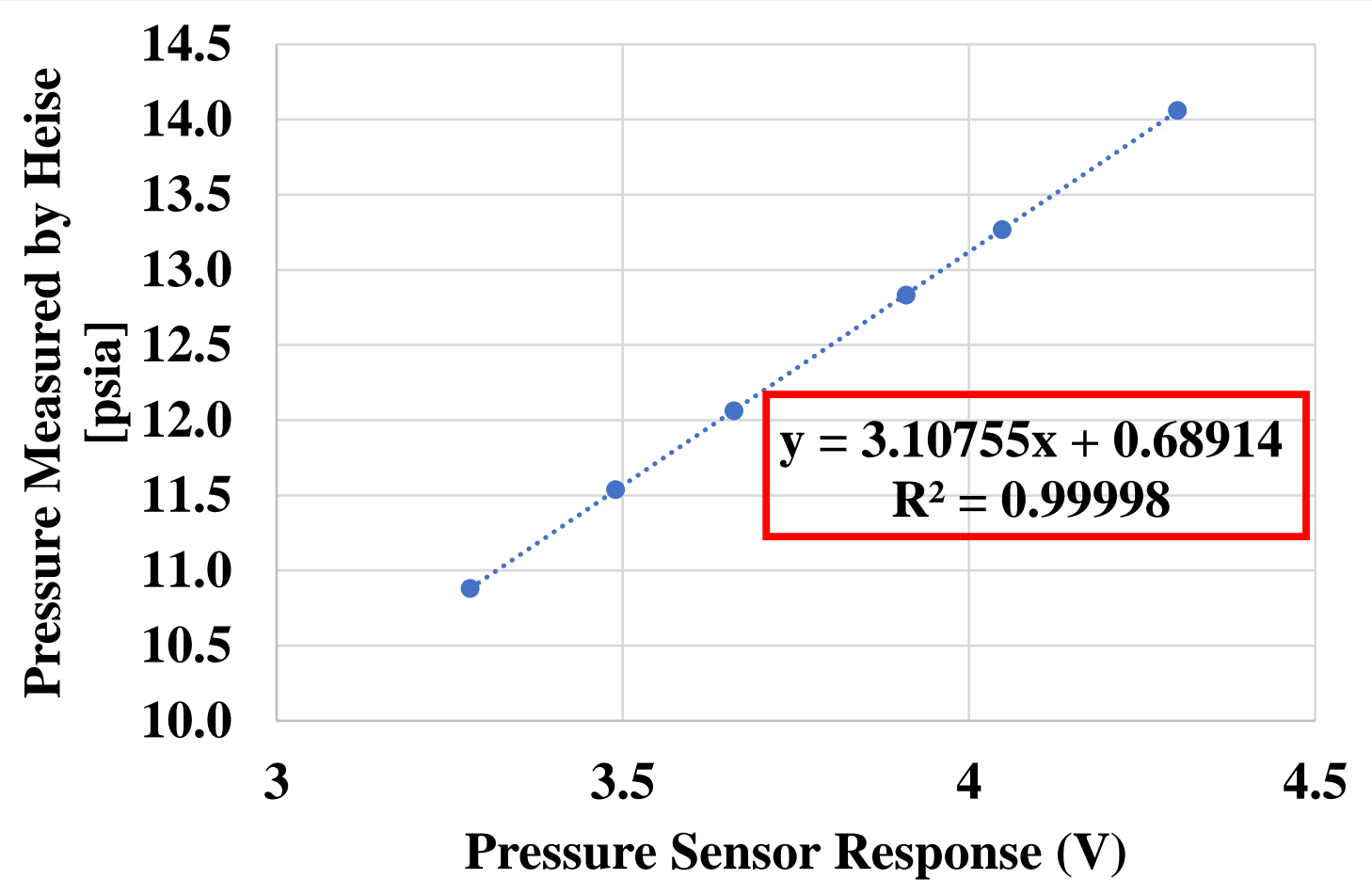

Figure 4.2-3: Calibration curve for the pressure sensors using Heise as static pressure reference.

Subsequent tests were conducted to verify the pressure sensor calibrations. Figure 4.2-4 and Table 4.2-2 show the verification of the pressure sensor calibration by comparing the measured values of the pressure sensor to the measured values of the Heise. Percent error values are presented in Table 4.2-2. The average error was $1.70 \%$ and the maximum error was $1.91 \%$, which was at the highest pressure calibration point. Therefore, all pressure calibration errors were within $\pm 2 \%$ accuracy, which was sufficient for our application. 


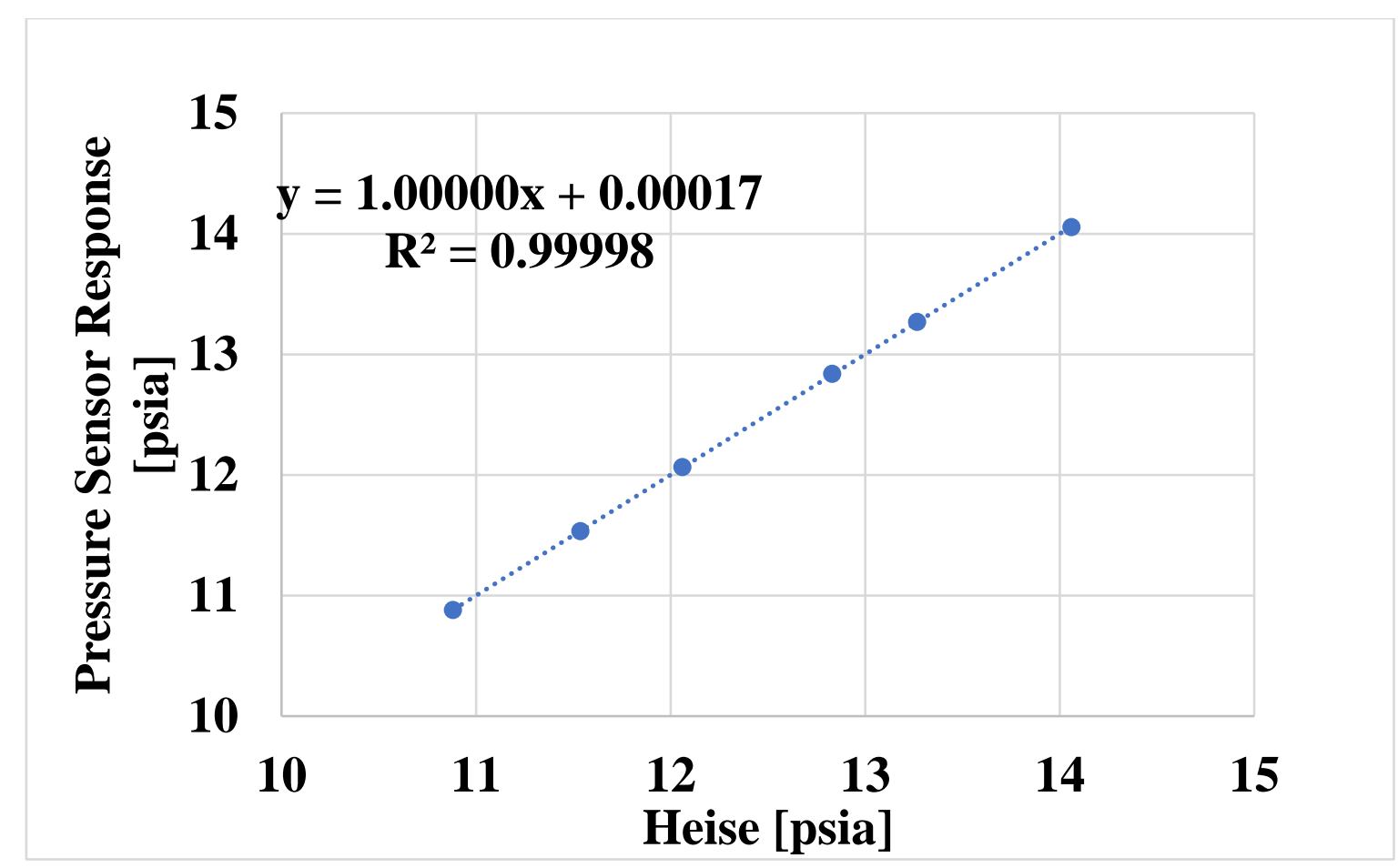

Figure 4.2-4: Pressure sensor calibration verification with Heise.

Table 4.2-2: Pressure sensor compared to Heise measurements.

\begin{tabular}{|c|c|c|}
\hline $\begin{array}{c}\text { Pressure Sensor } \\
{[\text { psia] }}\end{array}$ & $\begin{array}{c}\text { Heise } \\
{[\text { psia] }}\end{array}$ & $\begin{array}{c}\text { Error } \\
{[\%]}\end{array}$ \\
\hline $\mathbf{1 3 . 7 9}$ & 14.06 & 1.91 \\
\hline $\mathbf{1 3 . 0 3}$ & 13.27 & 1.79 \\
\hline $\mathbf{1 2 . 6 1}$ & 12.83 & 1.70 \\
\hline $\mathbf{1 1 . 8 6}$ & 12.06 & 1.64 \\
\hline $\mathbf{1 1 . 3 5}$ & 11.54 & 1.64 \\
\hline $\mathbf{1 0 . 7 1}$ & 10.88 & 1.54 \\
\hline
\end{tabular}

\section{$\mathrm{CH}_{4}$ Sensors}

\section{Climate and Flowrate Effects}

Figures 4.2-5 and 4.2-6 show the results of the three tests for the MOS and IRS, respectively. Temperature had a more significant effect on the MOS than the IRS, especially at lower $\mathrm{CH}_{4}$ concentrations. 


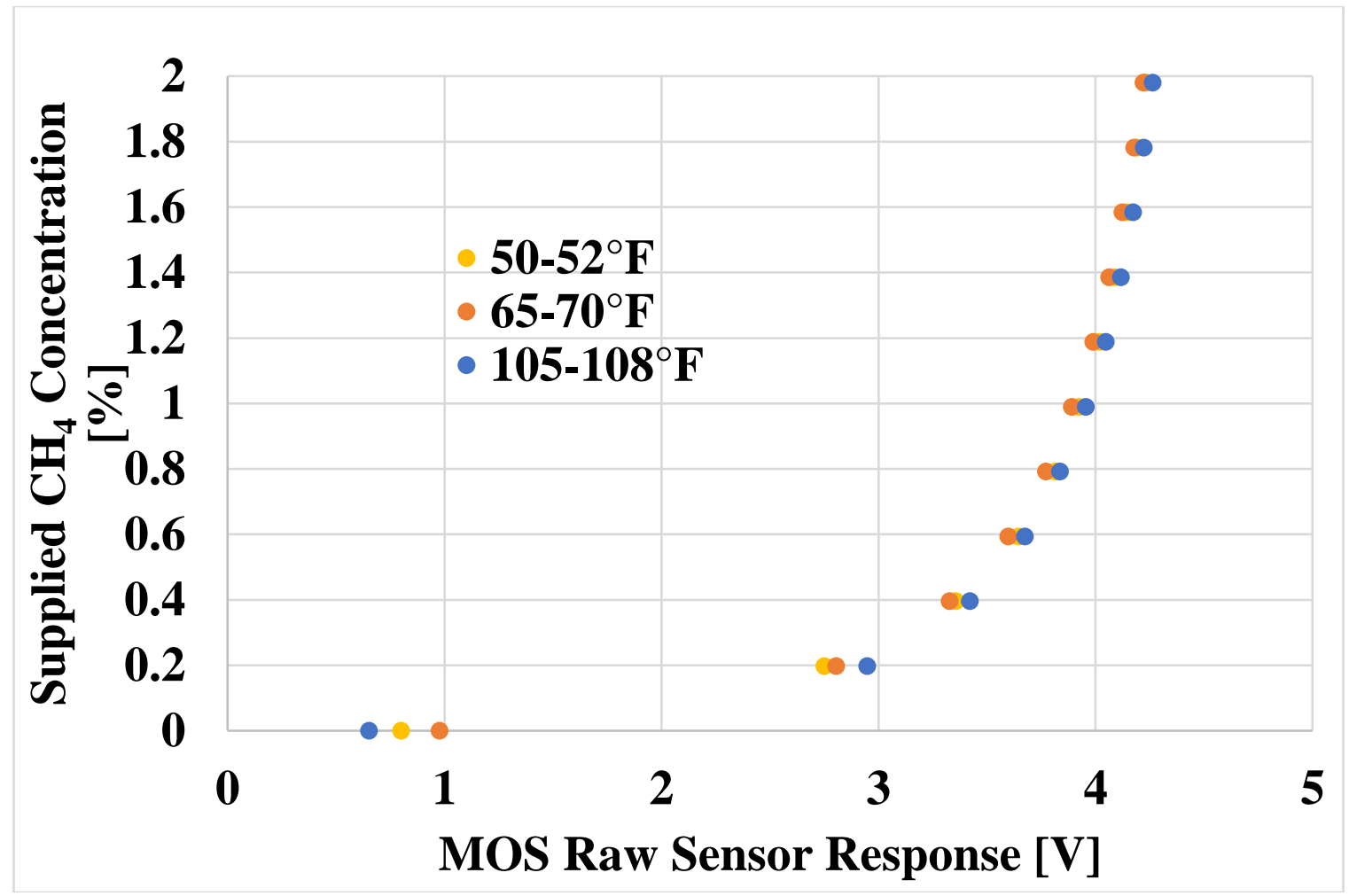

Figure 4.2-5: Initial testing to determine temperature effects on the MOS.

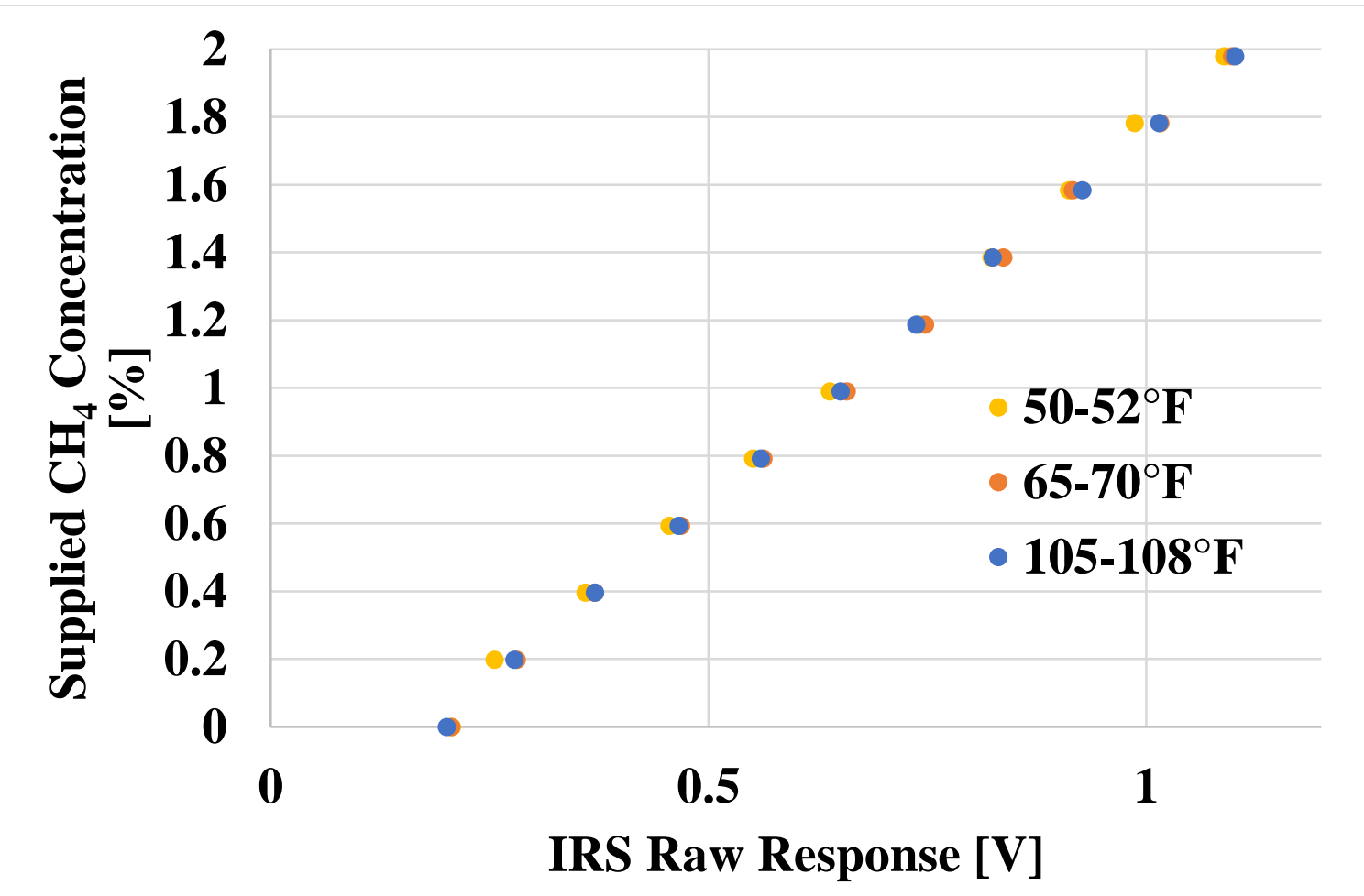

Figure 4.2-6: Initial testing to determine temperature effects on the IRS. 
Figure 4.2-7 shows the results of the humidity effect tests conducted for the MOS and IRS. A linear trendline was plotted for each data set in order to better show the RH effect on the sensors. A higher sloping line corresponded to a greater humidity effect. The MOS were more impacted by humidity than the IRS since the trendline for the MOS had a greater slope. Note that this test did not have any $\mathrm{CH}_{4}$ present. Due to the non-linear response of the MOS, climate effects are greater at lower $\mathrm{CH}_{4}$ concentrations. Therefore, the maximum effect of $\mathrm{RH}$ on the MOS sensors raw response occurred when no $\mathrm{CH}_{4}$ was present.

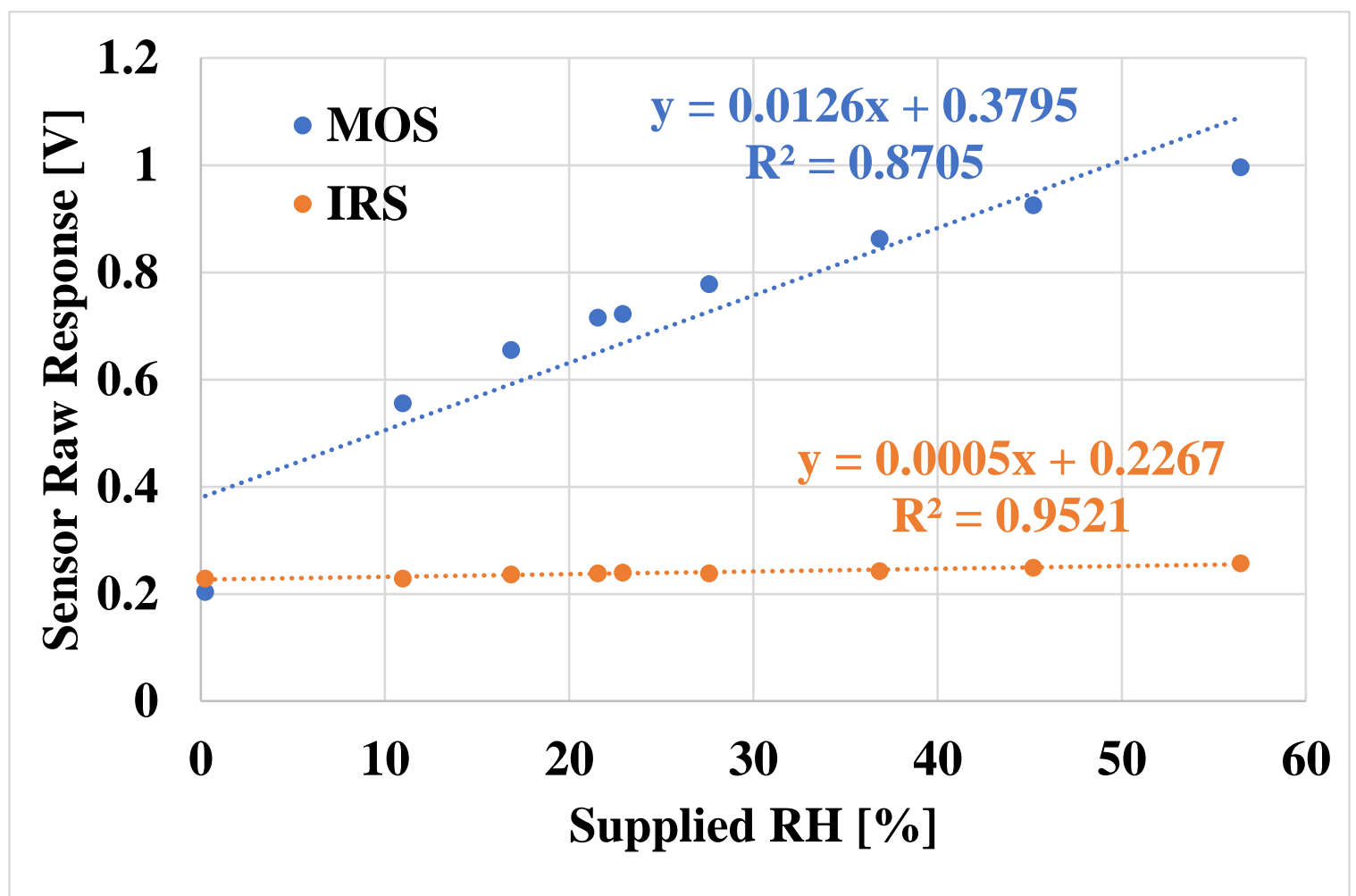

Figure 4.2-7: Humidity effects on MOS and IRS raw responses (no $\mathrm{CH}_{4}$ present).

Figure 4.2-8 shows the results from pressure effect test. Initial calibrations were applied to the sensors prior to this test, therefore the sensor response in percent $\mathrm{CH}_{4}$ was used to compare pressure effects. The IRS was more affected by pressure than the MOS. However, based on additional testing, the absolute pressure of the system when in operation should always be, at least, above $89.6 \mathrm{kPa}$ (13 psia) unless there was a major issue, such as a clogged sampling tube. Therefore, the plot has was "zoomed" into the area above $89.6 \mathrm{kPa}$ (13 psia) (Figure 4.2-9). From this new region of interest, it was determined that pressure effects could be neglected for both sensors. 


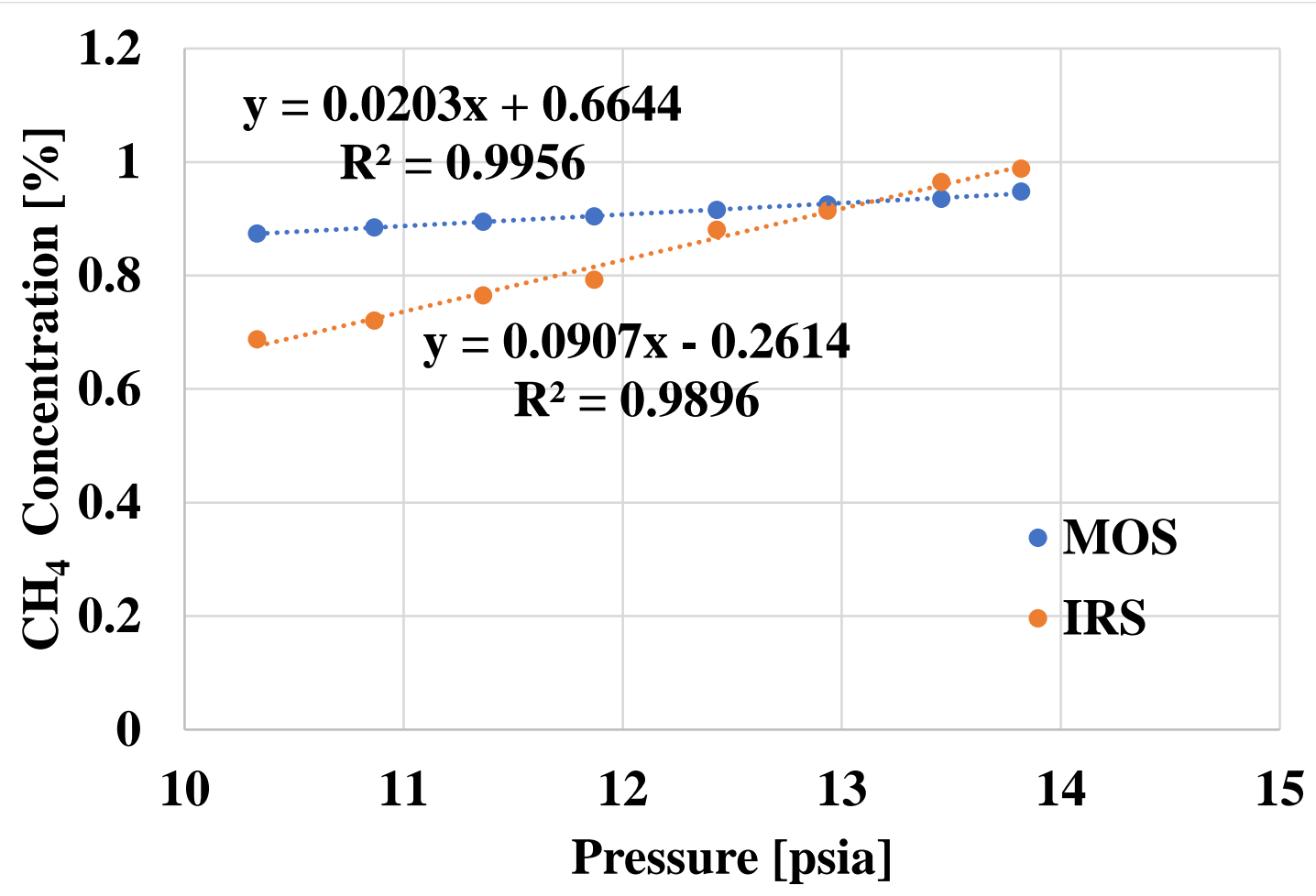

Figure 4.2-8: Pressure effects on MOS and IRS response with 1\% $\mathrm{CH}_{4}$ supplied.

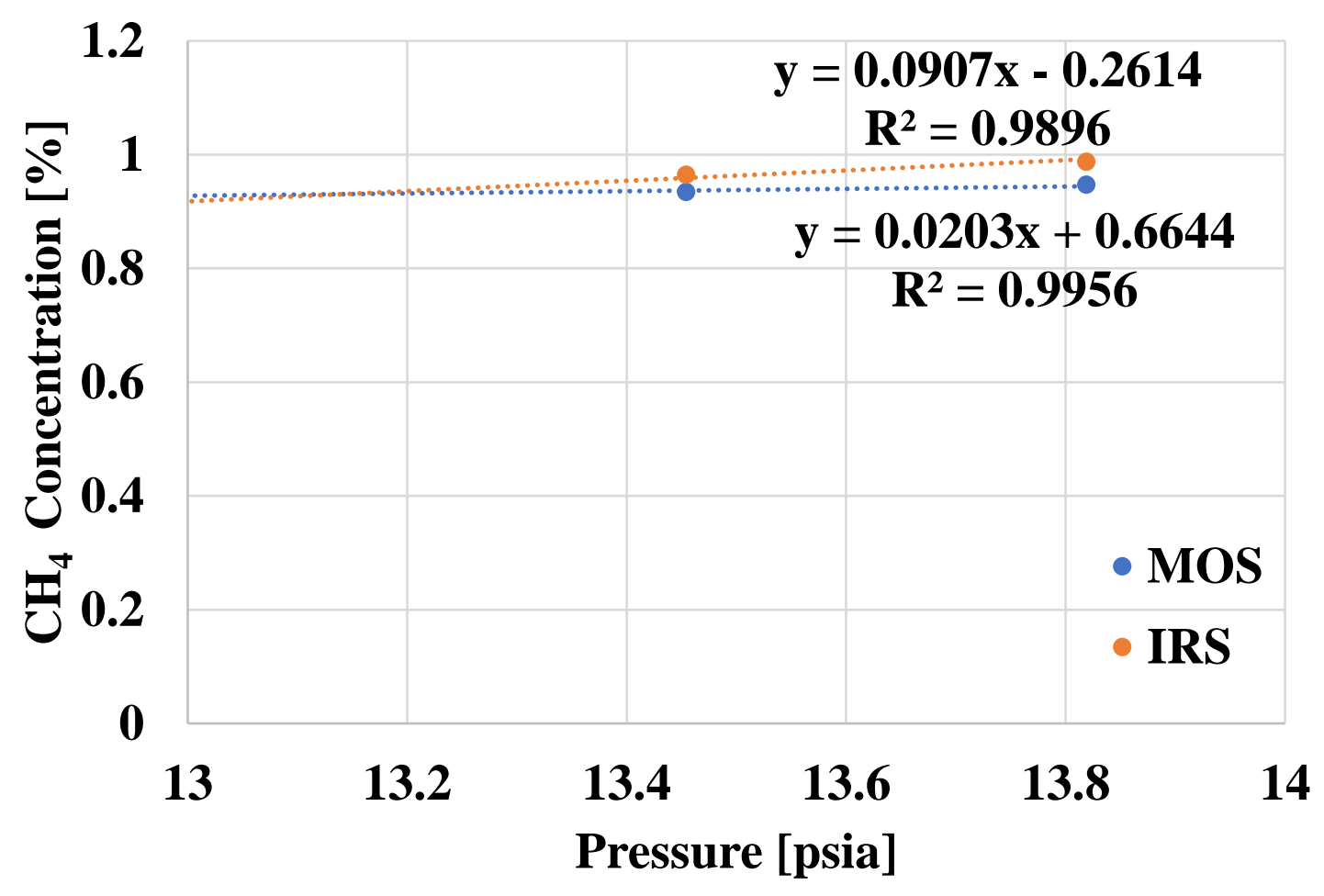

Figure 4.2-9: Pressure effects on MOS and IRS response zoomed in to expected minimum system pressure when in operation. 
Figure 4.2-10 shows the results for the flow rate effect test. Approximately $1 \% \mathrm{CH}_{4}$ was supplied at various flowrates. Neither of the sensors' responses were significantly affected by the sample flowrates between 1 and 3.5 SLPM ( 0.035 and $0.124 \mathrm{scfm})$. Trendlines have been added for each data set to show that the effect of the flowrate on sensor response was negligible; both trendline slopes are near zero.

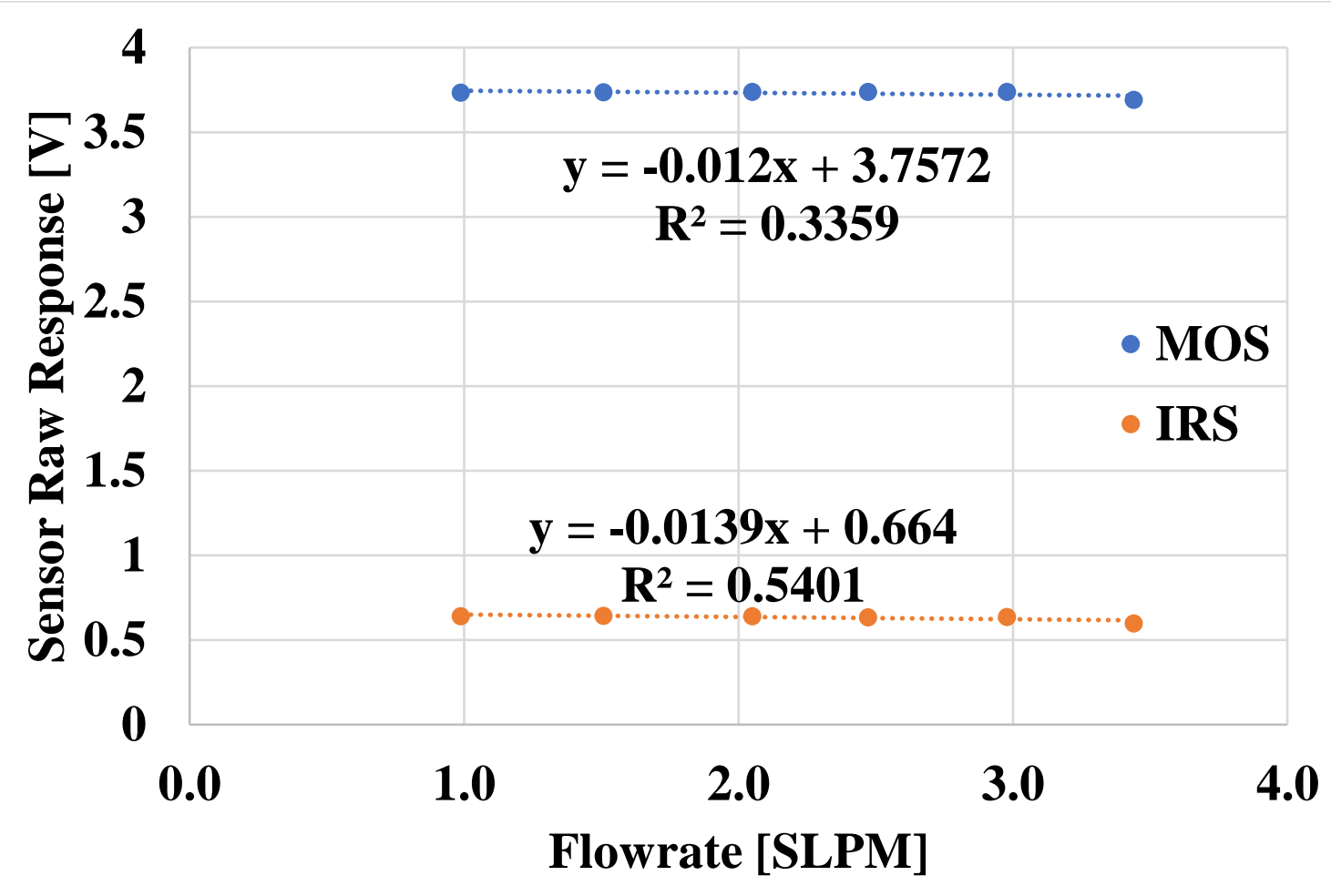

Figure 4.2-10: Flowrate effects on MOS and IRS raw responses with $\sim 1 \% \mathrm{CH}_{4}$ supplied. IRS Calibrations

Figure 4.2-11 shows an example of a calibration curve for an IRS where the dry calibration equation is shown in the red rectangle. Note this calibration was performed for all ten IRS individually. 


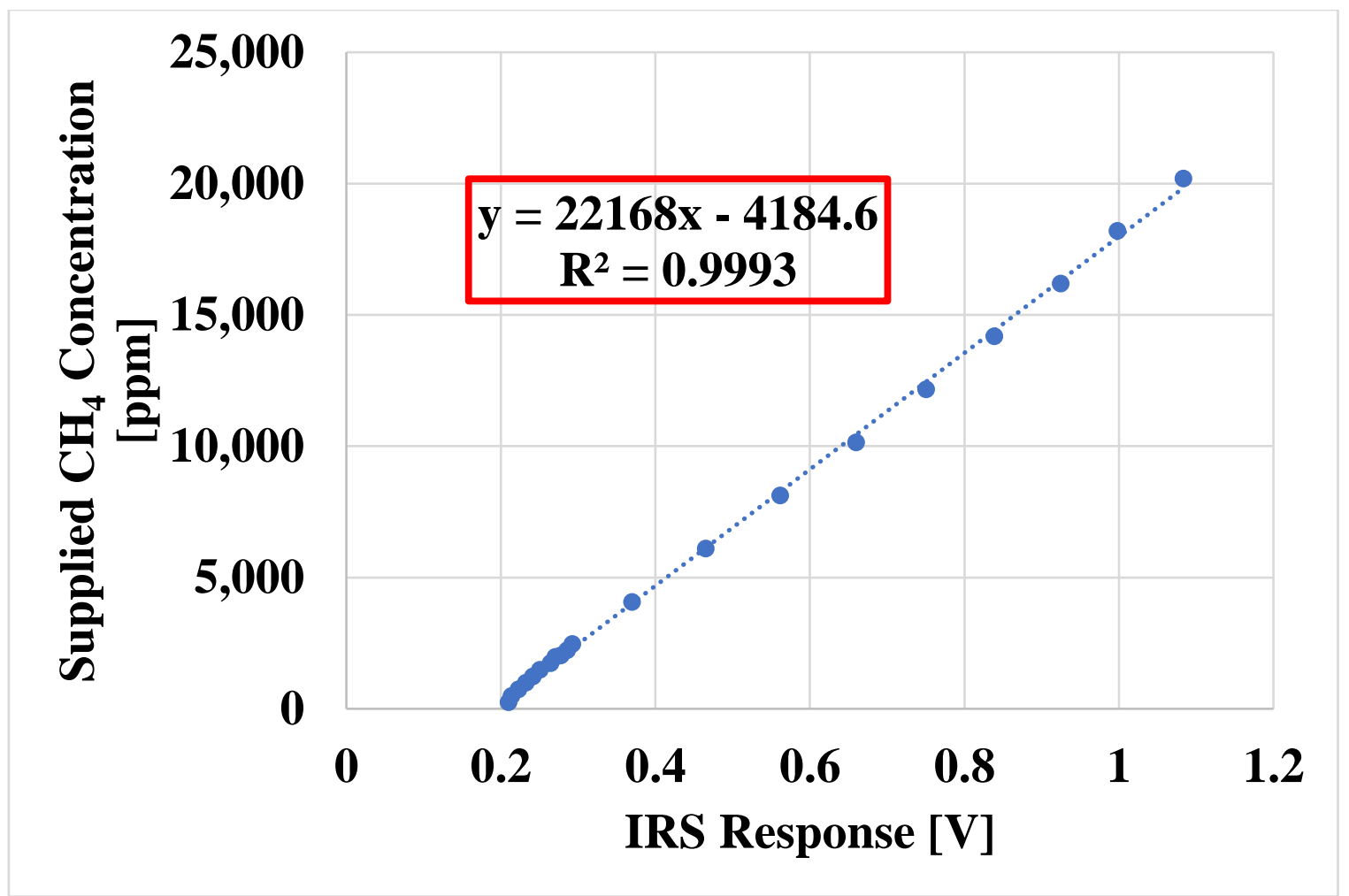

Figure 4.2-11: IRS calibration curve example.

The corrections applied to compensate for $\mathrm{RH}$, temperature, and pressure were a set of various raw response ranges and absolute humidity $(\omega)$ ranges. Figure 4.2-12 shows the results for the humidity calibration tests. Each line represents one test at a certain $\mathrm{CH}_{4}$ concentration while the humidity was varied. The trendline equations are shown to the right of the trendlines and are outlined corresponding to their respective test. These trendline equations were used to determine the correction factors for the various ranges. 


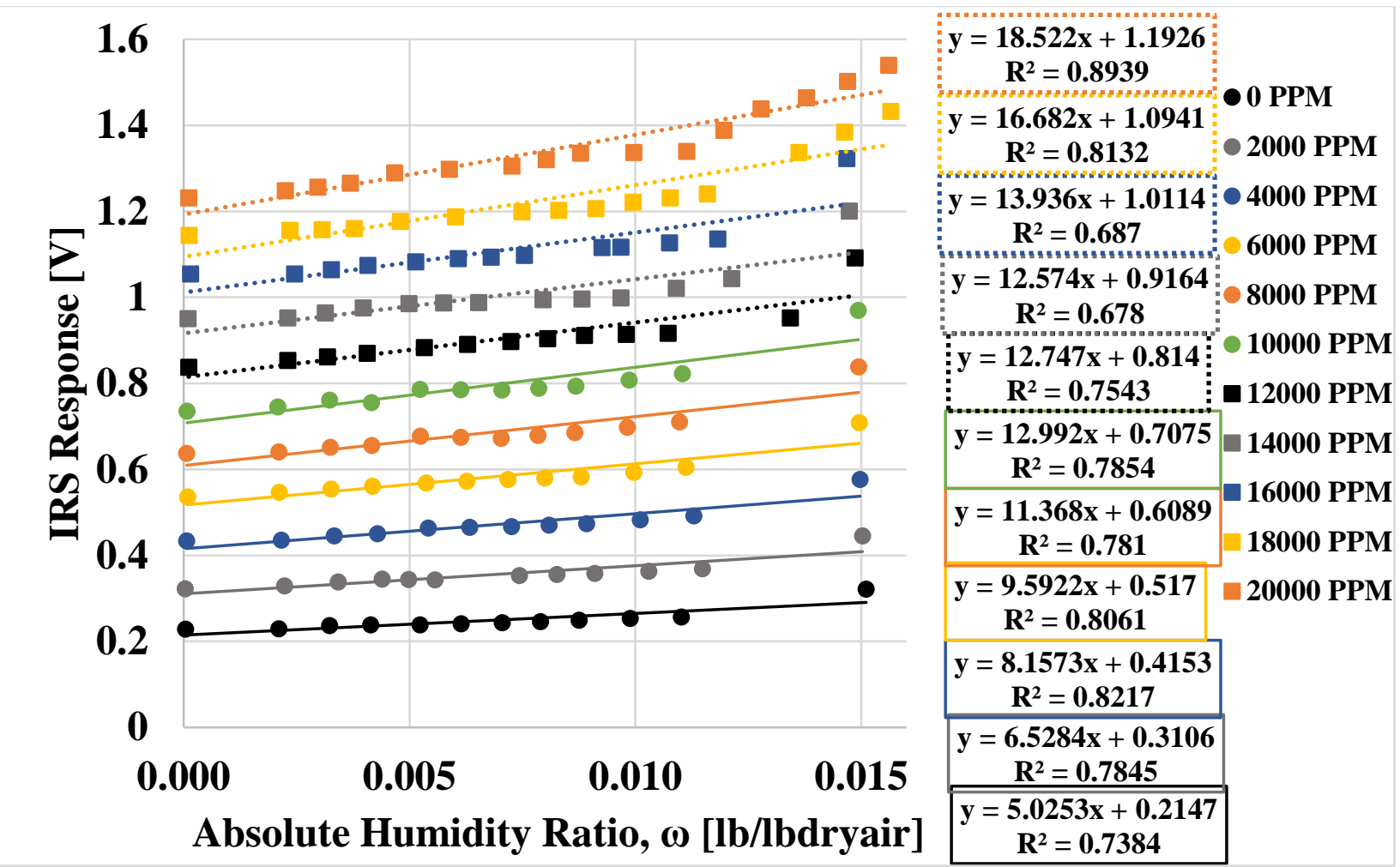

Figure 4.2-12: IRS plot used for humidity calibration corrections.

The correction factors for the various ranges for the IRS can be seen in Table 4.2-3 where the factors, $\mathrm{k}$ and $\mathrm{c}$, are used in Eq. 4.2.2 to calculate the corrected voltage which was then used in the individual dry calibration equation pertaining to the specific sensor.

$$
V_{\text {corrected }}=V-k * \omega-c
$$

In this equation, $\mathrm{V}_{\text {corrected }}$ is the corrected voltage to be used in the dry calibration equations, $\mathrm{V}$ is the raw sensor response voltage, and $\omega$ is the absolute humidity ratio. Note for the IRS calibrations, the "c" value was zero for all ranges.

Table 4.2-3: IRS calibration correction factors.

\begin{tabular}{|c|c|}
\hline $\begin{array}{c}\text { Raw Response } \\
\text { Range }\end{array}$ & $\mathbf{k}$ \\
\hline $\mathbf{V}<\mathbf{0 . 3}$ & 1.5 \\
\hline $\mathbf{0 . 3} \leq \mathbf{V}<\mathbf{0 . 6}$ & 2.5 \\
\hline $\mathbf{V} \geq \mathbf{0 . 6}$ & 5 \\
\hline
\end{tabular}




\section{MOS Calibrations}

Figure 4.2-13 shows an example of the MOS dry calibration curves, where the calibration equation for higher concentrations is shown in the solid-orange rectangle and the calibration equation for the lower concentrations is shown in the dashed-blue rectangle.

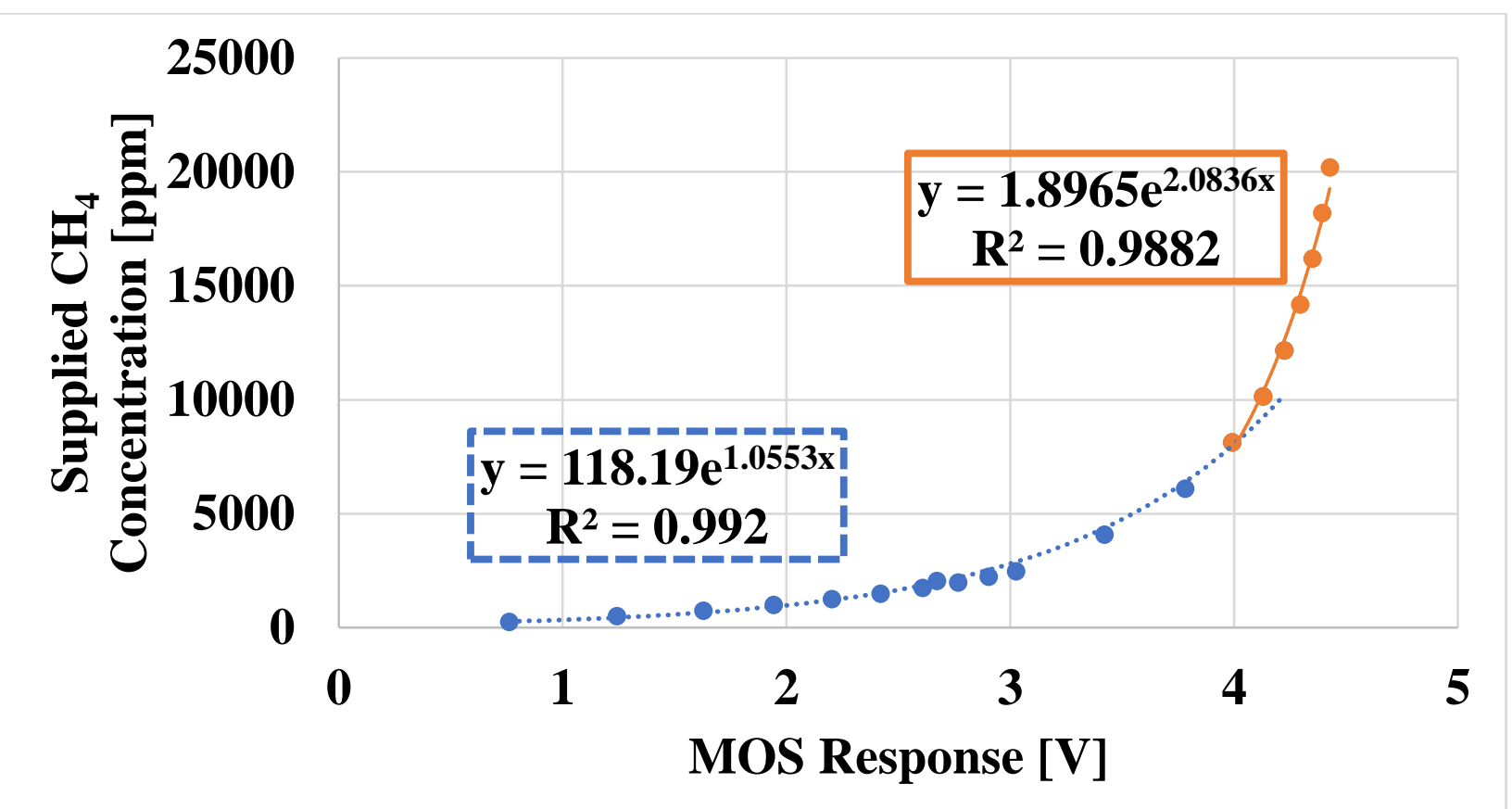

Figure 4.2-13: Example of MOS 20-Point dry calibration curve and equation.

The set of correction factors for the MOS had a greater number of ranges than for the IRS due to the complexity of their responses. Figure 4.2-14 shows the results of the humidity calibration tests from which the ranges were determined. It should be noted that the $14,000 \mathrm{ppm}$ and $18,000 \mathrm{ppm}$ tests have been omitted to provide a clearer plot. 


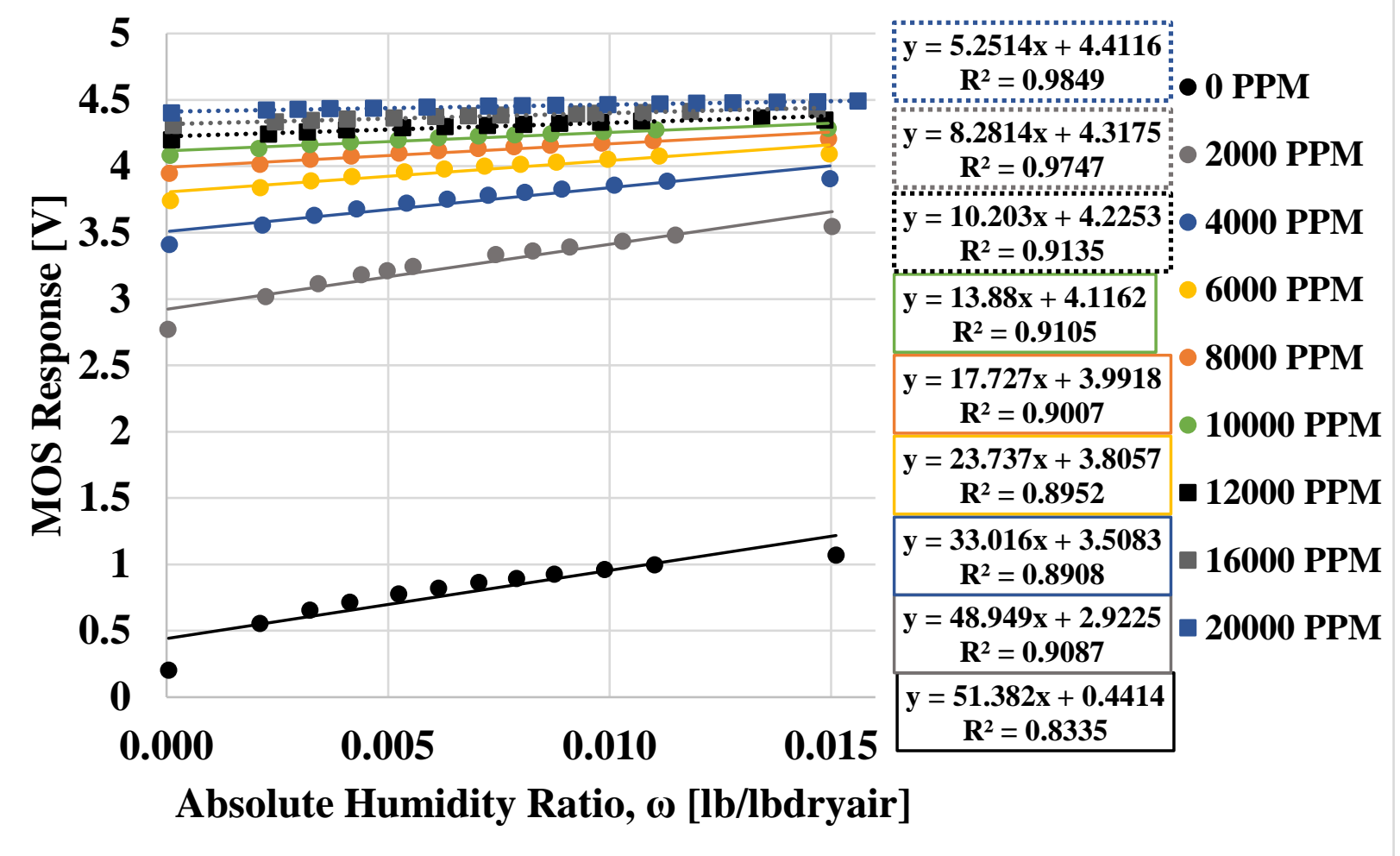

Figure 4.2-14: MOS plot used for humidity calibration corrections.

Table 4.2-4 presents the correction factors for the various ranges for the MOS. These factors applied to the same equation as for the IRS (Eq. 4.2.2) to calculate the corrected voltage to be used in the dry calibration equations.

Table 4.2-4: MOS calibration correction factors.

\begin{tabular}{|c|c|c|c|c|}
\hline \multirow{2}{*}{$\begin{array}{c}\text { Raw Response Range } \\
{[\mathbf{V}]}\end{array}$} & \multicolumn{2}{|c|}{$\boldsymbol{\omega} \leq \mathbf{0 . 0 0 5}$} & \multicolumn{2}{c|}{$\boldsymbol{\omega}>\mathbf{0 . 0 0 5}$} \\
\cline { 2 - 5 } & $\mathbf{k}$ & $\mathbf{c}$ & $\mathbf{k}$ & $\mathbf{c}$ \\
\hline $\mathbf{V}<\mathbf{3 . 3}$ & 70 & 0.1 & 80 & 0.1 \\
\hline $\mathbf{3 . 3} \leq \mathbf{V}<\mathbf{3 . 5}$ & 50 & 0.09 & 60 & 0.09 \\
\hline $\mathbf{3 . 5} \leq \mathbf{V}<\mathbf{3 . 7 5}$ & 40 & 0.05 & 55 & 0.05 \\
\hline $\mathbf{3 . 7 5} \leq \mathbf{V}<\mathbf{3 . 9}$ & 39 & 0.035 & 45 & 0.035 \\
\hline $\mathbf{3 . 9} \leq \mathbf{V}<\mathbf{4 . 0}$ & 32 & 0.035 & 37 & 0.035 \\
\hline $\mathbf{4 . 0} \leq \mathbf{V}<\mathbf{4 . 1}$ & 25 & 0.035 & 35 & 0.035 \\
\hline $\mathbf{4 . 1} \leq \mathbf{V}<\mathbf{4 . 2 3}$ & 13 & 0 & 18 & 0 \\
\hline $\mathbf{4 . 2 3} \leq \mathbf{V}<\mathbf{4 . 3}$ & 9.5 & 0 & 12 & 0 \\
\hline $\mathbf{4 . 3} \leq \mathbf{V}<\mathbf{4 . 4}$ & 8.8 & 0 & 10 & 0 \\
\hline $\mathbf{4 . 4} \leq \mathbf{V}<\mathbf{4 . 5}$ & 7 & 0 & 7 & 0 \\
\hline $\mathbf{V} \geq \mathbf{4 . 4}$ & 4 & 0 & 4 & 0 \\
\hline
\end{tabular}




\section{Verifications}

Tables 4.2-5 - 4.2-14 present the IRS and MOS measurements compared to the UGGA measurements. The percent difference values have been highlighted where anything less than $\pm 10 \%$ is green, values between $\pm 10-20 \%$ are yellow, and values above $\pm 20 \%$ are red. All the "red" values were calculated from the tests at the lower $\mathrm{CH}_{4}$ concentration (1200 ppm). It should be noted that the percent differences are absolute value in these tables; the percent difference values were both positive and negative. However, the MOS and IRS errors were typically positive. Note also that the MOS 9 was used to determine the calibration correction factors that were then applied to all 10 MOS. This most likely explains why MOS 9 had the lowest percent differences overall. The accuracy of MOS may increase if each sensor has it's own set of correction factors.

Table 4.2-5: MOS 1 and IRS 1 compared to the UGGA measurement.

\begin{tabular}{|c|c|c|c|c|c|}
\hline $\begin{array}{c}\text { Approximate } \\
\text { H2O } \\
\text { Concentration }\end{array}$ & MOS & IRS & UGGA & $\begin{array}{c}\text { Percent } \\
\text { Difference } \\
\text { between } \\
\text { MOS and UGGA }\end{array}$ & $\begin{array}{c}\text { Percent Difference } \\
\text { between } \\
\text { IRS and UGGA }\end{array}$ \\
\hline [ppm] & [ppm] & {$[\mathbf{p p m}]$} & {$[\mathbf{p p m}]$} & {$[\%]$} & {$[\%]$} \\
\hline \multirow{5}{*}{$\mathbf{6 0 0 0}$} & 1457 & 1202 & 1139 & 24.52 & 5.37 \\
\cline { 2 - 6 } & 4804 & 4007 & 4028 & 17.56 & 0.53 \\
\cline { 2 - 6 } & 13,276 & 12,592 & 11,833 & 11.50 & 6.22 \\
\cline { 2 - 6 } & 20,196 & 20,744 & 19,584 & 3.08 & 5.75 \\
\hline \multirow{3}{*}{$\mathbf{1 5 , 0 0 0}$} & 1481 & 1122 & 1185 & 22.23 & 5.44 \\
\cline { 2 - 6 } & 4842 & 4216 & 4171 & 14.89 & 1.09 \\
\cline { 2 - 6 } & 12,979 & 12,447 & 11,827 & 9.29 & 5.11 \\
\hline \multirow{3}{*}{$\mathbf{2 5 , 0 0 0}$} & 19,263 & 20,651 & 19,514 & 1.30 & 5.66 \\
\cline { 2 - 6 } & 1801 & 1204 & 1159 & 43.40 & 3.86 \\
\cline { 2 - 6 } & 4262 & 4025 & 4055 & 4.98 & 2.73 \\
\cline { 2 - 6 } & 12,041 & 11,939 & 11,598 & 3.74 & 6.90 \\
\hline
\end{tabular}


Table 4.2-6: MOS 2 and IRS 2 compared to the UGGA measurement.

\begin{tabular}{|c|c|c|c|c|c|}
\hline $\begin{array}{l}\text { Approximate } \\
\text { H2O } \\
\text { Concentration }\end{array}$ & MOS & IRS & UGGA & $\begin{array}{c}\text { Percent Difference } \\
\text { between } \\
\text { MOS and UGGA }\end{array}$ & $\begin{array}{c}\text { Percent } \\
\text { Difference } \\
\text { between } \\
\text { IRS and UGGA }\end{array}$ \\
\hline [ppm] & [ppm] & [ppm] & [ppm] & {$[\%]$} & {$[\%]$} \\
\hline \multirow{4}{*}{6000} & 1453 & 1293 & 1149 & 23.38 & 11.81 \\
\hline & 4868 & 3872 & 4062 & 18.05 & 4.78 \\
\hline & 14,217 & 12,300 & 11,831 & 18.32 & 3.88 \\
\hline & 20,560 & 20,713 & 19,659 & 4.48 & 5.22 \\
\hline \multirow{4}{*}{15,000} & 1297 & 1205 & 1206 & 7.22 & 0.12 \\
\hline & 4390 & 4058 & 4189 & 4.68 & 3.19 \\
\hline & 12,347 & 12,473 & 11,907 & 3.63 & 4.64 \\
\hline & 17,989 & 20,873 & 19,605 & 8.60 & 6.26 \\
\hline \multirow{4}{*}{25,000} & 1223 & 1291 & 1173 & 4.11 & 9.56 \\
\hline & 3599 & 3917 & 4074 & 12.37 & 3.93 \\
\hline & 10,687 & 11,854 & 11,660 & 8.70 & 1.65 \\
\hline & 15,687 & 20,590 & 19,366 & 20.99 & 6.13 \\
\hline
\end{tabular}

Table 4.2-7: MOS 3 and IRS 3 compared to the UGGA measurement.

\begin{tabular}{|c|c|c|c|c|c|}
\hline $\begin{array}{c}\text { Approximate } \mathbf{H}_{2} \mathbf{O} \\
\text { Concentration }\end{array}$ & MOS & IRS & UGGA & $\begin{array}{c}\text { Percent Difference } \\
\text { between } \\
\text { MOS and UGGA }\end{array}$ & $\begin{array}{c}\text { Percent } \\
\text { Difference } \\
\text { between } \\
\text { IRS and UGGA }\end{array}$ \\
\hline$[\mathbf{p p m}]$ & {$[\mathbf{p p m}]$} & {$[\mathbf{p p m}]$} & {$[\mathbf{p p m}]$} & {$[\%]$} & {$[\%]$} \\
\hline \multirow{3}{*}{$\mathbf{6 0 0 0}$} & 1433 & 1220 & 1187 & 18.81 & 2.76 \\
\cline { 2 - 6 } & 4351 & 3674 & 3688 & 16.48 & 0.40 \\
\cline { 2 - 6 } & 12,954 & 12,568 & 11,917 & 8.33 & 5.31 \\
\cline { 2 - 6 } & 19,821 & 20,821 & 19,794 & 0.13 & 5.06 \\
\hline \multirow{3}{*}{$\mathbf{1 5 , 0 0 0}$} & 1703 & 1237 & 1231 & 32.16 & 0.45 \\
\cline { 2 - 6 } & 4186 & 4092 & 4228 & 1.00 & 3.25 \\
\cline { 2 - 6 } & 12,321 & 12,411 & 11,969 & 2.90 & 3.63 \\
\cline { 2 - 6 } & 18,907 & 20,582 & 19,782 & 4.52 & 3.96 \\
\hline \multirow{3}{*}{$\mathbf{2 5 , 0 0 0}$} & 1605 & 1302 & 1207 & 28.31 & 7.53 \\
\cline { 2 - 6 } & 4889 & 4092 & 4122 & 17.02 & 0.73 \\
\cline { 2 - 6 } & 11,353 & 12,019 & 11,747 & 3.41 & 3.29 \\
\hline
\end{tabular}


Table 4.2-8: MOS 4 and IRS 4 compared to the UGGA measurement.

\begin{tabular}{|c|c|c|c|c|c|}
\hline $\begin{array}{c}\text { Approximate } \\
\begin{array}{c}\mathbf{H}_{\mathbf{2}} \mathbf{O} \\
\text { Concentration }\end{array}\end{array}$ & MOS & IRS & UGGA & $\begin{array}{c}\text { Percent } \\
\text { Difference } \\
\text { between } \\
\text { MOS and UGGA }\end{array}$ & $\begin{array}{c}\text { Percent } \\
\text { Difference } \\
\text { between } \\
\text { IRS and UGGA }\end{array}$ \\
\hline [ppm] & {$[\mathbf{p p m}]$} & {$[\mathbf{p p m}]$} & {$[\mathbf{p p m}]$} & {$[\%]$} & {$[\%]$} \\
\hline \multirow{4}{*}{$\mathbf{6 0 0 0}$} & 1466 & 1460 & 1185 & 21.17 & 20.78 \\
\cline { 2 - 6 } & 4659 & 4328 & 4119 & 12.30 & 4.93 \\
\cline { 2 - 6 } & 12,709 & 12,526 & 11,852 & 6.98 & 5.53 \\
\cline { 2 - 6 } & 18,949 & 20,916 & 19,701 & 3.89 & 5.98 \\
\hline \multirow{4}{*}{$\mathbf{1 5 , 0 0 0}$} & 1525 & 1286 & 1235 & 20.99 & 3.99 \\
\cline { 2 - 6 } & 4360 & 4203 & 4215 & 3.38 & 0.29 \\
\cline { 2 - 6 } & 11,698 & 12,631 & 11,937 & 2.02 & 5.66 \\
\hline \multirow{3}{*}{$\mathbf{2 5 , 0 0 0}$} & 17,364 & 20,877 & 19,651 & 12.36 & 6.05 \\
\cline { 2 - 6 } & 1595 & 1474 & 1199 & 28.33 & 20.55 \\
\cline { 2 - 6 } & 3951 & 4088 & 4074 & 3.06 & 0.35 \\
\cline { 2 - 6 } & 10,383 & 12,020 & 11,675 & 11.72 & 2.91 \\
\hline
\end{tabular}

Table 4.2-9: MOS 5 and IRS 5 compared to the UGGA measurement.

\begin{tabular}{|c|c|c|c|c|c|}
\hline $\begin{array}{c}\text { Approximate } \\
\begin{array}{c}\mathbf{H}_{\mathbf{2}} \mathbf{O} \\
\text { Concentration }\end{array}\end{array}$ & MOS & IRS & UGGA & $\begin{array}{c}\text { Percent } \\
\text { Difference } \\
\text { between } \\
\text { MOS and UGGA }\end{array}$ & $\begin{array}{c}\text { Percent } \\
\text { Difference } \\
\text { between } \\
\text { IRS and UGGA }\end{array}$ \\
\hline$[\mathbf{p p m}]$ & {$[\mathbf{p p m}]$} & {$[\mathbf{p p m}]$} & {$[\mathbf{p p m}]$} & {$[\%]$} & {$[\%]$} \\
\hline \multirow{4}{*}{$\mathbf{6 0 0 0}$} & 1508 & 1454 & 1200 & 22.80 & 19.14 \\
\cline { 2 - 6 } & 5011 & 4167 & 4170 & 18.33 & 0.07 \\
\cline { 2 - 6 } & 13,757 & 12,755 & 11,993 & 13.70 & 6.16 \\
\hline \multirow{4}{*}{$\mathbf{1 5 , 0 0 0}$} & 19,923 & 20,740 & 19,867 & 0.28 & 4.30 \\
\hline \multirow{3}{*}{$\mathbf{2 5 , 0 0 0}$} & 1699 & 1352 & 1247 & 30.64 & 8.08 \\
\cline { 2 - 6 } & 4920 & 4121 & 4222 & 15.27 & 2.43 \\
\cline { 2 - 6 } & 13,167 & 12,483 & 11,992 & 9.34 & 4.02 \\
\cline { 2 - 6 } & 18,917 & 20,838 & 19,793 & 4.53 & 5.14 \\
\cline { 2 - 6 } & 2098 & 1531 & 1218 & 53.10 & 22.76 \\
\cline { 2 - 6 } & 12,183 & 11,919 & 11,769 & 8.43 & 0.04 \\
\hline
\end{tabular}


Table 4.2-10: MOS 6 and IRS 6 compared to the UGGA measurement.

\begin{tabular}{|c|c|c|c|c|c|}
\hline $\begin{array}{c}\text { Approximate } \\
\mathbf{H}_{2} \mathbf{O} \\
\text { Concentration }\end{array}$ & MOS & IRS & UGGA & $\begin{array}{c}\text { Percent } \\
\text { Difference } \\
\text { between } \\
\text { MOS and UGGA }\end{array}$ & $\begin{array}{c}\text { Percent } \\
\text { Difference } \\
\text { between } \\
\text { IRS and UGGA }\end{array}$ \\
\hline \multirow{4}{*}{ [ppm] } & {$[\mathbf{p p m}]$} & {$[\mathbf{p p m}]$} & {$[\mathbf{p p m}]$} & {$[\%]$} & {$[\%]$} \\
\hline \multirow{5}{*}{$\mathbf{6 0 0 0}$} & 1379 & 1276 & 1173 & 16.17 & 8.44 \\
\cline { 2 - 6 } & 4874 & 4088 & 4104 & 17.16 & 0.38 \\
\cline { 2 - 6 } & 13,045 & 12,512 & 11,932 & 8.91 & 4.74 \\
\cline { 2 - 6 } & 19,191 & 20,661 & 19,708 & 2.66 & 4.72 \\
\hline \multirow{3}{*}{$\mathbf{1 5 , 0 0 0}$} & 1532 & 1231 & 1236 & 21.40 & 0.37 \\
\cline { 2 - 6 } & 4792 & 3984 & 4184 & 13.55 & 4.90 \\
\cline { 2 - 6 } & 11,274 & 12,285 & 11,909 & 5.47 & 3.11 \\
\cline { 2 - 6 } & 17,832 & 20,332 & 19,631 & 9.60 & 3.51 \\
\hline \multirow{3}{*}{$\mathbf{2 5 , 0 0 0}$} & 1729 & 1319 & 1202 & 35.97 & 9.28 \\
\cline { 2 - 6 } & 3904 & 3783 & 4066 & 4.05 & 1.21 \\
\cline { 2 - 6 } & 11,428 & 11,835 & 11,673 & 2.13 & 2.85 \\
\hline
\end{tabular}

Table 4.2-11: MOS 7 and IRS 7 compared to the UGGA measurement.

\begin{tabular}{|c|c|c|c|c|c|}
\hline $\begin{array}{c}\text { Approximate } \\
\begin{array}{c}\mathbf{H}_{2} \mathbf{O} \\
\text { Concentration }\end{array}\end{array}$ & MOS & IRS & UGGA & $\begin{array}{c}\text { Percent } \\
\text { Difference } \\
\text { between } \\
\text { MOS and UGGA }\end{array}$ & $\begin{array}{c}\text { Percent } \\
\text { Difference } \\
\text { between } \\
\text { IRS and UGGA }\end{array}$ \\
\hline$[\mathbf{p p m}]$ & {$[\mathbf{p p m}]$} & {$[\mathbf{p p m}]$} & {$[\mathbf{p p m}]$} & {$[\%]$} & {$[\%]$} \\
\hline \multirow{4}{*}{$\mathbf{6 0 0 0}$} & 1471 & 1389 & 1198 & 20.51 & 14.81 \\
\cline { 2 - 6 } & 4766 & 4132 & 4171 & 13.31 & 0.95 \\
\cline { 2 - 6 } & 13,305 & 12,358 & 11,996 & 10.35 & 2.97 \\
\hline \multirow{4}{*}{$\mathbf{1 5 , 0 0 0}$} & 19,328 & 20,527 & 20,009 & 3.46 & 2.55 \\
\hline & 1484 & 1372 & 1242 & 17.73 & 9.91 \\
\cline { 2 - 6 } & 4794 & 4014 & 4233 & 12.44 & 5.29 \\
\cline { 2 - 6 } & 12,527 & 12,420 & 12,077 & 3.65 & 2.80 \\
\hline \multirow{3}{*}{$\mathbf{2 5 , 0 0 0}$} & 18,437 & 20,693 & 19,911 & 7.68 & 3.85 \\
\hline & 1777 & 1492 & 1212 & 37.80 & 20.71 \\
\cline { 2 - 6 } & 4251 & 3775 & 4110 & 3.37 & 8.51 \\
\cline { 2 - 6 } & 11,723 & 11,800 & 11,831 & 0.92 & 0.26 \\
\hline
\end{tabular}


Table 4.2-12: MOS 8 and IRS 8 compared to the UGGA measurement.

\begin{tabular}{|c|c|c|c|c|c|}
\hline $\begin{array}{l}\text { Approximate } \\
\mathrm{H}_{2} \mathrm{O} \\
\text { Concentration }\end{array}$ & MOS & IRS & UGGA & $\begin{array}{c}\text { Percent } \\
\text { Difference } \\
\text { between } \\
\text { MOS and UGGA }\end{array}$ & $\begin{array}{c}\text { Percent } \\
\text { Difference } \\
\text { between } \\
\text { IRS and UGGA }\end{array}$ \\
\hline [ppm] & [ppm] & [ppm] & [ppm] & {$[\%]$} & {$[\%]$} \\
\hline \multirow{4}{*}{6000} & 1199 & 1438 & 1191 & 0.66 & 18.79 \\
\hline & 4486 & 4119 & 4089 & 9.27 & 0.74 \\
\hline & 11,718 & 12,529 & 11,775 & 0.48 & 6.21 \\
\hline & 17,521 & 21,126 & 19,574 & 11.07 & 7.63 \\
\hline \multirow{4}{*}{15,000} & 1383 & 1360 & 1231 & 11.63 & 9.96 \\
\hline & 4347 & 4224 & 4160 & 4.39 & 1.51 \\
\hline & 11,424 & 12,387 & 11,789 & 3.14 & 4.95 \\
\hline & 16,879 & 20,879 & 19,447 & 14.14 & 7.10 \\
\hline \multirow{4}{*}{25,000} & 1605 & 1497 & 1208 & 28.22 & 21.41 \\
\hline & 3977 & 4132 & 4030 & 1.33 & 2.51 \\
\hline & 10,654 & 12,444 & 11,535 & 7.95 & 7.57 \\
\hline & 15,609 & 21,037 & 19,206 & 20.67 & 9.10 \\
\hline
\end{tabular}

Table 4.2-13: MOS 9 and IRS 9 compared to the UGGA measurement.

\begin{tabular}{|c|c|c|c|c|c|}
\hline $\begin{array}{c}\text { Approximate } \\
\mathbf{H}_{2} \mathbf{O} \\
\text { Concentration }\end{array}$ & MOS & IRS & UGGA & $\begin{array}{c}\text { Percent Difference } \\
\text { between } \\
\text { MOS and UGGA }\end{array}$ & $\begin{array}{c}\text { Percent } \\
\text { Difference } \\
\text { between } \\
\text { IRS and UGGA }\end{array}$ \\
\hline$[\mathbf{p p m}]$ & {$[\mathbf{p p m}]$} & {$[\mathbf{p p m}]$} & {$[\mathbf{p p m}]$} & {$[\%]$} & {$[\%]$} \\
\hline \multirow{4}{*}{$\mathbf{6 0 0 0}$} & 1226 & 1314 & 1184 & 3.51 & 10.38 \\
\cline { 2 - 6 } & 4082 & 4061 & 3962 & 3.00 & 2.48 \\
\cline { 2 - 6 } & 11,895 & 12,298 & 11,788 & 0.90 & 4.23 \\
\cline { 2 - 6 } & 17,691 & 20,477 & 19,492 & 9.69 & 4.93 \\
\hline \multirow{5}{*}{$\mathbf{1 5 , 0 0 0}$} & 1234 & 1324 & 1235 & 0.10 & 6.97 \\
\cline { 2 - 6 } & 4189 & 4199 & 4144 & 1.09 & 1.32 \\
\cline { 2 - 6 } & 11,533 & 12,214 & 11,794 & 2.24 & 3.49 \\
\cline { 2 - 6 } & 16,901 & 20,528 & 19,493 & 14.24 & 5.17 \\
\hline \multirow{3}{*}{$\mathbf{2 5 , 0 0 0}$} & 1296 & 1454 & 1214 & 6.55 & 18.04 \\
\cline { 2 - 6 } & 3716 & 4044 & 4032 & 8.18 & 0.28 \\
\cline { 2 - 6 } & 10,533 & 11,880 & 11,607 & 9.70 & 6.33 \\
\cline { 2 - 6 } & 15,552 & 20,492 & 19,278 & 21.40 & 6.10 \\
\hline
\end{tabular}


Table 4.2-14: MOS 10 and IRS 10 compared to the UGGA measurement.

\begin{tabular}{|c|c|c|c|c|c|}
\hline $\begin{array}{c}\text { Approximate } \\
\begin{array}{c}\mathbf{H}_{2} \mathbf{O} \\
\text { Concentration }\end{array}\end{array}$ & MOS & IRS & UGGA & $\begin{array}{c}\text { Percent } \\
\text { Difference } \\
\text { between } \\
\text { MOS and UGGA }\end{array}$ & $\begin{array}{c}\text { Percent } \\
\text { Difference } \\
\text { between } \\
\text { IRS and UGGA }\end{array}$ \\
\hline$[\mathbf{p p m}]$ & {$[\mathbf{p p m}]$} & {$[\mathbf{p p m}]$} & {$[\mathbf{p p m}]$} & {$[\%]$} & {$[\%]$} \\
\hline \multirow{4}{*}{$\mathbf{6 0 0 0}$} & 1506 & 1412 & 1147 & 26.99 & 20.69 \\
\cline { 2 - 6 } & 4919 & 4325 & 3951 & 21.82 & 9.04 \\
\cline { 2 - 6 } & 14,808 & 12,484 & 11,695 & 23.50 & 6.53 \\
\cline { 2 - 6 } & 21,619 & 20,172 & 19,397 & 10.84 & 3.92 \\
\hline \multirow{3}{*}{$\mathbf{1 5 , 0 0 0}$} & 1727 & 1562 & 1236 & 33.13 & 23.34 \\
& 5484 & 4641 & 4111 & 28.62 & 12.10 \\
\cline { 2 - 6 } & 14,525 & 12,613 & 11,782 & 20.85 & 6.81 \\
\cline { 2 - 6 } & 20,762 & 20,564 & 19,452 & 6.51 & 5.56 \\
\hline \multirow{3}{*}{$\mathbf{2 5 , 0 0 0}$} & 2076 & 1369 & 1220 & 51.97 & 11.50 \\
\cline { 2 - 6 } & 4561 & 4364 & 4014 & 12.76 & 8.36 \\
\cline { 2 - 6 } & 13,231 & 12,158 & 11,555 & 13.52 & 5.08 \\
\cline { 2 - 6 } & 21,015 & 20,638 & 19,215 & 8.95 & 7.14 \\
\hline
\end{tabular}

From these tables and the tests for all four $\mathrm{CH}_{4}$ concentrations, $87.5 \%$ of the IRS and $50 \%$ of the MOS percent difference values were below $10 \%$. If the $1200 \mathrm{ppm}$ tests were omitted, about $95 \%$ of the IRS and 53\% of the MOS percent difference values were below $10 \%$. With the $1200 \mathrm{ppm}$ tests omitted, all the IRS percent difference values were below 13\%. This met the regulation requirements of less than $20 \%$ and ability to accurately detect $\mathrm{CH}_{4}$ concentrations of at least $0.25 \%$ $\mathrm{CH}_{4}$ [12]. The IRS were more accurate than the MOS when a single humidity correction was applied to all ten sensors. Due to the complexity and variety of the MOS responses, a humidity correction may need to be made specifically for each sensor to improve accuracy. It is also believed that if MOS were calibrated only to lower $\mathrm{CH}_{4}$ concentrations, such as concentrations below $0.2 \%$ $\mathrm{CH}_{4}$ that the IRS may not respond to, higher accuracy would be achieved.

\section{Flow Sensors}

Tables 4.2-15 and Figure 4.2-15 present the results of the flow sensor verification tests. Additional research should focus on a reduction in these errors. 
Table 4.2-15: Flow sensor verification with MFC.

\begin{tabular}{|c|c|c|}
\hline MFC & $\begin{array}{c}\text { Flow } \\
\text { Sensor }\end{array}$ & $\begin{array}{c}\text { Percent } \\
\text { Error }\end{array}$ \\
\hline SLPM & SLPM & \% \\
\hline $\mathbf{3 . 5 3}$ & 3.86 & 9.62 \\
\hline $\mathbf{3 . 0 0}$ & 3.34 & 11.35 \\
\hline $\mathbf{1 . 9 4}$ & 2.09 & 7.68 \\
\hline $\mathbf{1 . 0 2}$ & 0.82 & -19.98 \\
\hline
\end{tabular}

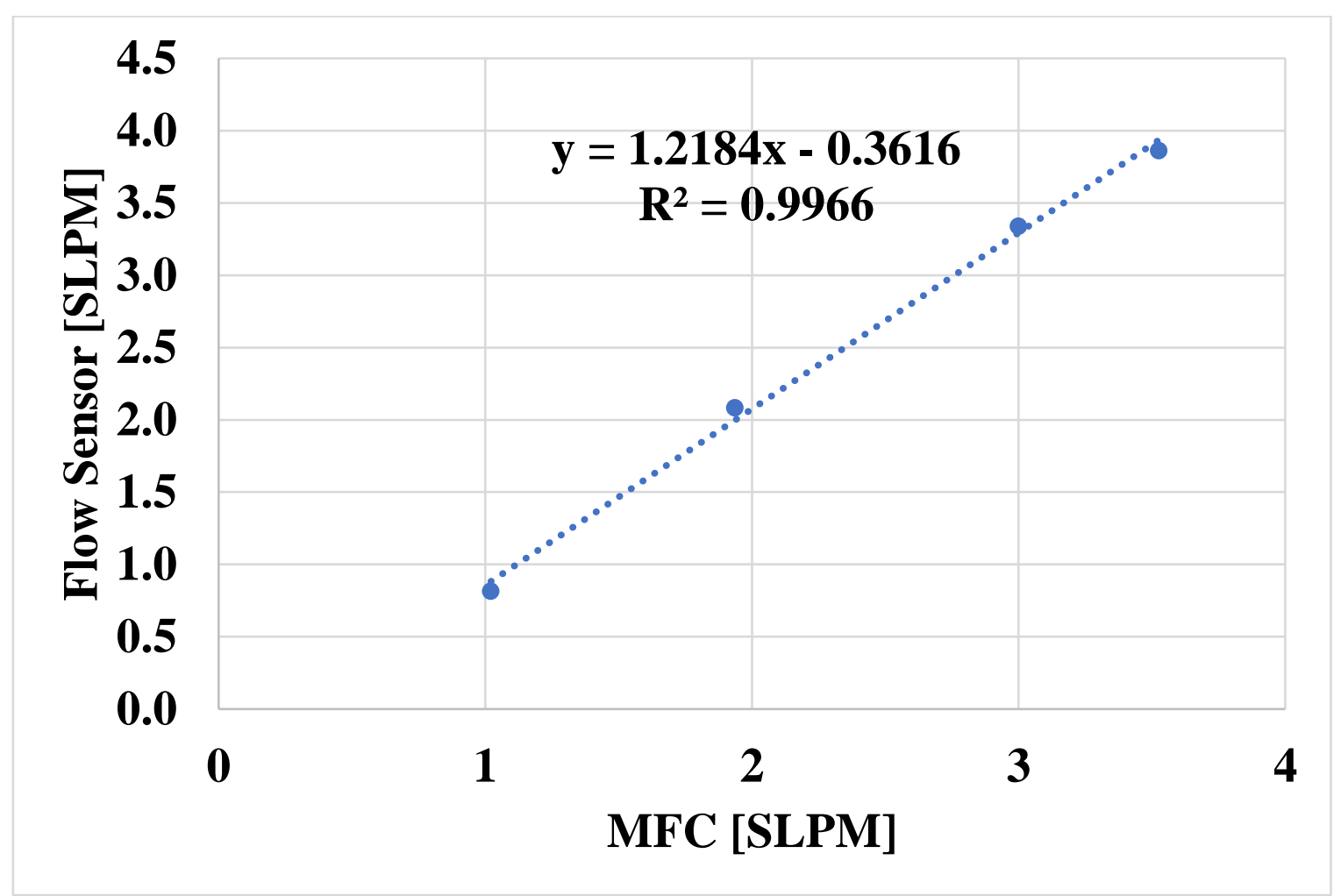

Figure 4.2-15: Flow sensor verification with MFC.

\section{3-Cup Anemometers}

Table 4.2-16 presents the results of the 3-cup anemometer verification tests, where the wind velocity measurements of the 3-cup anemometer were compared to the measurements of the WindSonic by calculating a percent error for the four velocity points. Based on these four points, it seemed that the percent error increased as the velocity decreased, moving closer to the minimum operational velocity (around $0.5 \mathrm{~m} / \mathrm{s}$ ) of the 3-cup anemometer. 
Table 4.2-16: 3-Cup anemometer verification with the WindSonic.

\begin{tabular}{|c|c|c|}
\hline $\begin{array}{c}\text { WindSonic } \\
{[\mathbf{m} / \mathbf{s}]}\end{array}$ & $\begin{array}{c}\text { 3-Cup } \\
\text { Anemometer } \\
{[\mathrm{m} / \mathrm{s}]}\end{array}$ & $\begin{array}{c}\text { Error } \\
{[\%]}\end{array}$ \\
\hline $\mathbf{3 . 4 6}$ & 3.58 & 3.57 \\
\hline $\mathbf{2 . 3 4}$ & 2.49 & 6.02 \\
\hline $\mathbf{1 . 9 6}$ & 2.16 & 10.55 \\
\hline $\mathbf{1 . 2 4}$ & 1.54 & 24.74 \\
\hline
\end{tabular}

\section{3 "Mock" Mine Verification of System}

Ambient/Baseline Tests (Temperature, RH, Pressure)

There were ten "long term" tests recorded at the mock mine where temperature, $\mathrm{RH}$, and pressure were recorded in each of the ten sampling units as well as with the iBTHX for reference. During these tests, the MWS sampled ambient conditions (no $\mathrm{CH}_{4}$ was supplied). It was known prior to these tests that the temperature inside the sensor block was generally higher than that of the surrounding ambient environment. This was most likely due to the heated operation of the MOS. Since the volume in the block was small, the heat emitted from the MOS increased the temperature of the sample. This rise in temperature also impacted the RH inside of the sensor block. There should be a slight decrease in pressure, when the MWS is in operation, due to the flow, therefore, the pressure in the sampling box would be slightly lower than the ambient pressure measured by the iBTHX. Figure 4.3-1 shows the temperature, RH, and pressure, respectively, for one of the "long-term" tests. The measurements of temperature were generally higher, RH lower, and pressure just slightly lower for all ten sampling nodes than for the iBTHX, as expected. These relationships were seen in all the "long-term" tests. 

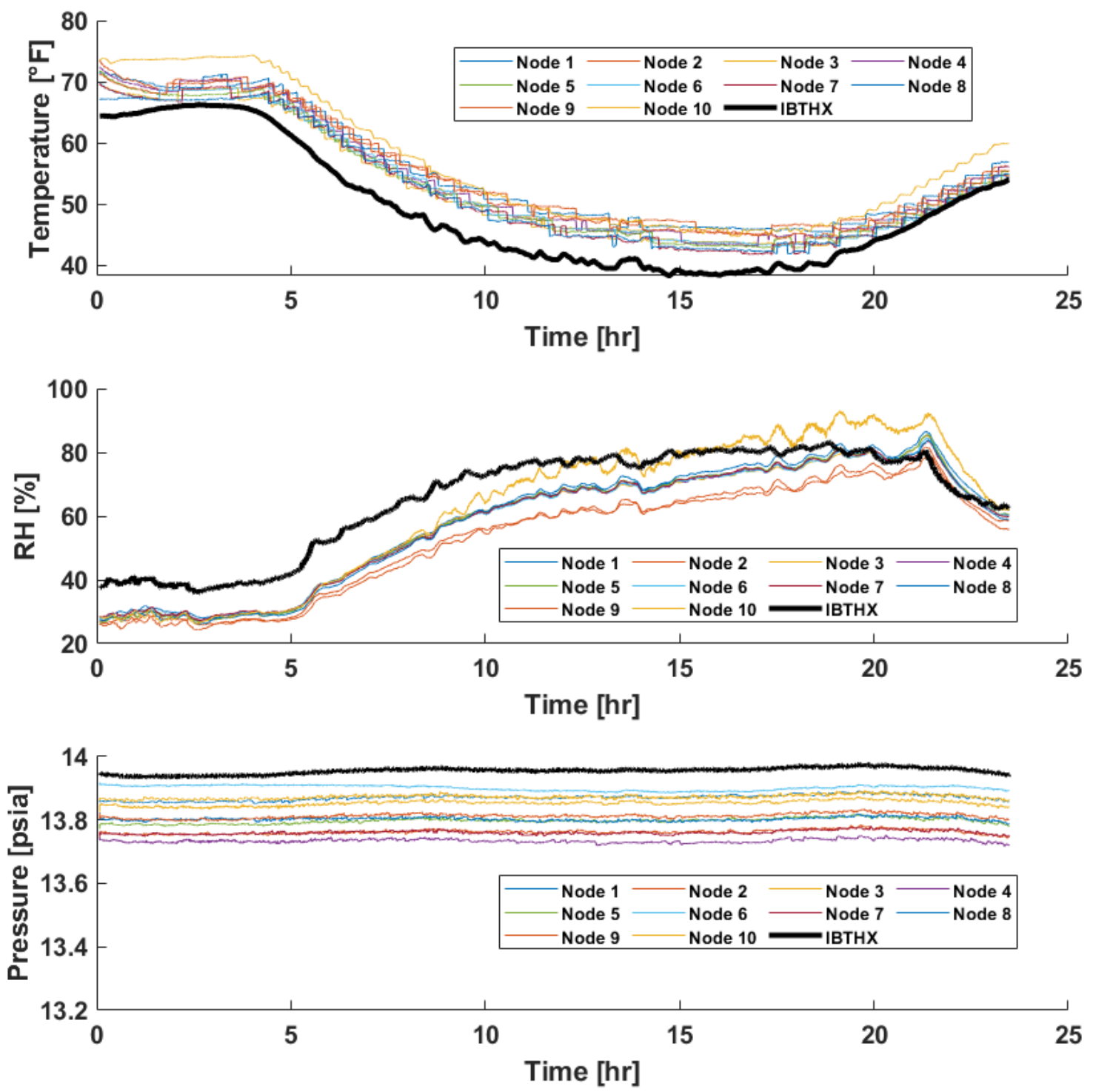

Figure 4.3-1: Temperature, $\mathrm{RH}$, and pressure during a long-term test (test 5).

\section{System Response Times in the Presence of $\mathrm{CH}_{4}$}

The four tests performed using Method 2 supplied the $\mathrm{CH}_{4}$ sample to the filter at four different flowrates. There was not a distinct correlation of supply flowrate to the response times. Table 4.31 shows the resulting response times for the MOS and IRS of node 5. 
Table 4.3-1: Response time test - Method 2 comparison of response times at different supply flowrates.

\begin{tabular}{|c|c|c|c|c|c|c|c|c|}
\hline & \multicolumn{2}{|c|}{ 3 SLPM } & \multicolumn{2}{c|}{ 1.4 SLPM } & \multicolumn{2}{c|}{ 1.3 SLPM } & \multicolumn{2}{c|}{ 1.2 SLPM } \\
\hline & MOS & IRS & MOS & IRS & MOS & IRS & MOS & IRS \\
\hline Rise Time [s] & 13 & 29 & 12 & 29 & 13 & 30 & 15 & 26 \\
\hline Decay Time [s] & 188 & 83 & 150 & 60 & 153 & 42 & 113 & 62 \\
\hline
\end{tabular}

Since there did not seem to be a correlation between the supply flowrates used and the response times, the results from the four tests which used Method 2 were also used to compare to the results of Method 1. Table 4.3-2 presents the averages of the rise and decay times for both the MOS and IRS of the four tests using Method 1 as well as for the four tests using Method 2. Since Method 2 occurred on a nodal basis, only averages for the face sampling location 5 were presented to allow for comparison of the two methods. The assumptions made for Method 1 were first brought into question when we noticed that the decay times for some sampling locations were much different than others. Figure 4.3-2 shows an example to help visualize this effect and includes the raw response as well as the calibrated response as a $\mathrm{CH}_{4}$ concentration in percent by volume. Figure 4.3-2 shows that the response of the MOS at sampling location 1 did not fall back down to the background response after being exposed to the $\mathrm{CH}_{4}$ supply as the other four appeared to; it seemed to get "hung-up" at a $\mathrm{CH}_{4}$ concentration of around $0.09 \%$ for approximately 200 seconds after the other sensor responses dropped close to the background concentration; this drop is shown in the circles in each plot of Figure 4.3-2. Since the response of the MOS at sampling location 1 "hungup" at a higher concentration and then eventually dropped to meet the rest, it was suspected that the majority of the $\mathrm{CH}_{4}$ diffusing from the supply tube was being pulled/sampled by box 1 (the box associated with sampling location 1). 


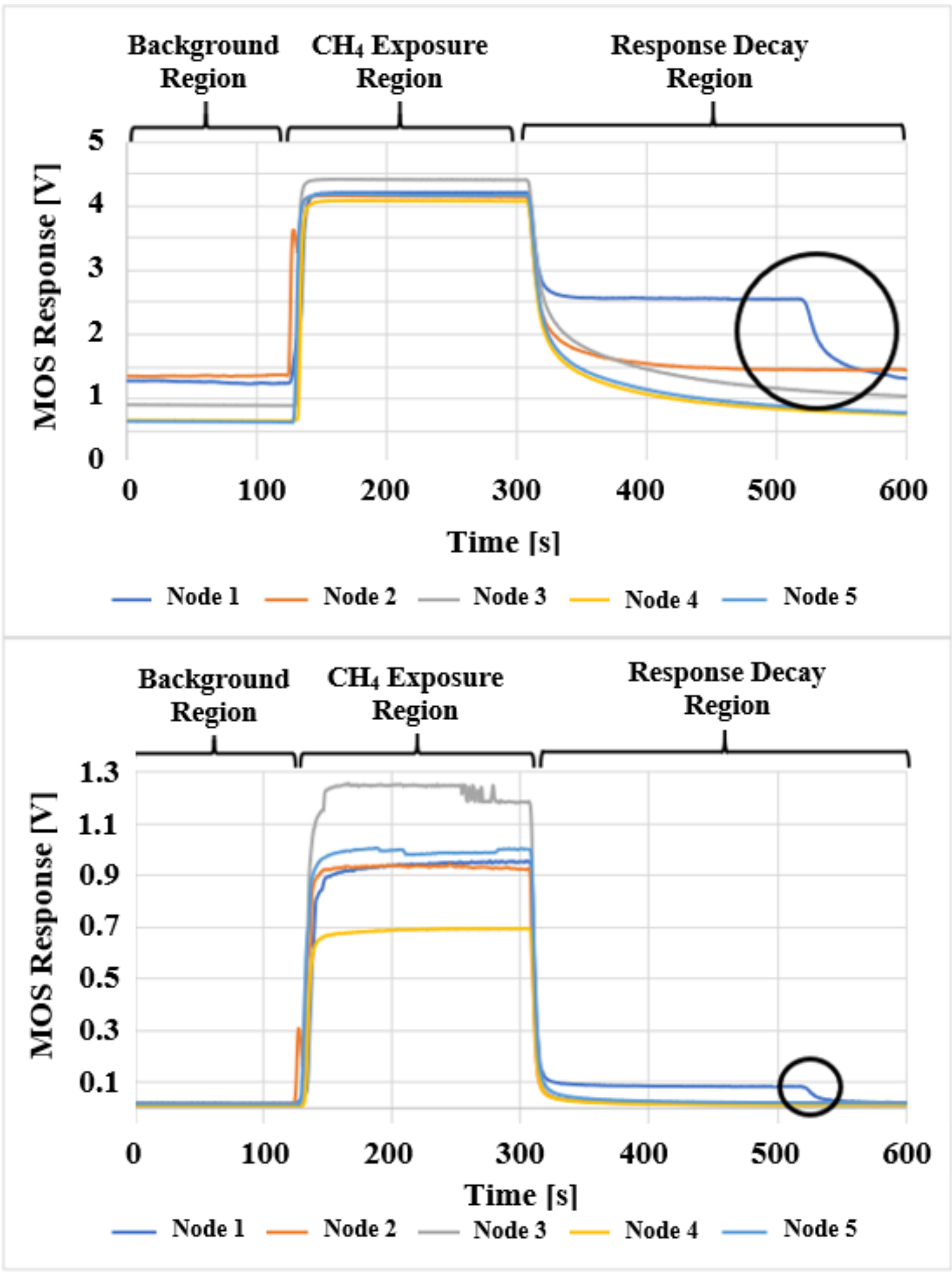

Figure 4.3-2: Example of MOS response for sampling locations 1-5 using method 1.

Results in Table 4.3-2 show that the rise times for Method 1 were greater than those of Method 2 for both the MOS and IRS. However, the response times of Method 2 were aligned with those of 
current sensors used in mining applications as presented in literature. The response times provided by the manufacturer were typically stated as less than 10 seconds for monitors containing CAT and MO sensors and less than 25-30 seconds for monitors containing IR sensors (see Table 2.4-1) [60], [64], [66], [70], [72], [91], [79], [81], [83], [85], [132]. It should be noted that response times calculated in this report include the transit time and sensor response time while those specified by manufacturers are sensor response times.

Table 4.3-2: Rise and decay times for both methods and the difference between them.

\begin{tabular}{|c|c|c|c|c|c|c|}
\hline & \multicolumn{2}{|c|}{ Method 1 } & \multicolumn{2}{c|}{ Method 2 } & \multicolumn{2}{c|}{ Differences } \\
\hline & MOS & IRS & MOS & IRS & MOS & IRS \\
\hline Rise Time [s] & 23.8 & 34.0 & 13.3 & 28.5 & 9.5 & 5.5 \\
\hline Decay Time [s] & 193.0 & 61.5 & 151.0 & 61.8 & 42 & 0.3 \\
\hline
\end{tabular}

It was determined that the greater rise times for Method 1 were due to the diffusion or leaking of the $\mathrm{CH}_{4}$ concentrated gas from the $\mathrm{CH}_{4}$ supply tubing that led to each sampling location. If this occurred, $\mathrm{CH}_{4}$ was not immediately supplied to the filter at the sampling location at the start time, as previously assumed. This meant that when the test started and the $\mathrm{CH}_{4}$ supply was turned on, the $\mathrm{CH}_{4}$ concentrated sample travelled through a portion, if not all, of the $19.8 \mathrm{~m}(65 \mathrm{ft})$ of tubing before reaching the filter at the sampling location, which then increased the rise time. Method 2 eliminated this issue because the $\mathrm{CH}_{4}$ supply tube that extends from the MFC to the filter at the sampling location is only $0.3 \mathrm{~m}(1 \mathrm{ft})$ as opposed to $19.8 \mathrm{~m}(65 \mathrm{ft})$.

It was also believed that the diffusion of the $\mathrm{CH}_{4}$ concentrated gas from the tube after the supply was turned off, in Method 1, was the reason the decay time for the MOS was higher for Method 1 than for Method 2. If the $\mathrm{CH}_{4}$ slowly diffused from the end of the supply tube, the sample would still contain trace amounts of $\mathrm{CH}_{4}$ that the MOS detected. It appeared that the differences in the two methods had little to no effect on the decay time for the IRS, which supported this hypothesis. This was most likely because the amount of $\mathrm{CH}_{4}$ in the sample after the supply had been turned off (the amount due to diffusion) was at the lower end of detection for the IRS, unlike the MOS. If the highest $\mathrm{CH}_{4}$ concentration that was sampled after the stop time was assumed to be $0.09 \%$, like for sampling location 1 in Figure 4.3-2, this concentration was most likely too low for the IRS sensor to detect. 
Tests Conducted Using the FFS

\section{Type 1 and Type 2}

Figure 4.3-3 - 4.3-5 show Type 1 tests, while Figure 4.3-6 - 4.3-8 show Type 2 tests. For these tests, a $\mathrm{CH}_{4}$ concentration of approximately $2 \%$ was leaked at a rate of 2832 SLPM (100 scfm). The metal oxide sensor (MOS) responses for the Type 2 (two fans) tests were noticeably "smoother" than those of Type 1 (one fan). Note the concentrations in the test section achieved with these types of tests were too low for the IRS's to respond since it was determined experimentally that the IRS had a lower response limit of around $0.1 \% \mathrm{CH}_{4}$; the IRS did not respond or did not accurately respond to concentrations below $0.1 \% \mathrm{CH}_{4}$. Figure 4.3-3 and Figure 4.3-6 show the MOS responses over the duration of the tests. Figure 4.3-4 and Figure 4.3-7 show a zoomed in portion of the respective test to show the sensors' initial responses. It should be noted that, for better visualization of the response order, all MOS raw responses have each been offset to show approximately zero when background data was being collected at the beginning of the test. These figures (easier seen in the zoomed in figures) also show the order in which the sensors responded, note that the leak was set nearest node 1 and aimed downstream. For Type 2 tests, the sensors seemed to consistently respond in order from Node 1 to 10 (this order is labeled with numbered circles in Figure 4.3-7), while for the Type 1 tests, the order of response is more difficult to determine. It should be noted that $\mathrm{CH}_{4}$ was supplied to the face sampling locations for the tests shown in all figures for test Types 1-4. 


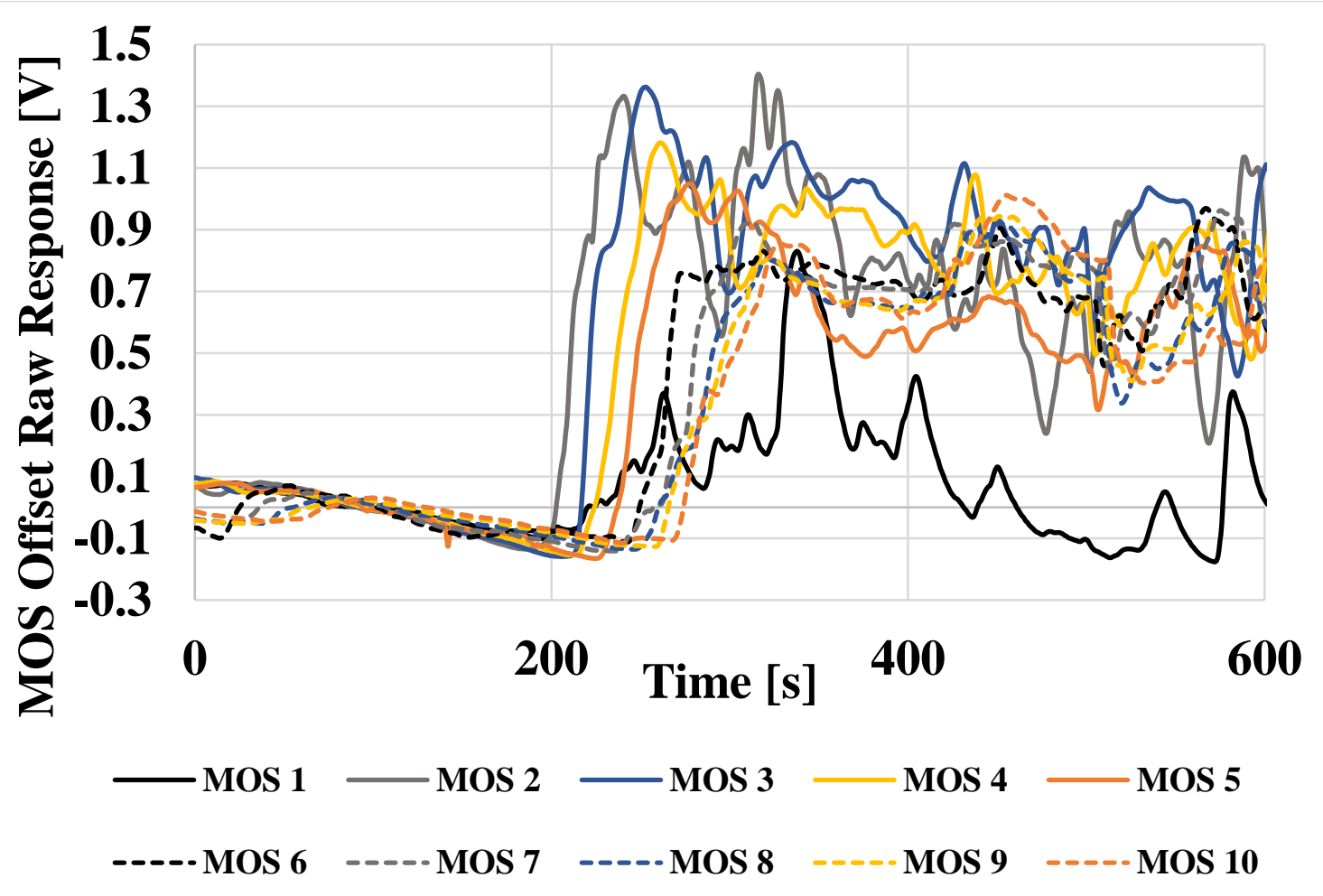

Figure 4.3-3: Type 1 FFS Test - MOS offset raw responses for sampling locations 1-10.

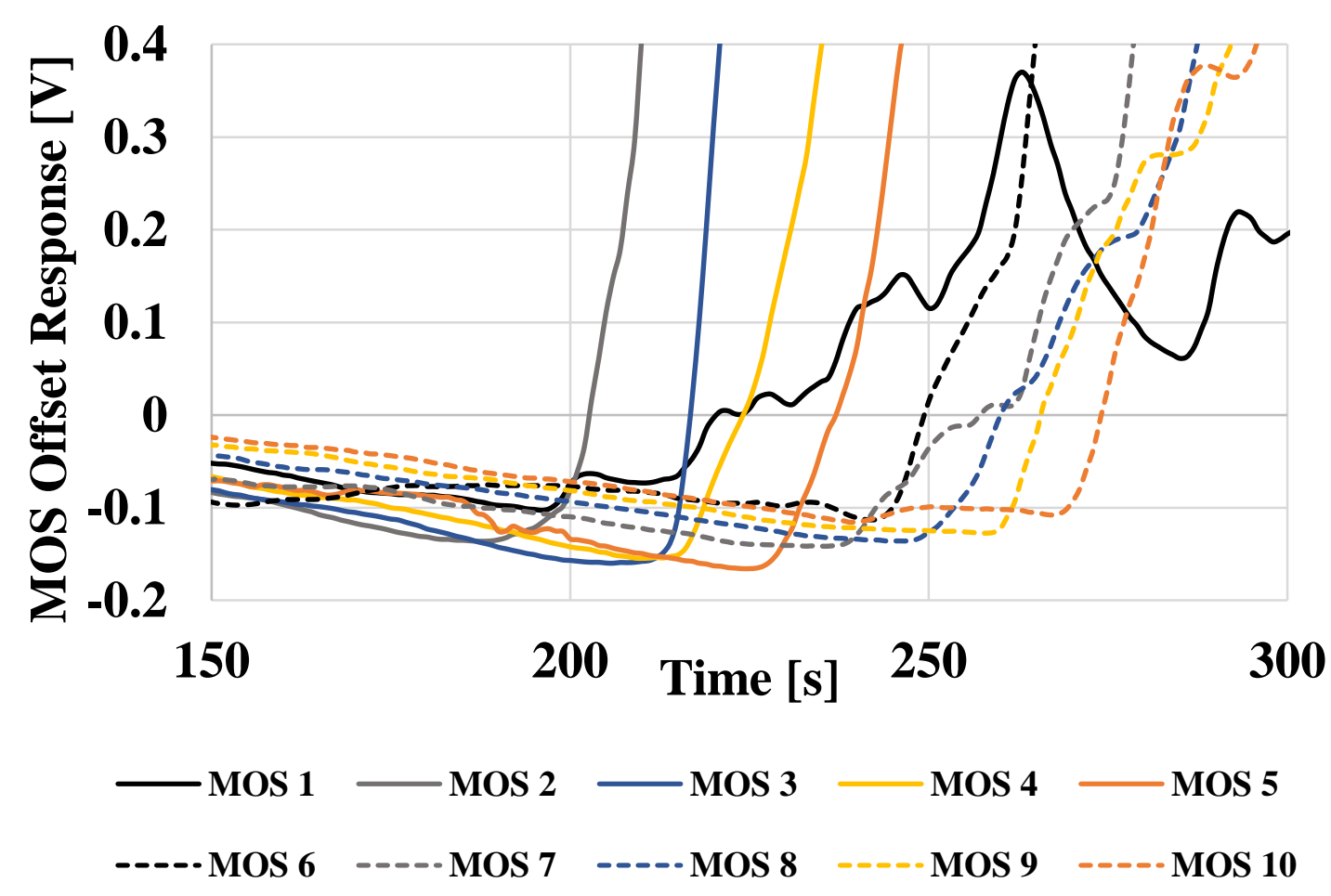

Figure 4.3-4: Type 1 FFS Test - MOS offset raw response zoomed into initial response. 

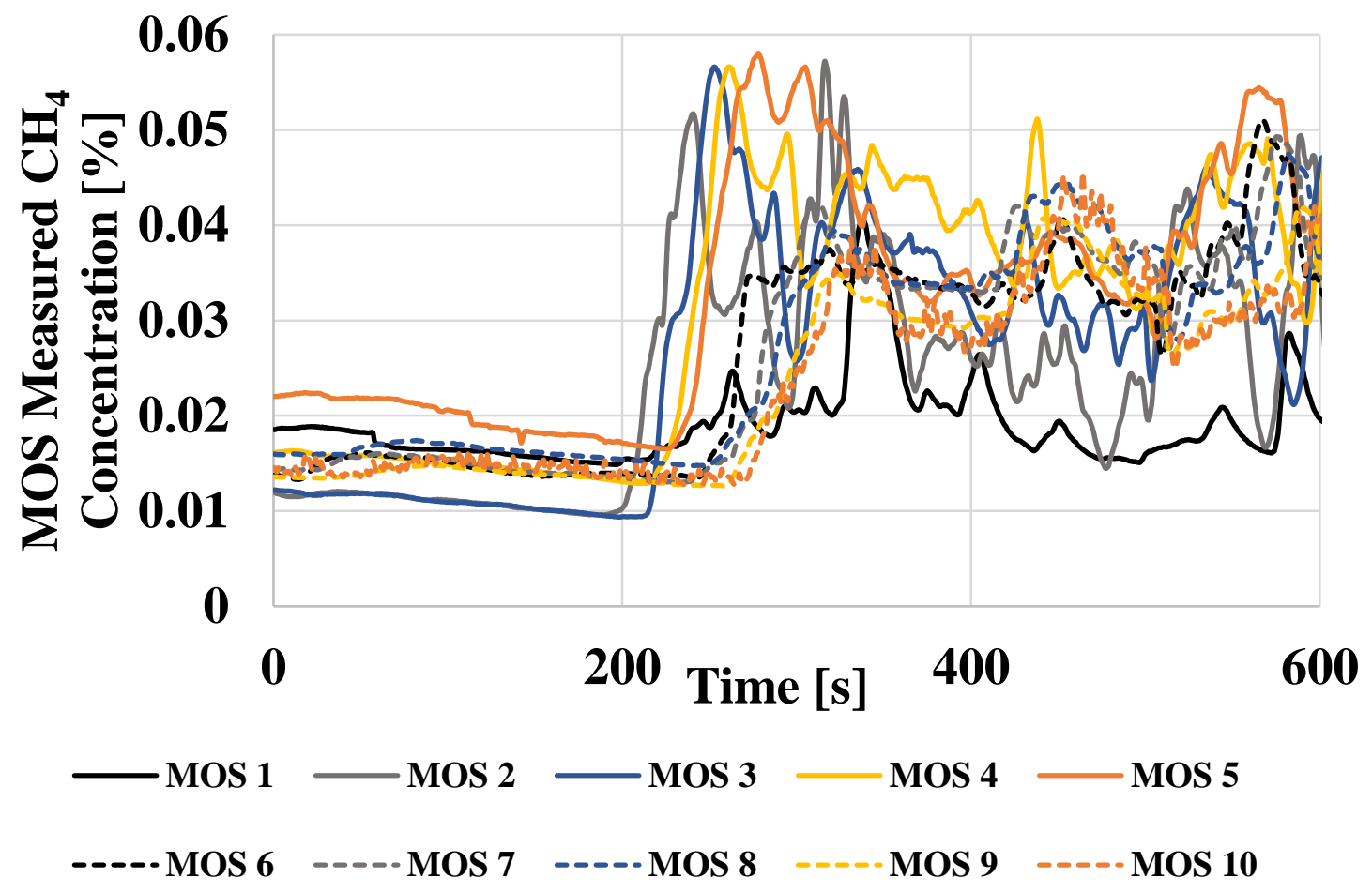

Figure 4.3-5: Type 1 FFS Test - MOS responses for sampling locations 1-10.

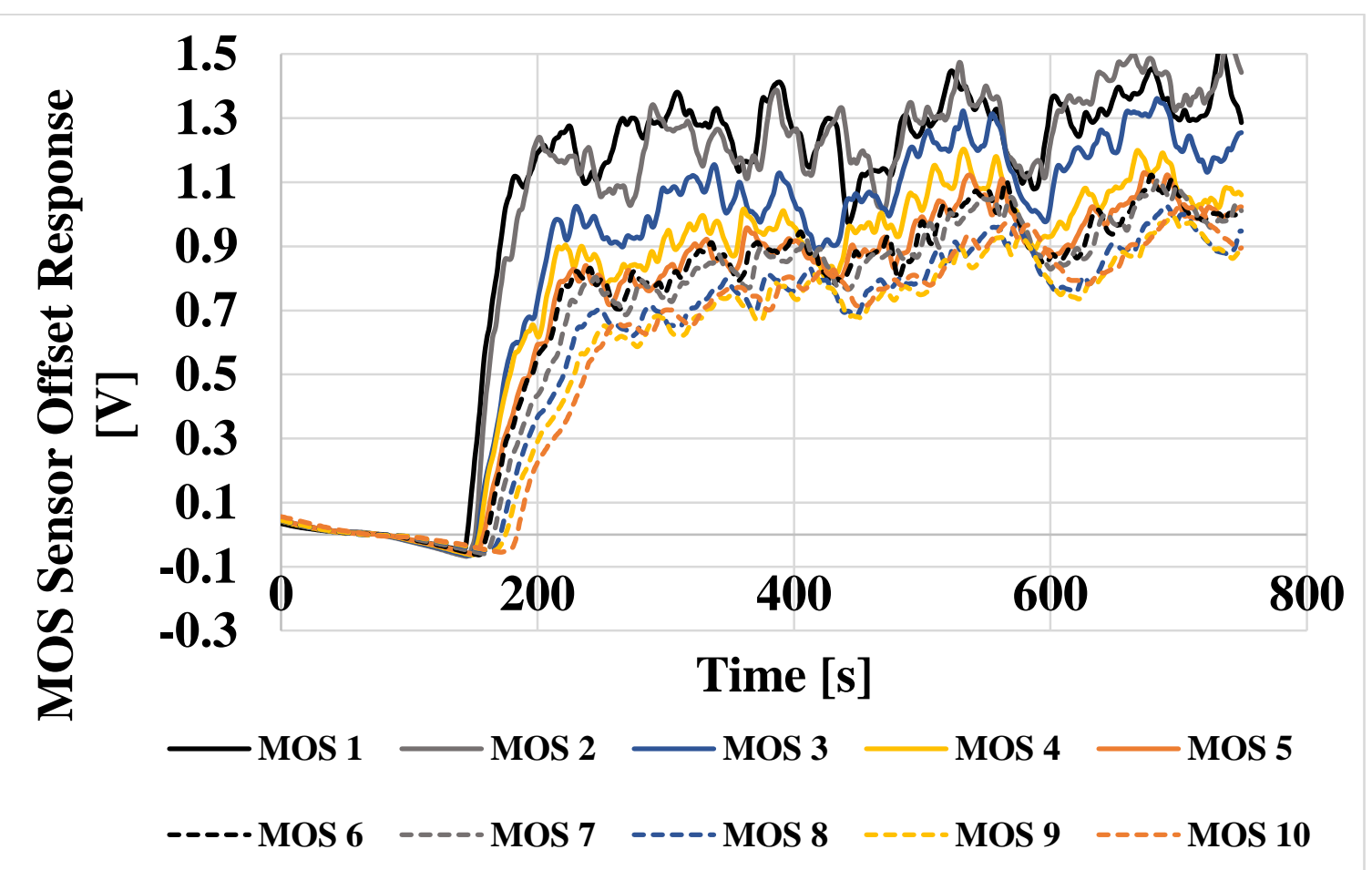

Figure 4.3-6: Type 2 FFS Test - MOS offset raw responses for sampling locations 1-10. 


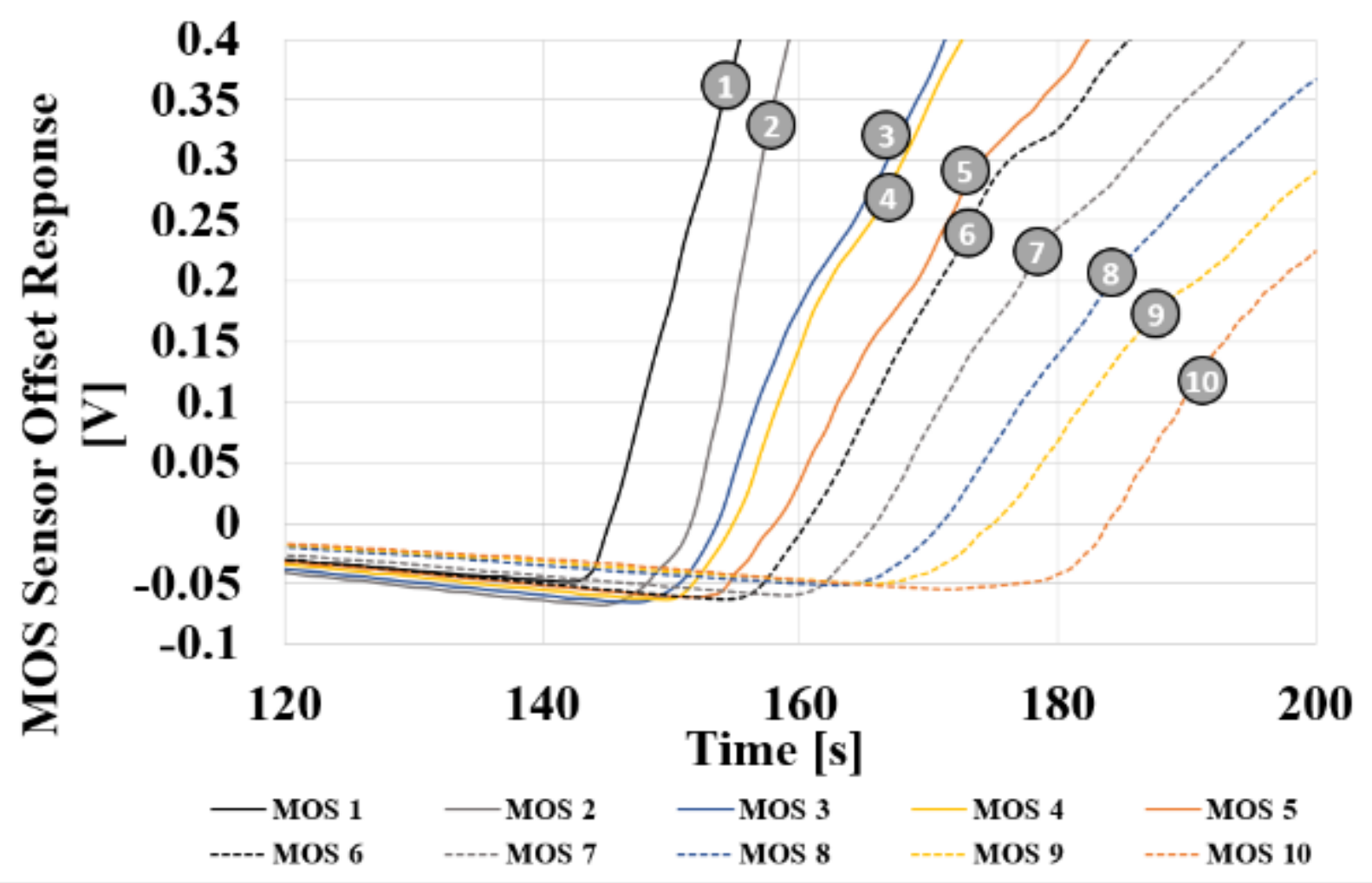

Figure 4.3-7: Type 2 FFS Test - MOS offset raw responses zoomed into initial response.
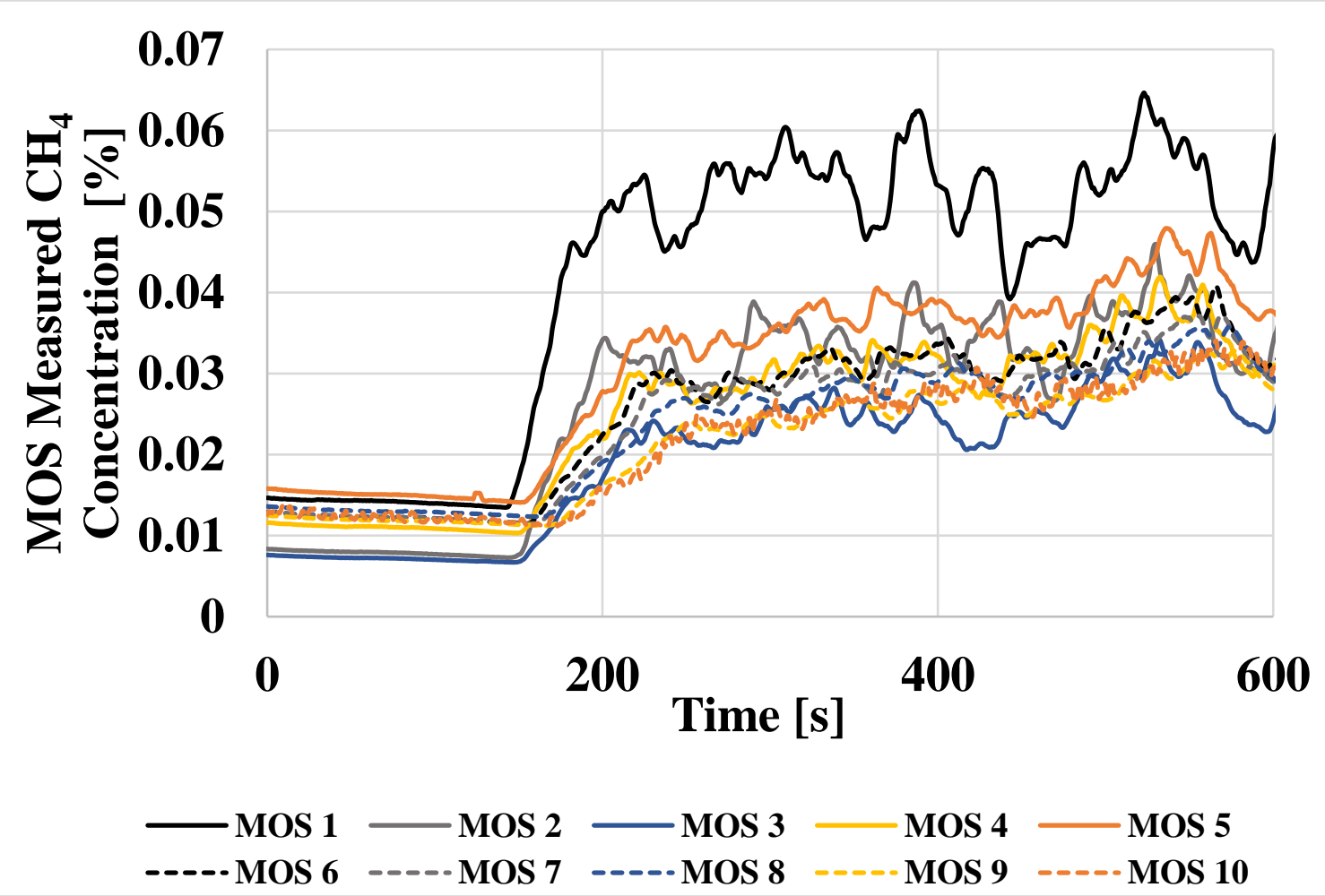

Figure 4.3-8: Type 2 FFS Test - MOS responses for sampling locations 1-10. 
Figure 4.3-9 shows the average of each response between 400 and 600 seconds. There appeared to be a general decrease in concentration as the $\mathrm{CH}_{4}$ leak progressed from Node 1 to Node 10; this would make sense as the amount of dilution and mixing would increase as the $\mathrm{CH}_{4}$ moved progressively further away from the leak location.

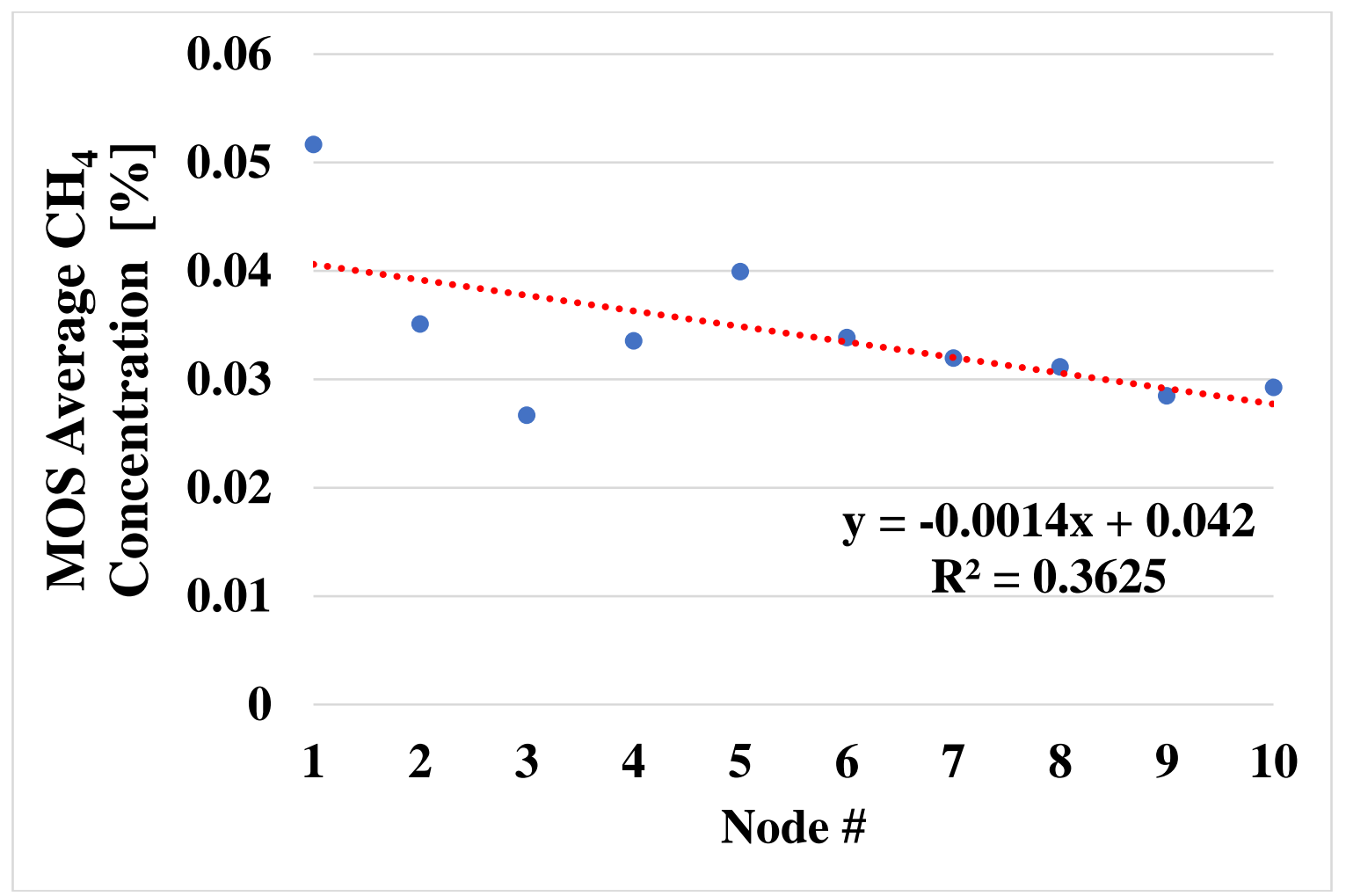

Figure 4.3-9: MOS response averages for nodes 1-10.

\section{Type 3 and Type 4}

As previously stated, approximately 2832 SLPM (100 scfm) of $2 \% \mathrm{CH}_{4}$ was "leaked" into the mock mine and diffused quickly before reaching the sampling locations. As such, the IRS sensors, which are more responsive and accurate nearer the control set points, did not show clear trends for tests of Type 1 and 2. Therefore, Type 3 and 4 tests were completed to assess both $\mathrm{CH}_{4}$ sensors. Figure 4.3-10 and Figure 4.3-11 show the responses of the IRS and MOS for a Type 3 test, respectively. To analyze the responses of the IRS and MOS, 20 second averages were taken at the peak response of each sensor. Table 4.3-3 presents the peak responses along with the percent difference between them. The percent difference values are highlighted with green, yellow, and red; where green represents a percent difference lower than $\pm 10 \%$ ("good"), yellow represents a percent difference between $\pm 10 \%$ and $\pm 20 \%$, and red represents a percent difference above $\pm 20 \%$ ("bad"). Out of the ten sampling nodes, seven were green, two were yellow, and only one was red. 
It should be noted that due to the shorter response times of the MOS, there was more fluctuation in concentration at the peaks than for the IRS; they are able to respond quicker to the inconsistencies of the $\mathrm{CH}_{4}$ concentration of the sample

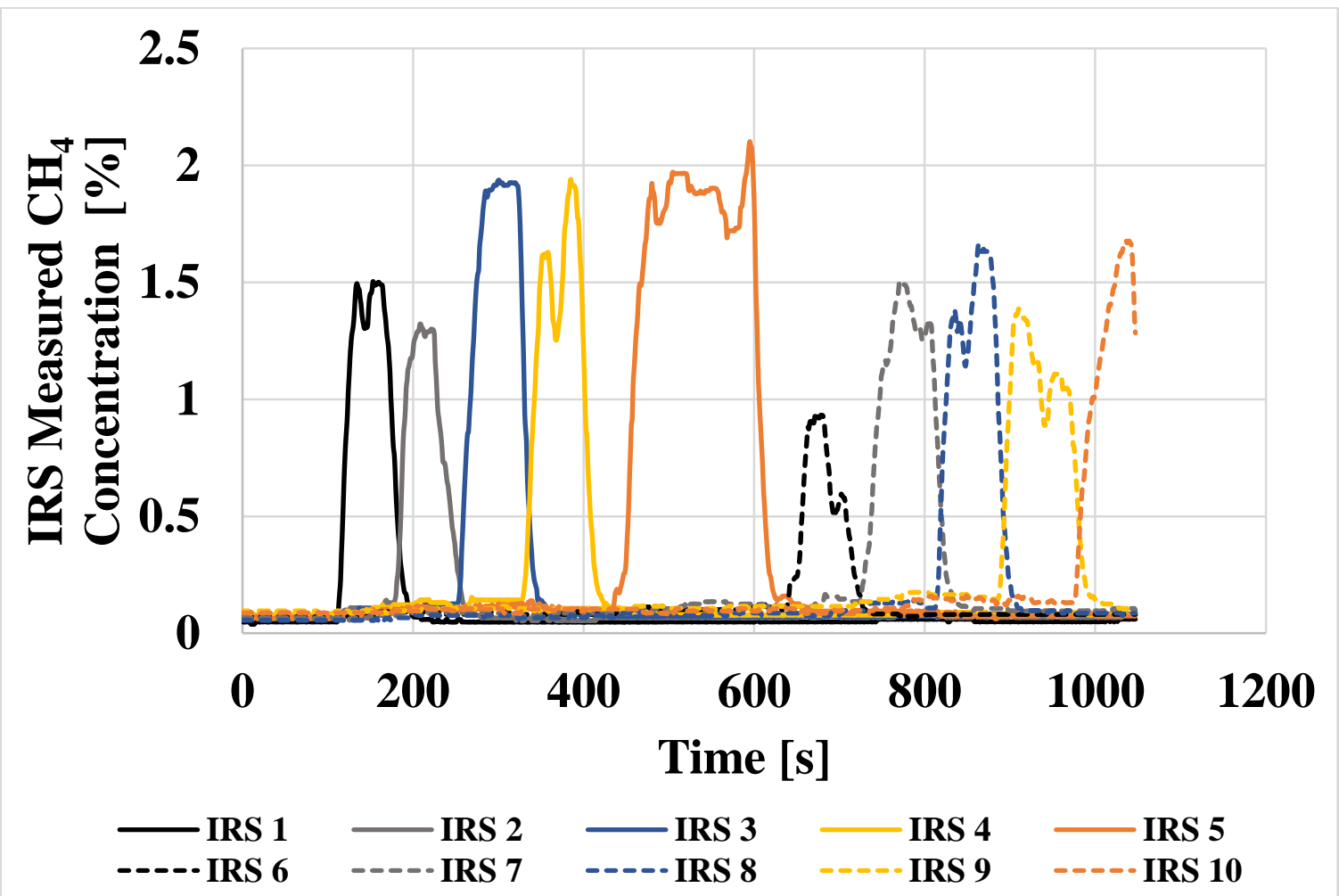

Figure 4.3-10: Type 3 FFS test - IRS responses for sampling locations 1-10. 


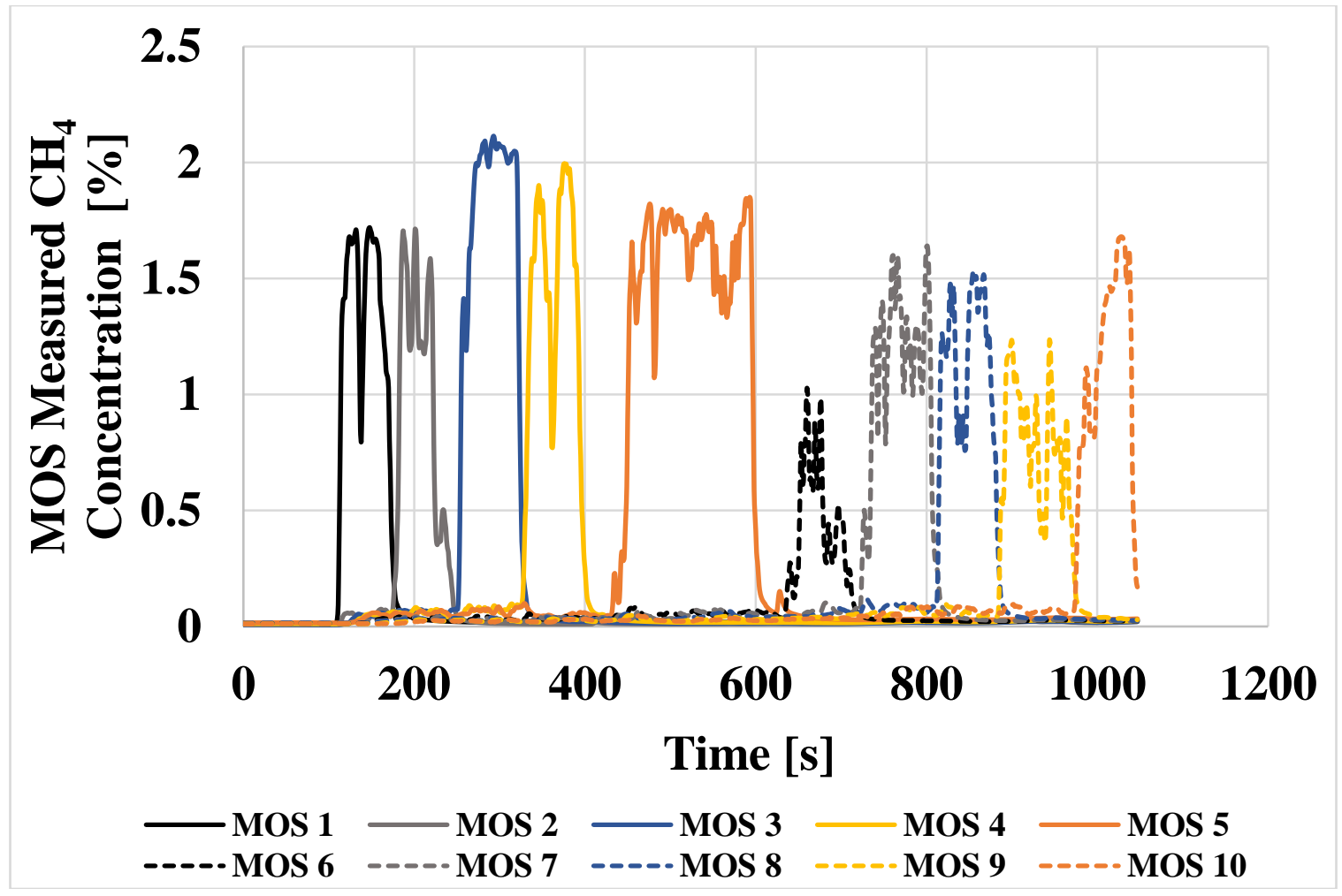

Figure 4.3-11: Type 3 FFS test - MOS responses for Sampling Locations 1-10.

Table 4.3-3: Type 3 FFS Test - Percent difference between peak responses (20 s averages) of MOS and IRS.

\begin{tabular}{|c|c|c|c|}
\hline \multirow{2}{*}{$\begin{array}{c}\text { Sampling Node } \\
\#\end{array}$} & \multicolumn{2}{|c|}{ Average Response } & \multirow{2}{*}{$\begin{array}{c}\text { Percent } \\
\text { Difference }\end{array}$} \\
\cline { 2 - 3 } & MOS & IRS & {$[\%]$} \\
\hline $\mathbf{1}$ & {$[\mathbf{p p m}]$} & {$[\mathbf{p p m}]$} & -6.49 \\
\hline $\mathbf{2}$ & 15,008 & 14,064 & -7.25 \\
\hline $\mathbf{3}$ & 13,626 & 12,672 & -7.66 \\
\hline $\mathbf{4}$ & 20,629 & 19,108 & -3.64 \\
\hline $\mathbf{5}$ & 14,889 & 14,357 & 10.70 \\
\hline $\mathbf{6}$ & 17,466 & 19,441 & 10.35 \\
\hline $\mathbf{7}$ & 13,115 & 8536 & 9.78 \\
\hline $\mathbf{8}$ & 14,135 & 14,464 & 1.02 \\
\hline $\mathbf{9}$ & 10,188 & 14,280 & 20.52 \\
\hline $\mathbf{1 0}$ & 14,901 & 12,518 & 8.30 \\
\hline
\end{tabular}

In further analyses of these results, an attempt was made to determine why Node 9 had a relatively high percent difference. Covariances with other variables such as $\mathrm{RH}$, temperature, and pressure were examined but none were found. Another factor taken into consideration was the greater 
response time for the IRS; if this were the issue, it would be expected that the IRS measurement would be lower than that of the MOS. However, this was not the case, the MOS measurement was lower. Therefore, it was believed that the high percent difference was due to issues with the MOS sensor itself.

Figure 4.3-12 and Figure 4.3-13 show the responses of the IRS and MOS for a Type 4 test. Table 4.3-4 provides the peak response values. The responses for the MOS were generally higher than for the IRS. This was most likely due to the shorter response times for the MOS; the IRS may not respond quick enough to see the full concentration of the sample before the $\mathrm{CH}_{4}$ supply source has moved past the sampling location.

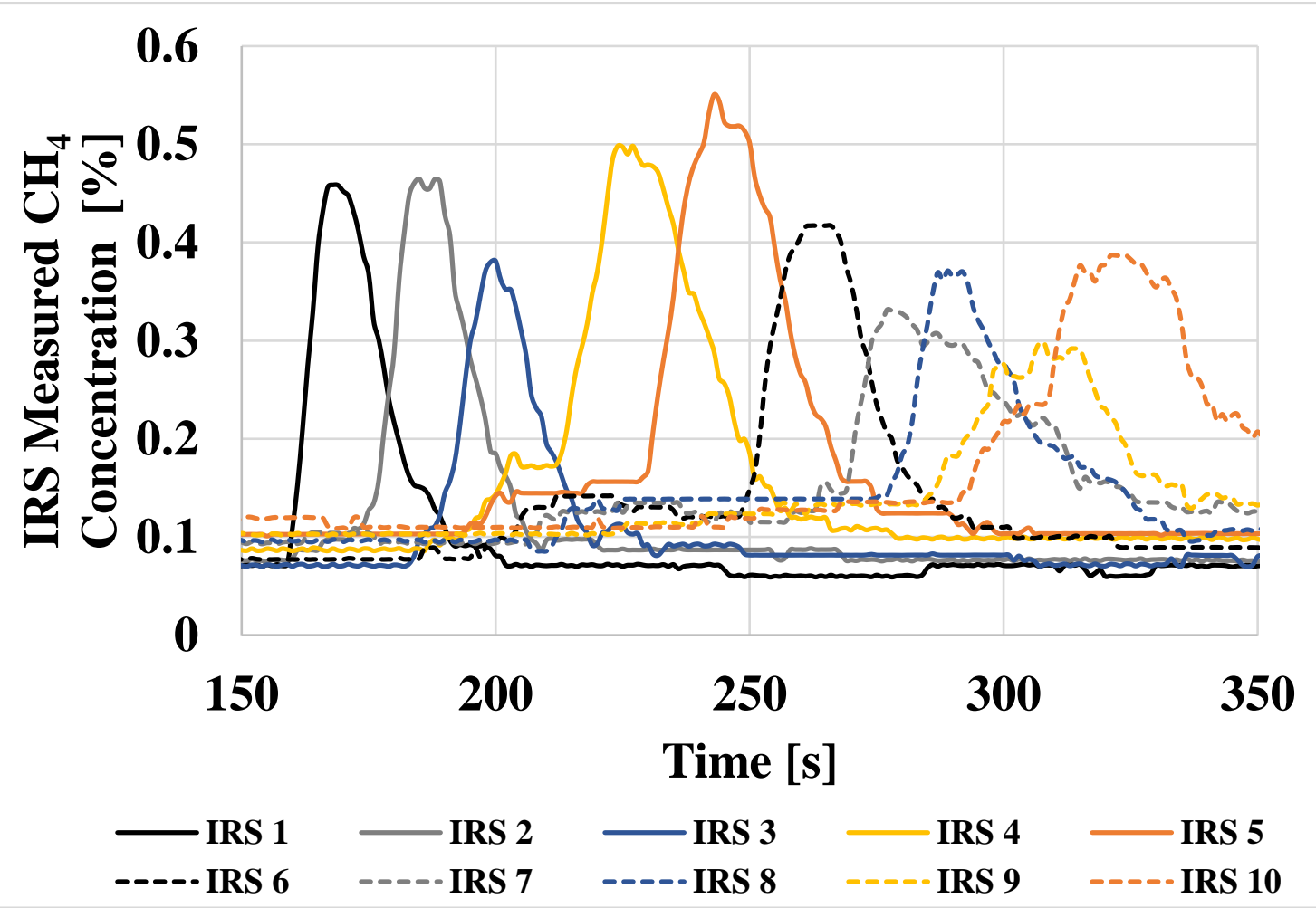

Figure 4.3-12: Type 4 FFS test - IRS responses for sampling locations 1-10. 


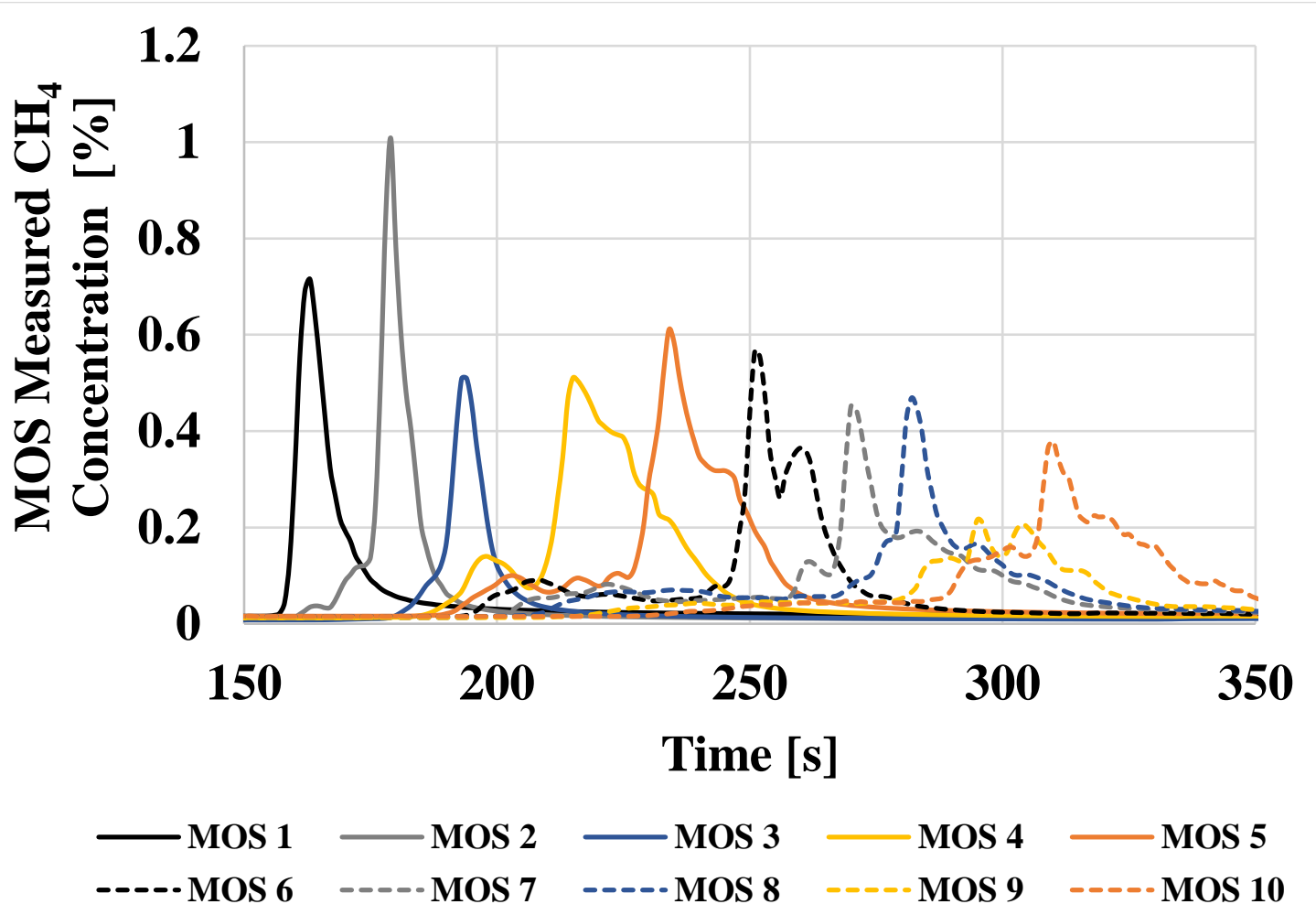

Figure 4.3-13: Type 4 FFS test - MOS responses for sampling locations 1-10.

Table 4.3-4: Type 4 FFS Test - Peak responses of MOS and IRS.

\begin{tabular}{|c|c|c|}
\hline & \multicolumn{2}{|c|}{ Peak Response } \\
\hline $\begin{array}{c}\text { Sampling } \\
\text { Node \# }\end{array}$ & $\left.\begin{array}{c}\text { MOS } \\
{[\% \mathbf{C H} \text { }}\end{array}\right]$ & $\begin{array}{c}\text { IRS } \\
{[\% \mathbf{C H} \text { ] }]}\end{array}$ \\
\hline $\mathbf{1}$ & 0.716 & 0.459 \\
\hline $\mathbf{2}$ & 1.008 & 0.465 \\
\hline $\mathbf{3}$ & 0.509 & 0.381 \\
\hline $\mathbf{4}$ & 0.510 & 0.498 \\
\hline $\mathbf{5}$ & 0.611 & 0.551 \\
\hline $\mathbf{6}$ & 0.567 & 0.417 \\
\hline $\mathbf{7}$ & 0.452 & 0.331 \\
\hline $\mathbf{8}$ & 0.469 & 0.371 \\
\hline $\mathbf{9}$ & 0.216 & 0.297 \\
\hline $\mathbf{1 0}$ & 0.379 & 0.387 \\
\hline
\end{tabular}

Relay/Alarm Control

Figure 4.3-14 shows the results of the alarm tests. When each sensor responded above and then dropped below the threshold of $1 \% \mathrm{CH}_{4}$, the relay was turned on and off, respectively. The shaded region on the plot represents the time where the relay was turned on. It should be noted that there was a connection issue with the sensor at Node 8 that was resolved for subsequent tests. 


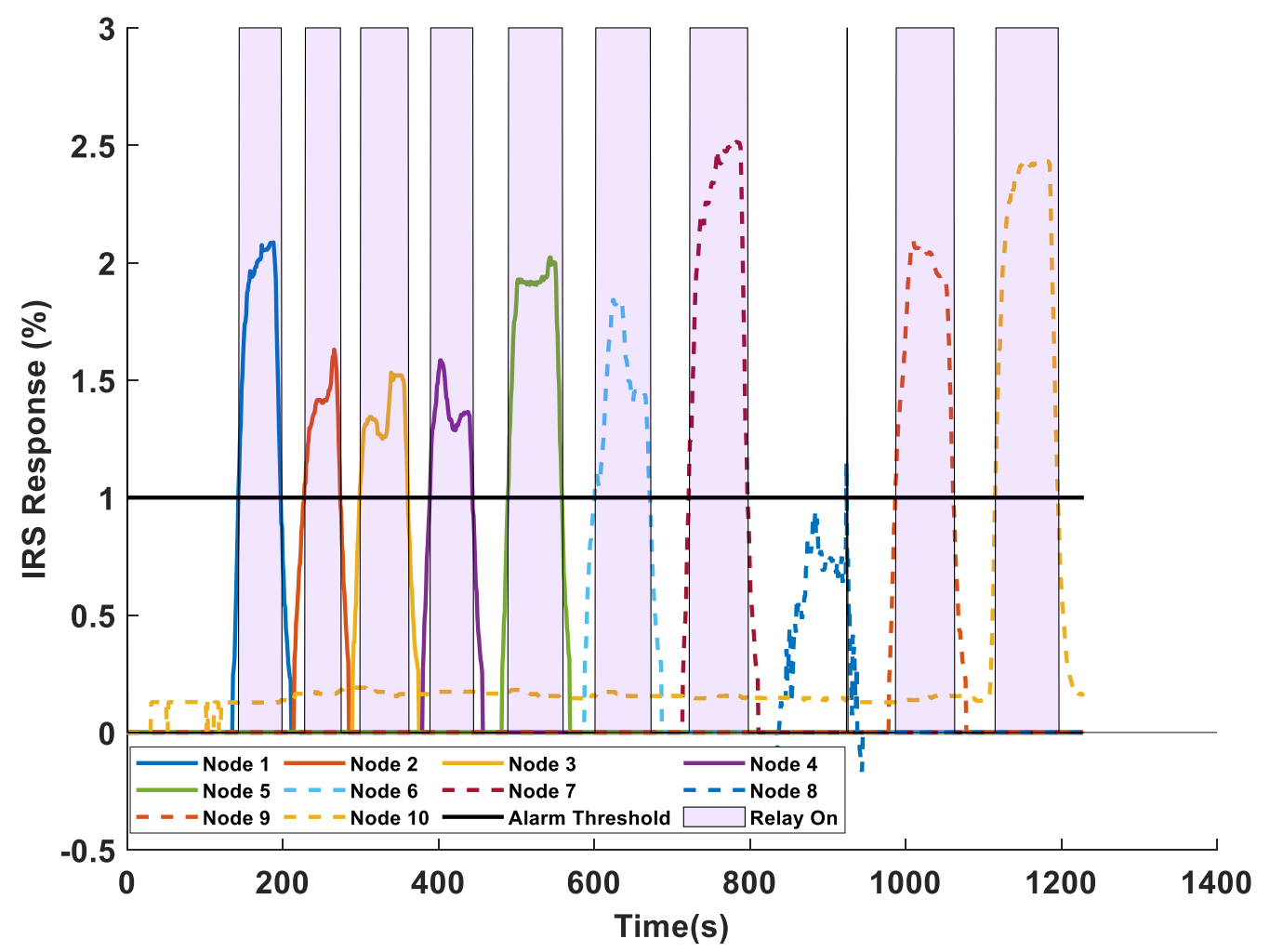

Figure 4.3-14: Visualization of relay control.

\subsection{Power Consumption}

Table 1.1-1 presents the results of the power consumption test for when the valve is turned off and when it is turned on. The valve comprised around $78 \%$ of the total power consumption. Komatsu integrated a 12 VDC 2.5 A power supply into each shield to power components such as the shield control unit [141]. Therefore, the integration of an additional, similar power supply could provide an already approved solution to power each sampling unit.

Table 4.4-1: Power Consumption for a Single Unit.

\begin{tabular}{|c|c|c|c|}
\hline & $\begin{array}{c}\text { Supply Voltage } \\
{[\text { V] }}\end{array}$ & $\begin{array}{c}\text { Current } \\
{[\mathbf{A}]}\end{array}$ & $\begin{array}{c}\text { Power } \\
{[\mathbf{W}]}\end{array}$ \\
\hline Valve Off & 24 & 0.199 & 4.8 \\
\hline Valve On & 24 & 0.919 & 22.1 \\
\hline
\end{tabular}




\subsection{Proposed Sampling Method (Water Ejector)}

\section{Initial Design}

Table 4.5-1 presents the designed ejector dimensions. A CAD drawing labelling these dimensions is shown in Appendix F. Figure 4.5-1 shows the 3D printed ejector.

Table 4.5-1: Initial ejector design dimensions.

\begin{tabular}{|c|c|}
\hline Nozzle Diameter & $\mathrm{D}_{\mathrm{n}}=1.1 \mathrm{~mm}$ \\
\hline Nozzle Angle & $\theta_{\mathrm{n}}=18^{\circ}$ \\
\hline Mixing Chamber Diameter & $\mathrm{D}_{\mathrm{m}}=2.2 \mathrm{~mm}$ \\
\hline Mixing Chamber Length & $\mathrm{L}_{\mathrm{m}}=22.1 \mathrm{~mm}$ \\
\hline Included Diffuser Angle & $\theta_{\mathrm{d}}=6^{\circ}$ \\
\hline Diffuser Length & $\mathrm{L}_{\mathrm{d}}=22.6 \mathrm{~mm}$ \\
\hline Diffuser Outlet Diameter & $\mathrm{D}_{\mathrm{d}}=4.6 \mathrm{~mm}$ \\
\hline Distance between nozzle outlet and mixing chamber inlet & $\mathrm{NXP}^{\circ}=1.1 \mathrm{~mm}$ \\
\hline Water Inlet Diameter & $\mathrm{D}_{\mathrm{w}}=3.2 \mathrm{~mm}$ \\
\hline Air inlet Diameter & $\mathrm{D}_{\mathrm{a}}=3.2 \mathrm{~mm}$ \\
\hline
\end{tabular}

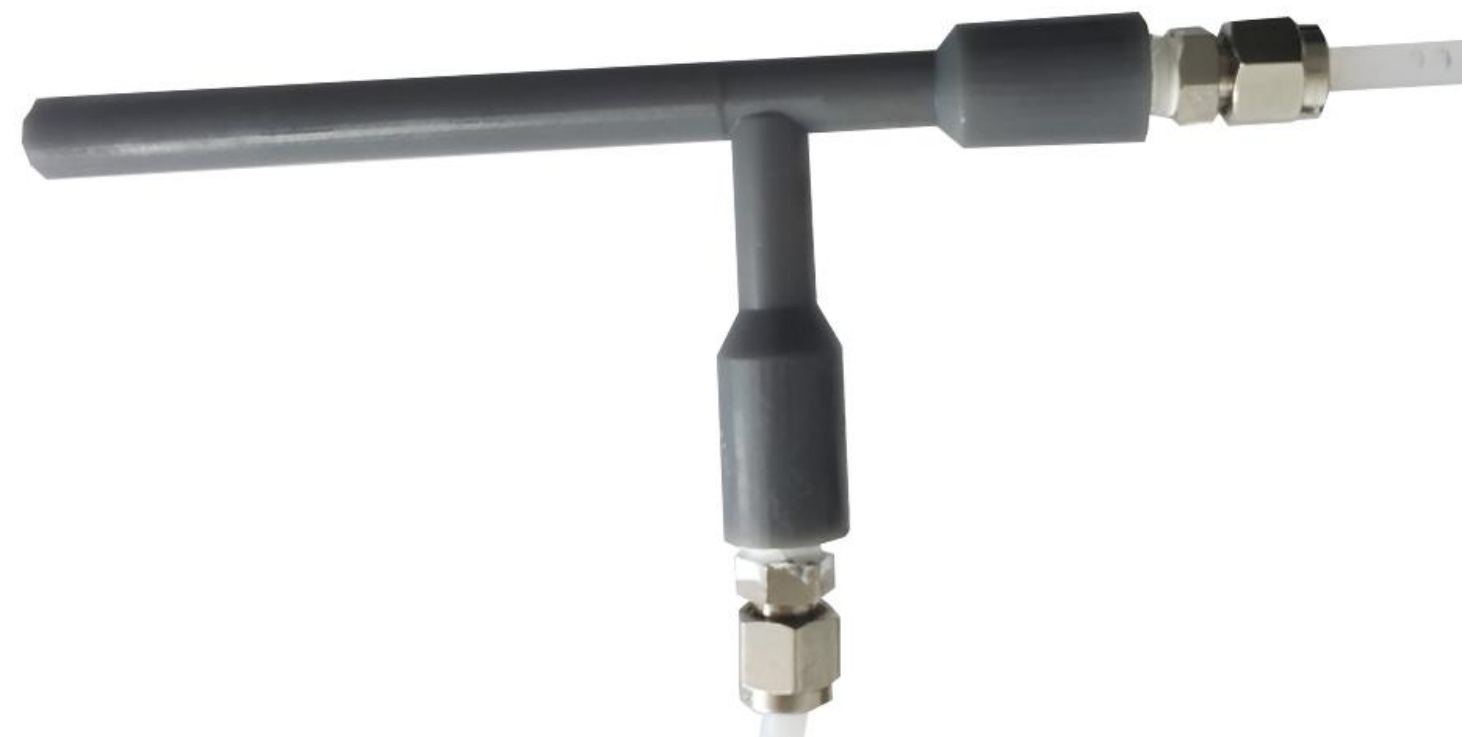

Figure 4.5-1: 3D printed ejector.

\section{Laboratory Testing}

The ejector was tested in the laboratory and eight operational points were achieved. Figure 4.5-2 and Table 4.5-2 provide the results of first test conducted with the 3D printed ejector, where the water pressure remained constant and the suction pressure was controlled with a valve. The ejector had two distinct operational curves. As the suction pressure was decreased with the valve, the 
ejector transitioned from the "High" pressure curve to the "Low" pressure curve around $93.8 \mathrm{kPa}$ (13.6 psia). It was believed that a flow regime transition occurred between the "High" and "Low" pressure curves. There was an audible and visual change in the ejector flow when this transition occurred. Dirix and Wiele investigated the mass transfer in a jet loop reactor, which consisted of a liquid-gas ejector. Their experiments showed that at higher gas flowrates, around a flow ratio of 1.3, a transition from bubble flow to jet flow occurred [176]. Otake et al. similarly concluded that the same transition occurred when the flow ratio was between 1 and 2 [177]. Dirix and Wiele also noted that in bubble flow, the interfacial area between the dispersed bubbles and the continuous liquid stream was directly proportional to the gas holdup, unlike in jet flow. They showed that the mass transfer rate in jet flow was independent of the gas holdup for flow ratios less than 3 [176]. In an ejector, a liquid jet forms as the liquid exits the nozzle and travels axially through the ejector. At some axial location, the jet breaks up and the gas disperses into the liquid, creating bubbly flow. According to Cunningham and Dopkin, an ejectors performance depends on the location of the jet break-up [178]. If this breakup occurs too soon (at an "early" location), like in the mixing chamber, the energy dissipation rate from the liquid inhibits the entrainment of the suction fluid. Cunningham and Dopkin concluded that the optimum location of jet breakup was at the end of the mixing chamber [178].

Based on the information found in the literature discussed above, it was believed that the transition which occurred in the multi-nozzle ejector tests was a bubble to jet flow regime transition. The jet breakup was likely occurring before the end of the mixing chamber when operating on the "High" pressure curve, before the transition. The ejector performance increased after the transition (on the "Low" pressure curve) since the air flowrate decreased at a lower rate with decrease in suction pressure than before the transition. Therefore, in order to keep the flowrate as consistent as possible with minor fluctuations in pressure that may occur, operation on the "Low" pressure curve was ideal. While all points on the "Low" pressure curve satisfied the capability to overcome pressure losses through the sampling unit, there were no points on the "Low" pressure curve which satisfied the requirement of sampling at an air flowrate of at least 2 SLPM $(0.071 \mathrm{scfm})$. Table 4.5-2 presents only the points on the "Low" pressure curve. Note that the water pressure and flowrate for all points were $482.633 \mathrm{kPa}$ (70 psig) and $1.7 \mathrm{LPM}(0.06 \mathrm{cfm})$, respectively. 


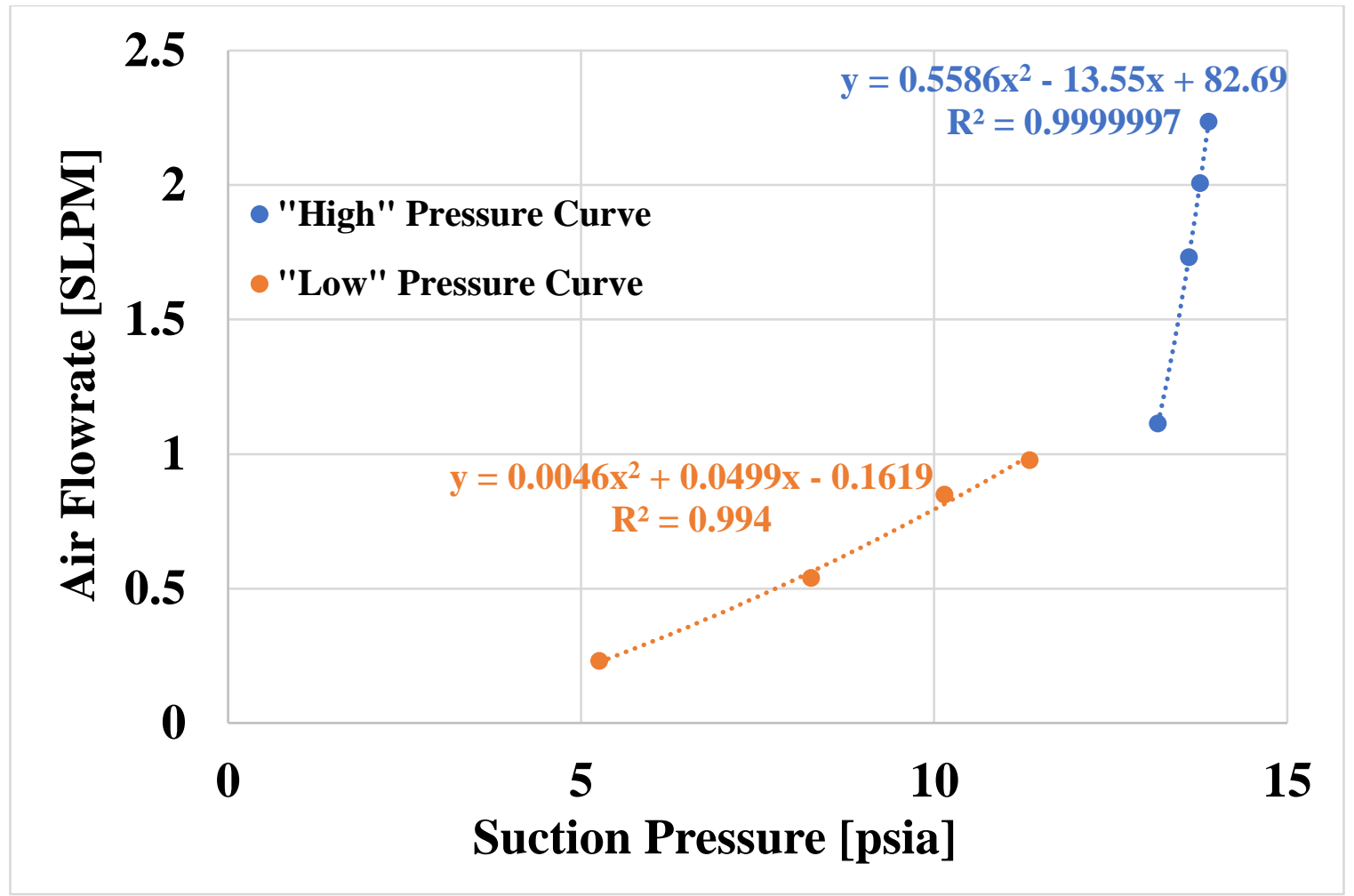

Figure 4.5-2: Ejector performance curves.

Table 4.5-2: Points of "Low" pressure curve.

\begin{tabular}{|c|c|c|}
\hline $\begin{array}{c}\text { Air Suction } \\
\text { Pressure } \\
{[\mathbf{k P a} \text { (psia)] }}\end{array}$ & $\begin{array}{c}\text { Air Flowrate } \\
\text { [SLPM] }\end{array}$ & $\begin{array}{c}\text { Air Flowrate } \\
\text { [LPM] }\end{array}$ \\
\hline $78.6(11.4)$ & 0.98 & 1.17 \\
\hline $69.6(10.1)$ & 0.85 & 1.14 \\
\hline $57.2(8.3)$ & 0.54 & 0.89 \\
\hline $36.5(5.3)$ & 0.23 & 0.60 \\
\hline
\end{tabular}

Table 4.5-3 presents the experimental results for the test where suction pressure remained constant and the water pressure was varied. 
Table 4.5-3: Initial design ejector test with constant air suction pressure.

\begin{tabular}{|l|c|c|c|c|c|}
\hline $\begin{array}{c}\text { Water } \\
\text { Pressure } \\
\text { [psig] }\end{array}$ & $\begin{array}{c}\text { Air Mass } \\
\text { Flowrate } \\
{[\text { [SLPM] }]}\end{array}$ & $\begin{array}{c}\text { Air } \\
\text { Volumetric } \\
\text { Flowrate } \\
{[\mathbf{L P M}]}\end{array}$ & $\begin{array}{c}\text { Water } \\
\text { Flowrate } \\
{[\mathbf{L P M}]}\end{array}$ & $\begin{array}{c}\text { Outlet } \\
\text { Pressure } \\
{[\text { psia] }]}\end{array}$ & $\begin{array}{c}\text { Flow } \\
\text { Ratio }\end{array}$ \\
\hline $\mathbf{4 0}$ & 0.50 & 0.70 & 0.69 & 13.47 & 1.01 \\
\hline $\mathbf{5 0}$ & 0.68 & 0.95 & 0.76 & 13.55 & 1.24 \\
\hline $\mathbf{6 0}$ & 0.91 & 1.27 & 0.83 & 13.65 & 1.52 \\
\hline $\mathbf{7 0}$ & 1.04 & 1.44 & 0.89 & 13.69 & 1.63 \\
\hline $\begin{array}{l}\text { Constants: } \\
\text { *Air Suction Pressure } \approx 11 \mathrm{psia} \\
\text { *Air Temperature } \approx 24^{\circ} \mathrm{C} \\
\text { *Water Temperature } \approx 24^{\circ} \mathrm{C}\end{array}$ \\
\end{tabular}

\section{Multi-Nozzle Design}

Table 4.5-4 presents a summary of the multi-nozzle ejector designed dimensions. Figures 4.5-6 and 4.5-7 show the CAD model of the multi-nozzle ejector disassembled and assembled, respectively. Figures 4.5-5 and 4.5-6 show the 3D printed multi-nozzle ejector de-assembled and assembled for testing, respectively. The CAD drawing with dimensions labeled is shown in Appendix F-2.

Table 4.5-4: Multi-Nozzle ejector design dimensions

\begin{tabular}{|c|c|}
\hline Nozzle Diameter & $\mathrm{D}_{\mathrm{n}}=0.45 \mathrm{~mm}$ \\
\hline Nozzle Angle & $\theta_{\mathrm{n}}=16^{\circ}$ \\
\hline Mixing Chamber Diameter & $\mathrm{D}_{\mathrm{m}}=4 \mathrm{~mm}$ \\
\hline Mixing Chamber Length & $\mathrm{L}_{\mathrm{m}}=24 \mathrm{~mm}$ \\
\hline Included Diffuser Angle & $\theta_{\mathrm{d}}=10^{\circ}$ \\
\hline Diffuser Length & $\mathrm{L}_{\mathrm{d}}=24 \mathrm{~mm}$ \\
\hline Diffuser Outlet Diameter & $\mathrm{D}_{\mathrm{d}}=8.2 \mathrm{~mm}$ \\
\hline Distance between nozzle outlet and mixing chamber inlet & $\mathrm{NXP}=4 \mathrm{~mm}$ \\
\hline Water Inlet Diameter & $\mathrm{D}_{\mathrm{w}}=6.35 \mathrm{~mm}$ \\
\hline Air inlet Diameter & $\mathrm{D}_{\mathrm{a}}=6.35 \mathrm{~mm}$ \\
\hline
\end{tabular}




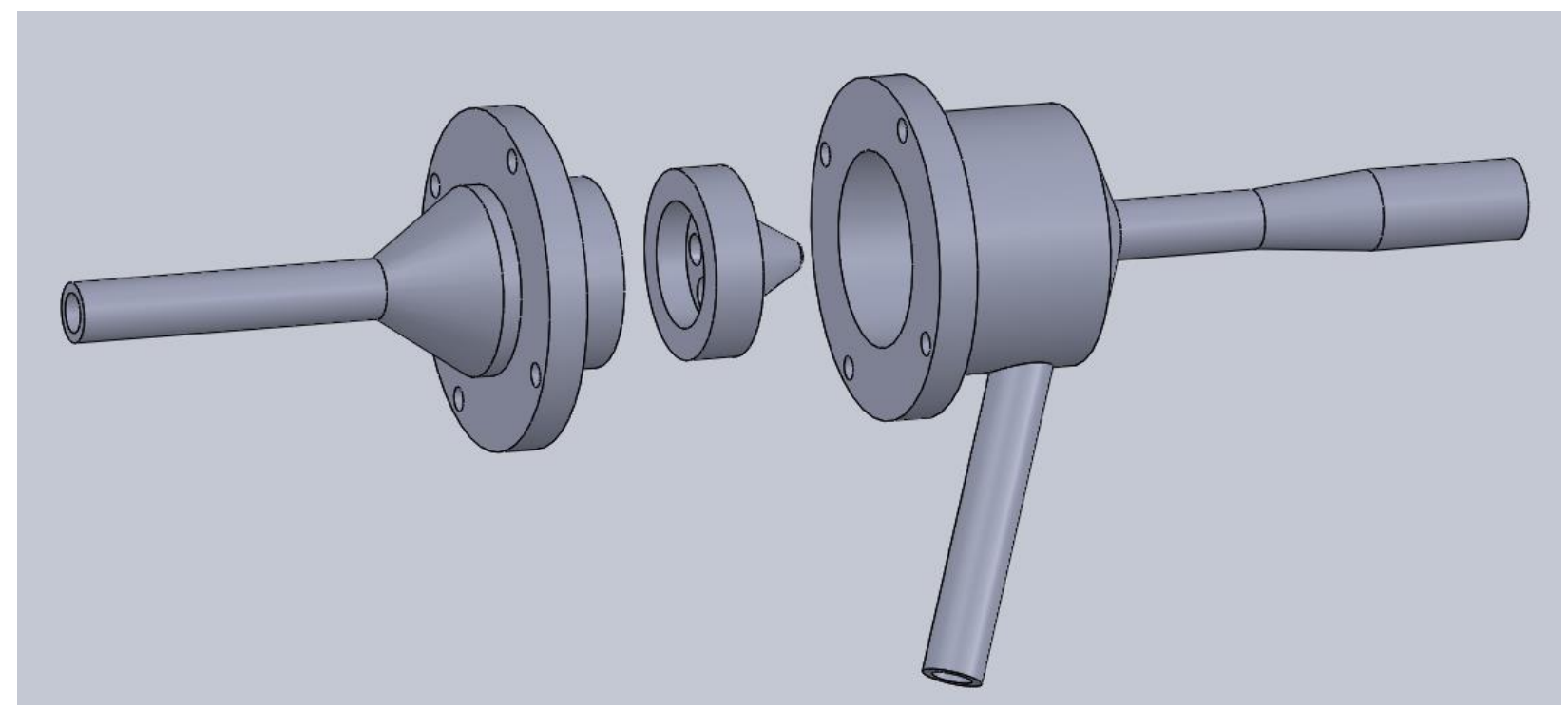

Figure 4.5-3: Disassembled multi-nozzle ejector CAD model.

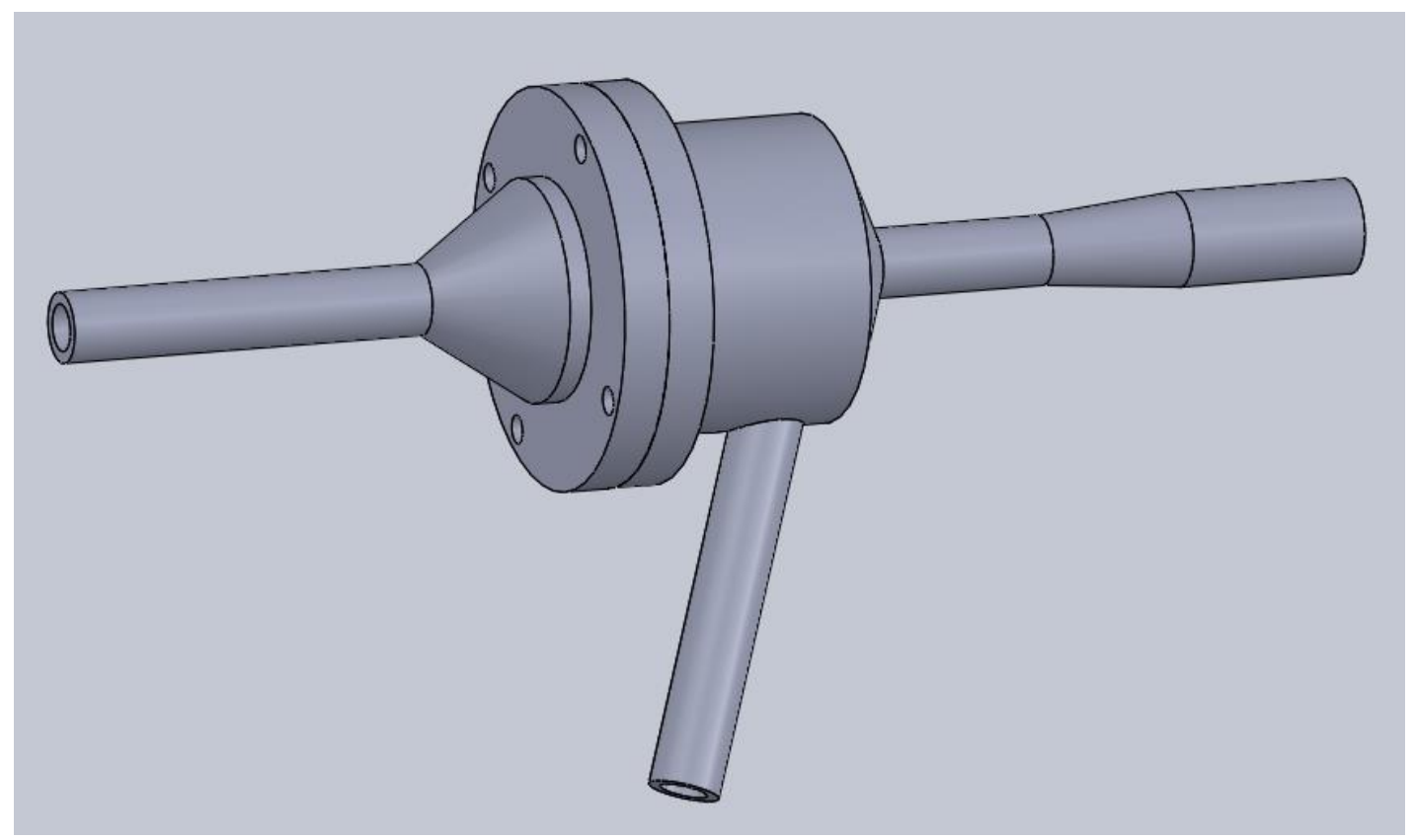

Figure 4.5-4: Assembled multi-nozzle ejector CAD model. 


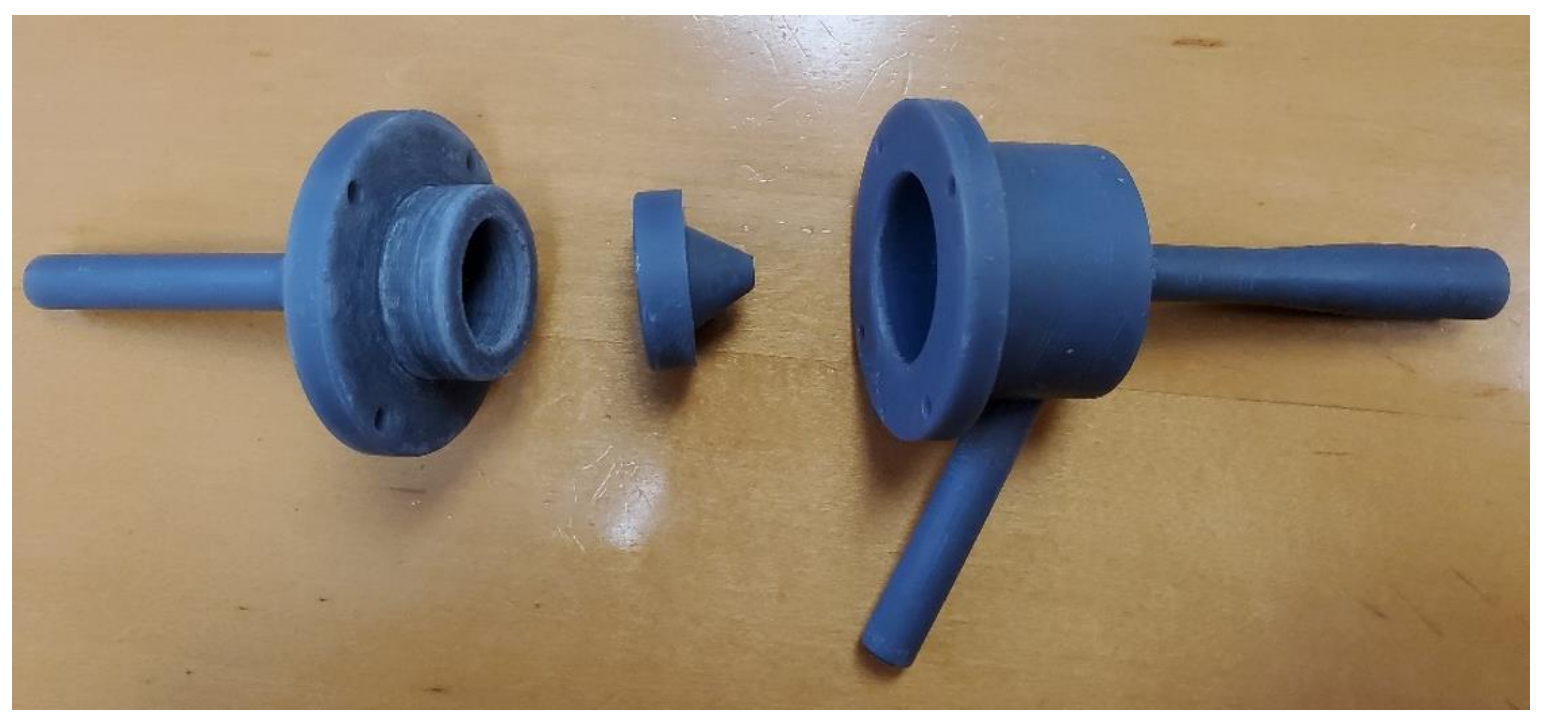

Figure 4.5-5: Disassembled multi-nozzle ejector.

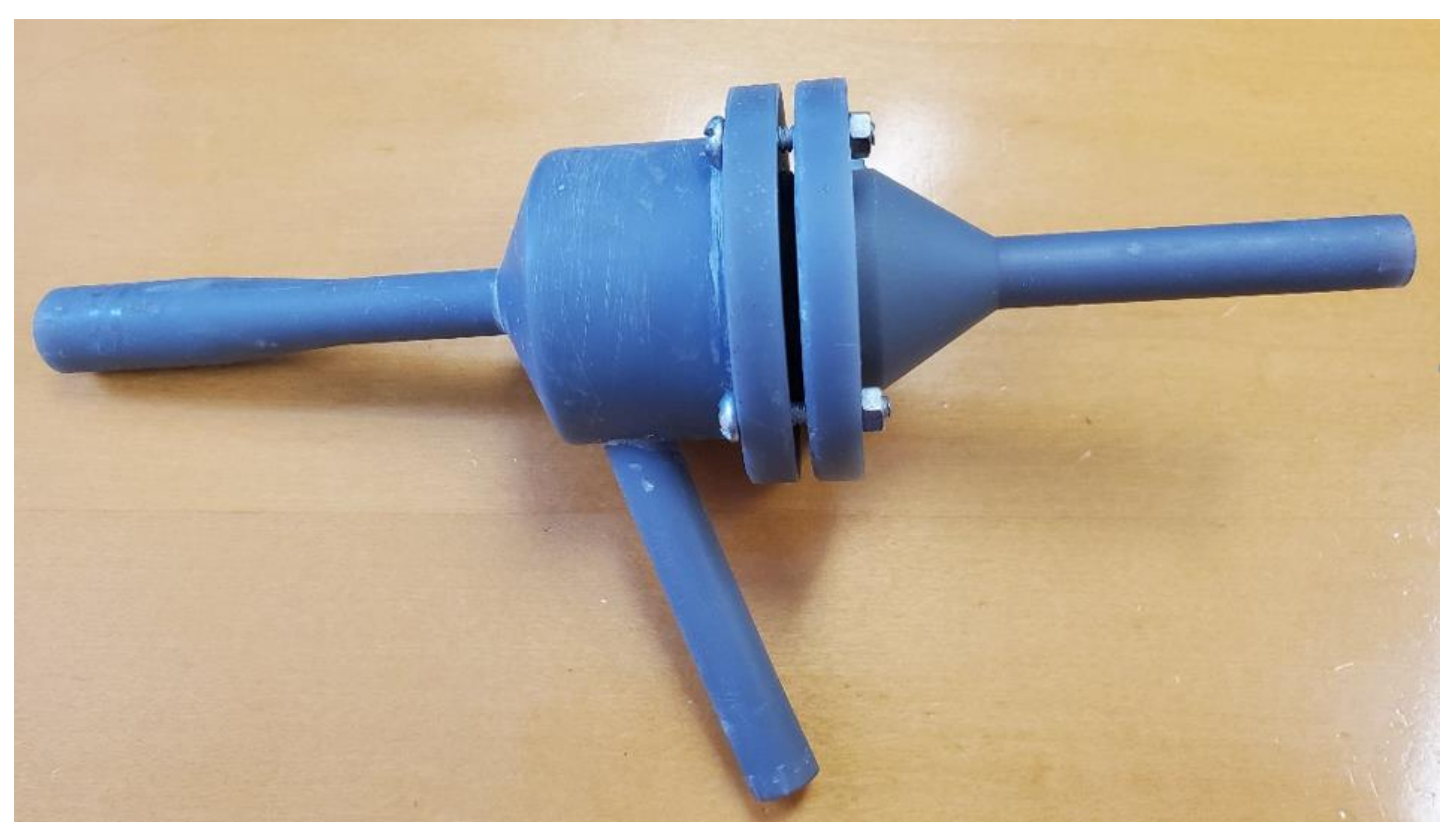

Figure 4.5-6: Assembled multi-nozzle ejector.

\section{Laboratory Testing}

Figures 4.5-7 through 4.5-11 show the results of the five tests conducted with the multi-nozzle ejector where the water pressure was around 207, 276, 310, 379, and $448 \mathrm{kPa}(30,40,45$, 55, and $65 \mathrm{psig}$ ), respectively. All five tests showed a similar phenomenon that occurred with the initial design, two distinct performance curves. The performance for the multi-nozzle ejector also increased when operating at lower pressures. The two curves are labeled in each figure. Like for the initial ejector design, operation on the "Low" pressure curve was ideal to utilize the increased 
performance and allow for more consistent flowrates with minor fluctuations in pressure that can occur. Note that to utilize the "Low" pressure curve, a throttling valve needs to be integrated with each ejector to control the suction pressure; this addition has been included in the cost estimate.

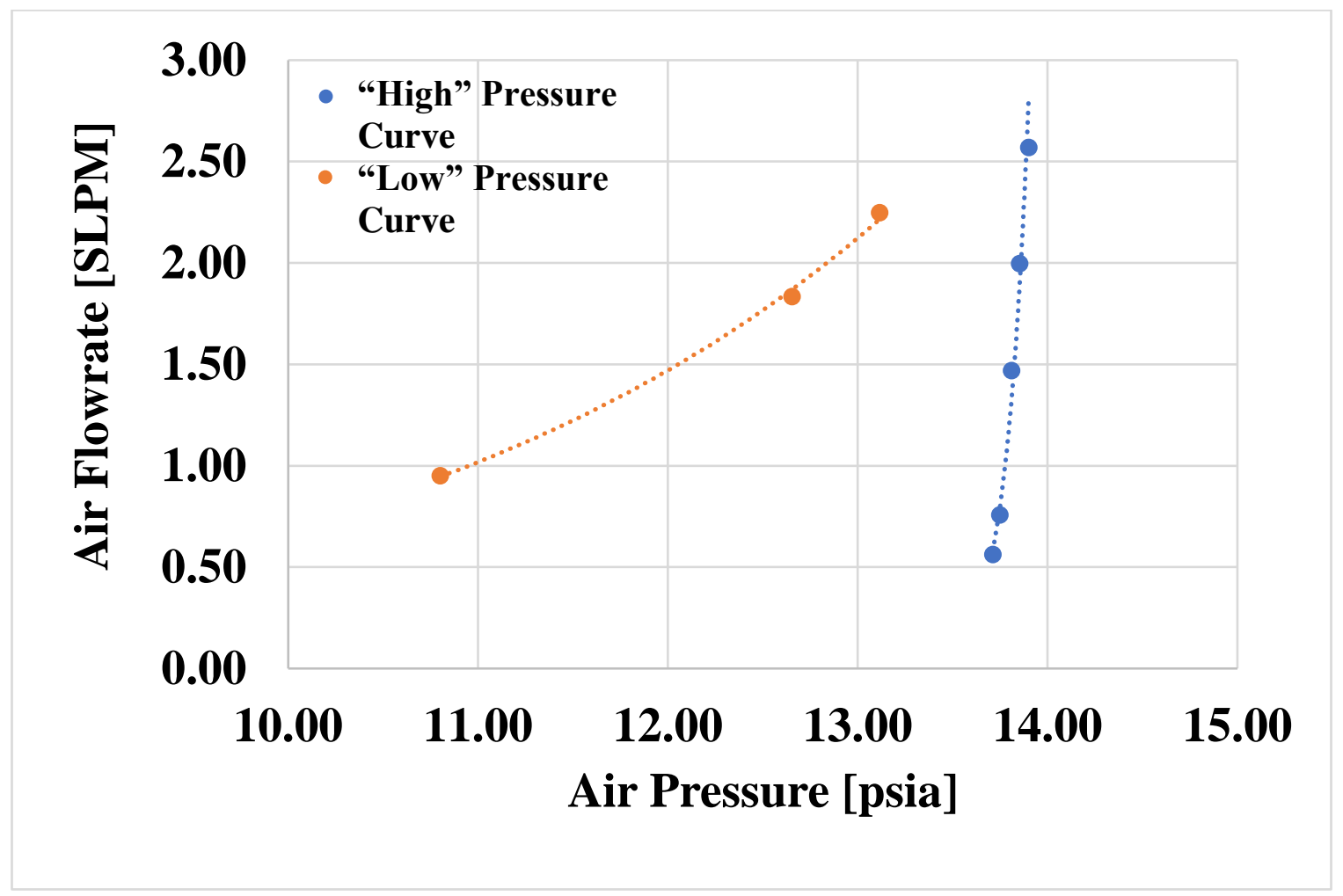

Figure 4.5-7: Multi-nozzle ejector test (water pressure $\approx 30 \mathrm{psig}$ ). 


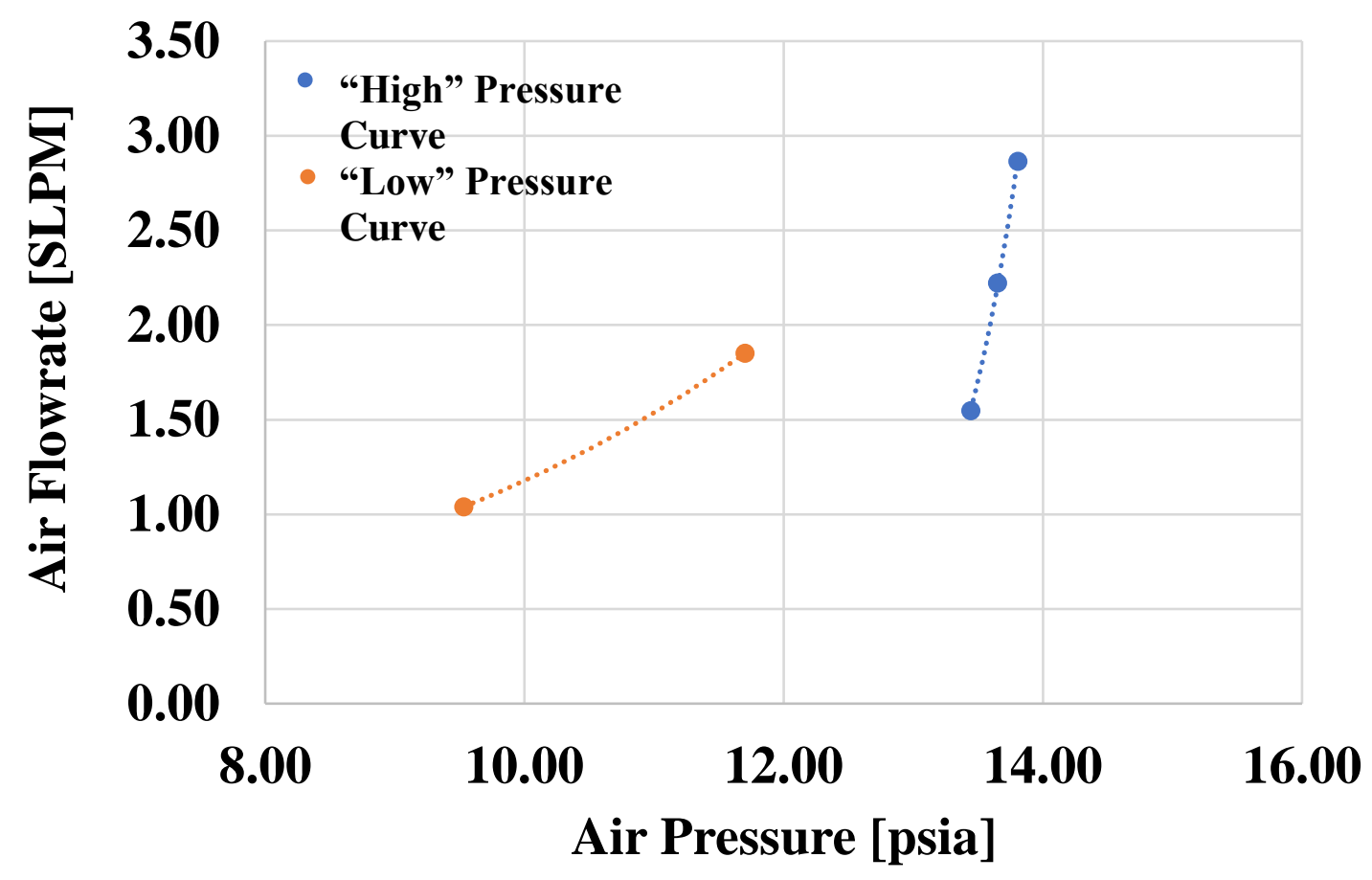

Figure 4.5-8: Multi-nozzle ejector test (water pressure $\approx 40 \mathrm{psig}$ ).

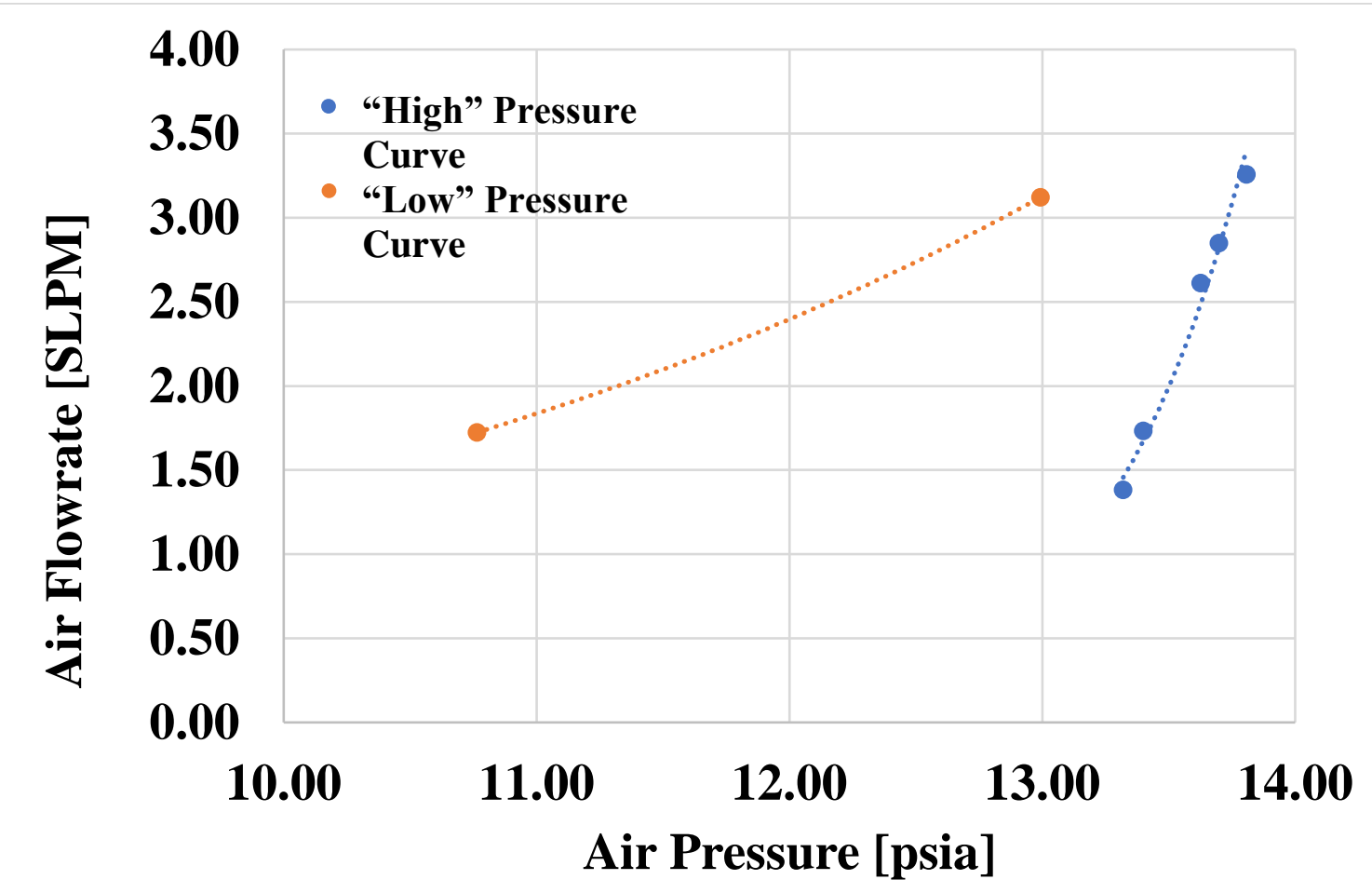

Figure 4.5-9: Multi-nozzle ejector test (water pressure $\approx 45 \mathrm{psig}$ ). 


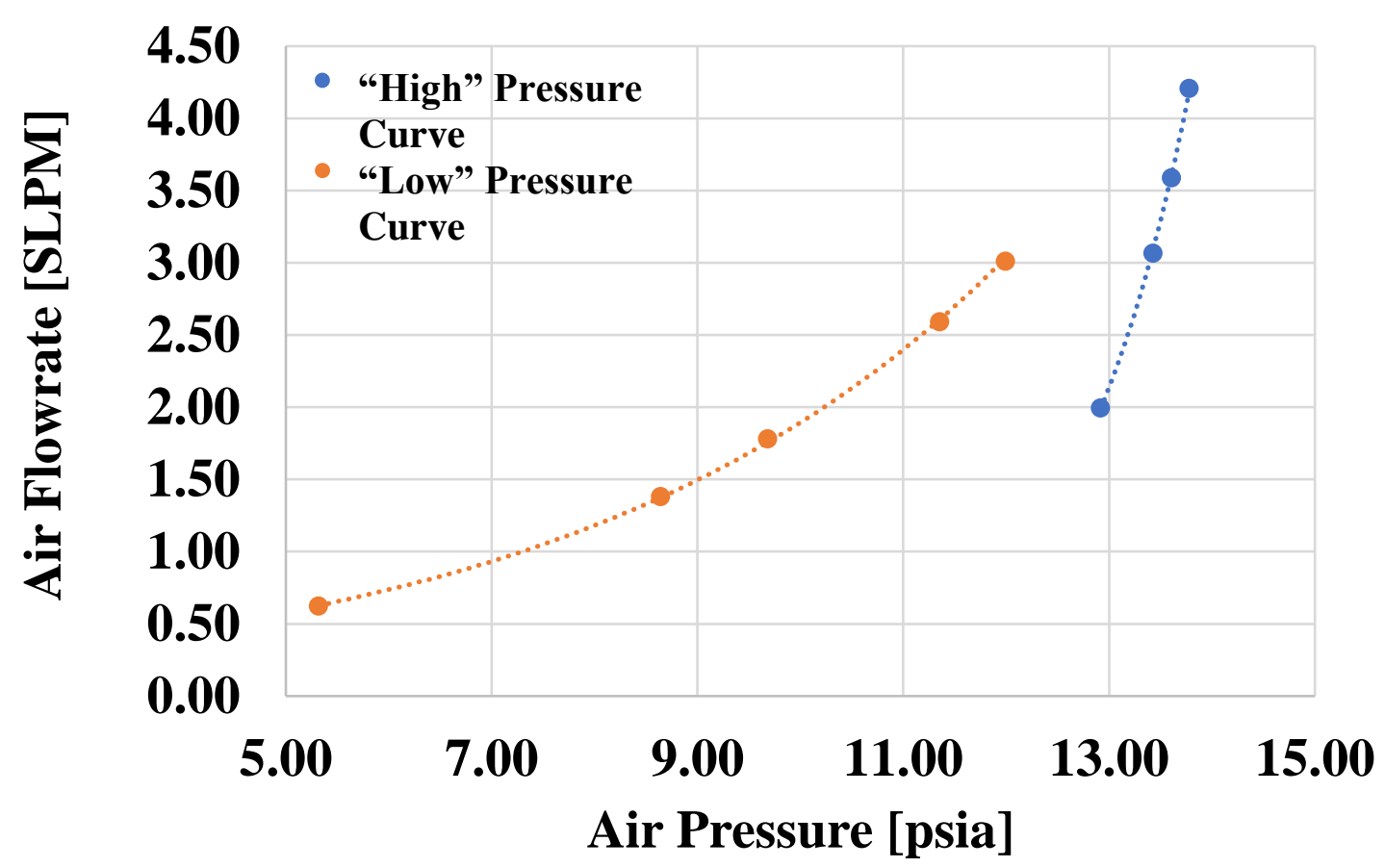

Figure 4.5-10: Multi-nozzle ejector test (water pressure $\approx 55 \mathrm{psig}$ ).

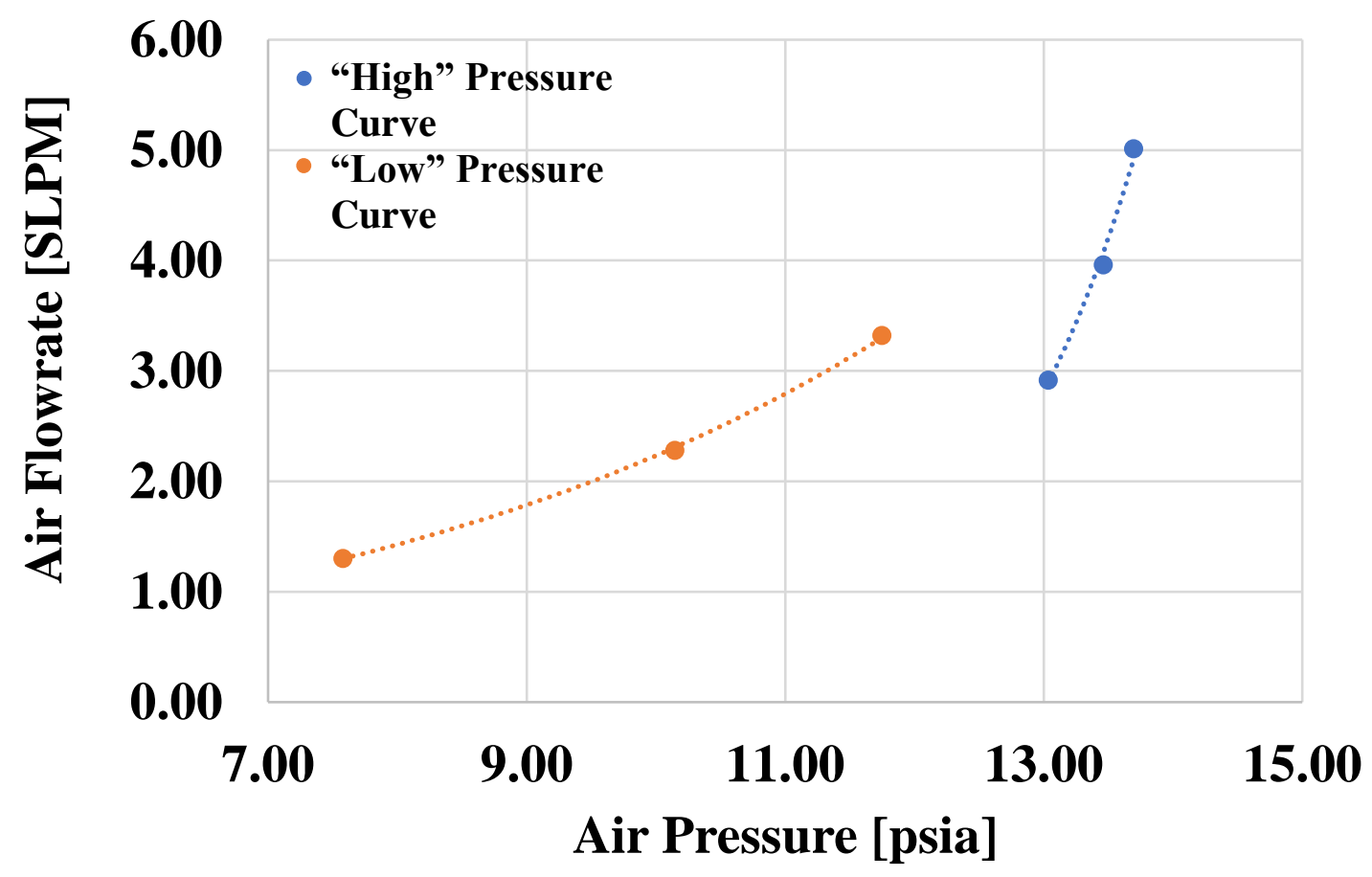

Figure 4.5-11: Multi-nozzle ejector test (water pressure $\approx 65 \mathrm{psig}$ ). 
Table 4.5-5 presents the results from the test where the absolute air suction pressure remained constant around $76 \mathrm{kPa}(11 \mathrm{psia})$ and the water pressure was increased in $69 \mathrm{kPa}$ (10 psig) increments. Figure 4.5-12 shows the relationship between the air flowrate and the water pressure and Figure 4.5-13 shows the relationship between the flow ratio and water pressure. Based on the trend curve in Figure 4.5-13, it seemed that the maximum flow ratio had nearly been achieved and that increasing the water pressure further would not significantly improve the flow ratio.

Table 4.5-5: Multi-nozzle ejector test with constant air suction pressure.

\begin{tabular}{|l|c|c|c|c|c|c|}
\hline & $\begin{array}{c}\text { Water } \\
\text { Pressure } \\
{[\mathbf{p s i g}]}\end{array}$ & $\begin{array}{c}\text { Air Mass } \\
\text { Flowrate } \\
{[\text { [SLPM] }}\end{array}$ & $\begin{array}{c}\text { Air } \\
\text { Volumetric } \\
\text { Flowrate } \\
{[\mathbf{L P M}]}\end{array}$ & $\begin{array}{c}\text { Water } \\
\text { Flowrate } \\
{[\text { LPM] }}\end{array}$ & $\begin{array}{c}\text { Outlet } \\
\text { Pressure } \\
{[\text { psia] }}\end{array}$ & $\begin{array}{c}\text { Flow } \\
\text { Ratio }\end{array}$ \\
\hline Point 1 & $\mathbf{1 0}$ & 0.04 & 0.06 & 0.56 & 13.81 & 0.11 \\
\hline Point 2 & $\mathbf{2 0}$ & 0.71 & 0.98 & 0.77 & 13.90 & 1.28 \\
\hline Point 3 & $\mathbf{3 0}$ & 1.20 & 1.65 & 0.91 & 13.91 & 1.81 \\
\hline Point 4 & $\mathbf{4 0}$ & 1.70 & 2.34 & 1.04 & 13.99 & 2.25 \\
\hline Point 5 & $\mathbf{5 0}$ & 2.13 & 2.94 & 1.15 & 14.11 & 2.56 \\
\hline Point 6 & $\mathbf{6 0}$ & 2.60 & 3.58 & 1.26 & 14.28 & 2.85 \\
\hline Point 7 & $\mathbf{7 0}$ & 2.89 & 3.98 & 1.33 & 14.50 & 3.00 \\
\hline $\begin{array}{l}\text { Constants: } \\
\text { *Air Suction Pressure } \approx 11 \text { psia } \\
\text { *Air Temperature } \approx 30^{\circ} \mathrm{C} \\
\text { *Water Temperature } \approx 24^{\circ} \mathrm{C}\end{array}$ \\
\hline
\end{tabular}




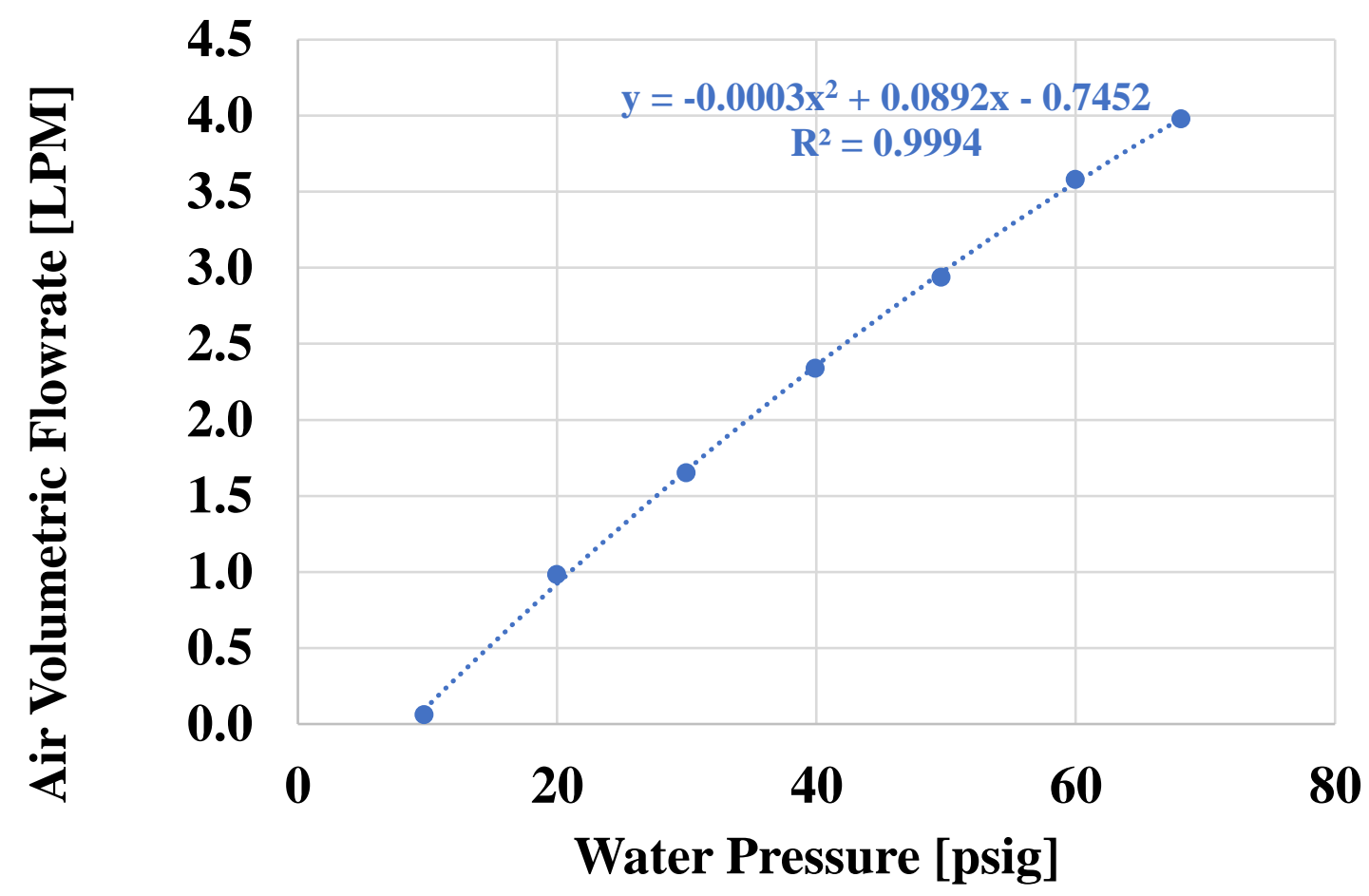

Figure 4.5-12: Relationship between air flowrate and water pressure.

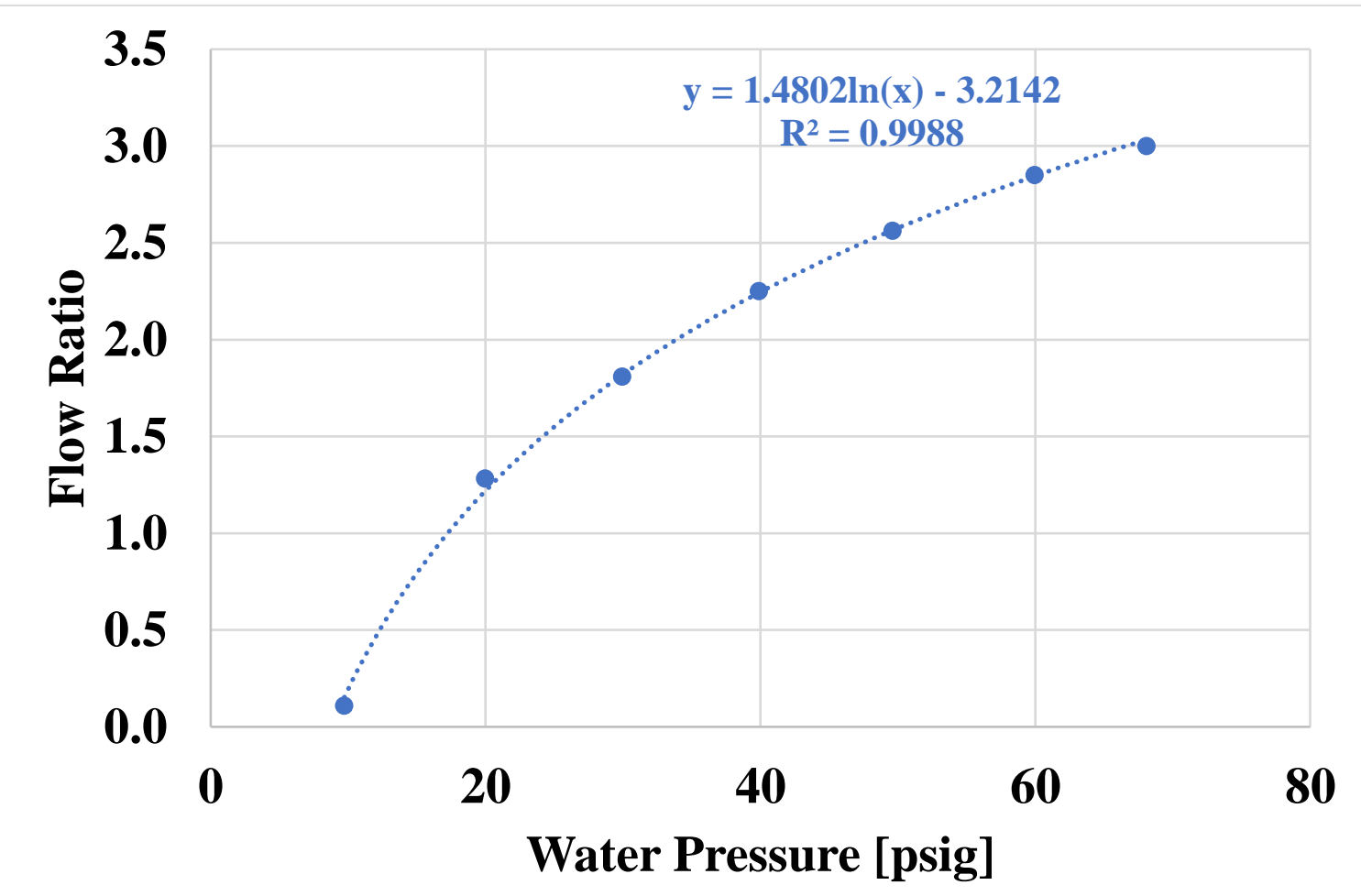

Figure 4.5-13: Relationship between flow ratio and water pressure. 


\section{CFD Modelling}

Table 4.5-6 provides the results from the CFD model of experimental Points 3 through 7 of the and Table 4.5-7 presents a summary of the comparison between experimental and modeled results. Points 1 and 2 are not shown since the model did not perform properly for these two lowest pressures. Percent difference values were calculated to compare the air flowrates (mass and volumetric) and the flow ratios. The modelled results showed good agreement with the experimental results where all percent difference values were less than $31 \%$ and all the percent difference values calculated to compare the flow ratios were less than $17 \%$. Based on these results, it was recommended that the model be used only for water pressures of $276 \mathrm{kPa}$ (40 psig) (Point 4) and greater. With Point 3 eliminated, all percent difference values were less than $20 \%$.

Table 4.5-6: CFD model results for Points 3 through 7.

\begin{tabular}{|c|c|c|c|c|}
\hline & $\begin{array}{c}\text { Standardized } \\
\text { Air } \\
\text { Volumetric } \\
\text { Flowrate } \\
\text { [SLPM] }\end{array}$ & $\begin{array}{c}\text { Air } \\
\text { Volumetric } \\
\text { Flowrate } \\
\text { [LPM] }\end{array}$ & $\begin{array}{c}\text { Water } \\
\text { Flowrate } \\
\text { [LPM] }\end{array}$ & Flow Ratio \\
\hline Point 3 & 1.64 & 2.19 & 1.03 & 2.13 \\
\hline Point 4 & 2.04 & 2.72 & 1.17 & 2.32 \\
\hline Point 5 & 2.40 & 3.19 & 1.29 & 2.47 \\
\hline Point 6 & 2.71 & 3.62 & 1.42 & 2.56 \\
\hline Point 7 & 2.92 & 3.90 & 1.50 & 2.59 \\
\hline
\end{tabular}

Table 4.5-7: Comparison of experimental to modeled results.

\begin{tabular}{|c|c|c|c|}
\hline & $\begin{array}{c}\text { Standardized } \\
\text { Air } \\
\text { Volumetric } \\
\text { Flowrate } \\
\text { [\% difference] }\end{array}$ & $\begin{array}{c}\text { Air Vol. } \\
\text { Flowrate } \\
\text { [\% difference] }\end{array}$ & $\begin{array}{c}\text { Flow Ratio } \\
\text { [\% difference] }\end{array}$ \\
\hline Point 3 & 30.90 & 27.80 & 16.24 \\
\hline Point 4 & 18.08 & 14.87 & 3.13 \\
\hline Point 5 & 11.55 & 8.38 & -3.79 \\
\hline Point 6 & 4.18 & 1.01 & -10.94 \\
\hline Point 7 & 1.15 & -2.02 & -14.64 \\
\hline
\end{tabular}


Figure 4.5-14 shows the modelled flow ratios overlapping the plot of the experimental flow ratios (Figure 4.5-13). The modelled flow ratio trend was "flatter" than that of the experimental results, meaning the water pressure had lesser effect on the flow ratio in the model than experimentally. However, both experimental and modelled flow ratio trends seem to have nearly reached a maximum value since there was only about a 5\% increase of the flow ratios from Point 6 to Point 7 of the experimental data. Therefore, it was predicted that increasing the water pressure further would not significantly improve the flow ratio. The maximum experimental flow ratio was around 3 and the corresponding modelled flow ratio was around 2.6. These flow ratios were 58\% and 37\% greater than the average flow ratio calculated from values found in the literature review, which was around 1.9 , respectively.

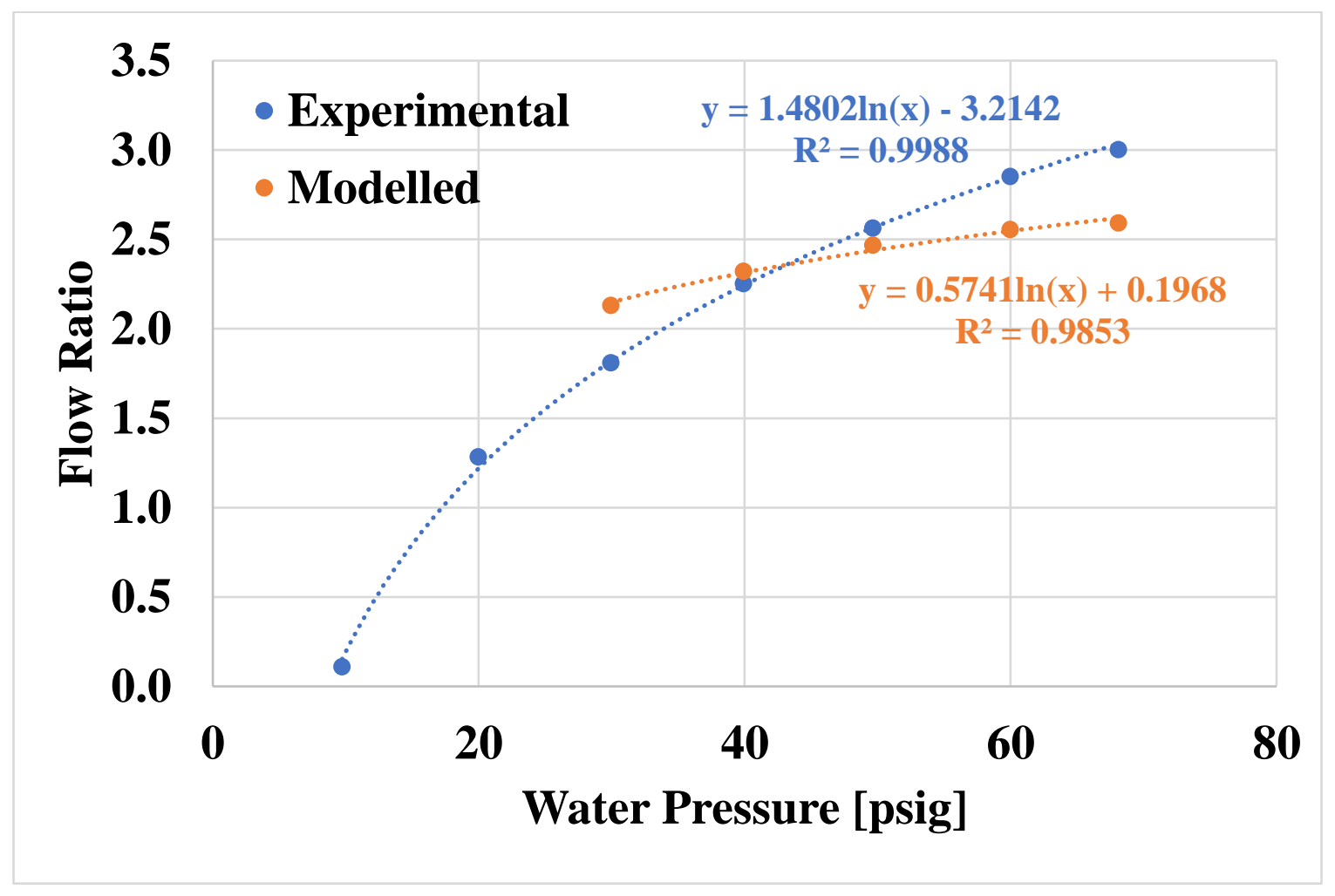

Figure 4.5-14: Modelled flow ratios compared to experimental.

The CFD model was then used to estimate the flowrates and flow ratio when the water pressure was increased to $689 \mathrm{kPa}$ and $1034 \mathrm{kPa}$ (100 psig and 150 psig). The models' outlet pressure input was estimated from the trendline of the outlet pressures in preceding experimental tests. Figure 4.5-15 shows the plot of outlet pressures, including the trendline and equation used for the input estimation. Table 4.5-8 presents the results from the two models. The results show that the flow ratio is nearly unchanged from that of Point 7 (see Table 4.5-6), as expected. 


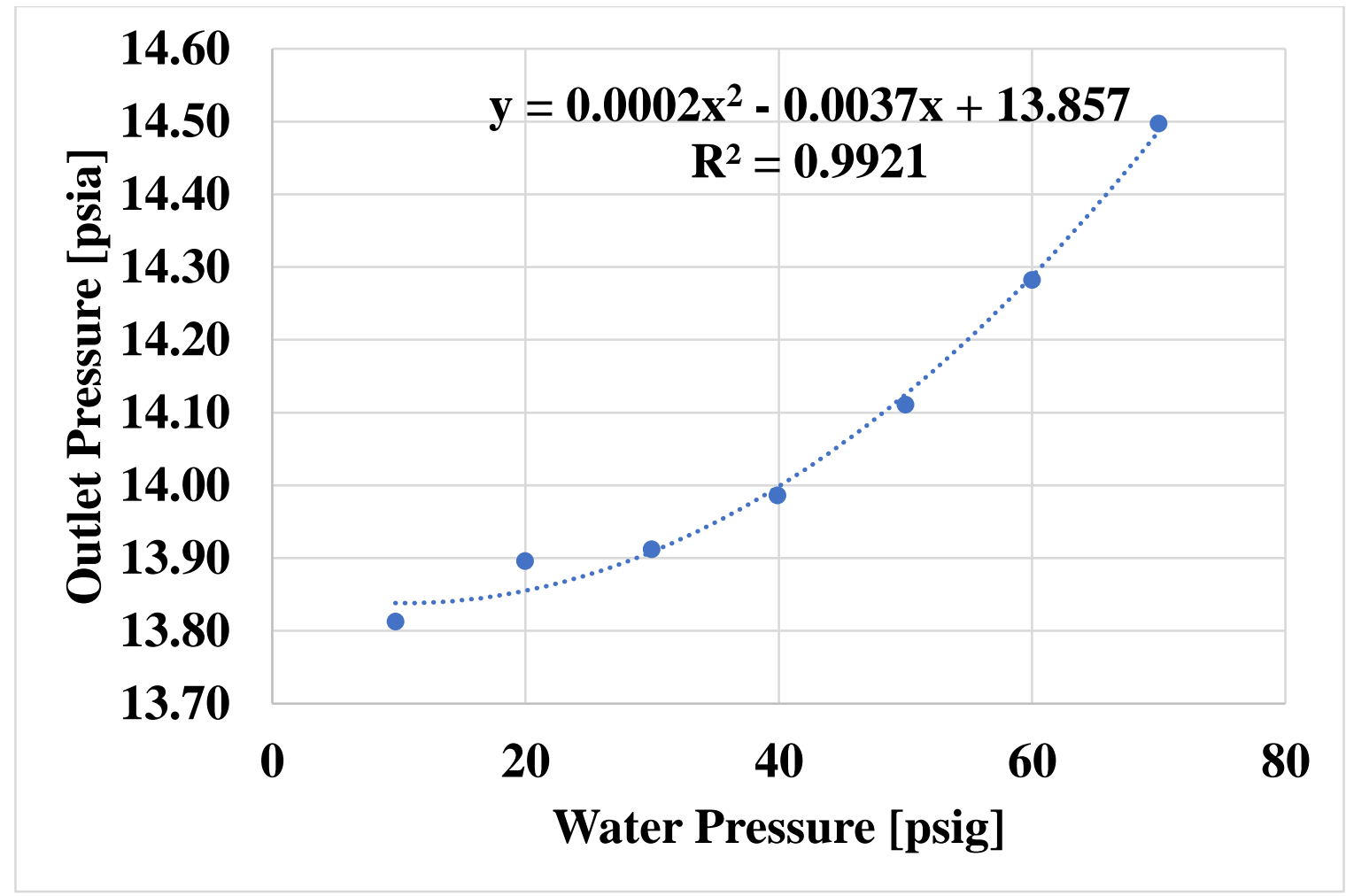

Figure 4.5-15: Outlet pressure trend from experimental data.

Table 4.5-8: Modelled results for water pressures of 100 and $150 \mathrm{psig.}$

\begin{tabular}{|c|c|c|c|c|}
\hline $\begin{array}{c}\text { Water } \\
\text { Pressure } \\
\text { [psig] }\end{array}$ & $\begin{array}{c}\text { Air Mass } \\
\text { Flowrate } \\
\text { [SLPM] }\end{array}$ & $\begin{array}{c}\text { Air Volumetric } \\
\text { Flowrate } \\
\text { [LPM] }\end{array}$ & $\begin{array}{c}\text { Water Volumetric } \\
\text { Flowrate } \\
\text { [LPM] }\end{array}$ & $\begin{array}{c}\text { Flow } \\
\text { Ratio }\end{array}$ \\
\hline $\mathbf{1 0 0}$ & 3.53 & 4.71 & 1.81 & 2.60 \\
\hline $\mathbf{1 5 0}$ & 4.24 & 5.65 & 2.20 & 2.56 \\
\hline
\end{tabular}

Since it seemed the flow ratio was nearly maximized and the modelled results showed that the ejector was capable of sampling at a flowrate above the requirement, a SDF of 0.75 was calculated and applied to the geometry. The CFD model was then used to calculate the resulting flowrates of the scaled-down ejector with a water pressure of $689 \mathrm{kPa}$ (100 psig). Table 4.5-9 presents the modelled results of the scaled-down ejector which verified that the application of the SDF resulted in a sampling flowrate of around 2 SLPM $(0.071 \mathrm{scfm})$ with less water consumption. There was around a $44 \%$ percent decrease in water consumption from the model of the original multi-nozzle design $(1.81 \mathrm{LPM}(0.06 \mathrm{cfm}))$ to the scaled-down design $(1.01 \mathrm{LPM}(0.04 \mathrm{cfm}))$. Therefore, for a 
10-node system, the total water consumption would be around 10.1 LPM $(0.36 \mathrm{cfm})$. According to KOMATSU's PRS Water Spray Summary, the longwall shields' sprayers used approximately 227 LPM (8.02 cfm) of water while in operation [179]. Therefore, with the integration of the MWS, shield water consumption would increase by only around $4.4 \%$. Based on water supply information provided by a regional longwall operator, total water consumption while in operation is around 1080 LPM (38.1 cfm), which includes water consumption for the shearer, belt drives, and leaks [180]. This means total water consumption would only increase by approximately $0.94 \%$ with the integration of the MWS. Table 4.5-10 presents the dimensions of the scaled-down multi-nozzle ejector design. Figures 4.5-16, 4.5-17, and 4.5-18 shows the contours for the air volume fraction, velocity, and pressure from the CFD model, respectively.

Table 4.5-9: CFD model results of the scaled-down design.

\begin{tabular}{|c|c|c|c|}
\hline $\begin{array}{c}\text { Air Mass } \\
\text { Flowrate } \\
\text { [SLPM] }\end{array}$ & $\begin{array}{c}\text { Air } \\
\text { Volumetric } \\
\text { Flowrate } \\
\text { [LPM] }\end{array}$ & $\begin{array}{c}\text { Water } \\
\text { Volumetric } \\
\text { Flowrate } \\
\text { [LPM] }\end{array}$ & $\begin{array}{c}\text { Flow } \\
\text { Ratio }\end{array}$ \\
\hline 1.98 & 2.64 & 1.01 & 2.61 \\
\hline
\end{tabular}

Table 4.5-10: Scaled-down design dimensions.

\begin{tabular}{|c|c|}
\hline Nozzle Diameter & $\mathrm{D}_{\mathrm{n}}=0.34 \mathrm{~mm}$ \\
\hline Nozzle Angle & $\theta_{\mathrm{n}}=16^{\circ}$ \\
\hline Mixing Chamber Diameter & $\mathrm{D}_{\mathrm{m}}=3 \mathrm{~mm}$ \\
\hline Mixing Chamber Length & $\mathrm{L}_{\mathrm{m}}=18 \mathrm{~mm}$ \\
\hline Included Diffuser Angle & $\theta_{\mathrm{d}}=10^{\circ}$ \\
\hline Diffuser Length & $\mathrm{L}_{\mathrm{d}}=18 \mathrm{~mm}$ \\
\hline Diffuser Outlet Diameter & $\mathrm{D}_{\mathrm{d}}=6.2 \mathrm{~mm}$ \\
\hline Distance between nozzle outlet and mixing chamber inlet & $\mathrm{NXP}=3 \mathrm{~mm}$ \\
\hline
\end{tabular}




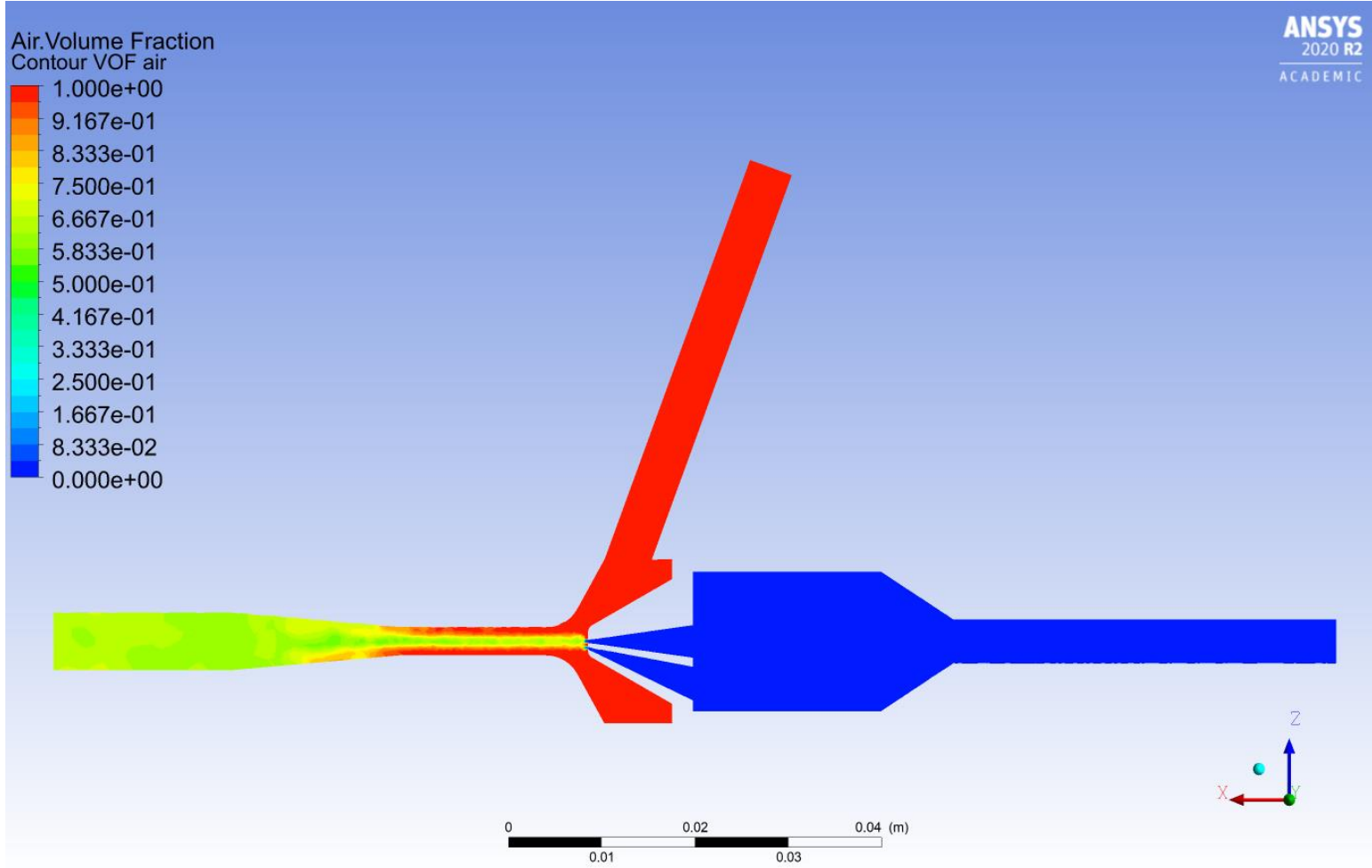

Figure 4.5-16: Air volume fraction contour.

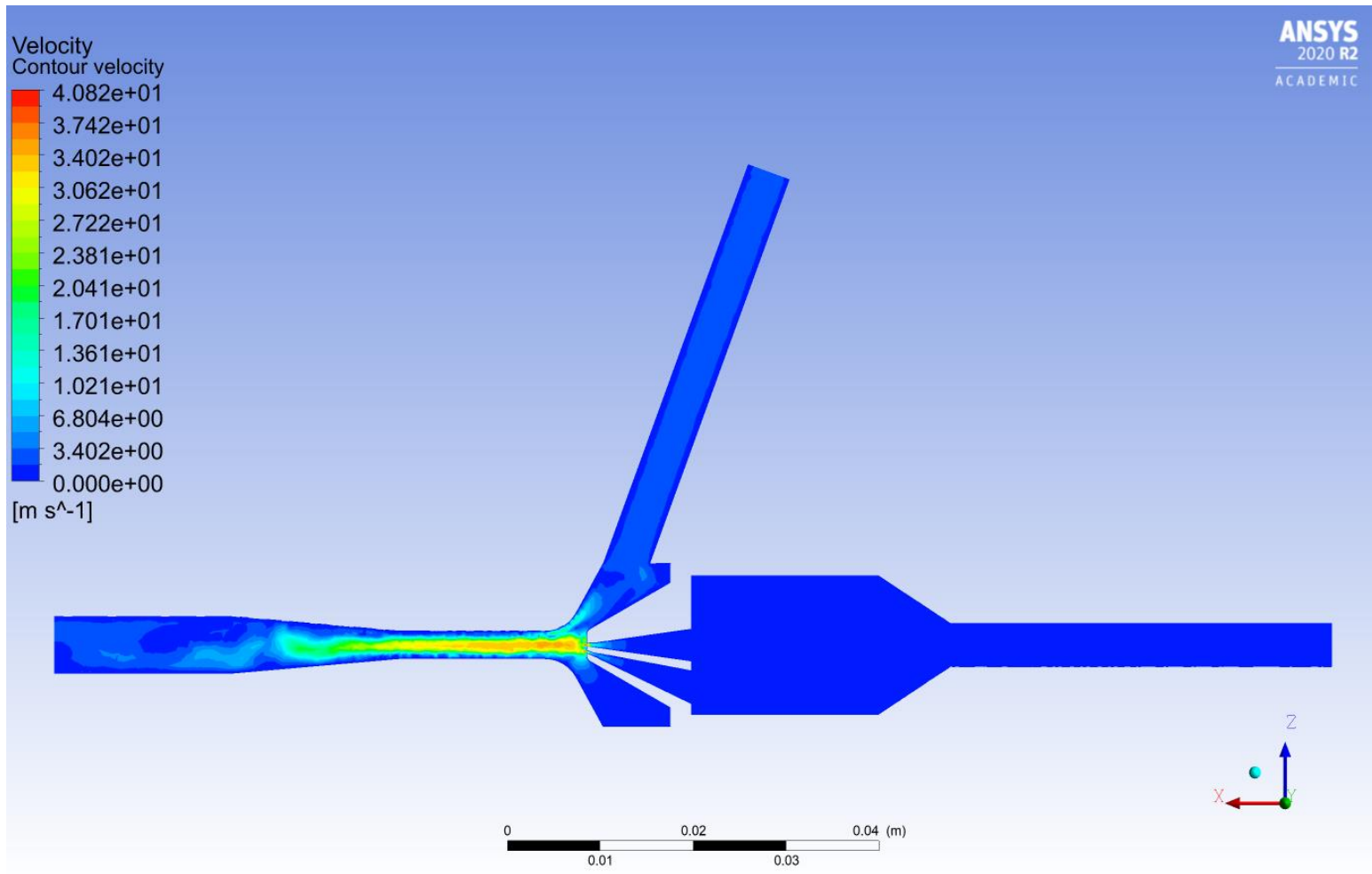

Figure 4.5-17: Velocity contour. 


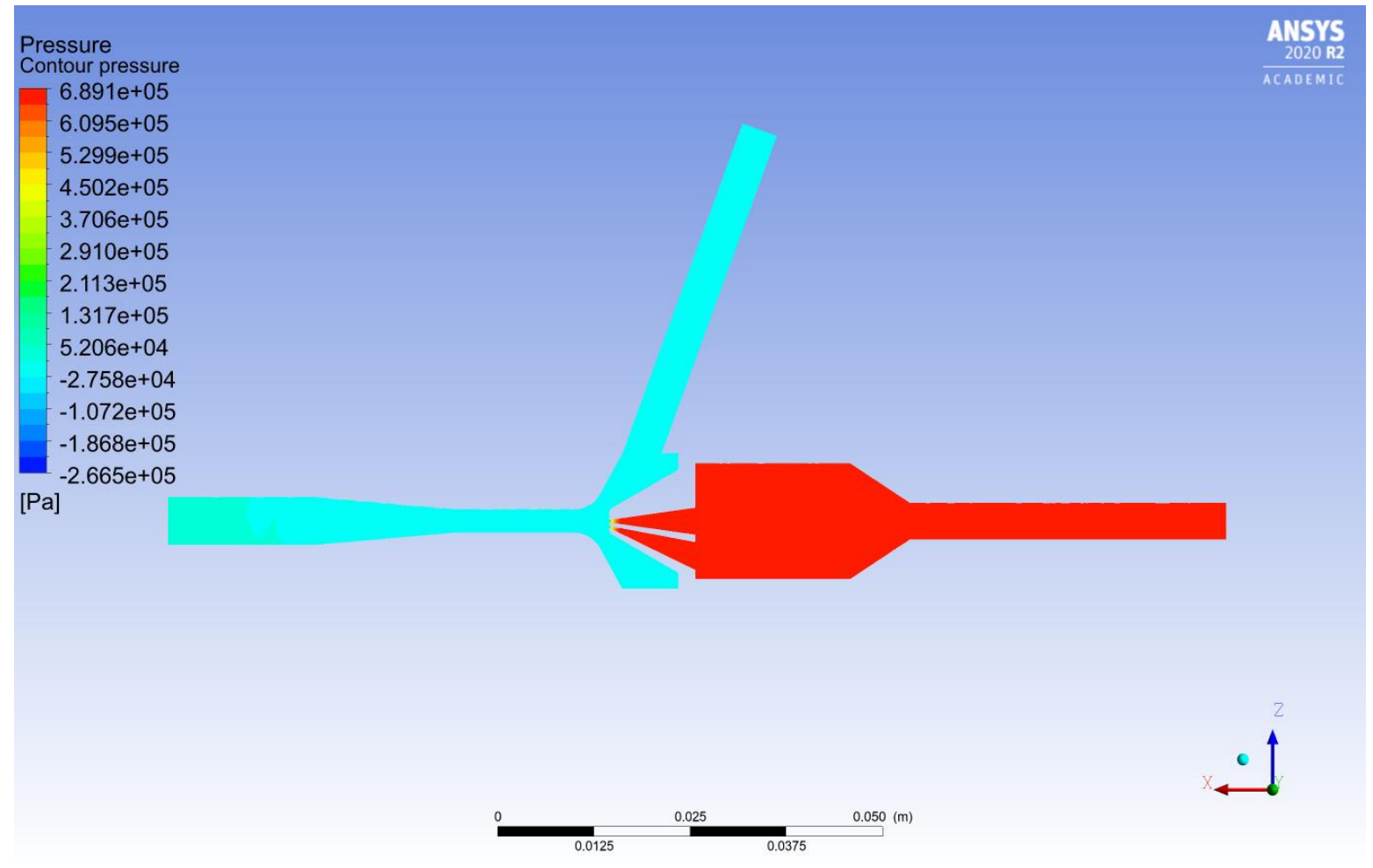

Figure 4.5-18: Pressure contour. 


\subsection{Conclusions}

Overall, designing the MWS and deploying and testing the MWS in the mock mine was successful. Early on, it was determined that climate sensors were necessary and were implemented along with the two $\mathrm{CH}_{4}$ sensors (MOS and IRS). They also provide continuous monitoring of climate conditions, which would be beneficial to a mine and future mining research. All sensors were calibrated and mounted into each of the 10 sampling units. A flow sensor was also integrated into each sampling unit to ensure consistent and adequate sample flow. Monitoring of the flow rate provides information which could determine issues such as when a filter is clogged/needs replaced or if there are problems with the ejector. Maintaining the flowrate ensures similar and adequate response times for each unit of the system; this is especially important if predictive controls are integrated into the system. Two 3-cup anemometers were mounted on two of the sampling units for wind speed measurements. Each node of the system was capable of safely and continuously sampling from two locations (face and gob) by use of a three-way valve and filtration at each location. The MWS 10-node prototype cost a total of around $\$ 14,000$, meaning the cost of

sampling at one of the ten nodes was around $\$ 1400$. The sampling node cost of an industry-ready MWS was estimated at around $\$ 4550$. The increase in cost was mostly attributed to the upgrade of the metal box to an MSHA approved explosion proof enclosure. If the units were integrated into the shields, the cost of each integrated shield only increases by approximately $1.76 \%$. Note a per shield analysis would be even lower based on the facts that not all shields would require a system node.

All electrical components in the sampling units utilized low-voltage DC power which was a design parameter for ease of integration onto/into shields. A power consumption test confirmed the 12 VDC $2.5 \mathrm{~A}(30 \mathrm{~W})$ power supply currently approved and integrated into the industry shields discussed could power a sampling unit as each unit had a maximum consumption of around $22 \mathrm{~W}$ [142]. Therefore, the integration of a second, intrinsically safe power supply with each unit would be adequate to power the system.

Once all ten units were assembled, they were successfully connected in series and deployed in a “mock" mine setup at a WVU research wind tunnel for system verification. While certain testing conditions in the mock mine were not ideal to accurately represent a longwall mine, such as wind speed and dust loading, conclusions of the operating abilities of the system were made. Testing in the mock mine confirmed the limits and capabilities of the two $\mathrm{CH}_{4}$ sensors (MOS and IRS) and 
why it was beneficial to employ both types in the system. The rise/decay time testing along with the testing utilizing the FFS confirmed the limitations of the IRS, like its longer response time, compared the MOS and its inability to detect $\mathrm{CH}_{4}$ concentrations less then approximately $0.1 \%$. Even though the IRS have these limitations, they were crucial for the MWS since they were more accurate at the $\mathrm{CH}_{4}$ concentrations used for control and federal regulations of $1 \%$ and $2 \% \mathrm{CH}_{4}$. Since regulations required that monitors responded with a $\pm 20 \%$ error for concentrations above $0.25 \% \mathrm{CH}_{4}$, IRS were also adequate in this aspect. Note also that the system response times using the IRS as reference (approximately 29 seconds) were still comparable to those of monitors found in literature, which were typically less than 25-30 seconds for monitors containing IR sensors, and were deemed acceptable for industry. Note also that manufacturers present sensor response times while response times calculated in this report include the sample's transit time to the senor. The IRS were also less impacted by sample conditions such as RH and temperature, which are major variables in a longwall mine. Although the MOS had lower accuracy and was more susceptible to drift, requiring regular calibration, their shorter response times (approximately 13 seconds), were beneficial to the system for rapid identification of low concentration changes.

Experiments in the mock mine were conducted where $\mathrm{CH}_{4}$ concentrations above regulation limits were provided to each node. The ability of the system to control a relay and set an alarm at regulated $\mathrm{CH}_{4}$ concentrations were successfully demonstrated in the mock mine. The alarm and relay were activated by the software controls when each node measured a concentration greater than $1 \% \mathrm{CH}_{4}$.

A water powered ejector was designed and $3 \mathrm{D}$ printed to operate as the active sampler for the system by providing the motive force required to draw the sample through the system. The ejector was designed to facilitate the flow of the sample past all the sensors for a single sampling unit at a flowrate of around 2 SLPM $(0.071 \mathrm{scfm})$. An initial ejector manufactured and tested in the laboratory by gradually decreasing the air inlet pressure (suction pressure) and recording the various parameters at each operating point. Water at $482.6 \mathrm{kPa}$ (70 psig) was provided to the ejector as the motive force. It was noticed that the ejector operated on two different, distinct curves ("High" and "Low" pressure curves), where it was believed a flow regime transition occurred. It was suggested that the ejector operate on the "Low" pressure curve to utilize the increased performance of the ejector when operating on this curve and allow for a more consistent flowrate with minor fluctuations in water pressure that could occur. However, no points on the "Low" 
pressure curve satisfied the sampling flowrate requirement. Further research indicated that a multinozzle ejector may increase the performance. Therefore, a multi-nozzle ejector was designed, 3D printed and tested similarly to the initial ejector. The multi-nozzle ejector also demonstrated two different operational curves. Points 3 through 7 (all on the "Low" pressure curve) were modeled using the ANSYS $^{\circledR}$ FLUENT $^{\circledR}$ CFD software and the model was validated based on the experimental results. The water pressures of the five points were 207, 276, 345, 414, and $483 \mathrm{kPa}$ $(30,40,50,60$, and $70 \mathrm{psig})$. The modelled results were compared to the experimental results and it was recommended that the model be used for water pressures of 40 psig (Point 4) and greater since percent difference values of the compared parameters were less than $20 \%$ for Points 4 and above. The CFD model was then used to calculate the results at water pressures of 689 and 1034 $\mathrm{kPa}$ (100 and $150 \mathrm{psig}$ ). It was determined that there was no significant change in the flow ratio for water pressures above $483 \mathrm{kPa}$ (70 psig). The maximum experimental flow ratio was around 3 and the corresponding modelled flow ratio was around 2.6; they were approximately 58\% and $37 \%$ greater than the average flow ratio calculated from values found in the literature review (around 1.9), respectively. Since the multi-nozzle results showed that it was capable of sampling at a flowrate greater than required, a SDF was calculated and applied to the design; a scaled-down version provided the same flow ratio with decreased water consumption. The SDF was calculated to be 0.75 based on the results of the CFD model at a water pressure of $689 \mathrm{kPa}$ (100 psig). The same CFD model was used to calculate the results of the scaled-down design. The results verified that the scaled-down design met all requirements at a reduced water consumption rate. The water consumption was reduced by approximately $44 \%$ from the original multi-nozzle design to the scaled-down design. Based on a single ejector water flowrate of around 1.01 LPM (0.04 cfm), water consumption for a 10-node system would be 10.1 LPM (0.36 cfm), which would only increase the total operational mine water consumption by about $0.94 \%$ with the MWS deployed. Note that the relatively low water pressures intended to be used ( $<150 \mathrm{psig})$ allow for the ejector to be $3 \mathrm{D}$ printed with plastic, instead of being manufactured with a metal, which is a cheaper manufacturing method. It was determined that the scaled-down multi-nozzle ejector design was sufficient to provide the motive force required for the sampling of the system, however, methods of integration into the shields should be further investigated.

Overall, the MWS proved its capabilities of continuously sampling at multiple locations considered to be hazardous in a mine. It also proved its ability to activate an alarm and relay at 
regulated $\mathrm{CH}_{4}$ concentrations. Through the evaluations of the system, it is believed that the MWS would be beneficial to enable a safer and more efficient longwall mining process. However, future research and evaluation of the system before deployment in an actual mine is necessary to maximize the system capabilities and ensure its safety. 


\subsection{Recommendations for Future Work}

Limitations for each type of $\mathrm{CH}_{4}$ sensor were discovered over the course of this project, therefore, future work should focus on the improvement of the $\mathrm{CH}_{4}$ sensing abilities of the system. The MOS lacked in accuracy in comparison to the IRS. It is believed that higher accuracy could be achieved for the MOS if they were only calibrated to lower $\mathrm{CH}_{4}$ concentrations. Since the MOS were designed for $\mathrm{CH}_{4}$ concentrations up to $1 \%$, higher accuracy could be achieved if calibrations were made only up to this limit; there was greater resolution in the sensor response under $1 \%$. The MOS could also, solely, be used to compensate for the lower detection limit of the IRS and be calibrated only up to that limit (about $0.1 \%$ ); correction factors for $\mathrm{RH}$, temperature, and pressure could also be made based on the lower calibration range to further improve accuracy. This would provide a larger response range of the overall system. Future research should expand on these possibilities. Another improvement that could be made pertaining to the $\mathrm{CH}_{4}$ sensors would be to consider the implementation of a different, single, $\mathrm{CH}_{4}$ sensor to replace the IRS and MOS in each sampling unit. One specific sensor that is currently being researched by the team is the dual wavelength Non-dispersive infrared (NDIR) sensor by Sensors Inc [181]. The team will order these sensors to test for future use in the MWS during the continuation of the project.

Since the system is desired to also be integrated into the mine controls, such as ventilation air and shearer speeds, future research should include the implementation of control algorithms. This may involve techniques such as signal sharpening for more adequate response times and species modeling to analyze the $\mathrm{CH}_{4}$ distribution and travel in a longwall mine.

Future research should also focus on involving the implementation of the system into an actual longwall mine. More research would be necessary to finalize methods for integrating the sampling units into the shields where the power and water supplies are used. While the MWS was designed to utilize a 24 VDC power supply, it should be modified to utilize a 12 VDC power supply, like the shield control system currently used in shields. Methods of integration for the ejector into the shields should be further researched to assure ease of installation.

Modifications to the design may be required for MSHA approval before deployment in a mine is permitted. Further testing should be conducted in a location that more similarly represents longwall mine conditions and dimensions before MSHA approval is sought after. 


\subsection{References}

[1] Energy Information Administration, Longwall Mining, Washington, DC: U.S. Department of Energy, 1995, pp. 2-13.

[2] S. Hao, S. Wang, R. Malekian, B. Zhang, W. Liu and Z. L. Li, "A Geometry Surveying Model and Instrument of a Scraper Conveyor in Unmanned Longwall Mining Faces," IEEE Access , vol. 5, pp. 4095 - 4103, 2017. doi: 10.1109/ACCESS.2017.2681201.

[3] "CFR: Title 30 Part 75," 9 March 2020. [Online]. Available: https://ecfr.io/Title30/pt30.1.75.

[4] F. N. Kissell, "Chapter 1.- - facts about methane that are important to mine safety," in Handbook for Methane Control in Mining, Cincinnati, OH, USA, NIOSH-Publications Dissemination, 2006, pp. 3-26.

[5] P. E. Liley and W. R. Gambill, "Section 3: Physical and Chemical Data," in Chemical Engineers' Handbook Fifth Edition, McGraw-Hill, Inc., 1973, p. 72.

[6] K. L. Cashdollar, "Coal Dust Explosibility," Journal of Loss Prevention in the Process Industries, vol. 9, no. 1, pp. 65-76, 1996. doi: 10.1016/0950-4230(95)00050-X.

[7] S. G. Davis, D. Engel and K. van Wingerden, "Complex Explosion Development in Mines: Case Study-2010 Upper Big Branch Mine Explosion," Process Safety Progress, vol. 34, no. 3, pp. 286-303, 2014. doi: 10.1002/prs.11710.

[8] M. F. Sindelar, "Review of Methane Monitoring and Automatic Shut-Down Regulations and Standards for Electrically Powered Underground Coal Mine Face Equipment," 2011.

[9] "Electronic Code of Federal Regulations: §75.336 Sampling and monitoring requirements.," [Online]. Available: https://www.ecfr.gov/cgi-bin/text$\underline{\mathrm{idx}}$ ?SID=b59f81c73c26b8a9b6e84a75788bbf08\&mc $=$ true $\&$ node $=$ se 30.1.75 $1336 \& \mathrm{rgn}=$ div8.

[10] "Electronic Code of Federal Regulations: §75.362 On-shift examination.," [Online]. Available: https://www.ecfr.gov/cgi-bin/text$\underline{\mathrm{idx}}$ ?SID=b59f81c73c26b8a9b6e84a75788bbf08\&mc=true \&node $=$ se 30.1.75 $1362 \& \mathrm{rgn}=$ div8.

[11] Center for Chemical Process Safety, Guidelines for Fire Protection in Chemical, Petrochemical, and Hydrocarbon Processing Facilities, New York: American Institute of Chemical Engineers, 2003, p. 246. 
[12] F. N. Kissell, "CHAPTER 2.-SAMPLING FOR METHANE IN MINES AND TUNNELS," in Handbook for Methane Control in Mining, Cincinnati, OH, USA, NIOSH-Publications Dissemination, 2006, pp. 27-36.

[13] Mine Safety and Health Administration Approval and Certification Center Electrical Safety Division, "Criteria for the Evaluation and Test of Intrinsically Safe Apparatus and Associated Apparatus," 2008.

[14] Alpha Foundation, "Who We Are," [Online]. Available: https://www.alphafoundation.org/who-we-are/.

[15] Department of Natural Resources, Mines and Energy, "Recognised standard 18: Management of heat in underground coal mines," State of Queensland, 2019.

[16] A. Mayton and J. Heberger, "Underground Mine Refuge Alternatives: A Look at Food, Water and Sanitation Requirements," Coal Age, vol. 120, no. 9, pp. 40-43, 2015.

[17] "Electronic Code of Federal Regulations: §7.504 Refuge alternatives and components; general requirements.," 2020. [Online]. Available: https://gov.ecfr.io/cgi-bin/text$\underline{\mathrm{idx}}$ ?SID=12c3b3dba295a2e833902f32dbc9d42b\&mc=true\&node=se30.1.7_1504\&rgn=d iv8.

[18] "What is Apparent Temperature?," [Online]. Available: https://meteor.geol.iastate.edu/ ckarsten/bufkit/apparent_temperature.html.

[19] D. Yantek, L. Yan, P. Bissert and M. Klein, "Effects of mine strata thermal behavior and mine initial temperatures on mobile refuge alternative temperature," Mining Engineering, vol. 69, no. 4, pp. 41-48, 2017. doi: 10.19150/ME.7393.

[20] M. Klein, D. Yantek, M. Hepokoski and L. Yan, "Prediction of human core temperature rise and moisture loss in refuge alternatives for underground coal mines," Transactions of the Society for Mining, Metallurgy, and Exploration, vol. 342, no. 1, pp. 29-35, 2017. doi: $10.19150 /$ trans.8105.

[21] "On the Temperature of Coal Mines," Scientific American, vol. 21, no. 8, pp. 115-116, 1869.

[22] H. Ozdeniz, O. Sivrikaya and C. Sensogut, "Investigation of Spontaneous Combustion of Coal in Underground Coal Mining," in 31st Annual International Pittsburgh Coal Conference: Coal - Energy, Environment and Sustainable Development, Pittsburgh, PA, USA, 2014. 
[23] M. Khanal and R. McPhee, "Study of Real Time Dry Bulb Temperature and Relative Humidity Monitoring Systems for Use in Underground Mines - Implementation Challenges," CSIRO, 2017.

[24] M. Khanal, R. McPhee, B. Belle, P. Brisbane and B. Kathage, "Study of Real-Time Dry Bulb and Relative Humidity Sensors in Underground Coal Mines," International Journal of Thermophysics, vol. 37, no. 117, 2016. doi: 10.1007/s10765-016-2127-0.

[25] F. Peng and W. Wang, "Respirable dust concentration distribution model on longwall faces - multiple dust source approach," Powder Technology, vol. 79, no. 2, pp. 121-133, 1994. doi: 10.1016/0032-5910(94)02817-6.

[26] M. J. Sapko, K. L. Cashdollar and G. M. Green, "Coal Dust Particle Size Survey of U.S. Mines," Journal of Loss Prevention in the Process Industries, vol. 20, no. 4-6, pp. 616620, 2007. doi: 10.1016/j.jlp.2007.04.014.

[27] Industrial Specialties Mfg. \& IS MED Specialties, "MESH AND MICRON SIZES," [Online]. Available: https://www.industrialspec.com/resources/mesh-and-micron-sizes.

[28] T. L. Barone, J. Patts, S. Janisko, J. Colinet, L. Patts, T. Beck and S. Mischler, "Sampling and analysis method for measuring airborne coal dust mass in mixtures with limestone (rock) dust," Journal of Occupational and Environmental Hygiene, vol. 13, no. 4, pp. 284-292, 2015. doi: 10.1080/15459624.2015.1116694.

[29] J. F. Brune and S. A. Saki, "Prevention of gob ignitions and explosions in longwall mining using dynamic seals," International Journal of Mining Science and Technology, vol. 27, no. 6, pp. 999-1003, 2017. doi: 10.1016/j.ijmst.2017.06.026.

[30] R. K. Zipf, V. N. Gamezo, M. J. Sapko, W. P. Marchewka, K. M. Mohamed, E. S. Oran, D. A. Kessler, E. S. Weiss, J. Addis, F. Karnack and D. Sellers, "Methane-Air Detonation Experiments at NIOSH Lake Lynn Laboratory," Journal of Loss Prevention in the Process Industries, vol. 26, no. 2, pp. 295-301, 2013. doi: 10.1016/j.jlp.2011.05.003.

[31] United States Mine Rescue Association, "Worst Mine Disasters in the U.S.," [Online]. Available: https://usminedisasters.miningquiz.com/saxsewell/historical.htm.

[32] Z. Wang, T. Ren, L. Ma and J. Zhang, "Investigations of Ventilation Airflow Characteristics on a Longwall Face-A Computational Approach," Energies, vol. 11, no. 6, 2018. doi: 10.3390/en11061564.

[33] R. Krog and S. Schatzel, "Frictional ignitions in underground bituminous coal operations 1983 to 2005," Mining Engineering, vol. 61, no. 8, pp. 28-35, 2009. 
[34] J. Nagy, "The Explosion Hazard in Mining," U.S. Department of Labor Mine Safety and Health Administration, 1981.

[35] R. C. Gilmore, J. A. Marts, J. F. Brune, S. Saki, G. E. Bogin, Jr. and J. W. Grubb, "Impact of regulator settings on the formation of explosive gas zones in bleeder ventilated longwall gobs," in SME Annual Meeting, Denver, CO, USA, 2015.

[36] S. Schatzel, R. Krog, F. Garcia and J. Marshall, "Prediction of longwall methane emissions and the associated consequences of increasing longwall face lengths: a case study in the Pittsburgh Coalbed," in U.S./North American Mine Ventilation Symposium, University Park, PA, USA, 2006.

[37] W. P. Diamond and F. Garcia, "Prediction of Longwall Methane Emissions: An Evaluation of the Influence of Mining Practices on Gas Emissions and Methane Control Systems," NIOSH-Publications Dissemination, Cincinnati, OH, USA, 1999.

[38] S. Krickovic and C. Findlay, "Methane Emission Rate Studies in a Central Pennsylvania Mine," U.S. Dept. of the Interior, Bureau of Mines, 1971.

[39] R. B. Krog, S. J. Schatzel and H. N. Dougherty, "Methane emissions and airflow patterns along longwall faces and through bleeder ventilation systems," International Journal of Mining and Mineral Engineering, vol. 5, no. 4, p. 328-349, 2016. doi: 10.1504/IJMME.2014.066580.

[40] "Electronic Code of Federal Regulations: §70.100 Respirable dust standards.," [Online]. Available: https://gov.ecfr.io/cgi-bin/text$\underline{\mathrm{idx}}$ ?SID=143272b9a6dc69d20ee5044379a0620f $\& \mathrm{mc}=$ true $\&$ node $=$ se $30.1 .70 \_1100 \& \mathrm{rgn}=$ div8.

[41] "Electronic Code of Federal Regulations: $\$ 75.401$ Abatement of dust; water or water with a wetting agent.," [Online]. Available: https://www.ecfr.gov/cgi-bin/text$\underline{\mathrm{idx}}$ ?SID=94a2b76d2aef8c2418eedeb0707e7c12\&mc=true\&node=se30.1.75_1401\&rgn= div8.

[42] J. F. Colinet and E. D. Thimons, "Dust Control Practices for Underground Coal Mining," in 32nd International Conference of Safety in Mines Research Institutes, Beijing, China, 2007.

[43] J. P. Rider and J. F. Colinet, Mining Engineering, vol. 63, no. 9, pp. 74-80, 2011. 
[44] R. Reed, S. Klima and J. Rider, "A laboratory investigation of underside shield sprays to improve longwall water directional spray system-preliminary results," in Longwall USA Exibition and Conference, Pittsburgh, PA, USA, 2019.

[45] CSE, "140B Methane Monitor," [Online]. Available:

https://www.csecorporation.com/Product-140B-Methane-Monitor.

[46] Instruments, RKI, "MSHA PERSONAL FOUR GAS MONITOR," [Online]. Available: https://www.rkiinstruments.com/pdf/gx2009msha.pdf.

[47] "W. Va. Code R. § 36-14-4," [Online]. Available: https://casetext.com/regulation/westvirginia-administrative-code/agency-36-coal-mine-health-and-safety/title-36-legislativerule-board-of-coal-mine-health-and-safety/series-36-14-electrical-equipment-in-minesrequired-examinations/section-36-14-4-electri.

[48] "W. Va. Code R. § 36-54-4," [Online]. Available: https://casetext.com/regulation/westvirginia-administrative-code/agency-36-coal-mine-health-and-safety/title-36-legislativerule-board-of-coal-mine-health-and-safety/series-36-54-rules-governing-machinemounted-methane-monitors-in-underground-coal-mines/.

[49] "Catalytic Combustible Gas Sensors," in Hazardous Gas Monitors: a practical guide to selection, operation and applications, New York, McGraw-Hill, 2000, pp. 37-45.

[50] C. Taylor, J. Chilton and A. Martikainen, "Use of infrared sensors for monitoring methane in underground mines," in U.S./North American Mine Ventilation Symposium, Reno, NV, USA, 2008.

[51] R. E. Henderson, "Understanding Combustible Sensor Performance," International Fire Protection, vol. 27, pp. 55-59, March 2006.

[52] GFG Instrumentation, "AP 1018: Understanding catalytic LEL combustible gas sensor performance," 2013. [Online]. Available: http://goodforgas.com/wpcontent/uploads/2013/12/AP1018_Combustible-sensor-performance_6_30_13.pdf.

[53] CNIguard, "Factors affecting gas sensor selection," 2020. [Online]. Available: https://www.cniguard.com/latest-news/factors-affecting-gas-sensor-selection/.

[54] General Monitors, "Combustible Gas Safety Monitoring: Infrared vs. Catalytic Gas Detectors," Lake Forest, CA, USA, 2013. [Online]. Available: http://s7d9.scene7.com/is/content/minesafetyappliances/IR\%20vs\%20Catalytic\%20Bead \%20Technology\%20White\%20Paper\#: :text=Expected\%20Detector\%20Life\&text=Cata lytic $\% 20$ detectors $\% 20$ can $\% 20$ be $\% 20$ calibrated,maximum $\% 20$ per $\% 20$ cylinder $\% 20 \mathrm{of} \% 2$. 
[55] F. N. Kissell, "Handbook for Methane Control in Mining," NIOSH-Publications Dissemination, Cincinnati, OH, USA, 2006.

[56] P. Pickering, S. Tewari and C. Twanow, "Metal Oxide Gas Sensing Material and MEMS Process," 2018. [Online]. Available:

https://www.fierceelectronics.com/components/metal-oxide-gas-sensing-material-andmems-process.

[57] C. Wang, L. Yin, L. Zhang, D. Xiang and R. Gao, "Metal Oxide Gas Sensors: Sensitivity and Influencing Factors," Sensors, vol. 10, no. 3, pp. 2088-2106, 2010. doi: $10.3390 / \mathrm{s} 100302088$.

[58] H. Meixner and U. Lampe, "Metal oxide sensors," Sensors and Actuators B: Chemical, vol. 33, no. 1-3, pp. 198-202, 1996. doi: 10.1016/0925-4005(96)80098-0.

[59] Grainger, "Replacement Sensor, Detects Combustibles, Sensor Range 0 to 100\%, $1 \%$ LEL Resolution," [Online]. Available: https://www.grainger.com/product/MSAReplacement-Sensor-5ERK9?cm_sp=solr_search_page\%20Products_You_Have_Recently_Viewed-_-AZNSZ_PBackupNullRecs\%20012320\&cm_vc=AZNSZ_P-BackupNullRecs012320\&req=Products_You_Have_Recently_Viewed\&opr=AZNSZ_P-BackupNullRecs$\underline{0}$.

[60] MSA NORTH AMERICA, "ALTAIR® 4X Multigas Detector Instruction Manual," MINE SAFETY APPLIANCES COMPANY, 2011. [Online]. Available: http://s7d9.scene7.com/is/content/minesafetyappliances/Altair\%204x\%20manual\%20\%20EN\%20FR\%20ES.

[61] Grainger, "Catalytic Sensor, Detects Methane, Sensor Range 0 to 100\% LEL, 0 to 5\% Vol, 1\%LEL Resolution," [Online]. Available: https://www.grainger.com/product/DRAEGER-Catalytic-Sensor$\underline{36 \mathrm{~F} 163}$ ? searchBar=true \&searchQuery $=6812950 \mathrm{v}$.

[62] Dräger, "Dräger Catalytic Ex-Sensors," Lübeck, Germany, 2017. [Online]. Available: https://www.draeger.com/Products/Content/catalytic-ex-sensors-pi-9045546-en-gb.pdf.

[63] Grainger, "Small Replacement Sensor, Detects Methane, Sensor Range 0 to 5\%, $0.01 \%$ vol.," [Online]. Available: https://www.grainger.com/product/INDUSTRIALSCIENTIFIC-Small-Replacement-Sensor49JZ96?searchBar=true\&searchQuery=17155304-M. 
[64] Industrial Scientific, "Ventis Pro Series Product Manual," Industrial Scientific Corporation, Pittsburgh, PA, USA, 2020. [Online]. Available: https://www.indsci.com/globalassets/documents/ventis-pro/ventis-pro-productmanual/17156830-1-ventis-pro-product-manual_en.pdf.

[65] Grainger, "Sensor, Detects Combustibles (LEL), Sensor Range 0 to $100 \%$ LEL, 0.5\% LEL Resolution," [Online]. Available: https://www.grainger.com/product/GFG-Sensor36LR59.

[66] GfG Instrumentation, "G460 Multi-gas Detector Field Operation Manual," Ann Arbor, MI, USA, 2018. [Online]. Available: https://goodforgas.com/wpcontent/uploads/2013/01/G460-Field-Operation-Manual_Hi.pdf.

[67] Grainger, "Replacement Sensor, Detects Methane, Sensor Range 0 to 100\% LEL, 1\% LEL Resolution," [Online]. Available: https://www.grainger.com/product/AIMSAFETYReplacement-Sensor-54XL89?.

[68] AimSafety, "AimSafety PM400: Multi-Gas Personal Monitor User Manual," Aerionics, Sioux Falls, SD, USA, 2018. [Online]. Available:

https://www.trutechtools.com/assets/images/PDFFiles/PM400-Manual.pdf.

[69] Grainger, "Replacement Sensor, Detects Methane, Lower Explosive Limit, Sensor Range 0 to $100 \%$ LEL," [Online]. Available: https://www.grainger.com/product/GFG-

Replacement-Sensor-48RN10?.

[70] GfG Instrumentation, "CC28 Transmitter for flammable gases and vapours," Dortmund, Germany, 2005. [Online]. Available: http://www.gfg-

inc.com/englisch/produkte/manuals/om_cc28.pdf.

[71] Component Distributors, Inc., "VQ21TSB," [Online]. Available:

https://www.cdiweb.com/products/detail/vq21tsb-sgX-sensortech/333433/.

[72] SGX Sensortech, "VQ21T Series Combustible Gas Sensor Elements," SGX Europe, 2018. [Online]. Available:

https://www.sgxsensortech.com/content/uploads/2014/07/VQ21T-datasheet-Version6_1.pdf.

[73] Component Distributors, Inc., "VQ23TB," [Online]. Available: https://www.cdiweb.com/products/detail/vq23tb-sgx-sensortech/593769/. 
[74] SGX Sensortech, "VQ23TB Combustible Gas Detector Elements," 2015. [Online]. Available: https://www.sgxsensortech.com/content/uploads/2014/07/A1A-VQ23TBVQ23TB-Datasheet-V5.pdf.

[75] "MH-440D Infrared Gas Sensor Methane Gas Sensor CH4 Detection Detector," [Online]. Available: https://www.ebay.com/itm/MH-440D-Infrared-Gas-Sensor-Methane-GasSensor-CH4-Detection-Detector-/133195960809.

[76] Zhengzhou Winsen Electronics Technology Co., Ltd., "MH-440D NDIR Infrared CH4 Sensor (V2.7)," [Online]. Available: https://www.winsen-sensor.com/d/files/MH440D.pdf.

[77] Grainger, "Replacement Sensor, Detects Methane, Sensor Range 0 to 5\% Vol, 0.01\% Vol Resolution," [Online]. Available: https://www.grainger.com/product/INDUSTRIALSCIENTIFIC-Replacement-Sensor-53UD33.

[78] SGX Sensortech, "IR32BC," [Online]. Available: https://sgx.cdistore.com/products/detail/ir32bc-sgx-sensortech/333411/.

[79] SGX Sensortech, "IR3 Single Gas Series Datasheet," SGX Europe, 2016. [Online]. Available: https://www.sgxsensortech.com/content/uploads/2014/07/DS-0251-IR3Single-Gas-Series-Datasheet-V1.pdf.

[80] Grainger, "Replacement Sensor, Detects Methane, Sensor Range 0 to $100 \%$ Vol, 1\% Vol Resolution," [Online]. Available: https://www.grainger.com/product/INDUSTRIALSCIENTIFIC-Replacement-Sensor-1TAN4?.

[81] Industrial Scientific Co., "iBrid MX6 Multi-Gas Monitor," Pittsburgh, PA USA, 2020. [Online]. Available: https://www.indsci.com/globalassets/documents/mx6-ibrid/mx6ibrid-product-manual/17130279-1_en.pdf.

[82] Dynament, "Methane Infrared Gas Sensors," [Online]. Available: https://www.dynament.com/gas-types/methane/.

[83] Dynament, "LOW POWER VERSION DUAL HYDROCARBONS AND CARBON DIOXIDE 'BIOGAS' SENSOR Technical Data Sheet," Nottinghamshire, UK, 2020. [Online]. Available: https://www.dynament.com/_webedit/uploadedfiles/All\%20Files/Data/tds0150_2.0_Low\%20power\%20Platinum\%20Dual\%20Biogas\% 20Sensor\%20\%28Certified\%29\%20Data\%20Sheet.pdf.

[84] Component Distributors, Inc., "MICS-5524," [Online]. Available: https://www.cdiweb.com/products/detail/mics5524-sgX-sensortech/333420/?pid=1752. 
[85] SGX Sensortech, "The MiCS-5524 is a compact MOS sensor.," Corcelles-Cormondrèche, Switzerland, [Online]. Available: https://cdn-shop.adafruit.com/product-files/3199/MiCS5524.pdf.

[86] SGX Sensortech, "MICS-4514," [Online]. Available: https://sgx.cdistore.com/products/detail/mics4514-sgx-sensortech/333417/.

[87] SGX Sensortech, "The MiCS-4514 is a compact MOS sensor with two fully independent sensing elements on one package.," [Online]. Available: https://www.sgxsensortech.com/content/uploads/2014/08/0278_Datasheet-MiCS4514.pdf.

[88] Transfer Multisort Elektronik, "MP-4 WINSEN," [Online]. Available: https://www.tme.com/us/en-us/details/mp-4/gas-sensors/winsen/.

[89] Zhengzhou Winsen Electronics Technology Co., Ltd, "Flammable Gas Sensor Model: MP-4," Zhengzhou, China, 2014. [Online]. Available: https://www.winsensensor.com/d/files/PDF/Flat-surfaced\%20Gas\%20Sensor/MP-4(V1.3).pdf.

[90] SparkFun Electronics, "Methane CNG Gas Sensor - MQ-4," [Online]. Available: https://www.sparkfun.com/products/9404.

[91] Zhengzhou Winsen Electronics Technology Co., Ltd, "Flammable Gas Sensor Model: MQ-4," Zhengzhou, China, 2014. [Online]. Available: https://cdn.sparkfun.com/datasheets/Sensors/Biometric/MQ-4\%20Ver1.3\%20\%20Manual.pdf.

[92] Conrad, "Figaro TGS-813 Gas Sensor Type Propane, butane, methane, alcohol, hydrogen (Ø x H) 17 mm x 10 mm," [Online]. Available: https://www.conrad.com/p/figaro-tgs-

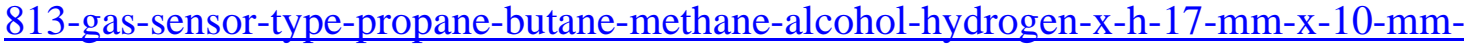
183474.

[93] FIGARO USA, INC., "TGS 813 - for the detection of Combustible Gases Product Information," Arlington Heights, IL, USA, [Online]. Available: https://docs.rsonline.com/5428/0900766b815a66d4.pdf.

[94] Los Gatos Research, "GHG Analyzer Travels Anywhere," ABB Inc., Quebec, Canada, [Online]. Available:

https://www.lgrinc.com/documents/LGR_Ultraportable_GGA_Datasheet.pdf. 
[95] PerkinElmer Inc., "Cavity-enhanced Absorption Spectroscopy for Trace Gas Detection with Frontier," Waltham, MA, USA, 2011. [Online]. Available: https://www.s4science.at/wordpress/wp-content/uploads/2018/10/Frontier-Trace-GasDetection_APP.pdf.

[96] Los Gatos Research, Price Quote For Parts and Services, Mountain View, 2014.

[97] C. Taylor, J. Chilton and J. Zimmer, "Use of a Test Box to Measure Response Times for Machine-Mounted Monitors," 2004.

[98] RKI Instruments, "GX-3R Pro Five Gas Monitor," [Online]. Available: https://www.rkiinstruments.com/pdf/gx3rpro.pdf.

[99] RKI Instruments, "Eagle Gas Detector," 2020. [Online]. Available: https://www.rkiinstruments.com/product/eagle/.

[100] F. D. Berkley, "Ejectors Have a Wide Range of Uses," Petroleum Refiner, 1958.

[101] transvac, "Principle of Operation of Ejectors," 2020. [Online]. Available: https://www.transvac.co.uk/how-an-ejector-works/.

[102] J. Chen, S. Jarall, H. Havtun and . B. Palm, "A review on versatile ejector applications in refrigeration systems," Renewable and Sustainable Energy Reviews, vol. 49, pp. 67-90, 2015. doi: 10.1016/j.rser.2015.04.073.

[103] X. Song, M. Cao, W. Shin, W. Cao, S. Kang and Y. Park, "Numerical Investigation of a Liquid-Gas Ejector Used for Shipping Ballast Water Treatment," Mathematical Problems in Engineering, 2014. doi: 10.1155/2014/259593.

[104] B. Giechaskiel, L. Ntziachristos and Z. Samaras, "Calibration and modelling of ejector dilutors for automotive exhaust sampling," Measurement Science and Technology, vol. 15, no. 11, p. 2199-2206, 2004. doi: 10.1088/0957-0233/27/2/027001.

[105] J. Björkstrand, "Design of an ejector diluter and a system for particulate mass measurements of diesel exhaust gases," M.S. thesis, KTH Industrial Engineering and Management., Stockholm, Sweden, 2006.

[106] B. Giechaskiel, D. Lesueur, R. Müller and A. Krasenbrink, "Prototype dilution system for on-board measurements compliant with the legislation and the Particle Measurement Programme (PMP)," European Communities, Ispra, Italy, 2009.

[107] T. Otake, S. Tone, R. Kuboi, Y. Takahashi and K. Nakao, "Dispersion of a gasby a liquid jet ejector," Int. Chem. Eng., vol. 21, pp. 72-80, 1981. doi: 10.1252/kakoronbunshu.5.366. 
[108] J. Zahradnik, J. Kratochvil, F. Kastanek and M. Rylek, "Energy effectiveness of bubble column reactors with sieve tray and ejector type gas distributors," Chemical Engineering Communications, vol. 15, no. 1-4, pp. 27-40, 1982. doi: 10.1080/00986448208911057.

[109] J. Zahradnik, J. Kratochvil, F. Kastanek and M. Rylek, "Hydrodynamic characteristicsof gas-liquid beds in contactors with ejector type gas distributors," Collection of Czechoslovak Chemical Communications, vol. 47, no. 7, pp. 1939-1949, 1982. doi: $10.1135 / \mathrm{cccc} 19821939$.

[110] S. Ogawa, H. Yamaguchi, S. Tone and T. Otake, "Gas-liquid mass transfer inthe jet reactor with liquid jet ejector," J. Chem. Eng. Jpn., vol. 16, no. 5, pp. 419-425, 1983. doi: 10.1252/jcej.16.419.

[111] M. Rylek and J. Zahradník, "Design of Venturi-tube gas distributors for bubble-type reactors," Collection of Czechoslovak Chimical Communications, vol. 49, no. 9, pp. 1939-1948, 1984. doi: 10.1135/cccc19841939.

[112] S. Bhutada and V. Pangarkar, "Gas induction and hold-up characteristics of liquid jet loop reactors," Chemical Engineering Science, vol. 43, no. 10, pp. 2904-2907, 1988. doi: 10.1016/0009-2509(88)80036-8.

[113] C. Dirix and K. van der Wiele, "Mass transfer in jet loop reactors," Chemical Engineering Science, vol. 45, no. 8, pp. 2333-2340, 1990. doi: 10.1016/0009-2509(90)80113-S.

[114] P. Cramers, L. van Dierendonck and A. Beenackers, "Influence of the gas density on the gas entrainment rate and gas hold-up in loop venturi reactors," Chemical Engineering Science, vol. 47, no. 9-11, pp. 2251-2256, 1992. doi: 10.1016/0009-2509(92)87043-P.

[115] P. Cramers, L. van Dierendonck and A. Beenackers, "Hydrodynamicsand mass transfer characteristics of a loop venturi reactor with a downflow liquid jet ejector," Chemical Engineering Science, vol. 47, no. 13-14, pp. 3557-3564. doi: 10.1016/00092509(92)85070-R, 1992.

[116] J. Zahradnik, M. Fialova, V. Linek and J. Sinkule, "Dispersion efficiency of ejector-type gas distributors in different operating modes," Chemical Engineering Science, vol. 52, no. 24, pp. 4499-4510, 1997. doi: 10.1016/S0009-2509(97)00294-7.

[117] P. Cramers and A. Beenackers, "Influence of the ejector configuration, scale and the gas density on the mass transfer characteristics of gas-liquid ejectors," Chemical Engineering, vol. 82, pp. 131-141, 2001. doi: 10.1016/j.jclepro.2018.04.135. 
[118] A. Mandal, G. Kundu and D. Mukherjee, "Gas holdup and entrainmentcharacteristics in a modified downflow bubble column with Newtonianand non-Newtonian liquid," Chemical Engineering and Processing: Process Intensification, vol. 42, no. 10, pp. 777-787, 2003. doi: 10.1016/S0255-2701(02)00134-4.

[119] A. Mandal, G. Kundu and D. Mukherjee, "Interfacial area and liquid-side volumetric mass transfer coefficient in a downflow bubble column," The Canadian Journal of Chemical Engineering, vol. 81, no. 2, pp. 212-219, 2008. doi: 10.1002/cjce.5450810206.

[120] A. H. Araghi and M. Khiadani, "Experimental investigation and analysis of a new singlestage vacuum spray flash desalinator utilising a gas-liquid ejector," Journal of Cleaner Production, vol. 190, pp. 118-127, 2018. doi:10.1016/j.jclepro.2018.04.135.

[121] H. M. Jeong, T. Utomo, Z. H. Jin and H. S. Chung, "A CFD Analysis on the Gas-Liquid Ejector," pp. 28-34, 2008.

[122] K. S. Almutairi, "An integrated modeling approach for design and optimization of ejector pumps carrying two-phase fluid," PhD Dissertation, Dept. of Mech. and Aero. Eng., Univ. of Missouri-Columbia, Columbia, Missouri, USA, Dec. 2017.

[123] J. Yan, W. Cai and Y. Li, "Geometry parameters effect for air-cooled ejector cooling systems with R134a Refrigerant," Renewable Energy, vol. 46, pp. 155-163, 2012. doi: 10.1016/j.renene.2012.03.031.

[124] B. Zhang, X. Song, J. Lv and J. Zuo, "Study on the key ejector structures of the waste heat-driven ejector air conditioning system with R236fa as working fluid," Energy and Buildings, vol. 49, pp. 209-215, 2012. doi: 10.1016/j.enbuild.2012.02.009.

[125] S. Hosseini, "Aviation Stack Exchange: What is motive flow and why is it used in some aircraft hydraulic systems?," [Online]. Available: https://aviation.stackexchange.com/questions/34301/what-is-motive-flow-and-why-is-itused-in-some-aircraft-hydraulic-systems.

[126] C. Li and Y. Li, "Investigation of entrainment behavior and characteristics of gas-liquid ejectors based on CFD simulation," Chemical Engineering Science, vol. 66, pp. 405-416, 2011 doi: 10.1016/j.ces.2010.10.041.

[127] M. E. Alshebani, K. Alawadhi, A. A. Alnaqi and A. A. Saker, "Numerical Investigation of a Liquid-Gas Ejector in Marine Ships," International Journal of Applied Engineering Research, vol. 12, no. 14, pp. 4663-4674, 2017. 
[128] G. Yuan, L. Zhang, H. Zhang and Z. Wang, "Numerical and experimental investigation of performance of the liquid-gas and liquid jet pumps in desalination systems," Desalination, vol. 276, no. 1-3, pp. 89-95, 2011. doi: 10.1016/j.desal.2011.03.029.

[129] ESDU, "Ejectors and jet pumps - design and performance for incompressible liquid flow. 85032," IHS ESDU, 1985.

[130] C. D. Taylor, J. E. Chilton and G. V. Goodman, "Guidelines for the Control and Monitoring of Methane Gas," National Institute for Occupational Safety and Health, Pittsburgh, PA, USA, 2010.

[131] GasLab, "Cubic SJH-5 Methane Sensor," [Online]. Available: https://gaslab.com/products/methane-gas-sensor-cubic-sjh-5.

[132] GasLab, Cubic SJH-5 Methane Gas Sensor User Manual, Ormond Beach, FL, USA: CO2Meter.com, [Online]. Available:

https://co2meters.com/Documentation/Manuals/Manual-Cubic-SJH-5-Methane-SensorCO2Meter.pdf.

[133] C. D. Taylor, J. Chilton and T. Mal, "Evaluating performance characteristics of machinemounted methane monitors by measuring response time," in U.S. Mine Ventilation Symposium, 2002.

[134] R. K. Zipf Jr., K. Mohamed, J. Addis and F. Karnack, "Tube bundle system: for monitoring of coal mine atmosphere," Min Eng., vol. 65, no. 5, pp. 57-63, 2013.

[135] R. B. Krog, "Critical Analysis of Longwall Ventilation Systems and Removal of Methane," The Research Repository @ WVU, 2016.

[136] B. Belle, "Underground Mine Ventilation Air Methane (VAM) Monitoring - an Australian Journey towards Achieving Accuracy," in 14th Coal Operators, 2014.

[137] "Electronic Code of Federal Regulations: Title 30 Part 27 Subpart B," 2020. [Online]. Available: https://www.ecfr.gov/cgi-bin/text$\underline{\mathrm{idx}}$ ?SID=4cf1bf652f2a252c83f354ea $25 \mathrm{cad} 34 \mathrm{c} \& \mathrm{mc}=$ true $\&$ node $=$ sp30.1.27.b $\& \mathrm{rgn}=\operatorname{div} 6$.

[138] "Electronic Code of Federal Regulations: Title 30 Part 27 Subpart C," 2020. [Online]. Available: https://www.ecfr.gov/cgi-bin/text$\underline{\mathrm{idx}}$ ?SID=4cf1bf652f2a252c83f354ea25cad34c\&mc=true $\&$ node $=\operatorname{sp} 30.1 .27 . c \& \mathrm{rgn}=\operatorname{div} 6$. 
[139] KOMATSU, "Longwall Systems," [Online]. Available:

https://mining.komatsu/underground-mining/longwall-systems.

[140] V. Richardson, Interviewee, Longwall Roof Support. [Interview]. 17 August 2020.

[141] KOMATSU, System: Roof Supports: Faceboss RS20s Technical Service Manual, Joy Global Inc., 2013.

[142] Swanson Industries, "Longwall Shield Repairs," [Online]. Available: https://swansonindustries.com/us/longwall-shield-repairs/.

[143] J. Rider, "Controlling Respirable Dust on Longwall Mining Operations," Office of Mine Safety and Health Research, 2014. [Online]. Available: https://arlweb.msha.gov/endblacklung/docs/5\%20Longwall\%20Dust\%20Control\%20\%20Beckley\%202014.pdf.

[144] Honeywell, "HIH-4602-L Series," [Online]. Available: https://sensing.honeywell.com/sensors/humidity-sensors/HIH-4602-L-series.

[145] Omega, "Quick Disconnect Thermocouples with Miniature Connectors," [Online]. Available: https://www.omega.com/en-us/sensors-and-sensingequipment/temperature/sensors/thermocouple-probes/jmqss/p/TMQSS-125U-4.

[146] Advance Auto Parts, "BWD Manifold Absolute Pressure Sensor," [Online]. Available: https://shop.advanceautoparts.com/p/bwd-manifold-absolute-pressure-sensorec7034/20971064-p?c3ch=PLA\&c3nid=20971064-

P\&adtype=pla_with_promotion\&product $\_$channel=online\&store $\_$code $=\& g$ clid=EAIaIQo bChMIvpuOgeq_5wIVBhgMCh3LcA9_EAQYASABEgJ0x_D_BwE\&gclsrc=aw.ds.

[147] Calt, "3 Cups Wind Speed Sensor Anemometer 5V 0-5V Analog Output," [Online]. Available: https://www.amazon.com/Speed-Sensor-Anemometer-AnalogOutput/dp/B01MZAO4BZ/ref=sxbs_sxwdsstvp?keywords $=3+$ Cups + Wind + Speed + Sensor + Anemometer $+0-$ 5V+Analog+Output\&pd_rd_i=B01MZAO4BZ\&pd_rd_r=eb20997c-47c1-4c5c-8e8ee4a776edf41b\&pd_rd_w=aZf1A\&pd_rd_wg=x3jmY\&pf_.

[148] Mouser Electronics, "FS2012-1100-NG," [Online]. Available: https://www.mouser.com/ProductDetail/idt-integrated-device-technology/fs2012-1100ng/?qs=YCa\%2FAAYMW03AHFO5VaDnVQ\%3D\%3D\&countrycode=US\&currencyco $\underline{\mathrm{de}=\mathrm{USD}}$. 
[149] Omega, "Quick Disconnect Thermocouples with Miniature Connectors Data Sheet," [Online]. Available: https://assets.omega.com/pdf/test-and-measurementequipment/temperature/sensors/thermocouple-probes/JMQSS.pdf.

[150] Honeywell International Inc, "HIH-4602-L Series Humidity Sensors," Minneapolis, MN, USA, 2008. [Online]. Available: https://sensing.honeywell.com/honeywell-sensinghih46021-series-product-sheet-009043-1-en.pdf.

[151] Renesas Electronics Corporation, "High Performance Flow Sensor Module FS2012 Series Datasheet," Tokyo, Japan, 2019. [Online]. Available: https://www.idt.com/us/en/document/dst/fs2012-datasheet.

[152] "YGC-FS-5V-A1 4-20mA 0-20mA output wind speed sensor 0-45m/s Measuring range Anemometer weather station sensor," [Online]. Available: https://www.aliexpress.com/item/32967680210.html.

[153] MegaDepot, "STC, 3S012-1/4A-2A-D-V 3S012 Direct Acting 3-Way Solenoid Valve," [Online]. Available: https://megadepot.com/product/stcvalve-3s012-1-4a-2a-d-v-3s01224vac-din-coil-1-4-npt-0-115-psi-direct-acting-3-way-ss-solenoid-valve.

[154] ICP DAS USA, "ET-7217-10," [Online]. Available: https://www.icpdasusa.com/et 7217 _10.html.

[155] TinaWood, "TinaWood 2PCS SSR-25DD Solid State Relay 25A 3-32V DC/5-200V DC (SSR-25DD x2)," [Online]. Available: https://www.amazon.com/TinaWood-SSR-25DDSolid-State-5-

200V/dp/B07F3WGRP4/ref=sr_1_19_sspa?keywords=solid+state+module+ssr25dd\&qid $=1581710784 \& \mathrm{sr}=8-19$ -

spons\&psc $=1 \&$ spLa $=$ ZW5jcnlwdGVkUXVhbGlmaWVyPUEzRVoyREtERIFZRTZBJm VuY3J5cHR1ZElkPUEwNjA5NTM0M0dKNUZONEQ5OURZ.

[156] HiComponent, "Intelligent RTD Thermocouple Temperature Transmitter 4-20mA Out," [Online]. Available: https://www.hicomponent.com/rtd-thermocouple-to-4-20matransmitter-converter.html?search=rtd.

[157] Edgetech Instruments, "DewMaster Chilled Mirror Hygrometer," 2018. [Online]. Available: https://edgetechinstruments.com/product/dewmaster-chilled-mirrorhygrometer/.

[158] Heise, "Heise® model pte-1 dual display lcd handheld digital calibrator," 2020. [Online]. Available: https://www.heise.com/Products/calibrators/Heise-Model-PTE-1-DualDisplay-LCD-Handheld-Digital-Calibrator.cfm. 
[159] Los Gatos Research, "Ultraportable Gas Analyzers," 2020. [Online]. Available: http://www.lgrinc.com/analyzers/ultraportable/.

[160] Scientific Sales Inc., "1405-PK-100 Gill UltraSonic Anemometer," [Online]. Available: https://www.scientificsales.com/1405-PK-100-Gill-UltraSonic-Anemometer-p/9894.htm.

[161] Edgetech Instruments, "Dewmaster Chilled Mirror Dew/Frost Point Hygrometer," 2015. [Online]. Available: https://edgetechinstruments.com/wpcontent/uploads/2018/10/DewMaster-Data-Sheet-v11.pdf.

[162] Heise, "PTE-1 Handheld Pressure Calibrator Operating Manual," Ashcroft Inc., Stratford, CT, USA, 2004. [Online]. Available: https://www.heise.com/Products/calibrators/upload/I-M002-10052-HHC-PTE-1.pdf.

[163] Los Gatos Research, "Ultra-Portable Greenhouse Gas Analyzer User Manual," Los Gatos Research, Inc., Mountain View, CA, USA, 2014. [Online]. Available: https://www.ecotech.com/wp-content/uploads/2015/03/UltraPortable-GGA-User-Manual$\underline{\text { Rev-1.01.pdf. }}$

[164] Alicat Scientific, "Mass Flow Controllers," 2020. [Online]. Available: https://www.alicat.com/product/mass-flow-controllers/.

[165] Alicat Scientific, "Technical Data for Alicat MC-Series Mass Flow Controllers," 2019. [Online]. Available: https://documents.alicat.com/specifications/DOC-SPECSMIDFLOWCONTROLLERS.pdf.

[166] Alicat Scientific, "Technical Data for Alicat MCQ and MCRQ Mass Flow Controllers," 2018. [Online]. Available: https://documents.alicat.com/specifications/Alicat_MCQ_Controller_Specs.pdf.

[167] Alicat Scientific, "Technical Data for Alicat MCP Moderate Mass Flow Controllers," 2018. [Online]. Available: https://documents.alicat.com/specifications/Alicat_MCP_Controller_Specs.pdf.

[168] Alicat Scientific, "Technical Data for Alicat M-Series Mass Flow Meters," 2018. [Online]. Available: https://documents.alicat.com/specifications/Alicat_Mass_Meter_Specs.pdf.

[169] Gill Instruments, Windsonic Wind Speed \& Direction Sensor, Gill Instruments, 2006. [Online]. Available: http://gillinstruments.com/data/manuals/WindSonic-WebManual.pdf. 
[170] Hantek, CC-65 AC/DC current clamp. [Online]. Available:

https://www.tme.eu/Document/6878b3a1e09498ecfee395be7d9b3198/CC65_Manual.pdf.

[171] Formlabs, "Form 3," [Online]. Available: https://formlabs.com/3d-printers/form3/?\&utm_source=google\&utm_medium $=c p c \& u t m \_c a m p a i g n=G P \_U S-N A-P r o s p e c t i n g-$ Search_Brand-Form_3-Brand-EN-BM-Paid-

Adwords\&utm_term=\&utm_content=Form_3_printer\&utm_device=c\&_bt=3413271453 30\&_bk=\%2Bform\%20\%2B3\%20\%2Bprinter\&_b.

[172] W. A. Aissa, "Effect of Multiple Nozzles on Air Ejector Performance," in 17th International Symposium on Airbreathing Engines, Munich, Germany, 2005.

[173] C. G. BLATCHLEY, "CONTROLLING EJECTOR PERFORMANCE," SCHUTTE \& KOERTING, Trevose, PA, USA, [Online]. Available: https://www.s-k.com/technicalreferences/ejector_performance.pdf.

[174] ANSYS, "ANSYS FLUENT 12.0 Theory Guide," ANSYS, Inc., 2009. [Online]. Available: https://www.afs.enea.it/project/neptunius/docs/fluent/html/th/main_pre.htm.

[175] S. Ghorbanzadeh and E. Lakzian, "Enhancement of the air ejector performance: primary nozzle and mixing chamber investigation," Journal of the Brazilian Society of Mechanical Sciences and Engineering, vol. 40, no. 2, 2018. doi: 10.1007/s40430-0180975-1.

[176] C. Dirix and K. van der Wiele, "Mass Transfer in Jet Loop Reactors," Chemical Engineering Science, vol. 45, no. 8, pp. 2333-2340, 1990.

[177] T. Otake, S. Tone, R. Kuboi, Y. Takahashi and K. Nakao, "Dispersion of Gas by a Liquid-Jet Ejector," Kagaku Kogaku Ronbunshu, vol. 5, no. 4, pp. 366-373, 1979. doi: 10.1252/kakoronbunshu.5.366.

[178] R. G. Cunningham and R. J. Dopkin, "Jet Breakup and Mixing Throat Lengths for the Liquid Jet Gas Pump," Fluids Engineering, vol. 96, no. 3, pp. 216-226, 1974. doi: doi.org/10.1115/1.3447144.

[179] KOMATSU, PRS Water Spray Summary.

[180] Murray Energy, Murray Energy Water Supply [Microsoft Excel spreadsheet], 2020.

[181] Sensors Inc., "Gas Measurement Gasmitter," 2020. [Online]. Available: http://www.sensors-inc.com/Products/Gas_Analysis/Gasmitter. 
[182] ICP DAS, "iPPC-xx31-WES7 User Manual," ICP DAS Co., Ltd., 2017. [Online]. Available: https://www.icpdas-usa.com/documents/user-manual_iPPC_xx31_WES7.pdf.

[183] H. Xue, L. Wang, H. Zhang, L. Jia and J. Ren, "Design and investigation of multi-nozzle ejector for PEMFC hydrogen recirculation," International journal of hydrogen energy, vol. 45, no. 28, pp. 14500-14516, 2020. doi: 10.1016/j.ijhydene.2020.03.166. 


\subsection{Appendices}

\section{Appendix A:}

MOS Specifications [91]:

\begin{tabular}{|c|c|c|c|}
\hline \multicolumn{3}{|c|}{ Model } & $M Q-4$ \\
\hline \multicolumn{3}{|c|}{ Sensor Type } & Semiconductor \\
\hline \multicolumn{3}{|c|}{ Standard Encapsulation } & Bakelite, Metal cap \\
\hline \multicolumn{3}{|c|}{ Target Gas } & Methane \\
\hline \multicolumn{3}{|c|}{ Detection range } & $300 \sim 10000 \mathrm{ppm}\left(\mathrm{CH}_{4}\right)$ \\
\hline \multirow{3}{*}{$\begin{array}{l}\text { Standard Circuit } \\
\text { Conditions }\end{array}$} & Loop Voltage & $\mathrm{V}_{\mathrm{c}}$ & $\leq 24 \mathrm{~V} \mathrm{DC}$ \\
\hline & Heater Voltage & $\mathrm{V}_{\mathrm{H}}$ & $5.0 \mathrm{~V} \pm 0.1 \mathrm{~V} A C$ or $\mathrm{DC}$ \\
\hline & Load Resistance & $\mathrm{R}_{\mathrm{L}}$ & Adjustable \\
\hline \multirow{5}{*}{$\begin{array}{l}\text { Sensor character } \\
\text { under standard } \\
\text { test conditions }\end{array}$} & Heater Resistance & $\mathrm{R}_{\mathrm{H}}$ & $26 \Omega \pm 3 \Omega$ (room tem.) \\
\hline & $\begin{array}{l}\text { Heater } \\
\text { consumption }\end{array}$ & $\mathbf{P}_{\mathrm{H}}$ & $\leq 950 \mathrm{~mW}$ \\
\hline & Sensitivity & S & $\begin{array}{l}\mathrm{Rs}(\text { in air) } / \mathrm{Rs}(\text { in } \\
\left.5000 \mathrm{ppmCH}_{4}\right) \geq 5\end{array}$ \\
\hline & Output Voltage & Vs & $\begin{array}{c}2.5 \mathrm{~V} \sim 4.0 \mathrm{~V} \text { (in 5000ppm } \\
\left.\mathrm{CH}_{4}\right)\end{array}$ \\
\hline & Concentration Slope & $\alpha$ & $\leq 0.6\left(R_{5000 \mathrm{ppm}} / \mathrm{R}_{1000 \mathrm{ppm}} \mathrm{CH}_{4}\right)$ \\
\hline \multirow{3}{*}{$\begin{array}{l}\text { Standard test } \\
\text { conditions }\end{array}$} & \multicolumn{2}{|c|}{ Tem. Humidity } & $20^{\circ} \mathrm{C} \pm 2^{\circ} \mathrm{C}: 55 \% \pm 5 \% \mathrm{RH}$ \\
\hline & \multicolumn{2}{|c|}{ Standard test circuit } & $\begin{array}{l}\mathrm{Vc}: 5.0 \mathrm{~V} \pm 0.1 \mathrm{~V}: \\
\mathrm{V}_{\mathrm{H}}=5.0 \mathrm{~V} \pm 0.1 \mathrm{~V}\end{array}$ \\
\hline & \multicolumn{2}{|l|}{ Preheat time } & Over 48 hours \\
\hline
\end{tabular}
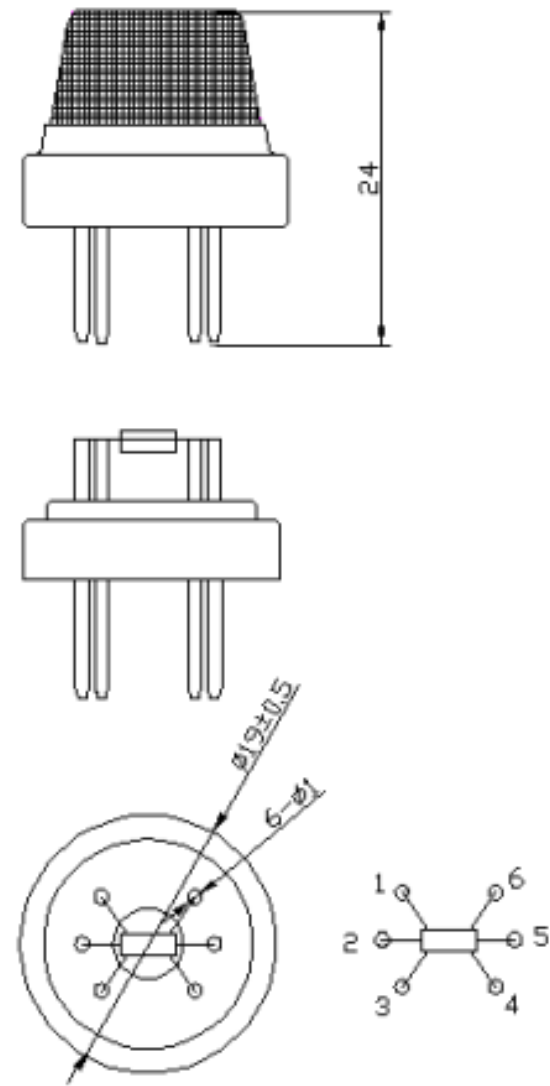

Fig1.Sensor Structure

Unit: $\mathrm{mm}$ 
Appendix B:

IRS Specifications [83]:

\begin{tabular}{|c|c|}
\hline \multicolumn{2}{|c|}{ GENERAL SPECIFICATION } \\
\hline Operating Voltage Range: & $3.0-5.0 \mathrm{~V} \mathrm{d.c}$ \\
\hline Operating Current: & Average current $15 \mathrm{~mA}$. See graph on page 7 \\
\hline Operating temperature range: & $-20^{\circ} \mathrm{C}$ to $+50^{\circ} \mathrm{C}\left(-4^{\circ} \mathrm{F}\right.$ to $\left.122^{\circ} \mathrm{F}\right)$ \\
\hline Warm up time: & To final zero $\pm 2 \%$ of full scale: 1 minute @ $20^{\circ} \mathrm{C}\left(68^{\circ} \mathrm{F}\right)$ ambient \\
\hline Storage temperature range: & $-20^{\circ} \mathrm{C}$ to $+50^{\circ} \mathrm{C}\left(-4^{\circ} \mathrm{F}\right.$ to $\left.122^{\circ} \mathrm{F}\right)$ \\
\hline Humidity range: & 0 to $95 \% \mathrm{RH}$ non-condensing. \\
\hline Digital signal format: & 8 data bits, 1 stop bit, no parity. $2.8 \mathrm{~V}$ logic level \\
\hline Standard baud rates: & $38,400,19,200,9600,4800$ \\
\hline User configurable parameters: & $\begin{array}{l}\text { Full-scale value, resolution, } \\
\text { Sensor 'zero' function } \\
\text { Sensor 'span' function }\end{array}$ \\
\hline MTBF: & $>5$ years \\
\hline Weight: & 15 grams \\
\hline Pressure & $\pm 5 \%$ of the calibration pressure to maintain the accuracy limits \\
\hline
\end{tabular}

\begin{tabular}{|c|c|}
\hline \multicolumn{2}{|c|}{ HYDROCARBON CHANNEL SPECIFICATION } \\
\hline Methane measuring range: & $0-5 \%, 0-100 \%$ volume or both \\
\hline Hydrocarbon measuring range & $0-100 \%$ LEL equivalent \\
\hline Resolution: & $\begin{array}{l}0.01 \% \text { for readings up to } 5 \% \text { volume methane } \\
0.1 \% \text { for readings from } 5 \% \text { up to } 100 \% \text { volume methane } \\
0.01 \% \text { propane for all readings }\end{array}$ \\
\hline Accuracy: & $\begin{array}{l} \pm 10 \% \text { of the reading @ } 20^{\circ} \mathrm{C}\left(68^{\circ} \mathrm{F}\right), 1 \text { bar pressure, applied } \\
\text { gas. }\end{array}$ \\
\hline Response Time T90: & $<30 \mathrm{~s} @ 20^{\circ} \mathrm{C}\left(68^{\circ} \mathrm{F}\right)$ ambient \\
\hline Zero Repeatability: & $\pm 1 \%$ of full scale @ $20^{\circ} \mathrm{C}\left(68^{\circ} \mathrm{F}\right)$ ambient \\
\hline Span Repeatability: & $\pm 2 \%$ of full scale @ $20^{\circ} \mathrm{C}\left(68^{\circ} \mathrm{F}\right)$ ambient \\
\hline Long term zero drift: & $\begin{array}{l} \pm 1 \% \text { of full scale per month } @ 20^{\circ} \mathrm{C}\left(68^{\circ} \mathrm{F}\right) \text { ambient, } \\
\text { (max } \pm 3 \% \text { of full scale per year) }\end{array}$ \\
\hline $\begin{array}{l}\text { Temperature performance: } \\
\text { - May not be appllcable when using gas crose-reterence factors }\end{array}$ & $\begin{array}{l} \pm 0.1 \% \text { volume or } \pm 10 \% \text { of reading up to } 50 \% \text { of full scale, } \pm \\
15 \% \text { of reading from } 50 \% \text { to } 100 \% \text { of full scale, or } 2 \% \text { of full } \\
\text { scale whichever is greater over the range }-20^{\circ} \mathrm{C} \text { to }+50^{\circ} \mathrm{C}\left(-4^{\circ} \mathrm{F}\right. \\
\left.\text { to } 122^{\circ} \mathrm{F}\right)\end{array}$ \\
\hline $\begin{array}{l}\text { User configurable parameters and } \\
\text { functions: }\end{array}$ & $\begin{array}{l}\text { Sensor 'zero' function } \\
\text { Sensor 'span' function } \\
\text { Over-range value }\end{array}$ \\
\hline
\end{tabular}




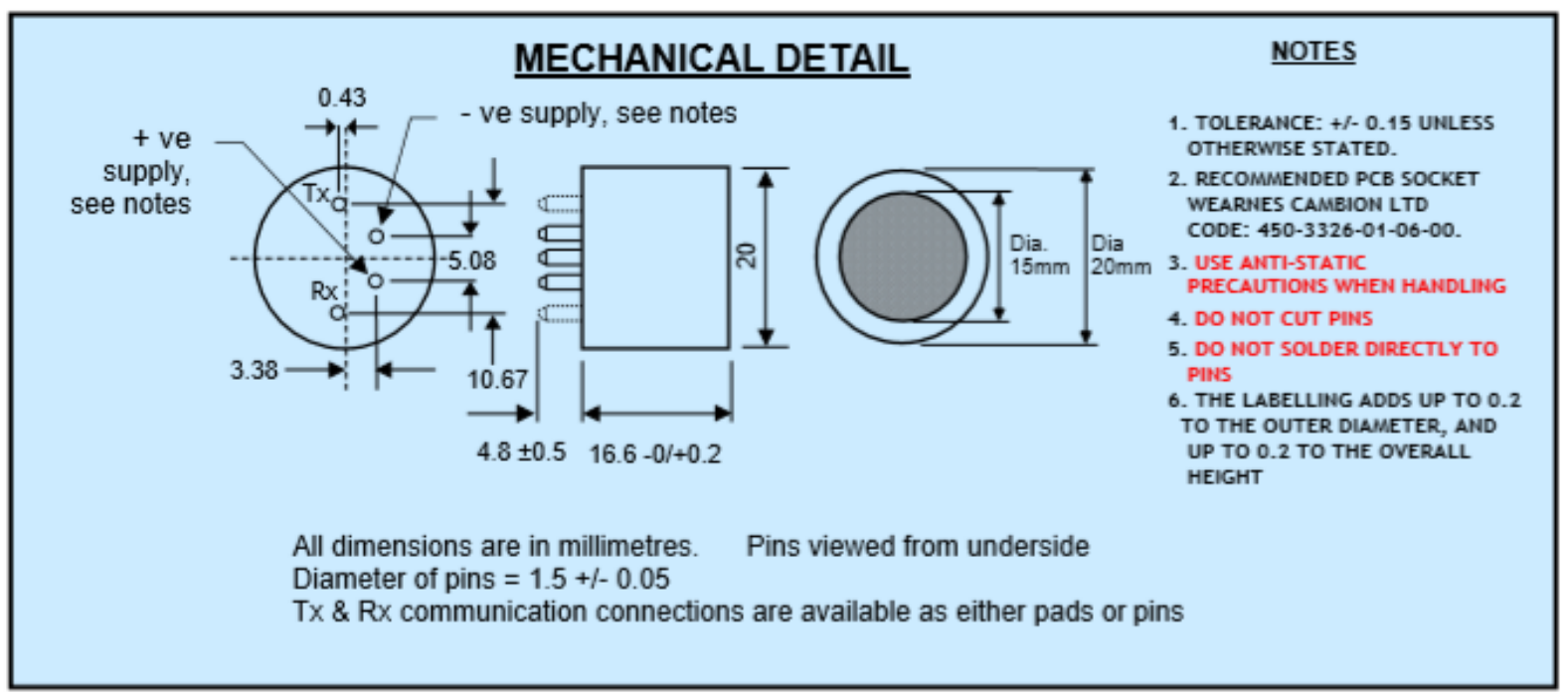


MWS 10-Node Prototype Cost Analysis:

\begin{tabular}{|c|c|c|c|}
\hline Item & Quantity & $\begin{array}{l}\text { Cost per } \\
\text { Item } \\
(\$)\end{array}$ & $\begin{array}{c}\text { Item Cost } \\
(\$)\end{array}$ \\
\hline Methane CNG Gas Sensor - MQ-4 & 10 & 4.95 & 49.50 \\
\hline Gas Sensor Breakout & 10 & 0.95 & 9.50 \\
\hline Dynament Premier Infrared Sensor & 10 & 156.56 & 1565.60 \\
\hline $\begin{array}{l}\text { Quick Disconnect Thermocouples with Miniature } \\
\text { Connectors }\end{array}$ & 10 & 35.54 & 355.40 \\
\hline Honeywell RH Sensor & 10 & 34.16 & 341.60 \\
\hline BWD Map Sensor & 10 & 21.99 & 219.90 \\
\hline 6061 Aluminum Bar 2"x2"x6" & 10 & 19.33 & 193.30 \\
\hline $\begin{array}{l}\text { Compact Air-Intake Filter with Silencer 1/4 NPT } \\
\text { Male }\end{array}$ & 10 & 15.24 & 152.40 \\
\hline $\begin{array}{l}\text { fittings for block inlet and outlet of block, valve, } \\
\text { and RH Sensor } \\
\text { (1/4" NPT Male to } 1 / 4 " \text { Swagelok) }\end{array}$ & 60 & 9.27 & 556.20 \\
\hline $\begin{array}{c}\text { fittings for thermocouple (1/4" NPT Male to } 1 / 16^{\prime \prime} \\
\text { Swagelok) }\end{array}$ & 10 & 25.45 & 254.50 \\
\hline fittings for filter & 20 & 9.34 & 186.80 \\
\hline 10-32 Machine Screws (1/2") (pack of 100) & 1 & 9.06 & 9.06 \\
\hline 10-32 Machine Screws (3/4") (pack of 100) & 1 & 11.19 & 11.19 \\
\hline 10-32 Machine Screws (1.5") (pack of 50) & 1 & 10.82 & 10.82 \\
\hline 1" Aluminum Cylinders for MQ-4 (1" dia x 12") & 1 & 6.74 & 6.74 \\
\hline Aluminum Plates for MQ-4 (1"x24"x1/8" bar) & 1 & 12.78 & 12.78 \\
\hline Loctite Epoxy EA E-120HP & 1 & 16.89 & 16.89 \\
\hline O-ring for Dynament (pack of 100) & 1 & 9.23 & 9.23 \\
\hline O-ring for MAP Sensor (pack of 100) & 1 & 4.25 & 4.25 \\
\hline O-ring for MQ-4 (pack of 100) & 1 & 7.37 & 7.37 \\
\hline $\begin{array}{l}\text { STC, 3S012-1/4A-2A-D-V 3S012 Direct Acting } \\
\text { 3-Way Solenoid Valve }\end{array}$ & 10 & 35.28 & 352.80 \\
\hline wire & 7 & 7.00 & 49.00 \\
\hline Teflon tape & 3 & 0.50 & 1.50 \\
\hline Barrier Terminal Blocks & 20 & 1.21 & 24.20 \\
\hline $24 \mathrm{~V}$ to $5 \mathrm{~V}$ Converter & 10 & 20.00 & 200.00 \\
\hline Box & 10 & 29.59 & 295.90 \\
\hline Transmitters & 10 & 15.88 & 158.80 \\
\hline Daisychain & 10 & 356.15 & 3561.50 \\
\hline iPPC (industrial computer) & 1 & 2549.15 & 2549.15 \\
\hline 2-Guage Wire (Red and Black) & 16 & 40.00 & 640.00 \\
\hline Ethernet cables & 10 & 5.10 & 51.00 \\
\hline
\end{tabular}




\begin{tabular}{|c|c|c|c|}
\hline Through-wall yorlocks & 30 & 22.00 & 660.00 \\
\hline Tube & 200 & 3.73 & 746.00 \\
\hline through panel 2 terminal & 10 & 15.74 & 157.40 \\
\hline Anemometer & 2 & 35.00 & 70.00 \\
\hline 3D printed ejector & 10 & 60.00 & 600.00 \\
\hline & & & \\
\hline & & total & $14,090.28$ \\
\hline
\end{tabular}

Appendix C-2:

Summary of Estimated Cost Modifications for Industry-Ready MWS

\begin{tabular}{|c|c|}
\hline Additional Components per Unit & $\begin{array}{c}\text { Cost } \\
{[\mathbf{\$}]}\end{array}$ \\
\hline Explosion Proof Box & 3000.00 \\
\hline Power Supply & 100.00 \\
\hline Throttling Valve for Ejector & 60.00 \\
\hline Pressure Regulator for Ejector & 75.00 \\
\hline Total Estimated Additional Costs & \\
\hline
\end{tabular}

\begin{tabular}{|c|c|}
\hline Cost of 1 Prototype Unit & 1090.11 \\
\hline Cost of 1 Unit w/o Box & 1060.52 \\
\hline Cost of 1 Unit w/ Additional Components & 4295.52 \\
\hline Cost of 10 New Units & $42,955.23$ \\
\hline Cost of New System & $45,504.38$ \\
\hline Cost per Sampling Node of Industry-Ready MWS & $\mathbf{4 5 5 0 . 4 4}$ \\
\hline
\end{tabular}


Appendix D:

CPH Industrial Computer Specifications [182]:

\begin{tabular}{|c|c|c|}
\hline & iPPC-6731-WES7 & iPPC-6831-WES7 \\
\hline \multicolumn{3}{|l|}{ System Software } \\
\hline OS & \multicolumn{2}{|c|}{ Microsoft Windows Embedded Standard 7 SP1 } \\
\hline Framework Support & \multicolumn{2}{|c|}{ Net Framework 3.5, 4.0, 4.5} \\
\hline Embedded Service & \multicolumn{2}{|c|}{ IE11, FTP Server, IIS 7.0, ASP (Java Script, VB Script) } \\
\hline SDK Provided & \multicolumn{2}{|l|}{ DIl for Visual Studio.Net } \\
\hline Multilanguage Support & \multicolumn{2}{|c|}{$\begin{array}{l}\text { English, German, French, Spanish, Portuguese, Russian, } \\
\text { Italian, Korean, Japanese, Simplified Chinese, Traditional } \\
\text { Chinese }\end{array}$} \\
\hline \multicolumn{3}{|l|}{ CPU Module } \\
\hline CPU & $\begin{array}{l}\text { E3827 }(1.75 \mathrm{GHz}, 64 \text {-bit dual } \\
\text { core) }\end{array}$ & $\begin{array}{l}\text { E3845 (1.91 GHz, 64-bit } \\
\text { quad core) }\end{array}$ \\
\hline SDRAM (DDR3) & $2 \mathrm{~GB}$ & $4 \mathrm{~GB}$ \\
\hline MRAM & \multicolumn{2}{|l|}{$128 \mathrm{~KB}$} \\
\hline Flash (SSD) & \multicolumn{2}{|c|}{ mSATA slot with one 32 GB SSD } \\
\hline EEPROM & \multicolumn{2}{|l|}{$16 \mathrm{~KB}$} \\
\hline Memory Expansion & \multicolumn{2}{|c|}{ CF slot with a 8 GB CF card (support up to $32 \mathrm{~GB}$ ) } \\
\hline RTC (Real Time Clock) & \multicolumn{2}{|c|}{$\begin{array}{l}\text { Provide second, minute, hour, date, day of week, month, } \\
\text { year }\end{array}$} \\
\hline Hardware Serial Number & \multicolumn{2}{|c|}{ 64-bit Hardware Serial Number for software copy protection } \\
\hline Dual Watchdog Timers & \multicolumn{2}{|l|}{ Yes (0.8 second) } \\
\hline Rotary Switch & \multicolumn{2}{|l|}{ Yes $(0 \sim 9)$} \\
\hline \multicolumn{3}{|l|}{ Communication Ports } \\
\hline Ethemet & \multicolumn{2}{|l|}{2 x RJ-45 10/100/1000 Base-TX } \\
\hline USB 2.0 & \multicolumn{2}{|l|}{3} \\
\hline COM 2 & \multicolumn{2}{|c|}{$\begin{array}{l}\text { RS-232 (RxD, TxD, CTS, RTS, DSR, DTR, CD, RI and } \\
\text { GND); Non-isolated }\end{array}$} \\
\hline
\end{tabular}

iPPC-xx31-WES7 (WES7 based PAC) User Manual

version1.0.0 Page: 8

Copyright (9) 2017 ICP DAS Co., Ltd. All Rights Reserved. E-mail: service@icpdas.com 


\begin{tabular}{|c|c|c|}
\hline & iPPC-6731-WES7 & IPPC-6831-WES7 \\
\hline \multicolumn{3}{|l|}{ Communication Ports } \\
\hline $\operatorname{com} 3$ & \multicolumn{2}{|c|}{ RS-485 (Data+, Data-, GND); 2500 V $_{\text {DC }}$ isolated } \\
\hline COM 4 & \multicolumn{2}{|c|}{$\begin{array}{l}\text { RS-232/RS-485 (RxD, TxD, CTS, RTS and GND for } \\
\text { RS-232, Data+ and Data- for RS-485); } 2500 V_{D C} \text { isolated }\end{array}$} \\
\hline Audio & \multicolumn{2}{|c|}{ Mic-in and Earphone-out } \\
\hline \multicolumn{3}{|c|}{ MMI (Man Machine Interface) } \\
\hline LCD & \multicolumn{2}{|l|}{$15^{n}$} \\
\hline Resolution & \multicolumn{2}{|l|}{$1024 \times 768$} \\
\hline Brightness (cd/m2) & \multicolumn{2}{|l|}{400} \\
\hline Contrast Ratio & \multicolumn{2}{|l|}{$500: 1$} \\
\hline LED Backlight Life (hrs) & \multicolumn{2}{|l|}{50,000} \\
\hline Touch Panel & \multicolumn{2}{|c|}{ 5-wire, resistive type; light transmission: $80 \%$} \\
\hline LED Indicator & \multicolumn{2}{|c|}{4 (RUN, PWR, L1, L2; L1 and L2 are user programmable) } \\
\hline \multicolumn{3}{|l|}{ VO Expansion Slots } \\
\hline Slot Number & \multicolumn{2}{|c|}{3 (for high profile $\mathrm{I}-8 \mathrm{~K}$ and $\mathrm{I}-87 \mathrm{~K}$ series $\mathrm{I} / \mathrm{O}$ modules) } \\
\hline \multicolumn{3}{|l|}{ Mechanical } \\
\hline Dimensions $(\mathrm{W} \times \mathrm{H} \times \mathrm{D})$ & \multicolumn{2}{|c|}{$381 \mathrm{~mm} \times 305 \mathrm{~mm} \times 88 \mathrm{~mm}$} \\
\hline Panel Cut-Out $(\mathrm{W} \times \mathrm{H})$ & \multicolumn{2}{|c|}{$366 \mathrm{~mm} \times 290 \mathrm{~mm}, \pm 1 \mathrm{~mm}$} \\
\hline Installation & \multicolumn{2}{|l|}{ Panel mounting } \\
\hline Ingress Protection & \multicolumn{2}{|l|}{ Front panel: NEMA 4/IP65 } \\
\hline \multicolumn{3}{|l|}{ Environmental } \\
\hline Operating Temperature & \multicolumn{2}{|l|}{$-20^{\circ} \mathrm{C} \sim+60^{\circ} \mathrm{C}$} \\
\hline Storage Temperature & \multicolumn{2}{|c|}{$-20^{\circ} \mathrm{C} \sim+70^{\circ} \mathrm{C}$} \\
\hline Ambient Relative Humidity & \multicolumn{2}{|c|}{$10 \% \sim 90 \% \mathrm{RH}$ (non-condensing) } \\
\hline \multicolumn{3}{|l|}{ Power } \\
\hline Input Range & \multicolumn{2}{|l|}{$+10 V_{D C} \sim+30 V_{D C}$} \\
\hline Redundant Power Inputs & \multicolumn{2}{|l|}{ Yes } \\
\hline Isolation & \multicolumn{2}{|l|}{$1 \mathrm{kV}$} \\
\hline Consumption & \multicolumn{2}{|l|}{$25 \mathrm{~W}$} \\
\hline
\end{tabular}


Appendix E:

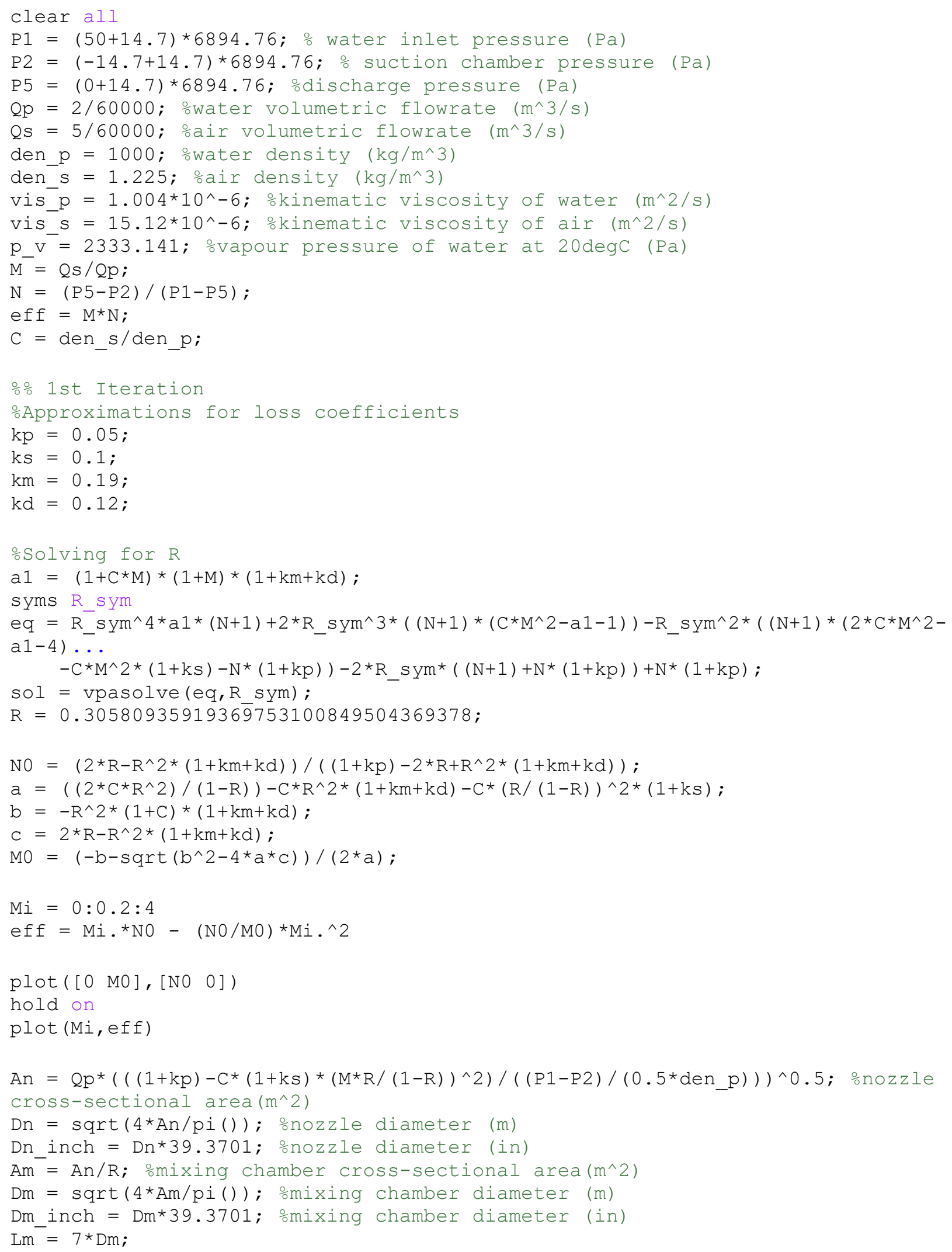




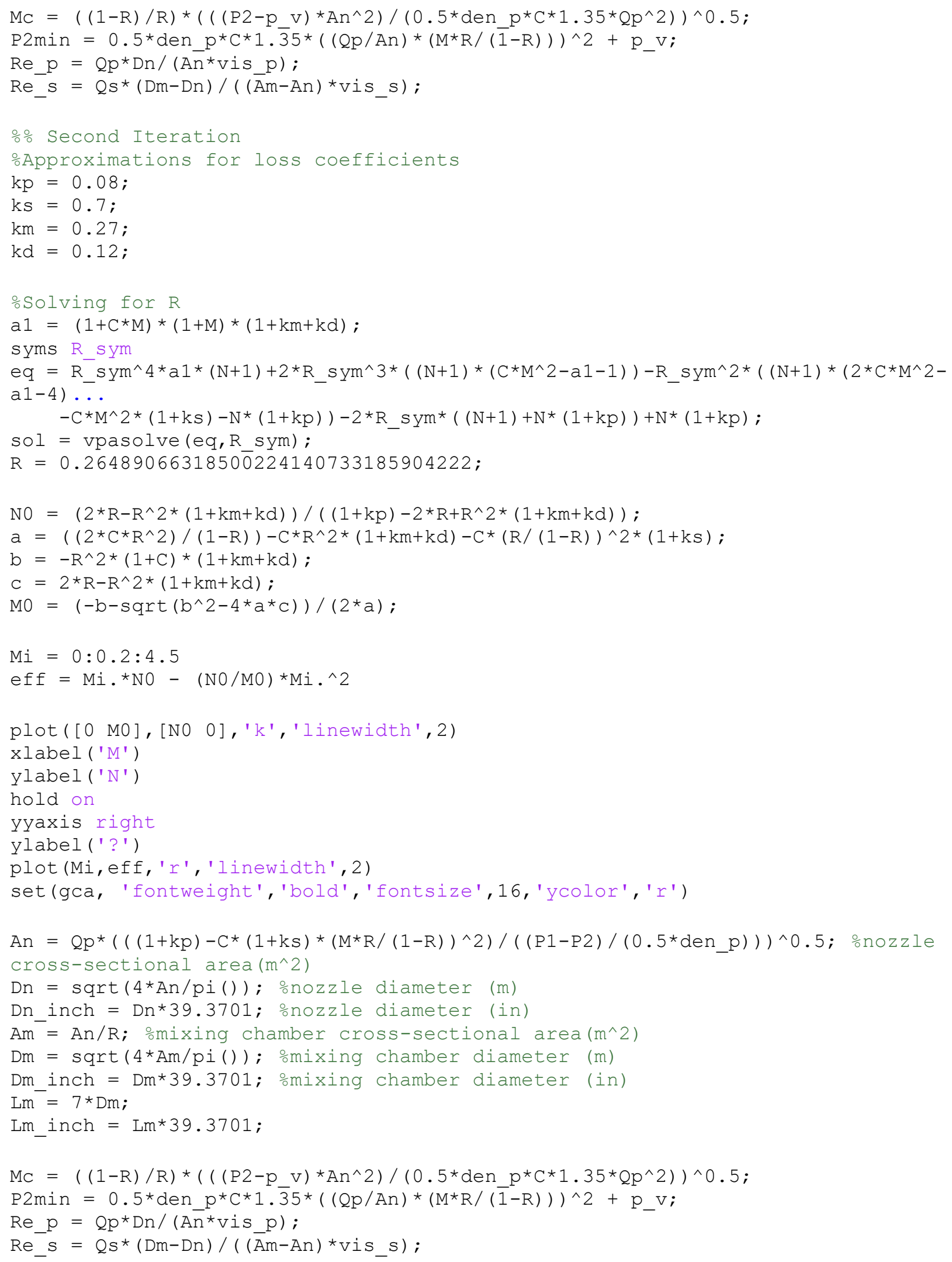




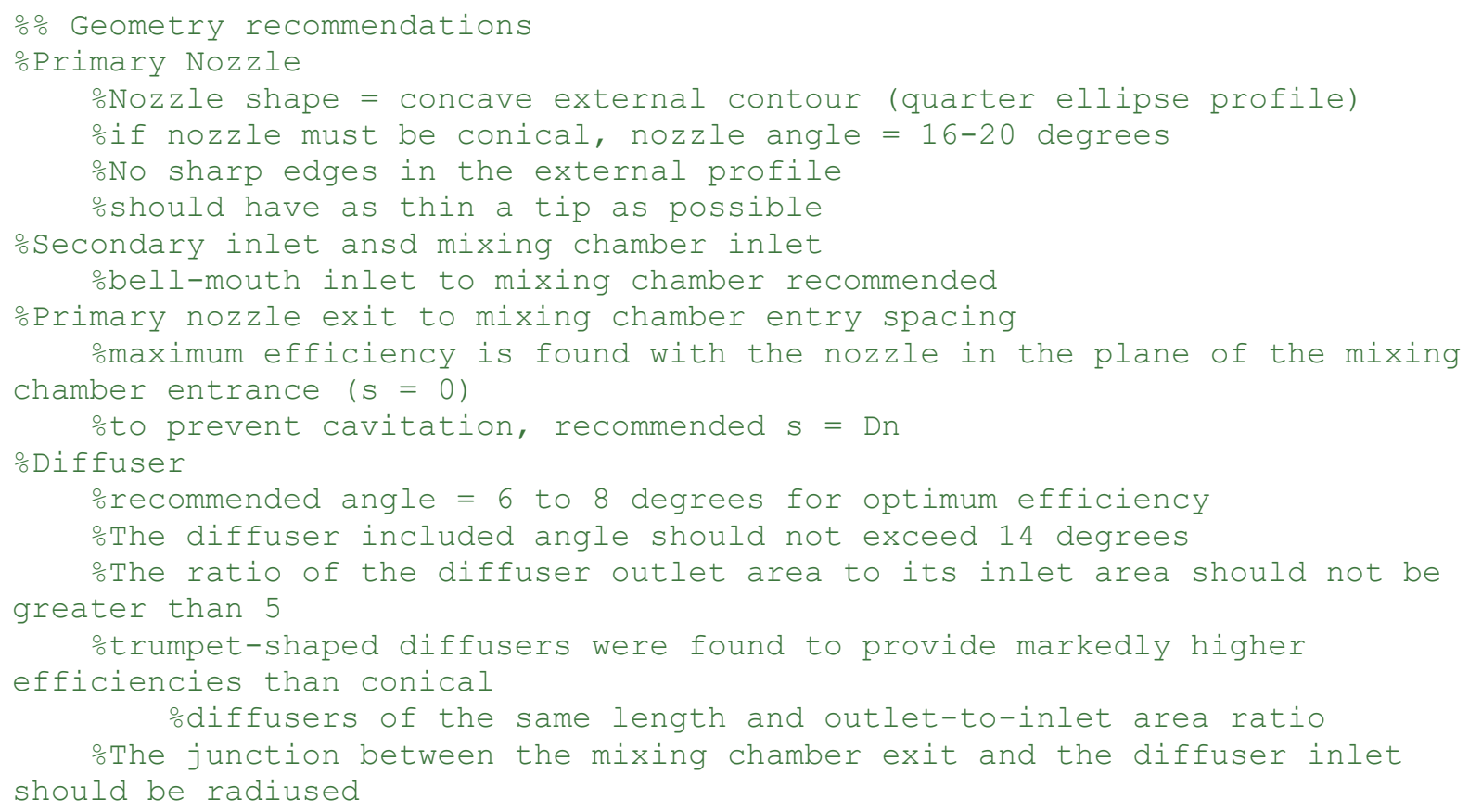


Appendix F-1:

\section{Initial Ejector CAD Drawing}

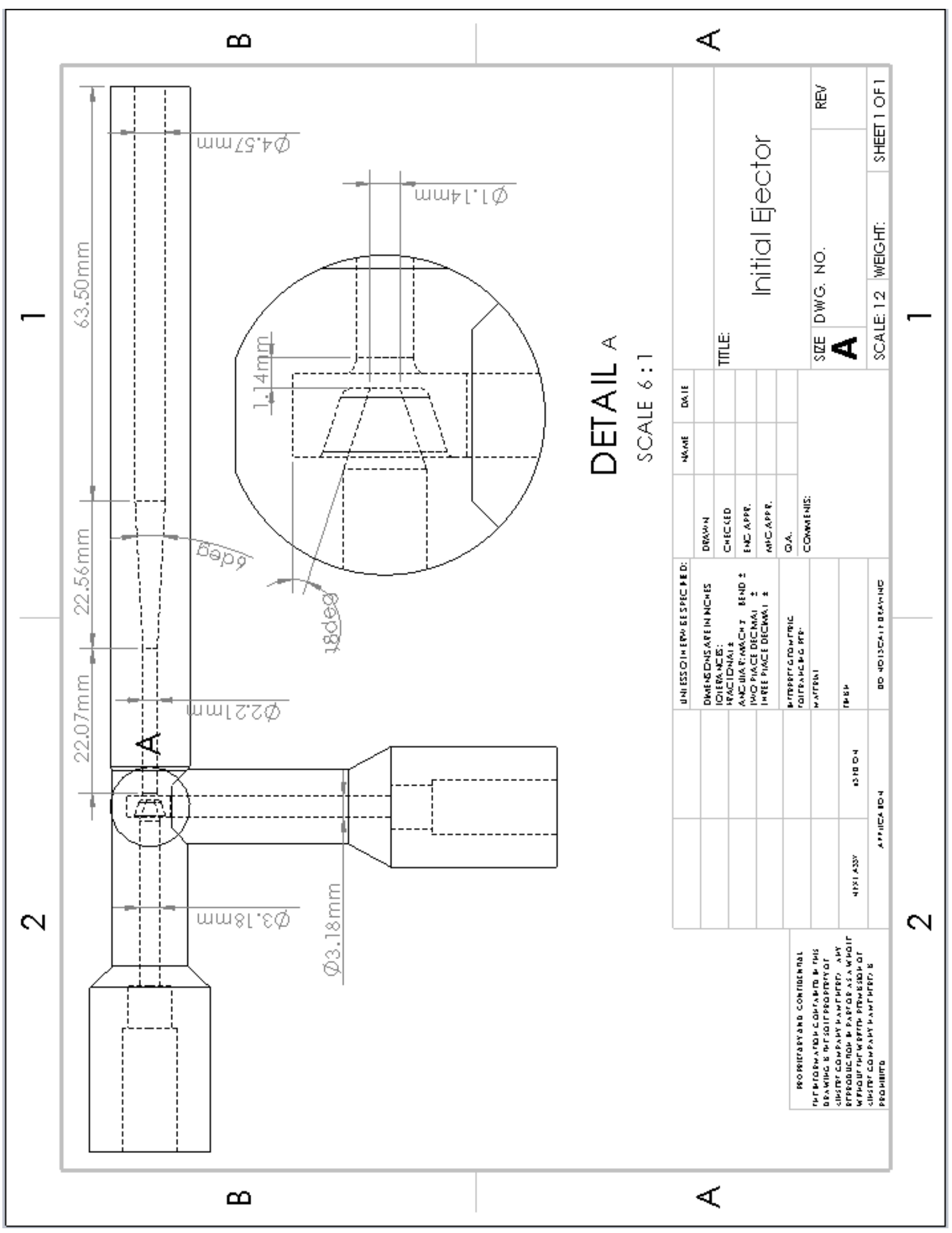


Appendix F-2:

\section{Multi-Nozzle Ejector CAD Drawing}

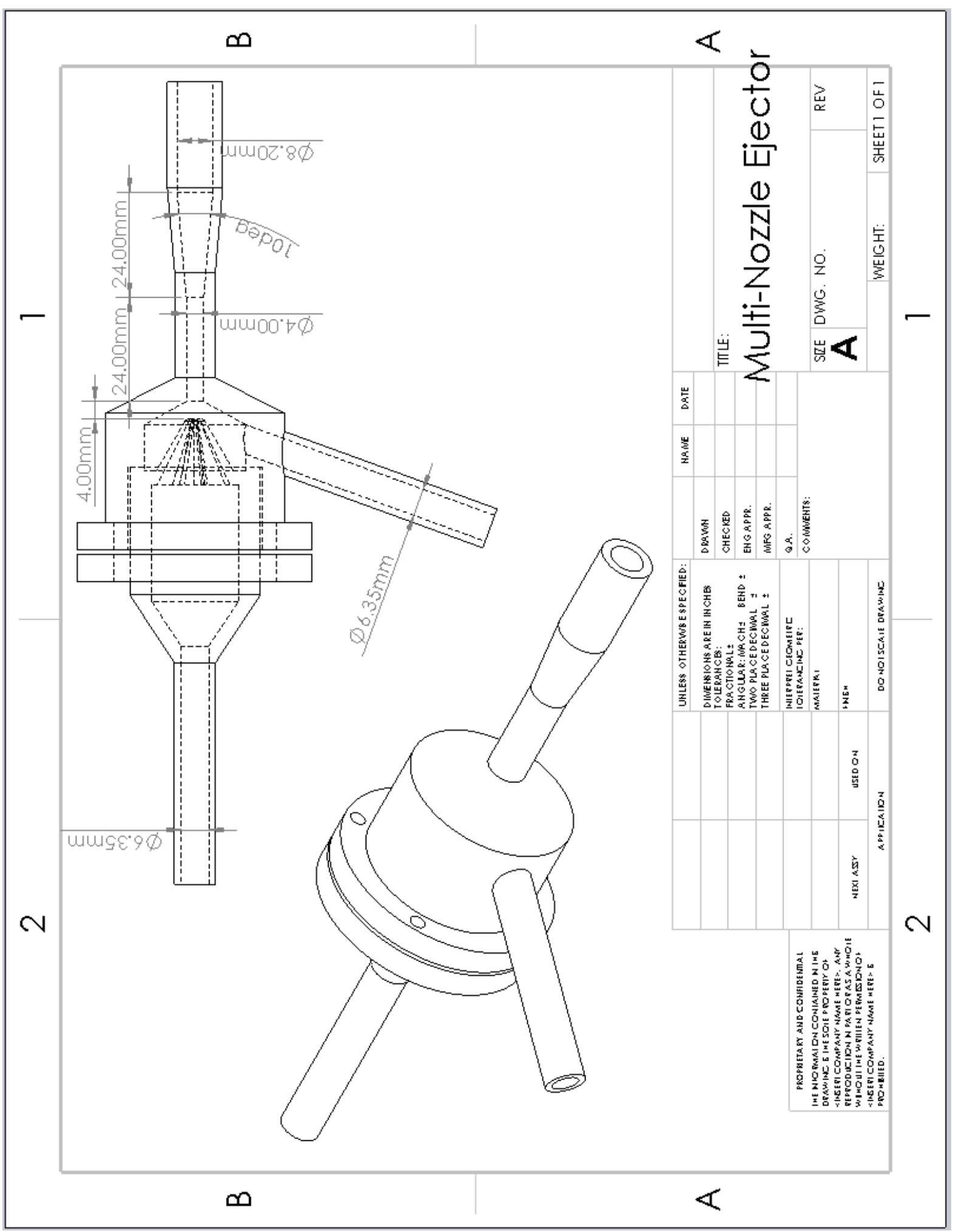


Multi-Nozzle Ejector CAD Drawing - Nozzle Component

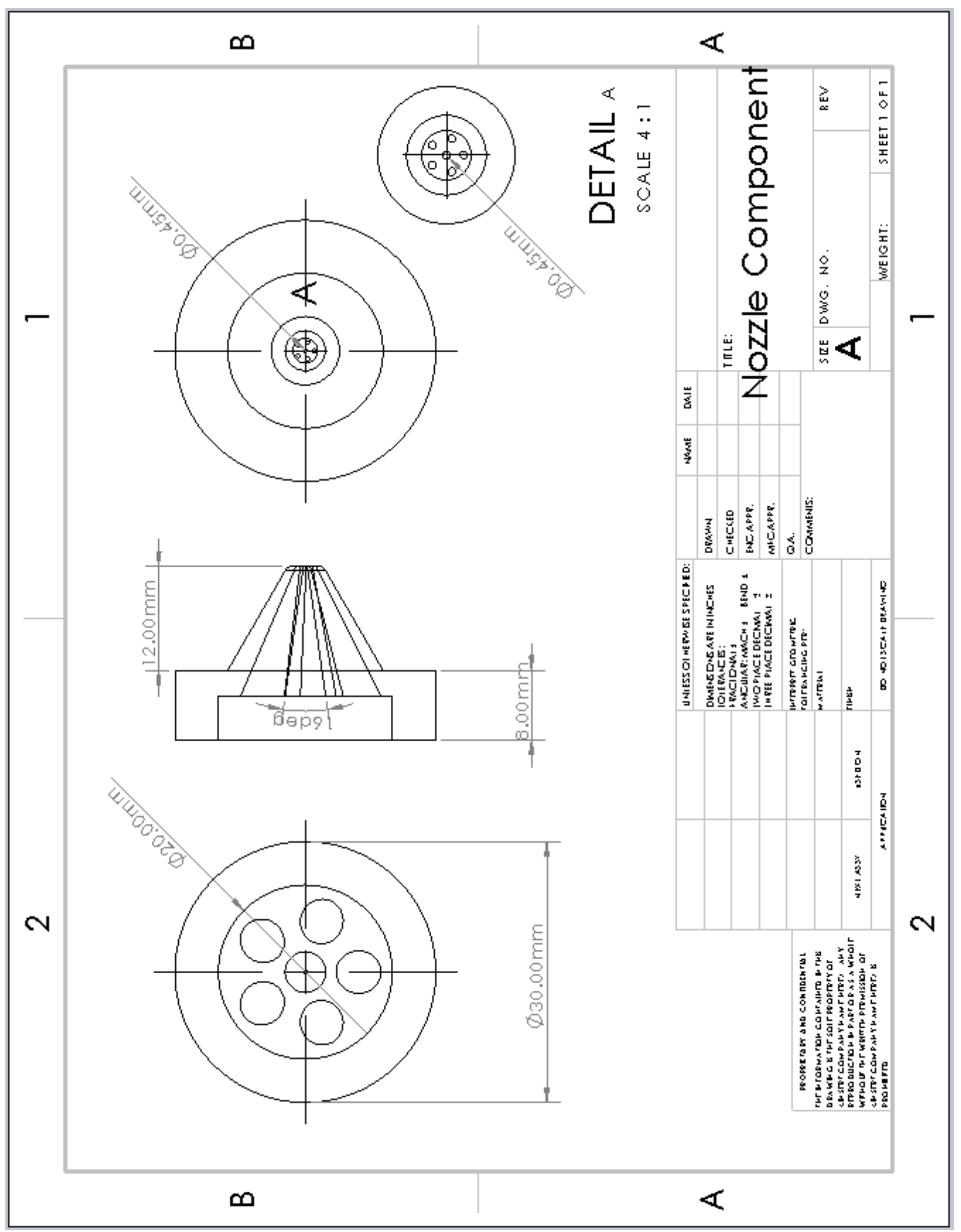




\subsection{Disclaimer}

"This study was sponsored by the Alpha Foundation for the improvement of Mine Safety and Health, inc. (ALPHA FOUNDATION). The views, opinions and recommendations expressed herein are solely those the authors and do not imply any endorsement by the ALPHA FOUNDATION, its Directors and Staff." 